Portland State University

PDXScholar

$5-5-1994$

\title{
Characteristics of Marginally Achieving Secondary Students and the Nature of their School Experience
}

Aeylin Summers

Portland State University

Follow this and additional works at: https://pdxscholar.library.pdx.edu/open_access_etds

Part of the Elementary and Middle and Secondary Education Administration Commons Let us know how access to this document benefits you.

\section{Recommended Citation}

Summers, Aeylin, "Characteristics of Marginally Achieving Secondary Students and the Nature of their School Experience" (1994). Dissertations and Theses. Paper 1384.

https://doi.org/10.15760/etd.1383

This Dissertation is brought to you for free and open access. It has been accepted for inclusion in Dissertations and Theses by an authorized administrator of PDXScholar. Please contact us if we can make this document more accessible: pdxscholar@pdx.edu. 


\title{
CHARACTERISTICS OF MARGINALLY ACHIEVING SECONDARY STUDENTS AND THE NATURE OF THEIR \\ SCHOOL EXPERIENCE
}

by

AEYLIN SUMMERS

A dissertation submitted in partial fulfillment of the requirements for the degree of

\author{
DOCTOR OF EDUCATION \\ in \\ EDUCATIONAL LEADERSHIP : \\ LEADERSHIP AND SUPERVISION
}

Portland State University

O1994 
DISSERTATION APPROVAL

The abstract and dissertation of Aeylin Summers for the Doctor of Education in Educational Leadership:

Administration and Supervision were presented May 5, 1994, and accepted by the dissertation committee and the doctoral program.

COMMITTEE APPROVALS: Robert B. Everhart, Chair

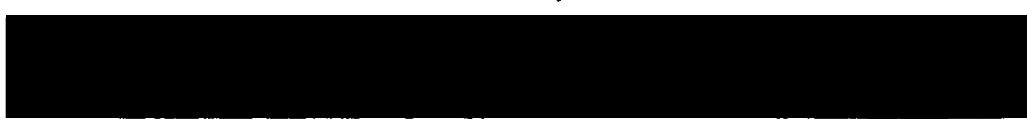

Thomas G. Chenoweth
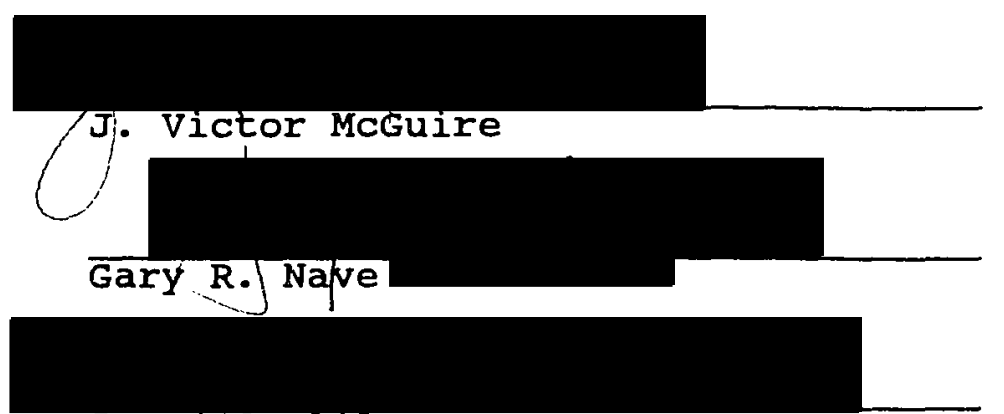
Jameg/Carlile

DOCTORAL PROGRAM APPROVAI

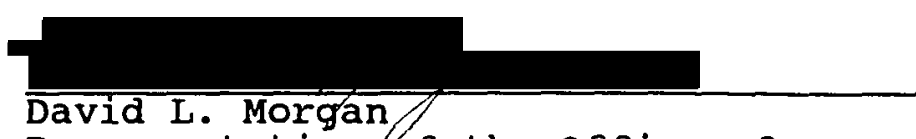
Representative $6 \mathrm{f}$ the office of Graduate studies

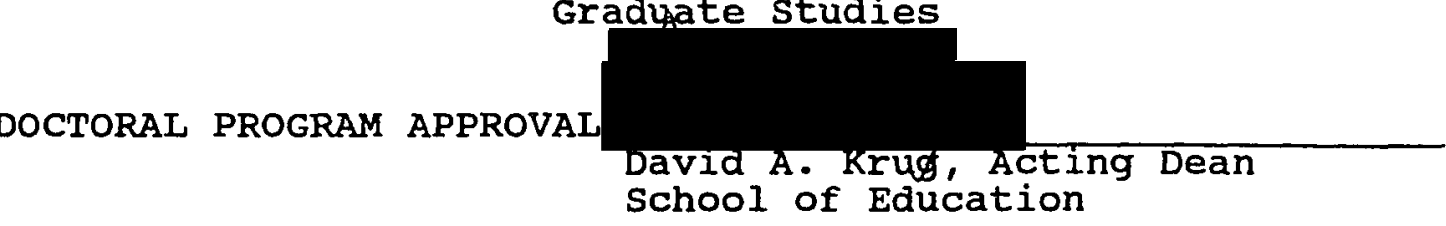

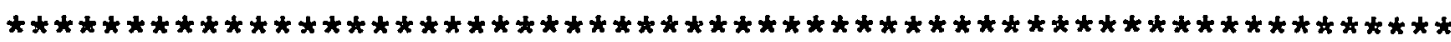
ACCEPTED FOR PORTLAND STATE UNIVERSITY BY THE LIBRARY

by

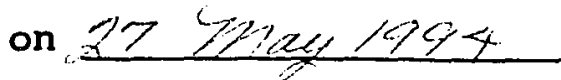


ABSTRACT

An abstract of the dissertation of Aeylin Summers for the Doctor of Education in Educational Leadership:

Administration and Supervision presented May 5, 1994.

Title: Characteristics of Marginally Achieving Secondary Students and the Nature of Their School Experience

In American high schools, students are sorted into three "tracks" to cluster resources for students of similar abilities and interests. Much is known about the high track student, and especially in the past decade, the low track or "at-risk" student. However, the middle track--or marginally achieving student--has been largely overlooked in the literature. Acknowledged as "lost in the middle" (Judson, 1992), as well as deserving of higher quality of service in their school systems (Powell, Farrar, \& Cohen, 1985), marginal achievers-defined here as having a GPA of 1.5-2.5, still maintain a profile of invisibility. current reform efforts to increase student engagement and achievement increase the importance of understanding the characteristics of this student population to enhance the quality of instructional practices, program options, and support services. 
This study described the characteristics of marginal achievers and the nature of their school experiences. Five groups of students were interviewed in two local high schools. These data were combined with the results of a quantitative analysis of 165 variables from the National Longitudinal Educational study for a 500 case sample. The results indicated:

- Gender, race, and socio-economic status could not be used to identify marginal achievers. Seventy-nine point four percent of the students reported being in two-parent families. Most students indicated feelings of high selfesteem.

- No demographic characteristics could be used to identify any school structure that was more likely to foster marginality, however, several climate factors emerged.

- Marginal achievers were not visible in their school's system of rewards or sanctions.

- Marginal achievers did not believe they had much value in their school system. They believed high track achievers were most valued.

- Marginal achievers had no intentions of dropping out of high school. They believed they would have little trouble being successful in college. They reported their parents had the same expectations.

- The students reported the primary parental support activity was student-parent discussions about school. 
- The cost of college led many students to consider attendance at a community college. The reduced financial burden of a community college, along with lower GPA expectations, influenced how hard they worked in high school. 


\section{DEDICATION}

This work is dedicated to my mother, Anne M. Zeumer, who has always believed in my capabilities. 


\section{ACKNOWLEDGMENTS}

I would like to thank the members of my committee: Jim Carlile, Dr. Tom Chenoweth, Dr. Victor McGuire, Dr. David Morgan, and Dr. Gary Nave. Each of you has come along with me on my journey, and I am reminded, once again, that so many great accomplishments reflect the help of good friends. I would like to thank Dr, Robert Everhart, my chairperson, for his time, attention, and assistance with my study. If not for his help. I would never have gotten to the joyful ending of all of this work. Thanks to you all.

Also, I would like to thank my sons, Cody and Jeremy Hinton, who have been a big part of my academic career at PSU. Some day, when they understand what all this has meant, I hope they are proud of their mom, and I hope they are inspired to be willing to think hard about a problem and work hard to make a difference.

Finally, and most of all, I wish to thank my husband, Thomas Hinton, the second most knowledgeable person in this world about marginally achieving secondary students. Thanks, T. 
TABLE OF CONTENTS

PAGE

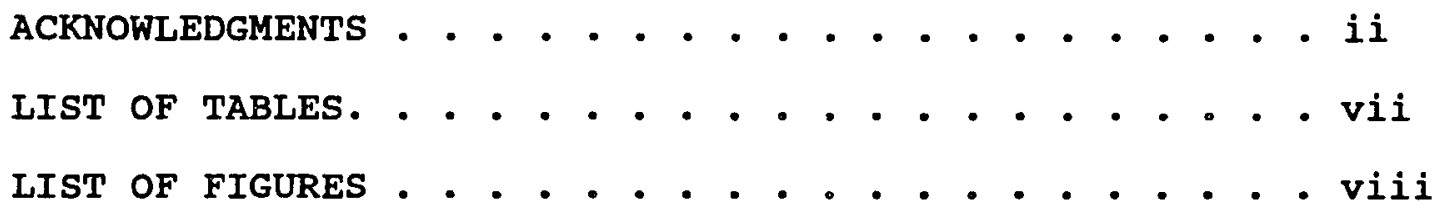

CHAPTER

I OVERVIEW. . . . . . . . . . . . . . 1

Introduction. . . . . . . . . . . 1

Statement of the Problem. . . . . . 4

Significance of the study . . . . . 5

Methodology Overview. . . . . . . 8

Summary .. . . . . . . . . . 10

II A REVIEW OF THE LITERATURE. . . . . . . . . 11

Introduction. . . . . . . . . . . 11

Review of the Literature. . . . . . . 11

Achievement Tracks: High and Low

The Middle Achiever

School Organization, Tracking, and Marginality

Marginality: Student Characteristics. . 27

Describing the "Invisible Students"

Summary . . . . . . . . . . . 34

III METHODOLOGY . . . . . . . . . . 36

Introduction. . . . . . . . . . 36 
Statement of the Problem. . . . . 36

Operational Definition of Marginality . 37

Methodology .. . . . . . . . . 40

Qualitative Methodology . . . . . . 44

Focus Group Sites

Focus Group Sample

Research Questions

Data Collection and Analysis

Procedures

Quantitative Methodology. . . . . . 50

NELS

NELS Sample

NELS Variables

Research Questions

Data Analysis Procedures

Summary . . . . . . . . . . . 56

IV PRESENTATION OF RESULTS . . . . . . . . 58

Introduction. . . . . . . . . 58

student characteristics . . . . . 60

Gendex, Race, and SES Variables

Family Composition

Personality Characteristics

Non-School Activities

Student Part-Time Employment

Student Characteristics Summary

School Characteristics. . . . . . 74

School Characteristics

climate Issues: Student/Teacher

Relations in School

climate Issues: Teachers'

Instructional style and

Expertise

climate Issues: Level of Interest

in Course content

Level of Expectation and Challenge

school Characteristics summary 
School Experiences. . . . . . . . 97

Positive School Interactions

Negative School Interactions

student Abilities as Achievers

Patterns in student Achievement

Teacher Favoritism

School Experiences Summary

Parent/Home Environment--Future Plans . 114

Student and Parent Expectations

Parental Academic Support

Behaviors

The Nature of Parental Influence for the Marginal Achieving Student

Future Career Opportunities

Parent/Home Environment--Future

Plans Summary

Data Summary. . . . . . . . . . 130

student Characteristics

School Characteristics

School Experiences

Parent/Home Environment--Future

Plans

Summary . . . . . . . . . . . 136

$V$ DISCUSSION, CONCLUSIONS, LIMITATIONS,

SIGNIFICANCE, AND RECOMMENDATIONS

FOR FURTHER RESEARCH. . . . . . . . . 137

Introduction. . . . . . . . . . 137

Discussion of Results . . . . . . . 137

Conclusions . . . . . . . . . . . 144

Student Characteristics

School Characteristics

School Experiences

Parent/Home Environment--Future

Plans

Limitations to the Study. . . . . . . 148 
Significance to Educational

Leadership. . . . . . . . . . 151

Point \#1: Communicate Findings

Point \#2: Offer Data Collection

Options to Teachers

Point \#3: Staff Development in

student Engagement Techniques

Point \#4: Staff Development in

student Assessment strategies

Point \#5: staff Development in the

Creation of Assessment Rubrics

Point \#6: Communicate with Parents

Point \#7: Communicate with students

Recommendations for Further Research. . 166

Summary . . . . . . . . . . . 168

REFERENCES. • . . . . . . . . . . . . . . . 170

APPENDICES

A LETTER TO DR. KATTERLE. • . . . . . . . 175

B LETTER TO PRINCIPALS. . . . . . . . . 179

C CONSENT LETTER AND PERMISSION FORM. • • • 182

D STUDENT INTERVIEW INFORMATION SHEET • • • . 185

E STUDENT FOCUS GROUP QUESTIONS . . . . . . . 187

F NELS QUESTIONNAIRE--1988 FOLLOW-UP. • . • 192

G NELS CATEGORIES . . . . . . . . . . 224

H NELS VARIABLES. . . . . . . . . . . . 258

I STATISTICAL DATA/FREQUENCIES. . . . . . 262 
1. Demographic Characteristics

(NELS $\mathrm{N}=4,644)$. . . . . . . . . . . 62

2. Comparison Data to NELS Sample $(\underline{N}=20,706) \quad$. 63

3. Self-Reported Self-Assessment Qualities

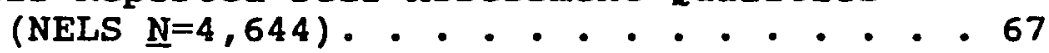

4. Non-School Activities (NELS $\underline{N}=4,644$ ). . . 69

5. Marginal School Performance and School Characteristics (NELS $\underline{N}=4,644$ ). . . . . 77

6. Student Reported Classroom Climate Variables Cross Tabulated with Gender, Race, and SES (NELS $N=4,644) . . . . .78$

7. Level of Expectation in Required Classes

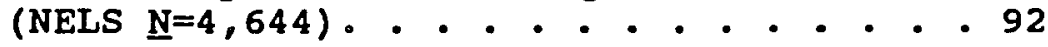

8. Students' Self-Reported Grades in Required Classes (NELS $\underline{N}=4,644)$. . . . 94

9. Positive School Interactions: student Recognition (NELS $\underline{N}=4,644$ ). . . . . . 99

10. Positive School Interaction: Activity Participation (NELS $\underline{N}=4,644$ ). . . . . 100

11. Negative School Interactions (NELS $\underline{N}=4,644)$. . . . . . . . . . 102

12. Student Post High School Educational Expectations (NELS $\underline{\mathrm{N}}=4,644)$. . . . . . 115

13. Parental Post High School Educational Expectations: Std. Responses (NELS $\underline{N}=4,644)$. . . . . . . . . . . . 117

15. Parental support Activities in the Student's School Career: Std. Responses (NELS) . . . . . . . . . . 119 


\section{LIST OF FIGURES}

FIGURE

PAGE

1.

Research Question Categories. . . . . 56 
CHAPTER I

OVERVIEW

\section{Introduction}

In 1983, A Nation at Risk (National Commission on Excellence in Education [NCEE]) proclaimed that the system of education in the United States was producing students who reflected "a rising tide of mediocrity," and our country would be at great competitive disadvantage, both nationally and internationally, as long as this situation remained unaltered. Since the report, a great variety of committees, task forces, blue ribbon panels, etc., have addressed the issues of student engagement and achievement and have made recommendations regarding the direction in which education must go. America's Choice (National Center on Education and the Economy, 1990), America 2000: Where School Leaders Stand (American Association of School Administrators, 1991), and Workforce 2000 (Johnston, 1987) are a few of the many reports which have examined America's educational systems and its position in the world marketplace, now and in the future. Put simply, these reports claim the United states will not be competitive on a global basis unless dramatic changes occur to increase student achievement and make education more relevant, more engaging, and more related to 
useful workplace skills than current practice demonstrates. The various reports in turn have led to multiple efforts to restructure educational systems to improve student engagement and achievement.

Certainly, for reform efforts to be successful, proposed system and program changes must serve students better than those systems in place presently. However, while this focus on systemic practices could be very productive, the critical examination of the students themselves who are a part of this "tide of mediocrity" is all but missing. As a part of the effort to accomplish any increase in student achievement, there is an important need for greater examination and understanding of students as "achievers." Such is the focus of this study.

It is generally understood that in most secondary schools, students are separated into three broad categories, or "tracks," of achievers--usually some division of high, middle, and low levels. In the fundamental discussion of this practice, Keeping Track: How Schools Structure Inequality, Oakes (1985) states:

Tracking is the process whereby students are divided into categories so that they can be assigned in groups to various kinds of classes. Sometimes students are classified as fast, average, or slow learners and placed into fast, average, or slow classes on the basis of their scores on achievement or ability tests. Often teachers' estimates of what students have already learned or their potential for learning more determine how students are identified and placed. sometimes students are classified according to 
what seems most appropriate to their future lives. (p. 3)

While many educators argue the advantages and disadvantages of the system of tracking, there are few, if any, who would deny its existence and extensive use in shaping the three main classifications of student achievers. Oakes maintains that:

and maybe 60 percent of the elementary schools
still use some form of between-class grouping
based on perceptions educators have about
children's ability to learn. (O'Neil, 1992 , p.
18) 18)

This study advanced with the acknowledgment of these identified groups of achievers (which are examined in greater detail in the review of literature in the second chapter). A great deal is known about the high and low tracks of achievers--the high track because these students reflect the pride of any school system, the low track students because they draw great human concern. It is the middle track which seems to be the least defined and the least understood. It is this group that is the focus of this study.

The term "marginal" has been applied to the middle track achiever to describe the ". . disconnection between students and the conditions designed for learning" (Sinclair \& Ghory, 1987, p. 14) which these students experience. The occurrence is not that uncommon, since some estimates suggest that a significant percentage of the national high 
school population, perhaps $50 \%$ or more, can be characterized as "marginal" achievers. Perhaps it is the state of "strained, difficult relationships with the school environment" (Sinclair \& Ghory, 1987, p. 3) which accounts for the lack of accurate details regarding so vast a number of students. School systems publicize the achievements of their best students and make visible (though not often successful) efforts to better serve the needs of students who are "at risk" of failure. However, such attention is not paid to marginal, middle track students who continue to exist in a system which largely ignores them.

- . they have been touched least by the personalization of public education that has benefited the brightest students, those identified as gifted and talented, and lately the most troubled, those identified as "at risk." The last to be treated as individuals, most of these students are intellectual dropouts. They manage to graduate, but leave high school undereducated and often uninspired to continue. (Judson, 1992, p. 1)

\section{Statement of the Problem}

If proposed change efforts are to better serve the marginal achievement population, it is critical to gain a better perspective regarding these young people as individuals and to understand the nature of their high school experiences. If educators do not understand more about the students who form the middle, marginal track of achievers, it will be difficult, if not impossible, to determine their primary educational needs. If such 
determinations are not addressed specifically, is there any reason to assume that educational systems of the future will attend to the needs of this population any better than current practice demonstrates? There is little specific information regarding the types of students who enter high school and either choose, drift, or are placed into the middle group of marginal achievers. The centering research problem for this study then is: What are the characteristics of marginal achievement students (secondary), and what is the nature of their school experience?

\section{Significance of the study}

As the nation continues in its massive efforts to restructure educational systems to increase the level and quality of achievement of our students, inclusion of marginal achievement students as a target population is critical for three key reasons:

First, while it is undoubtedly true that students who are at-risk of dropping out of school prior to graduation represent a significant challenge facing educators today, it can be argued that marginal achievement students represent a phenomenon of at least equal, if not greater, concern. It is clear that educational systems do not serve at-risk students well. However, by dropping out, these students sever their relationships and connections with school and 
sacrifice the diploma as proof of achievement, or at least attendance. But marginal achievement students do not leave. They stay and graduate with a state certified diploma, which itself attests, not only to their "completion" of high school, but also to a richness of opportunities these students did not experience and a level and quality of knowledge and skill they may or may not possess. While these students may be capable of performing at a higher degree of excellence, their school experiences do not challenge them to work to their academic potential. If a centering goal of education is excellence, there is a powerful responsibility to serve these students who have been neglected for far too long.

second, the phenomenon of marginality represents the failure of education at a broad, systems level, because marginal students encompass more of the total population than either the high or low tracks of students. Any system could not be achieving its organizational objectives and fail to serve that many people. We know that marginal achievers are present in high schools in large numbers. Many examinations of school systems and practices have raised legitimate questions regarding which segments of the total population, if any, are being served by our current public school system. While it was the purpose of this study to focus only on the marginal achievement category of students, our understanding about this segment of the 
population can contribute critical evidence for the need for broad system changes.

Finally, recalling the work of the multitude of committees inspired by A Nation at Risk (NCEE, 1983), the issues supporting a systematic inquiry into the nature of marginal students and their school experiences can be framed in a current economic context which creates an even greater sense of urgency. Magaziner's (1990) influential America's Choice: High Skills or Low Wages describes the link between education and the national economy.

More than 70 percent of the jobs in America will not require a college education by the year 2000 . These jobs are the back-bone of our economy, and the productivity of workers in these jobs will make or break our economic future. No nation has produced a highly qualified technical workforce without first providing its workers with a strong general education. (p. 54)

The current economic prospect has been characterized as ". - a mismatch between the labor force the nation needs - . and the one our educational system is making available" (Salamon, 1991, p. 23). Estimates suggest that 30-70\% of the current school population is comprised of marginal achievers who leave school without strong workplace skills. If more accurate percentages are only half as great, the term "mismatch" still seems generous, to say the least.

The concept of human capital provides a useful theoretical framework for this study. Central to the theory is the belief that an investment in people is every bit as 
critical as an investment in land, equipment, etc., and this investment is worthwhile from an economic, as well as a human perspective. A business or industry can expect a greater return on the initial investment in its people--the human capital--as the level and quality of skills increases, creating a more efficient and effective workforce better able to face the competitive challenges of the world marketplace.

\section{Methodology Overview}

The study explores the characteristics and experiences of marginal students from two perspectives. First, qualitative information drawn from focus groups of students from two local high schools provides descriptive data with personal information describing marginal students as achievers. These student focus groups generated anecdotal material regarding the nature of their high school experiences and permit me to offer their perspective on proposed educational changes. The basic question in the focus groups was: What has school been like and how would it have to change to engage and motivate these marginal students to achieve?

second, drawing from a national data base of high school sophomores (National Education Longitudinal Study-NELS description, see Chapter III), descriptive information further tested and explored the characteristics 
of students who make up this broad population. Are certain students more apt to be marginal achievers than other students? For example, what is the representation based on gender for this middle group? Does race or socio-economic status (SES) seem to be a factor in marginality? The outcome of the combination of these two research approaches is an understanding of the characteristics of students who occupy the middle track of achievers and a more complex description of the nature of their own school experiences.

It is as important to clarify what this study is not as well as what it is. This study did not search for a single or mixture of characteristics that support a "deficit model" to explain why some students are incapable of producing at a higher level of academic achievement. It was the firm assumption of this research effort that, given the appropriate educational environment, these students are capable of achieving at a higher level of excellence. Gathering more information to describe the nature of such an environment was a key research concern.

The intent of the identification of characteristics of marginal achievement students is to use this information to shape educational reform efforts to serve these students better than they are being served currently. Also, by identifying the unique features of students who make up the marginal population, these students can be included in 
future change efforts and become agents for their own educational success.

\section{Summary}

Efforts to restructure educational systems to increase student achievement must include marginal achievement students as a target population for change. Any new programs which do not have a significant impact on this population's school experiences would represent only a modest improvement over the present system. In order for new systems to be a strong match for these students, there is a need for better information and greater understanding regarding the students who make up this group, as well as the perspective of these students themselves regarding their own school experiences. This study examines marginal achievement students at the secondary level by combining qualitative information from interviews from student focus groups to explore the student perspective regarding their own school experiences with quantitative data drawn from a national student database to describe the characteristics of marginal achievers. 
CHAPTER II

A REVIEW OF THE LITERATURE

Introduction

Two specific areas of literature relate to the study of marginality. The areas examined are: (a) the literature regarding student achievement levels (e.g. students as high, low, and middle track achievers) and (b) the literature focusing on marginal student achievement from both an organizational and characteristics perspective. A final section of the chapter examines the gaps in the information available currently regarding marginality.

\section{Review of the Literature}

Achievement Tracks: High and LOW

In many schools, students are separated into three broad categories or "tracks" of achievers: high, middle, and low. The high track represents students who are, for the most part, engaged and successful in their school work.

The students in the top-track program have to be committed to the academic purposes of high school; in return they are recognized by being given a variety of services, resources, and privileges not available to others. (Powell, Farrar, \& Cohen, 1985, p. 119) 
Their grades reflect achievement at an A or B level primarily, with a very occasional c grade. The typical selection of courses is geared toward entry into a four-year college or university program.

Inside of the high school environment, these upper track students receive strong support, service, and praise. They reflect the best of the public school system in intent and practice as they make progress toward their diplomas.

Their special courses provide sources of identification and prestige. Not only are they driven by deeply instilled momentum, but their trajectory is applauded by the wider community. They have high visibility and acclaim . . .

(Lightfoot, 1983, p. 149)

Outside of school, their high levels of achievement provide them with a variety of options including opportunities in higher education and employment. As a percentage of the entire high school population, the upper track accounts for ". . a liberal estimate . . is perhaps 15 to 20 percent" (Sedlak, Wheeler, Pullin, \& Cusick, 1986, p. 9) .

Once we account for this upper group of students, the remaining students can be viewed in terms of increasing disengagement from their school work. On one end, there are low track students who are unsuccessful and extremely uninvolved with academic work. A sizable portion of the low track group, often termed "at-risk," hovers close to dropping out of school completely. Many of these students do leave public high school for equivalency programs, vocational training, jobs, or, in many cases, drifting. 
Nationally, the percentage of students who drop out of school stands at approximately 25\%. The range of non-completion is from $50 \%$ or more in major cities (e.g. Chicago, New York, etc.) to $5 q$ in smaller urban, suburban, or rural locations (Boyer, 1983).

In the high school environment, the academic work of lower track students is characterized primarily by $F$ grades, resulting in failed classes that must be repeated and passed for credit in order to graduate with a standard diploma. Occasional D grades mark brief episodes of interest and some degree of marginal success. The experiences of the lower track of students seen as one of the most serious problems in education today. The "at-risk" student population has received a staggering amount of attention in research, literature, resources, and programming in an attempt to understand and provide for the successes of these young people who will leave school virtually unemployable at any but the most menial jobs and with small hope for a successful future.

\section{The Middle Achiever}

Subtracting this lower track of students leaves a significant block of students in the middle, characterized as relatively disengaged and usually experiencing marginal levels of achievement. Whether they are viewed as "lost" or "drifting," "just out there," or "not really anywhere," the description of the middle track student floats as much as 
the students themselves float, which is a situation that demands some further attention.

In studying the current literature, it is apparent that the ambiguity regarding the middle achieving student's characteristics has given rise to multiple definitions of these students. The concept of a student being a "marginal achiever" is often intermixed with the term "underachiever," both signifying a level of performance that is lower than expected for an individual student and lower than is satisfactory according to established academic standards. However, how those terms are applied to a given student case is not consistent in the literature. Butler-Por (1987) states:

Broadly, underachievement is defined as a large discrepancy between the child's school performance and some manifestation of the child's true ability such as teachers' and parents' observations or achievement, creativity and intelligence measures. For research purposes different methods of identifying underachievers are used. Most studies define underachievers by the large gap between the under-achiever's school performance and potential. (p. 6)

Sinclair and Ghory (1987) take a similar case of a student not reaching expected standards and label this as "marginal" achievement. "All students need to learn what schools are expected to teach, but in every school some students are not achieving. These are the students we consider marginal" (p. 14). Sinclair and Ghory continue to identify the types of students who can become marginal: 
Various types of students become marginal, such as the learner not working up to potential, the understimulated exceptional learner, the one with a long history of academic failure or substandard achievement, and the one suddenly performing poorly despite previous success. Students can become marginal regardless of sex, race, family structure, or economic background. Marginal learners, then, can include "children at risk" from low-income minority homes as well as youth from well-to-do families who are forced to maintain a delicate balance on the margins because they face less-than-constructive circumstances in the school setting . . . For many learners, being marginal becomes a way of life in school. (p. 14)

These definitions blend together cognitive abilities, demographic features, environmental factors, etc., in a manner that makes it difficult to extract a clear or consistent set of terms. For the purposes of this study, a critical distinction is made regarding the identification of a "marginally achieving student." Marginally achieving students are, in fact, performing at a level that is below established expectations of quality for academic work. However, different from "at-risk" students, they are consistently achieving at a level that is sufficient to earn them passing grades of $C$ or $D$ in most, if not all, of their classes, thus, enabling them to make gainful progress toward their diplomas.

While these parameters may establish the population of students to be studied in this research effort, it should be remembered that considerable ambiguity about the population really still exists. Because they do not fit into either the high or low end groups, middle track students are often 
described either in ambiguous, imprecise terms or by exclusion from the other, better defined populations. - - for those who are not dramatically achieving or in the midst of a visible crisis--the regular kids--(their school) is a place they pass through unnoticed. (Lightfoot, 1983, p. 149)

Glasser (1990) likened a class of students to

- . a gang of street repair workers. If they were working as hard as the students do in class, half or more would be leaning on their shovels, smoking and socializing, perfectly content to let the others do the work. (p. 1)

In the scenario, middle track or marginally achieving students are the ones who do nothing more than show up to the work site and observe.

The fact that these students are willing to come to school without coercion, behave appropriately without causing undue problems, and make progress (marginal though it may be) toward a diploma, seems to render them ineligible for the kind of attention and definition conferred on others. And yet, in his book, Horace's Compromise, sizer (1984) entitles his chapter regarding marginal students, "Docility," and states:

No more important finding has emerged from the inquiries of our study than that the American high school student, as student, is all too often docile, compliant, and without initiative. Some who have initiative use it to undertake as little engagement as possible with school. (pp. 54-55)

This lack of engagement is reflected in the school work of the marginal student, earning primarily $C$ and $D$ grades, with occasional Fs and Bs to mark examples of even greater than 
usual disinterest or uncharacteristic motivation. While the academic performance level is low, marginal students do not exhibit all of the behaviors of at-risk students (e.g. failing classes, leaving school, etc.) because they do attend on a regular basis and make progress toward their diplomas. Yet, middle track students do not seem to be nearly as engaged in their school work as upper track students, for they submit work of marginal quality and accept grades at just passing levels. They exist somewhere in the middle of engagement and dropping out, with a strong inclination to slide academically toward the lower track. Inside of the high school environment, this group of middle track or marginal achievement students is estimated to be very large in number. Whether it be a general description captured in the title, The Neglected Majority (Parnell, 1985), reference to ". . the masses in the 90-120 IQ range" (McNeil, 1988, p. 75), or attempts at more precise percentages ranging from "exceeding two-thirds of the number of high school students" (Sedlak et al., 1986, p. 9) to ". . 70 of the total school population" (Powell et al., 1985, p. 174), it appears that the portion of students who are experiencing only marginal success accounts for a major share of the total school population. However, as Judson (1992) notes:

- . no one knows just how large that group might be, as so many of its members drift through school without sending up the red flags that educators use to recognize students in trouble.. . those 
who suffer in silence, or who know how to blend in, can be invisible to the system. (p. 2)

In addition to large numbers, it is acknowledged that these students could and should be achieving at higher levels than current performance indicators (e.g. standardized test scores, achievement tests, grades, etc.) suggest. Often, however, school resources are focused on the needs of the upper and lower track students, and those in the middle are left to fend for themselves. In The Shopping Mall High School (Powell et al., 1985), teachers, psychologists, administrators, parents, and the students themselves describe the experiences of the marginally achieving high school student as follows:

Few characteristics of the shopping mall high school are more significant than the existence of unspecial students in the middle who are ignored and poorly served. Teachers and administrators talk a great deal about the problem. "We do very much for the top, top students and the real problems," one teacher asserted, "but for these average 'nice' kids with low motivation we don't do much of anything." "Honors kids are fine and kids with handicaps are fine, but what are we doing for the average kid?" another said. An administrator made the same point: "We're doing a lot for the accelerated kids, we're doing a lot for the student who needs special help, but this kid in the middle gets the least attention." (pp. 173-174)

If it is acknowledged by school personnel that this large group of "Unspecial" students is deserving of better support and resources in educational systems, then how is it this great imbalance between student needs and school services exists? To answer this concern, we turn to a brief 
examination of some of the key aspects of the organizational structures of most high schools which, we shall see, contribute to the perpetuation of the experiences of the students "in the middle."

\section{School organization, Tracking, and Marginality}

The objectives of any organization play a major role in shaping the services offered to the clientele. A major objective of the educational system of this country is:

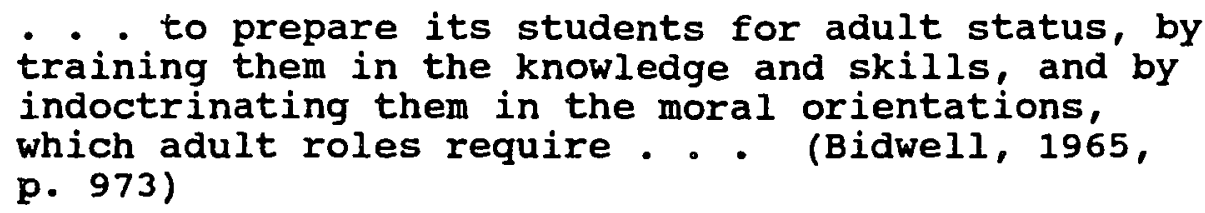

If this "training and indoctrination" is ". . an American version of the egalitarian ideal, that is, to provide each student with an opportunity for social, political, and economic equality" (Cusick, 1983, p. 1), then the enormity and complexity of this educational objective becomes profound.

The goal of providing educational services to every school-age person in the nation--regardless of race or religion, ability or desire--and guiding each person through an educational process culminating in a common endpoint--a high school diploma--has been likened to taking all of the world's children and passing them through the eye of a needle. Educational systems begin with students at a wide variety of "starting points," with different abilities, 
personal goals, and perspectives. These diverse students are moved through 12 or more years of common school opportunities and experiences to arrive at a homogenous endpoint--graduation--signified by the receipt of a common diploma.

To fulfill this goal of educating such a dissimilar national population, certain organizational structures which support a consistent, uniform operation for many different students are normally present. At least two components of the secondary structure--curricular tracking and teacher/student role relationships--seem to actually contribute to the marginal school experiences for a large portion of the students the system is supposed to educate. Therein lies a fundamental problem for the middle group of students.

The tracking of students into various achievement groups has been proffered both as a necessary sorting system for managing the quantity of students attending school and as a system for placing students in classes with a curriculum best suited to their ability levels, thereby increasing the opportunities for student success. Yet the practices of tracking profoundly shape the marginal experiences of many high school students.

The content of middle track classes is usually described in terms of "general education." For students who are not certain what their specific field of study or 
specialization will be, a general education track represents a selection of classes designed to offer exploratory experiences in a variety of disciplines, such as the arts, sciences, etc., without, however, any curricular "road map" or a clearly defined set of classes such as those clustered and available to identify the path of the high track, college-bound student or the vocational student. Without a more precise curricular organization, the middle track student can become lost almost immediately upon entering into the secondary system. Students in this generalized curriculum seldom are pushed to exceed the minimum number of classes required for graduation. Consequently, a minimum standard often becomes a maximum ceiling. The characterization that these students "drift" through the system acknowledges a lack of guidance from teachers, counselors, etc., to help make more complicated curricular choices. In fact, it is this lack of advocacy that is one feature of ". . . the structure and tone of school which encourage invisibility" (Lightfoot, 1983, p. 149).

In some schools, the content in middle track classes is somewhat aligned with the academic work associated with the high track curriculum (Goodlad, 1984). However, distinctive to the middle track courses is a reduced level of teacher expectation for student performance. This level of expectation, based on a role definition of students and teachers for self and others, is sometimes termed the 
classroom "bargain." The bargain is based on the mutual acknowledgment by the teacher and the middle track students that both parties wish for students to "get through the class." Yet, some students are not interested in being pushed toward higher levels of academic achievement, and, given this level of ambition, teachers decide not to expend the energy to motivate reluctant students. The bargain, then, is a tacit agreement between students and the teacher that if the students show up, behave according to general school standards, and produce work at even a marginal level, the teacher will reward them with passing grades (e.g. D or C). The students will earn the accompanying credit and eventually graduate. The teacher's perspective is grounded in "giving the students what they want--this is all they can handle" and may include:

relatively little concern for academic content; a willingness to tolerate, if not encourage, diversion from the specified knowledge to be presented or discussed; the substitution of genial banter and conversation for concentrated academic exercises; improvisational instructional adaptation to student preference for or indifference toward specific subject matter of pedagogical techniques; the "negotiation" of class content, assignments, and standards; and a high degree of teacher autonomy in managing the level of academic engagement, personal interaction, and course content. (Sedlak et al., 1986, p. 7)

other literature describes how this congenial arrangement shapes the marginal experiences of the middle student. A history class described in Horace's Compromise (Sizer, 1984) gives an example of the student's role in the 
middle track classroom, where there is a distinct lack of pressure to achieve:

over ten minutes into the period, (Mr.) Brody finally turned to history and announced that the purpose of this class was "to cover chapter six." The students, slouched or leaning, just looked at him. No one (save me) picked up the heavy textbook. I discovered that chapter six covered some aspects of the American westward movement. Brody moved through the text, slowly asking a question of no one in particular and then slowly answering it himself. The students quietly watched this performance. (p. 155)

Almost as a return "payment" for not being pushed by the teacher to achieve, the middle track student, in turn, does not demand much of the teacher. Students "behave," remain quiet, and, thus, put little, if any, pressure on the instructor to work hard with these students. Compare the bargain with those for the "bright kids." In The shopping Mall High School (Powell et al., 1985), two sections of a junior English class are taught by the same teacher, one a high track class for college-bound students and one a middle track class for "regulars." The differences in the

"bargains" are evident:

(Mr.) Cleveland adjusted classroom procedures in various ways to accommodate the two groups. The regular students received no more than twenty-five minutes night of homework and the advanced students double that amount, though neither group got homework every day. Many advanced students would submit five-page term papers--the maximum cleveland allowed--while he would accept from regular students a term paper of eighty words. He felt regular students did not like to talk, so he held discussions to a minimum and required oral presentations only in the advanced class. When discussions did occur in the regular class, they emphasized concrete details rather than analysis. 
Regular kids, Mr. Cleveland explained, preferred more variation in classroom activities than the advanced class. If he employed two activities during an advanced class (say, a film and discussion), he would often use four in a regular class (film, discussion, lecture, and seatwork). (p. 185)

Finally, as evidence of the critical component of the marginal bargain--"don't make any trouble and we'll get along," Cusick (1983) offers an example of a social studies teacher who was discussing railroad mileage:

All the time the teacher was talking about railroad mileage. Some had their books open but did not look at them. Others just sat and stared or talked to their friends. This apparently didn't bother $M r$. P. No individual was getting singularly disruptive so he just went on until even he became bored and concluded quickly that although "America has a lot of problems it is still the best country in the world." (p. 54)

Curricular tracking and classroom bargaining are only two components of a complex organizational structure which appear to support the phenomenon of marginality. It would seem the experiences of the middle track student are at least accommodated, if not initiated, to a great extent by the educational systems in place in most secondary schools in this nation.

Some believe the objective of educating so diverse a student population necessitates an organizational structure that is somewhat bureaucratic in design. These uniform organizational processes lead as many students as possible to the accepted symbol of the completion of public education--a high school diploma. However, inherent in this 
bureaucratic design of secondary schools is a consistent, stable set of policies and procedures that is inflexible or less adaptable to the unique needs of the student population. For students to be successful then, quite often it is the student who must adapt and conform to the systems of the school.

Certainly, students who are genuinely motivated to participate actively and work hard to achieve at high levels of excellence will have an easier time with this process of adaptation, and they can enjoy the smoothest, most productive educational experiences. However, students who are willing to simply "act the part," even without such intrinsic encouragement, will likewise arrive at the same outcome--receipt of a diploma--with only the minimum level of commitment, engagement, and performance. Attendance, acquiescence, and an uninspired academic performance are sufficient to enable many students to complete the standard secondary program and receive a high school diploma, hence, the phenomenon of marginality.

However, the fact that the system may support a marginal, middle track experience, coupled with the knowledge that a large portion of students may find themselves accurately described as "lost in the middle," does not signify an easy compromise or a series of simple choices students can routinely make. For some students, the process of adapting and conforming to the systems of 
secondary schools in this country represents an extremely challenging experience. An excerpt from a letter written by a high school senior one semester from graduation shares one price of this adaptation to the system. This student dropped out of school rather than conform and be "invisible" any longer, a victim of "irreconcilable differences between school systems and children who don't seem to fit" (Cray-Andrews, 1989).

Like a fingernail, I've been filed and manicured to look and act like the system wants. Through the years, I have deviated from the system and have paid many a consequence for that. Every time I try to do something in school that doesn't fit the mold, I'm punished. What does this punishment accomplish? Nothing. Absolutely nothing. I apologize, although I shouldn't have to, for being the way I am. . . I can no longer sit back in this system and just go with it. I have to be an individual. If I'm not allowed to do that, I go crazy. (p. 35)

A compelling body of literature suggests some important trends regarding the difficulty of the "fit" of certain portions of the population. These populations can be examined according to characteristics which identify student groups who consistently experience unequal treatment in the educational system, unequal expectations, and unequal instructional opportunities. There is a need to examine the relationship regarding what is known about these student populations, identified by various characteristics including race, gender, and social class, and the experience of marginality. 
Marginality: student Characteristics

Considerable research focuses on race, class, and gender as factors influencing educational achievement. This research often concludes that certain students experience diminished opportunities normally available for white, middle and upper class children, especially males.

Two distinct theoretical frameworks summarize the systematic differences of achievement in this nation's schools. One branch maintains that there are certain deficiencies in the children's experiences which render them unable to achieve at a higher level of scholarship. Certain groups are less able or "disadvantaged" in terms of their ability to learn and succeed. Socially, different attitudes and values, inherent in the cultures of these population groups, have the effect of limiting their achievement in school (Weis, 1988). Reduced levels of achievement, therefore, are an effect or result of student-centered deficiencies. A second framework maintains that children are born with basically similar abilities to learn and achieve. Outcome differences are determined by human interests, exposure to opportunities, and predilections toward one subject area over another. Once in school, the differences in the achievement levels of various portions of the student population are the results of dramatically different treatment within a school system. Schools, therefore, are viewed as sorters of students according to 
social, economic distinctions which mirror the social and economic place they will hold as adults in society outside of school. For students of specific populations, reduced levels of achievement or academic interest areas skewed toward certain career outcomes are caused by radically different treatment within educational systems (Hare, 1987; Simms \& Contreras, 1980).

While the "weightings" of race, class, and gender are not clear as distinct entities (Haw, 1991), there is considerable evidence to support systemic differences in the treatment and achievement outcomes of various student groups. By race, black students are more frequently identified as low achievers qualified for special educational services than white students. Conversely, white students are more likely to be identified for gifted classes than black students (Meier, Stewart, and England, 1989). Hispanics have the lowest levels of educational attainment, as compared to black and white student groups. From preschool programs through college, Hispanic students are statistically underrepresented in all student populations (National Council of La Raza, 1992; National Institute of Education, 1977).

one area of the secondary educational systems of this country where the experiences of students as identified by race seem to coincide and, in some cases, undoubtedly overlap with the experiences of students as identified by 
social class, is vocational education. A predominant number of students who are routinely steered away from high-track, college-bound coursework in favor of vocational skill training include students who are non-white and poor. In her study of tracking, Oakes (1985) states:

Rather than change the character of the academic curriculum to meet the needs of a diverse student population (and thereby preserve the common school), the inclusion of vocational programs permitted schools to differentiate their curricula and to sort students. As a result, vocational programs provided a means of encouraging working-class children not to drop out of school while keeping them from receiving an academic education. In these programs lower-class students learned attitudes and skills appropriate to manual-labor positions.

A recent analysis of the vocational experiences provided for black adolescents in schools argues that these programs from their inception have been limited largely to preparing youngsters for jobs traditionally held by blacks. (p. 153)

A division similar to those arguments related to race separate the position of education in relation to social class. Some theorists maintain that school experiences work to provide mobility out of poverty toward more and better economic and social opportunities, while others view the structure of schools instrumental in perpetuating social class stratification much the same way racial stratification is maintained (Hauser, 1971).

The academic outcomes for children of low socio-economic status (SES), however, often echo those for non-white children, finding low-SES students rated significantly lower in all measures of achievement than 
high-sEs students. "They received lower test scores, lower grades, and fewer prizes . . " (Herriott \& St. John, 1966, p. 5).

The information related to different treatment on the basis of gender is equally significant in terms of differential educational treatment. A "hidden curriculum" seems to create a dramatically different school experience for girls than for boys, which seems to reinforce traditional social sex roles of male superiority and female subordination (Delamont, 1990; Gough, 1976).

In the lower grades, girls achieve at levels equal to or higher than the achievement levels of boys. However, in the higher grades, the levels of achievement for girls begin to fall until they are surpassed by boys, especially in the areas of math and science. However, this decline in achievement test scores exists contrary to the fact that girls will typically receive better grades than boys, which - . may be one of the rewards they get for being more quiet and docile in the classroom . . . Girls are more likely to be invisible members of classrooms. They receive fewer academic contacts, less praise, fewer complex and abstract questions, and less instruction on how to do things for themselves. (Sadker \& Sadker, 1982, p. 101)

Girls who are achievers at the high end of the spectrum in math are less likely to be identified than boys, while girls who are learning disabled are similarly less likely to be placed in special programs. Academic advisors and teachers may try to steer girls toward classes including 
typing, business machines, etc., which support stereotypically female occupations such as office oriented, clerical work, instead of courses designed for transition into post high school, university work in math or the sciences (Chapman, 1988). Numerous research efforts support the findings that language and textbooks consistently reinforce gender bias in the classroom (stitt, 1988).

Examined together, the literature regarding race, class, and gender issues builds a strong case that children who are non-white, "non-male," and poor will have a different educational experience than white, male, middle or upper-class students. Their experiences will be shaped by specific expectations from within the school system, which are reinforced through tracking, teacher bias, language, and instructional materials, as well as a complex network of external attitudes, values, and social expectations which have a powerful reinforcing impact on these students. one academic outcome of these internal and external forces is a product of marginal experiences for students who are identified by race, class, and gender. In these cases, the "fit" between students and school systems is set in very specific, fairly narrow terms. As stated previously, the extent to which a student is able to approximate the profile of the centering, mainstream student and follow basic school policy plays a large role in determining the ease with which she or he will "pass through the eye of the needle" and 
attain a high school diploma. It would seem that the pressures to make such personal adaptations are very powerful.

Describing the "Invisible Students"

The relationship between what is known about the experience of marginally achieving secondary students and what is evident regarding the educational experiences of certain student populations is not clear. It may be, for students of a certain race, class, or gender, that marginality is a function of all or some of the characteristics. Differential treatment within the system may cause some students to decline from the highest levels of achievement to float somewhere in the middle.

It may be, however, that for some students, marginality is not a function of any of these characteristics. There are certainly representatives in the middle group of achievers who are white, or male, or both, who bring another perspective to life as a marginal student. A great deal of research regarding students who are identified as talented and gifted (TAG) who are achieving at levels far below their potential suggests another unanswered facet to the description of marginal achievers (Parish \& Parish, 1989; Wolfie, 1991). And there may be many more.

It may be that the strength and pervasiveness of classroom bargains which enable students to invest very 
little and still achieve a diploma entices students to float in the middle ground of marginality in patterns that cut across racial, class, and gender distinctions. Since the student population of middle track achievers is consistently described in terms that are not only ambiguous but homogenous, it is difficult to get a clearer perspective regarding who these students are and what the true nature of their school experiences has been. By describing so vast a population with a single classification--middle track students--it is easy to participate in the same types of behaviors and attitudes which contribute to the marginal performance. The presence of these students is acknowledged, but their complexity and diversity are not. One point that does seem to be apparent, however, is the fact that the features internal and external to school systems which serve to keep this phenomenon of marginality securely in place are complex, powerful, and pervasive. These students will probably not find their way out of marginal academic performance without significant attention and intervention from the very system in which their role is defined. Unless educational systems gain a sharper understanding of the vast population of middle achievers as individuals with unique characteristics and needs, it is difficult to envision a different educational outcome for students. 
Summary

The literature clearly indicates that a large portion of the secondary school population in this country achieves at marginal levels of performance. This phenomenon is acknowledged in two ways: First, within the three "tracks" of student performance, a vast number of high school students are experiencing only marginal levels of achievement and engagement--attending school and investing enough effort to achieve a diploma, but not enough to achieve an education. Second, certain segments of the student population, characterized by minority status, low SES, and gender, experience this minimal academic success in disproportionate numbers.

While these factors are born out by the literature, it is not clear how these two bodies of information are related, if at all. Does the system's bureaucratic structure and lack of flexibility cause students to become only marginally attached, willing to participate to the degree required to attain a diploma but no more? Is marginality an effect of the various attitudes and social expectations experienced by students who do not fit the narrow parameters of a successful, mainstream student? In what ways are race, class, and gender associated with marginality and how is marginality manifested for these students? Finally, and perhaps most significantly, can a clearer perspective regarding marginal students and the 
nature of their school experiences guide reform efforts to better meet the needs of a portion of the large population for whom schooling is little more than a "stop-over" on a nebulous journey? 
CHAPTER III

METHODOLOGY

Introduction

This chapter describes the problem that was examined and the methodology used in this study. The methods were related and twofold. First, a qualitative dimension used interviews from student focus groups in local high schools to gather anecdotal material regarding the nature of the school experiences of these marginally achieving students. Second, a quantitative dimension focused on selected variables from the National Educational Longitudinal study (NELS) data set to further define the characteristics and experiences of the students. The combination of research methodologies allows a rich and complex characterization of marginally achieving secondary students and their school experiences.

\section{Statement of the Problem}

As discussed in Chapter II, a significant portion of the secondary students in this country is disengaged and experiencing only marginal academic success in school. For the majority, their efforts will be sufficient to enable them to complete high school and receive a diploma. Yet, 
there is inadequate information regarding the phenomenon of marginality that characterizes a sizable group of students. We know very little about the characterization of the population itself, and even less about how students in this population view their status in the school. Gaining a clearer view of the characteristics of marginally achieving secondary students and understanding what school has been like for them is essential to shaping educational services to better meet their needs. Thus, the primary research question in this study is: What are the characteristics of marginally achieving secondary students, and what is the nature of their school experience?

Operational Definition of Marginality

For the purpose of this research study, marginally achieving students were identified strictly on the basis of achievement data, which is reported as academic grades. The total sample was drawn according to the grouping variable GRADES, which reflects a student's Grade Point Average (GPA). The GPA is calculated on a 4-point scale $(A=4, B=3$, $C=2, D=1$, and $F=0$ points). For the purposes of this study, a marginal student was defined as a student whose GPA falls within the GPA range of $1.50-2.50$.

This GPA range represents the grade profile of a student who has passed virtually all of her/his classes at primarily the D or C level, with the inclusion of occasional 
Fs and Bs to keep the grade point at this level. The upper limit of this range (2.50) was determined by calculating the GPA of a student whose work was consistently assessed as "average" or "C" level, which would generate a GPA of 2.00 . A $2.00 \mathrm{GPA}$ would be the highest level of academic achievement a student could attain consistently and still be considered a marginal achieving student. An extra .5 was added to reflect the fact that many of these students may have received grades that were somewhat inflated and thus increased the GPA. Still, the overall quality of their work is judged to meet a minimal standard.

The lower range limit (1.50) was determined by calculating the GPA of a student whose work is consistently assessed as "below average" or "D" level, which would generate a GPA of 1.00 , the lowest level of academic achievement a student could attain and still pass a class, gain credit, and make progress toward a diploma. An extra .5 was added to the lower range to indicate the same inflated grade values and the unlikely occurrence of a straight 1.00 cumulative GPA.

The concept of grade inflation brings up a concern regarding the use of grades as the indicator of achievement and engagement in school. While grading policies and practices are standardized within certain guidelines of acceptable, professional practices, grades still reflect the perceptions or judgment of teachers, that is, arguably, 
somewhat subjective in nature. Any given grade could represent an inaccurate picture of a student's level of achievement, either by inflating or deflating the grade beyond a justified level. Such practice is not uncommon, and standards vary widely from teacher to teacher, school to school, etc. However, despite this subjectivity, certain patterns emerge over time regarding student achievement, supporting the basic profiles identified previously as high, middle, and low "tracks."

Certainly, the use of grades is appropriate as a measure of student achievement levels, and, therefore, a fitting indicator of marginality. However, the use of grades as the sole indicator of marginality acknowledges a critical aspect of the relationship between grades and the attainment of a high school diploma. There are other features which could be acknowledged and/or measured as rightful and appropriate demonstrations of a student's engagement in school, including participation in after school activities, athletics, music or drama programs, a student's self-assessment of success or engagement, etc. However, the diploma reflects a student's academic achievement, and it is only the acquisition of the required credits, representing work of at least a D, or marginal, level of quality, that will result in a diploma.

This study involves students who are sophomores, which means they will have interacted with more than a dozen 
teachers in the two years of high school they have experienced. Individual differences by teacher may be less significant, while larger patterns of engagement and achievement will have begun to emerge.

\section{Methodology}

This study examines the characteristics of the portion of the secondary school population that occupies the middle track or "marginal" achievers and describes the nature of their school experiences. The study necessitated two complimentary approaches to best address the research question. First, interviews of a purposeful sample of sophomores and juniors were used to gather personal, anecdotal material from secondary students regarding the nature of their school experiences. The interview questions centered on four categories of inquiry: student Characteristics, School Characteristics, School Experiences, and Parent/Home Environment--Future Plans. Second, in order to better understand the universal characteristics of marginally achieving students, this study drew a sample from the National Educational Longitudinal study (NELS) data set, to examine the selected variables in the same four categories of information. The NELS data used for this research is drawn from the survey responses of approximately 20,000 sophomore students in the second round of a national study examining patterns in high school attendance and 
completion. More details of this study are forthcoming in this chapter.

There is an important connection between the two methodologies. The qualitative portion examines marginality from the viewpoint of a small sample of local students who are, themselves, middle track, marginally achieving students. The focus group methodology is appropriate to gather such student perspectives, which serves to contextualize further descriptive data through an understanding of real school experiences, thus providing insight into how these students actually function. Also, interviews gave students the opportunity to indicate what schools would have to be like for them to become more engaged and achieve at higher levels (Morgan, 1988).

Focus groups as a method of qualitative research represent a very appropriate data collection technique with particular benefits for this study. According to Krueger (1988):

Focus groups can be used before an experience such as in planning (including strategic planning), needs assessment, assets analysis, program design, or market research. Each of these tasks typically draws upon information from several sources, one of which is particularly suited to focus groups-the perceptions of both current and potential clientele. (p. 31)

As stated in Chapter II, marginally achieving students are often overlooked in the working systems of a school. Chronicling their perspectives and experiences gives a "voice" to a portion of the secondary "clientele" that 
deserves the opportunity for such input. The group format has the advantage of providing support for the students who may be somewhat hesitant to participate in any discussion of their experiences. Focus groups also stimulate interaction and serve to increase the quality of the discussion (Krueger, 1988; Morgan, 1988).

The quantitative section drew from a national sample population to further explore the critical variables and provide descriptive data regarding the characteristics of marginally achieving students. This portion of the research has the attribute of drawing from a large sample population of students who participated in a study surveying a wide variety of interest areas, many of which are directly pertinent to the examination of marginal achievement. of critical interest is the confirmation or disconfirmation of characteristics which surfaced in the focus groups or the emergence of unique variables.

The methodologies employed in this study gathered student data only, both in the focus groups and in the sample survey group of student-reported information. This decision was made for two main reasons. First, in order to describe any population, it is suitable to include the responses and perceptions of the people in that population as a source of significant information. At a future point, the inclusion of responses from other populations, such as teachers, parents, etc., may provide additional insights 
into the marginal achieving student. This study began with the students, themselves, as the research target.

The second reason for the student focus is that a great deal of literature has been produced describing programs, materials, curriculum and instructional techniques, etc., aimed at increasing student engagement and achievement. In some cases, these strategies have been developed with little, if any, involvement of the students for whom they were designed. If it is our professional intent to increase the involvement, engagement, and quality of the academic experiences of these students, then student responses must become a primary source of information and input. Understandably, using student material as a sole data source carries certain risks in terms of validity and generalizability. When asked to self-report their perceptions of their own abilities or how their teachers might regard their work or their attitudes in class, students may present a view that would be challenged by teachers, parents, or any other stakeholders in the school experience.

However, if it is true that the self-reported perceptions of these students do, in fact, constitute their sense of what school means to them, and if this understanding carries any influence over how they function in the school environment, this information must be factored in as one component in the complex decision-making and 
design process used to determine the course of study made available for these students. This study proceeded with the acknowledgment that it serves to describe the phenomenon of marginality from the student perspective only regarding the topics of student Characteristics, school Characteristics, School Experiences, and Parent/Home Environment--Future Plans. We turn now to a more in-depth discussion of the research methods employed.

\section{Qualitative Methodology}

The focus group interviews were conducted during a two week period in April and May of 1993 with the objective of gathering anecdotal data from students who are, themselves, marginal achievers, to understand what school has been like for them and how they perceive their school experiences. The focus group work was accomplished in several stages, beginning with the selection of two interview sites.

\section{Focus Group Sites}

Data collection began with student focus groups in two local high school settings. School site $A$ is a large school, located in the center of a commercial area of a suburban community. Approaching the school at the lunch hour, there was a sense of noise, traffic, and large groups of students moving around the grounds. A fast food restaurant located across the street from the school drew a steady stream of teenagers inside, while others sat on the 
sidewalk out front or rode by in cars. According to student registration data, approximately 158 of the 1,600+ students are Black, Asian, or Hispanic.

Site $B$ is located about 10 miles away in a more rural area of the same community. The site is somewhat isolated, and most of the traffic on the main road turns into the school. Except for a few homes, there is little reason to drive on the road except to go to the school. Although it was lunch time, there were no students in front of the school on either day when I arrived. It was extremely quiet and almost pastoral in the setting. Once inside the school building, the difference between these students and those at School site A was striking. The student population of over 1,600 is almost $100 \%$ white. If there is a "minority" population at the school, it might reflect a group of students, termed by one focus group participant as "rednecks."

\section{Focus Group Sample}

Five sets of student focus groups were formed. The focus groups consisted primarily of sophomore students whose GPAs fell in the range of 1.50-2.50. A small selection of juniors in the same GPA range was included in the groups to provide a perspective reflecting one more year in the high school environment.

students were selected for inclusion in focus groups through a specific sampling process. In each school, lists 
of all students in the sophomore and junior classes arranged according to cumulative GPA were examined, and the cutoff points of 1.50 and 2.50 were established. A name was selected at random as an initial starting point, and every ninth name was marked until 50 names were identified. The total of 50 names for each school was established to increase the opportunity to have 25 participants at each site. Once the student names were selected, the progression for the focus group work was as follows:

1. District permission was secured with a letter of intent and an outline of basic research procedures to district personnel (Superintendent) (see Appendix A) .

2. Narrative information was submitted to each building principal to increase their understanding of the project. Communication took place with all appropriate school personnel to increase site awareness, understanding, and support for the project (e.g. counselors, teachers, etc.). Concerns were identified and addressed (see Appendix B).

3. School personnel were enlisted to distribute study information to student sample population from current sophomore and junior enrollment lists. Packets included (see Appendix C):

--descriptive letter to explain research project-emphasis on anonymity and voluntary aspects of the interviews/procedural information 
--parent/guardian and student permission forms

4. Due to the age of the participants, active parent consent was required. From the pool of students who were available to participate, contacts were made and dates and times for interviews were secured in each site.

5. Interviews were conducted during a two week period in April/May, 1993.

Although a total of 100 packets were distributed between the two schools, only 22 students were available to participate in the study, which was a lower number than anticipated. Although lunch was provided, the students were not interested in giving up any social time with their friends during the lunch hour to participate in a research study.

The low numbers of participants available for the student focus groups left no opportunity to arrange the placement of students into groups of a certain makeup. The makeup of the groups varied more at site $A$ than site $B$, which is a reflection of the overall student populations at both schools. At Site A, group one included two black male students, and group two included one Hispanic male. All of the rest of the students at both sites were white.

of the 22 participants, there were 12 males and 10 female students. By chance, two groups consisted of all girls, two groups were all boys, and only one group was of mixed gender. To a certain degree, the gender dynamics of 
each focus group shaped the proceedings and responses for each session. Identical questions asked in the setting of all boys prompted different responses from a group consisting of all girls or the group of boys and girls together.

\section{Research Questions}

The research questions that shaped the qualitative segment of the study were designed to gather information about the students' own perspectives regarding their school experiences. The four categories examined in these interviews were: student characteristics, school Characteristics, School Experiences, and Parent/Home Environment--Future Plans. As suggested by Knodel (1993), the topic organizers were left somewhat broad and were ". . formulated as a set of discussion guidelines that can be used by the moderator during the focus group sessions" (p. 36).

This section of the study addresses the nature of the school experiences for the marginally achieving student. Some of the areas examined include: What has school been like for them? How have they been treated in the school system? How have they responded? What factors produce an achievement record of Cs and Ds? Do they perceive themselves as marginal achievers? Also, what factors would cause a change in these students to increase their level of engagement and achievement? 
Data Collection and Analysis

Procedures

Three interview sessions were conducted at site $A$ and two at site $B$. In each building, a conference room was secured to minimize interruptions and distractions. A pizza lunch was provided for the students, and information sheets were distributed for completion prior to the main interview session (see Appendix D). The information sheets were used to gain some basic background data from the students, and to get them thinking about the main topics of the discussion to come. Also, as they ate, talked, and filled out the sheets, the experiences served as an "ice-breaker" in this new situation (D. L. Morgan, personal communication, April 19, 1994).

A protocol of questions addressing the four categories of inquiry shaped each of the sessions (see Appendix E), and information from the focus groups was collected by audio recordings. Students were identified by first names only, which were recoded in the final analysis. Field notes were compiled and analyzed at the completion of each session. Upon completion of the five sessions, all tapes were transcribed into text form. Since the protocol was largely the same for each session, there was a basic structure to the student information. Areas of similarities and differences were code-mapped (Knodel, 1993) through a color-coding process for further analysis after the completion of the quantitative portion of the study. Some 
of the responses from the focus group interviews became factors in the selection of variables to be included in the NELS portion of the study. A specific "transfer code" was created for the overview grid (Knodel, 1993) to indicate data points that were explored in both the focus group interviews and the NELS research, since these variables represented potential areas of confirmation or disconfirmation in the study.

From this preliminary sorting, consistent themes emerged in the four categories. As seen in other focus group research,

Interpretation is facilitated by the fact that statements can be examined within the context of the broader discussion and in light of information available from other sources based on different methodologies such as surveys, case studies, or in-depth interviews. (Knodel, 1993, p. 43)

In combination with the results of the quantitative portion of the study, these themes became the primary areas for interpretation and analysis in chapters IV and V.

\section{Quantitative Methodology}

Upon completion of the focus group interviews, a sample was drawn from the NELS database in order to further explore the student characteristics through analysis of specific variables. Since the NELS data comprise a substantial component of this study, a brief description of the research is provided here. 
NELS

In 1988, the National Center for Educational Studies initiated a series of National Educational Longitudinal studies (NELS) which focused on the transition experiences of students as they left junior high or middle school, attended high school, and began their careers. The research sample consisted of 24,599 students in the base year survey $(20,706$ students in the first follow-up survey, 1990), selected at random from 1,035 public and private schools from across the United states. The data sources include student, parent, teacher, and school administrator questionnaires (see Appendix F), as well as 8 th grade achievement test scores in reading, math, science, and history. Data content includes 17 categories representing student characteristics, home environment, teacher attitudes, and school characteristics (see Appendix G) .

Four objectives constituted the basis for creating the NELS database:

1. To predict/explain future student outcomes as measured in later survey waves.

2. To obtain valuable cross-sectional descriptive data.

3. To explain student achievement with cross-sectional descriptive data.

4. To support educational policy analysis. 
Although all four objectives are part of this study of marginally achieving secondary students, objective \#3 is the most critical to this research project. The primary objective for utilizing the NELS data base was to develop profiles of students who are included within the middle or marginal track of student achievers.

\section{NELS Sample}

Using the SPSS software program, the NELS sample of 20,706 sophomores was accessed. From that population, a sub-sample of 4,644 cases was drawn. The selected cases met the criteria of students who reported a Grade Point Average (GPA) that fell in the span of 1.50-2.50 and who had participated as eighth graders in the initial survey in 1988 and as tenth graders in the first follow-up survey in 1990. The tenth grade first follow-up information was used for this study. It is important to note this sample was not stratified according to specific gender, racial, or ethnic categories of the population. The objective was to draw a sample according to GPA and examine the characteristics of any student who was included. Since the NELS sample constituted a random sample, it is assumed that the sub-sample of 4,644 cases is both valid and reliable.

\section{NELS Variables}

From the student questionnaire data set, a total of 165 variables was selected from the NELS database and sorted to 
examine each research category. The variables were drawn according to the following considerations:

Did the variable offer descriptive information about marginally achieving students in one of the four research categories?

Did the variable match a data point from the focus groups?

Did the variable offer new details in an area that was explored in the focus groups?

Did the variable challenge information that was explored in the focus groups?

\section{Research Questions}

The quantitative portion of the study examined specific variables related to the students who are marginal achievers. As with the interview data, four basic areas constitute the broad topics for inquiry: student Characteristics, School Characteristics, School Experiences, and Parent/Home Environment--Future Plans. The following are examples of the types of variables explored in each category:

Student characteristics: The purpose of examining student characteristics is to create a profile of the marginally achieving student population regarding race, class (as measured by SES), and gender. The following questions shape this portion of the quantitative research: 
- What is the frequency of male students in the marginally achieving student sample?

--What is the frequency of females students?

--What is the frequency of white students in the sample?

--What is the frequency of non-white students?

School Characteristics: The purpose of examining school characteristics is to create a profile of the marginally achieving student population regarding school location and size. The following questions shape this section of inquiry:

- What is the frequency of students in the sample population who attend schools in an urban location?

- What is the frequency of students in the sample population attending large schools (with an ADM over 1,000 students) or the frequency for students in smaller schools (with an ADM below 1,000 )?

School Experiences: The purpose of examining school experience is to create a profile of the marginally achieving student population regarding interactions with their school's system of rewards and sanctions. The following questions shape the inquiry:

--What is the frequency of students in the sample who had received recognition awards for academic achievement or positive behavior? 
-What is the frequency of students in the sample who had been disciplined for school rule infractions?

Parent/Home Environment--Future Plans: The purpose of examining home environment is to create a profile of the marginally achieving student population regarding the frequency of parental support for school work (e.g. homework checks, homework help) and the frequency of student/parent discussions about school and post-secondary education (PSE). The following question shapes the inquiry:

-What is the frequency of parental support and assistance for academic work?

\section{Data Analysis Procedures}

The four category headings of student Characteristics, School Characteristics, School Experiences, and Parent/Home Environment--Future Plans paralleled the organizers from the focus groups and shaped the analysis of the quantitative data as well. The variables were sorted by research category (see Appendix H), and frequency and percentage data were drawn to provide descriptive information regarding marginally achieving students. Based on the literature presented in Chapter II, chi-square analysis was included to test the significance of gender, race, SES, and level of parent education in relation to specific student responses (see Appendix I). 
summary

This research study employed both qualitative and quantitative research methodologies to describe the characteristics of marginally achieving secondary students and their school experiences. Both portions of the study were structured around four broad organizers, which are indicated in Figure 1.

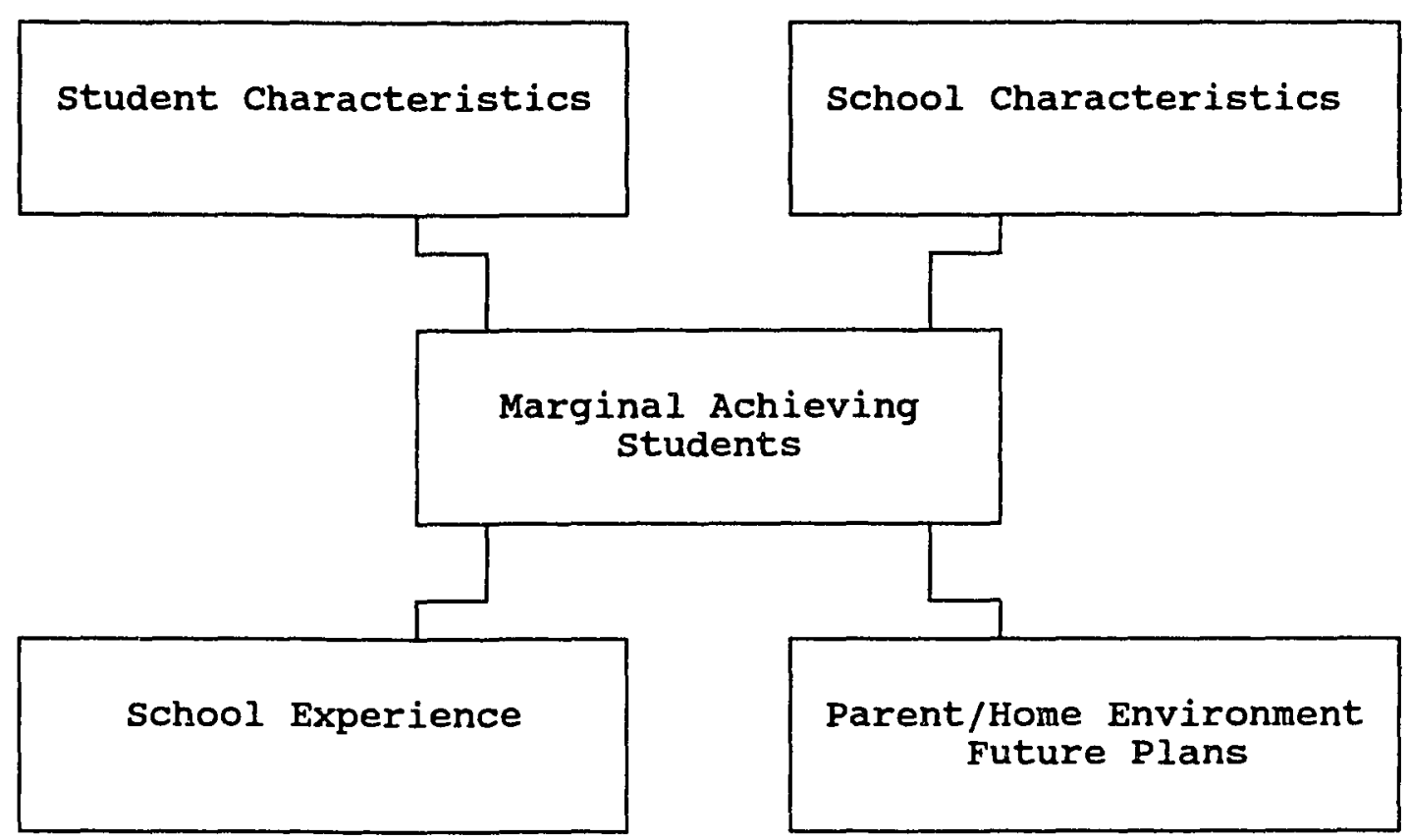

Fiqure 1. Research question categories.

The study began with a qualitative segment involving focus groups of marginally achieving secondary students to generate anecdotal information regarding their school experiences and their perceptions of how schools need to change to motivate them to become more engaged and achieve 
at higher levels of excellence. This information was explored further with a quantitative study using the NELS database to continue the description of characteristics and experiences of students who are a part of the middle track of student achievers. The results of the two methodologies are presented in Chapter IV. 
CHAPTER IV

PRESENTATION OF RESULTS

Introduction

As described in the review of the literature in Chapter II, the middle-achiever, or the marginally achieving student, is often characterized by their position relative to other, well-defined levels of achievers, i.e. "They're not high and they're not low." In schools, significant programming decisions regarding curriculum and materials, instructional technique, placement in coursework, etc., are made with little, if any, knowledge about who these students are and what services would best meet their needs. Because these students constitute a large percentage of the student population, it is clear that a significant portion of the overall school population is not being well-served.

The primary research goal of this study is to describe the characteristics of marginally achieving secondary students and the nature of their school experiences. There are four major categories of inquiry: student Characteristics, school Characteristics, School Experiences, and Parent/Home Environment--Future Plans. First, in relation to student characteristics, what can we learn about the characteristics describing the students who fall into 
this achievement span as measured by a GPA of 1.50-2.50? Are there particular demographic features which distinguish this population? Second, in relation to school Characteristics, since the field of interest is academic achievement and school experiences, are there certain characteristics that describe the school demographics and the instructional environment in which these students exist? Much like student characteristics, are there larger, defining features related to the school systems themselves that give insights into the phenomenon of marginality? Third, in relation to school Experiences, how can we describe the nature of the school experiences for these students? What is it like to attend school and earn $C$ and $D$ grades? How do these students function and how are they regarded in the school environment? Finally, in relation to Parent/Home Environment--Future Plans, how do parents and the home environment factor into the experiences of the marginally achieving student? What is the nature of their influence on the experiences of the marginal achiever?

The findings are organized around the specific research questions shaping each category. Frequency and percentage data and results of tests of statistical significance may be found in Appendix $\mathrm{H}$. For the purposes of reporting, codes of $S=$ Student, $T=T e a c h e r$, and $R=$ Respondent were used. Brief summary remarks will end each section. After all four sections of information have been presented, a composite 
summary of the characteristics of marginal achieving secondary students and the nature of their school experiences concludes the chapter.

\section{student characteristics}

The intention in compiling the demographic characteristics of a marginally achieving student was to create an identifying composite of such an individual. Were there key variables which would begin to describe a student in the 1.5-2.5 GPA achievement range? The specific research questions (RQ) examined the following areas:

1. What is the distribution of students in terms of gender, race, and socio-economic status (SES)?

2. What is the distribution of students in terms of family composition?

3. What is the distribution of students in terms of self-reported personality characteristics, such as self-worth and personal capabilities?

4. What is the distribution of students in terms of non-school activities?

5. How did students describe the impact of working part-time in their lives?

Based on the literature about student underachievement, basic demographic information was collected in order to gain some perspective of who these marginal achievers are as individuals ( $R Q 1,2$ ). Questions addressing the students' 
assessment of their personal qualities were used to ascertain how marginally achieving students see themselves and evaluate their level of capability (RQ 3). Non-school activities were examined for level of engagement and support of academic pursuits ( $R Q 4$ ). What do these students do in their non-school, discretionary time, and how does this relate to their school achievement? The opportunity to earn money distinguished working at a job from other non-school activities. What was the impact of this on the marginal achieving student's life (RQ 5)?

Gender, Race, and SES

Variables

The NELS information regarding the distribution of responses for gender, race, and SES for the 4,644 student sample population of marginally achieving sophomores is presented in Table 1.

For the purposes of providing comparison information, Table 2 presents the data for the same demographic variables from the total NELS student sample. For Race and sES, the frequencies for missing responses $(2,038)$ were sufficiently high to warrant the presentation of the percentages for the total sample of 20,706 , as well as the adjusted percentages for the total sample minus the missing responses, or 18,668 student respondents. 
Table 1

Demographic Characteristics (NELS $\underline{N}=4,644$ )

\begin{tabular}{ccc}
\hline Variable & Frequency & Percentage \\
\hline Gender & & \\
Male & 2,521 & 54.3 \\
Female & 2,123 & 45.7 \\
Race & & \\
Asian/Pac Islander & 175 & 3.8 \\
Hispanic & 600 & 12.9 \\
Black & 482 & 10.4 \\
White & 3,323 & 71.7 \\
American Indian/ & 57 & 1.2 \\
Alaskan & & \\
Socio-Economic Status (SES) & Quartiles \\
Q1=Low & 1,179 & 25.4 \\
Q2 & 1,337 & 28.8 \\
Q3 & 1,241 & 26.7 \\
Q4=High & 887 & 19.1 \\
\hline
\end{tabular}

Based on the literature reviewed in Chapter II, there may have been some cause for the expectation that females, minority students, and students in the low sEs quartile would have increased representation in the marginally achieving sample. Beginning with gender, however, the distribution of students favored males, both in the survey sample and in the student interview groups. While the males represented only 50.58 of the total NELS sample, their percentage increased to 54.38 in the marginally achieving sample. The corresponding ratio for females was $49.5 \%$ in the total sample which declined to $45.7 \%$ in the marginally achieving group. While these percentages are not 
dramatically distinct, the differences do represent approximately 800 more male students and 700 fewer female students whose GPAs were in the marginally achieving range when compared to the total sample. The male/female distribution represented in Table 1 was matched in the five focus groups, where there were 12 male students and 10 females. In the student interviews, while the numbers may have distributed more evenly, the response patterns were not always the same.

Table 2

Comparison Data to NELS Sample $(\underline{\underline{N}}=20,706)$

\begin{tabular}{lccc}
\hline Variable & Frequency & Percentage & $\begin{array}{c}\text { Adjusted } \\
\text { Percentage } \\
\text { (N=18,668) }\end{array}$ \\
\hline Gender & & & \\
\hline Male & 10,462 & 50.5 & \\
Female & 10,244 & 49.5 & \\
Race & & & \\
Asian/Pac & & & \\
Islander & 1,302 & 6.3 & 14.7 \\
Hispanic & 2,751 & 13.3 & 11.9 \\
Black & 2,218 & 10.7 & 1.4 \\
White & 13,837 & 66.8 & - \\
Am Indian/Alaskan & 259 & 1.3 & \\
Missing Value & 339 & 1.6 & 24.4 \\
Socio-Economic Status & $($ SES) & & 24.0 \\
Q1=Low & 4,556 & 22.0 & 23.5 \\
Q2 & 4,472 & 24.0 & 28.2 \\
Q3 & 4,378 & 21.1 & - \\
Q4=High & 5,262 & 25.4 & \\
Missing Value & 2,038 & 9.8 & \\
\hline
\end{tabular}


For the most part, the boys groups were louder, noisier in a "rowdy" or disruptive manner, and more active than the girls groups. In both boys groups, there were instances where the students got up out of their seats to act out and move around during the sessions. The girls groups were noticeably quieter, more compliant, and watchful for cues regarding the rules and expectations in the research setting, which was unfamiliar to them. If, as suggested in the literature in Chapter II, it is accurate that students who are compliant and well-mannered can have a smoother school experience than those who are loud, disruptive, or who call attention to themselves in negative ways, the contrasts between focus groups suggested that gender, may, in fact, play a role in the treatment the students receive in the school system. Gender issues are discussed further in the "School Experiences" category.

While gender issues were reflected in group responses and behaviors in the interview sessions, racial issues did not surface as a meaningful feature of marginality, either in the interviews or the student survey. Recalling the literature suggesting differential treatment in the school system may cause minority students to experience diminished opportunities in relation to white students, from the NELS survey, the predominant response in the marginally achieving sample was White $(71.7 \%)$, with representation in the other racial or ethnic categories which matched the corresponding 
percentages in the total NELS sample. One exception to this pattern was for Asian students, whose representation of 7.08 in the total population fell to $3.8 \%$ in the sub-sample of marginally achieving students. Recalling the makeup of the focus groups, with so few non-white students in the interviews, it is not surprising that race did not emerge as a factor in marginal achievement.

The issue of SES and its influence on school experiences was not addressed in the focus groups, as no reliable vehicle was available in school records to determine the SES of students. From the NELS sample, SES showed a relatively even distribution of students in quartiles 1, 2, and 3, which basically paralleled the comparison data from the total sample. However, there was a substantial decrease in the number of students in the marginally achieving sample who came from the highest sES range, where the percentage comparison reflected a drop from 28.28 total representation to 19.18 in the sub-sample. While it can be said that the phenomenon of marginality cuts across all economic lines, students in the highest sES quartile were less represented than students in the other three quartiles.

\section{Family Composition}

Sinclair and Ghory (1987) include "family structure" as one feature of a student's profile that could be factored into an examination of that student's level of achievement 
(see Chapter II of this text). Analysis of the NELS sample indicated that while $19.3 \%$ of the students reported living in a single parent household, and an additional 13.78 lived with one birth parent and a step parent, the majority, $64.2 \%$, still lived with both birth parents. From the information sheets the students were asked to complete prior to each interview session, of the 22 participants, 14 students lived with both birth parents, 4 lived with the birth mother and a stepfather, and 4 lived with one birth parent. Thus, it would appear that these students live in a family structure that was relatively stable.

\section{Personality Characteristics}

The students selected for the interviews as well as those in the NELS database reported grades of primarily cs and Ds in their major subjects. However, these same populations of students still seemed to maintain a strong sense of personal worth and faith in their own abilities. As shown in Table 3 , the responses to the four NELS variables report a strong, positive feeling of esteem.

This pattern was reinforced in the interviews, as students presented a vivid contradiction to the image of an "invisible person" or a part of a "great, gray mass." They were articulate, direct, quick to laugh at each other's stories and able to laugh at themselves. Some of the students were known to be part of the "popular crowd" of their class, either according to sports participation, 
physical attractiveness, or outgoing personality features. At various times in the sessions, the students sang, danced, and demonstrated the proper technique for a free-throw in basketball. In general, they were animated and active.

Table 3

Self-Reported Self-Assessment Qualities

(NELS $\underline{N}=4,644$ )

Variable

of strongly

Agree \& Agree

$R$ feels good about him/herself

$29.6 \quad 60.2$

$R$ feels $s /$ he is a person of worth

28.2

61.2

$R$ able to do things as well as others

25.2

64.3

On the whole, $R$ satisfied with self

22.1

60.0

Overall, all of the students indicated that they felt very good about themselves and their individual abilities. These self-assessment features could represent a powerful source of motivation to these young people. However, rather than use this apparent sense of self-esteem as inspiration to pursue higher levels of academic engagement, consistently, these students earned grades indicating only marginal achievement. Further, the phenomenon of marginal engagement seemed to be as apparent outside of school, when the students could make independent choices with their discretionary time. 


\section{Non-School Activities}

The NELS study asks students to indicate their participation in a range of non-school activities. The intent of these questions is to ascertain how they spend their discretionary time. Results of 16 variables related to non-school activities are summarized in Table 4. Students were asked to indicate how often they participated in each activity. The responses were grouped into three sections according to the response rate.

--Activities in which $60 \%$ or more of the students often participated are grouped together in the first section.

--Activities that received sizable percentages for students who participated often and students who never participated are grouped together.

--Activities in which $60 \%$ or more of the students never participated are in the final category.

High participation activities--talking on the phone with friends, visiting friends at the local hangout, and driving or riding around (presumably with friends)--are those in which these students participate on the most frequent basis. While these activities may define the students more as typical teenagers rather than identify characteristics unique to marginal achievement, they share the characteristics of involving little academic or mental challenge. 
Table 4

Non-School Activities (NELS $\underline{N}=4,644$ )

\begin{tabular}{lll} 
Response Choice & f often & seld ser \\
\hline High Participation & & \\
Talk on phone w/friends & 80.7 & 19.3 \\
Visit w/friends at local hangout & 72.2 & 27.8 \\
Drive, ride around & 61.4 & 38.6 \\
Some Participation & & \\
Do things w/mom and dad & 58.8 & 41.3 \\
Go to park, pool, gym & 44.8 & 55.2 \\
play ball, other sports & 46.5 & 53.5 \\
Low Participation & & \\
Perform community service & 5.3 & 94.7 \\
Use P/C & 11.3 & 88.7 \\
Sports lessons & 11.8 & 88.2 \\
Attend youth groups & 15.2 & 84.8 \\
Music, art, dance class & 17.1 & 82.9 \\
Attend religious activities & 22.4 & 75.6 \\
Read for pleasure & 34.7 & 65.3 \\
Work on hobbies & 38.9 & 61.1 \\
Talks w/other adults & 39.4 & 60.6 \\
\hline
\end{tabular}

For the purposes of reporting, participation once or twice a week and every day or almost every day are reported as "Often." Rarely or never and less than once a week are reported as "Seldom." Percentages for multiple or missing responses are not included in the table.

Conspicuously less favorable are activities of an academic nature (such as using a computer or reading for pleasure), or regular activities involving a higher level of commitment (such as attending classes in music or art or participating with youth groups or in religious activities). Loosely structured, open-ended activities such as playing in a ball game or going to the park evidence an even split with about half of the respondents participating and a like 
number not participating. While engagement in some hobbies could represent a more challenging opportunity, less than $40 \%$ of the respondents claim regular participation.

\section{Student Part-Time Employment}

Based on data collected during interview sessions, part-time employment surfaced as a main feature of non-school activities for the focus group students. Seven of the 10 juniors and 5 of the 12 sophomores worked for pay, with restaurant and grocery work being most typical. The hours varied from Jill, a sophomore who worked saturdays only, to Jacob, a junior who claimed to work 35 hours per week at a local restaurant.

The impact of working at a job as a non-school activity was examined at some length, specifically in terms of the role a job played in the lives of these marginal achievers and the effect a work schedule could have on school effort and level of achievement. The consensus of the student interviews was that the opportunity to earn money was a greater priority than school, even though the money was used for "discretionary" items such as clothing, entertainment, and car expenses, and not for basic family needs. Overall, students did not perceive work as interfering with school demands, as long as they remained relatively consistent in their attendance and were attentive to some studying, the usual amount of homework which the school gave required 
little, if any, time outside of the classroom. Mike, a sophomore who worked about 20 hours per week, claimed,

I have had homework about three times this year. It's not the same as when my parents were in school, which they don't understand. The teachers today just don't want to grade papers, so they don't give homework any more.

Final exams and projects presented a bit more pressure in terms of needing to balance work with time to prepare school materials. However, this was pronounced very manageable, since school usually demanded very little, exams were basically once a term, and work was too important to miss.

From the students' perspectives, the reduced study time had little effect on the quality of the schoolwork produced. Most of the students agreed with the statement made by Steve, a sophomore working almost 25 hours a week at a car detailing shop, when he stated:

It doesn't matter what my schedule is anyway. I only put so much time in on school stuff, and when that time is up, I quit on it whether I have to go to work or not. At work, my boss decides how many hours I have to put in and how hard I have to work. But in school, I decide when it's time to quit, and for me, that's usually pretty early.

Working a job was a fairly defined feature of the students' non-school activities. The rest of the time, for those who worked, and most of the time for those who did not, was spent "hangin' out, bein' with friends, walkin' around." Only clarence, who played varsity football, and Jerry, who played basketball, participated in school sports. 
For the remainder of the students interviewed, there was no current participation in organized school sports, or sports in general, beyond "shootin' hoop" every now and then. There were no references to hobbies, music lessons, any regular club participation, or activities of a particularly significant interest to the students.

After putting in a fairly uneventful day in terms of academic performance at school, students said they went home to spend their personal time in a similarly undemanding fashion. Still, while their level of engagement in school may not have been particularly high, students emphasized that they had, in fact, gone to school, did most of what was asked of them, and had put in quite a bit of time. Therefore, the students felt they had earned a break when they went home.

Mark, a TAG student, summarized his personal profile

like this:

I make it through my classes, no sweat. I see my friends, eat some lunch, and go home. When I get home, I hang out. I listen to music, I chow. Three times a week, I get organized and take a shower before I have to go to work. I come home, and it starts all over again. My teachers stay off of my back, because I pass everything, and I show up for class. My parents stay off my back because I go to school, I have a job, and I don't do drugs. It's all completely under control. Right now, I'd say my life is perfect. I don't know how long it's going to last, but right now, it's right where I want it. 
student Characteristics

Summary

The information collected from the student Characteristics segment is summarized according to three main points.

1. Specific demographic variables such as gender, race, SES, or family composition did not seem to be significant identifiers of the marginal achieving student. Although there were more male students in the sub-sample than females, and strong perceptions of gender issues surfaced in the interviews, it is not clear how this factors into characterizing the marginal achieving student, if at all.

2. The students who are identified as marginal achievers still seemed to maintain a secure sense of who they are and what they are able to accomplish as individuals. They believe they are strong and capable at this point in their lives. They do not look at their current lifestyles and see examples of people who are "lost" or "forgotten." Rather, they see themselves as meeting, at an adequate level, the multiple expectations held at school, at home, and, for some, at a job. They do not see themselves as "marginal."

3. The level of participation and active engagement in self-selected, non-school activities followed a pattern of easy access, low risk options, with an emphasis on relationships. The students spent a great deal of time 
operating at a modest level of challenge, engagement, or effort, a condition that was satisfactory to them. They believed that their responsibilities to schoolwork and to their jobs were easy to balance, with work being a higher priority. Those who were employed seemed to accept the increased performance expectations fairly easily.

These points support an important conclusion of the student Characteristics segment. While the students in the middle achievement group see themselves as capable and satisfied with who they are and how they perform academically, teachers, counselors, other school personnel, and even parents characterize them, according to the literature presented in Chapter II, as "lost" and "invisible." The study was designed to address more precisely how school shapes the characteristics and experiences of the marginal achieving student in the secondary environment. In the next section, we examine the organizational correlates of marginal achievement.

\section{School Characteristics}

The previous segment examined the student demographics to try to identify specific characteristics of the marginal achiever. This section, School Characteristics, begins to narrow to the field of interest, academic achievement, by exploring the school environment in which the students function. Are students more likely to fall into the middle 
group in a school characterized by a given size, location, etc.? How do climate variables, such as general level and/or quality of the teacher/student relationships, level of interest or class expectation, factor into student engagement and achievement? The specific research questions examined the following areas:

1. What was the distribution of schools in terms of size (ADM), location (urbanicity), and SES?

2. What was the distribution of students' perceptions of teacher/student relations in their school?

3. What were the student-reported perceptions of their teachers' instructional style and expertise?

4. What was the student-reported level of interest in the general content?

5. What was the student-reported level of expectation and challenge felt in the general coursework?

To build an initial sense of the scope of school systems from which the sample of marginally achieving students was drawn, basic demographic features were gathered (RQ 1). In order to provide a context for their school experiences, it is necessary to gain a sense of how the students perceived the general environment of their school. Questions addressing the students' feelings and perceptions regarding school climate and content issues were a direct reflection of the concerns that surfaced in the literature review (RQ 2, 3, and 4). Finally, since high school 
academic achievement is primarily a performance-oriented construct, students reflected on their school environment specifically from a performance standpoint. How much did they feel challenged in school and how hard did they actually work (RQ 5)?

\section{School Characteristics}

The sample of students drawn from the NELS research data was not stratified for region, location, or size of school. Thus, there is a strong representation of types and sizes of schools from all areas of the country. These characteristics are summarized in Table 5 .

If descriptors of marginality include being "lost" or "invisible in the system," there may have been an expectation of data supporting lower percentages of marginally achieving students in smaller schools or in locations out of urban areas, where school systems may have had the resources to better serve this population. In fact, in examining Table 5, this was not necessarily the case, with approximately equal percentages of marginally achieving students found in schools with enrollments of 700 students or less and schools of 2,000 students or less. Also, there was a substantial increase in the percentages of marginally achieving students in suburban areas as contrasted to urban locations. Marginal student performance does not seem to be confined to any type of school classification, location, or enrollment. 
Table 5

Marginal School Performance and School Characteristics (NELS $\underline{N}=4,644$ )

\begin{tabular}{llr}
\hline Variable & Response Choice & Percentage \\
\hline \multirow{2}{*}{ Classification } & Public & \\
& Private: & 89.5 \\
& Catholic & 5.4 \\
& Private (other religion) & 2.0 \\
Urbanicity & Urivate (non-religious) & 2.8 \\
& Urban & 26.3 \\
& Suburban & 57.5 \\
Region of Country & Nural & 16.2 \\
& & \\
& Northeast & 17.5 \\
& South Central & 29.7 \\
& West & 32.2 \\
Size of School & $1-399$ & 20.5 \\
& $400-599$ & 11.2 \\
& $600-799$ & 12.1 \\
& $800-999$ & 9.8 \\
& $1,000-1,199$ & 11.9 \\
& $1,200-1,599$ & 13.4 \\
& $1,600-1,999$ & 16.9 \\
& $2,000-2,499$ & 12.4 \\
& $2,500+$ & 6.0 \\
& & 6.4 \\
& & \\
& &
\end{tabular}

Climate Issues: Student/ Teacher Relations in School

Narrowing the focus from a global picture of school demographics to the immediate classroom environment, several research questions addressed the students' perceptions of general climate issues. Herein, I assumed that how a student perceives the teacher's level of interest or response on an individual basis can have a profound effect on a student's level of engagement and achievement. Seven 
NELS variables related to the concept of classroom climate are summarized in Table 6 , with statistical data reflecting student responses as functions of gender, race, and SES (see Appendix I) :

1. Students get along well with teachers.

2. The teaching is good at school.

3. Teachers are interested in students.

4. When $\mathbf{R}$ works hard, teachers praise effort.

5. In class, often feel put down by teachers.

6. Often feel put down by students in class.

7. Most teachers listen to R.

Table 6

Student Reported Classroom Climate Variables Cross Tabulated with Gender, Race, and SES (NELS $\underline{N}=4,644)$

\begin{tabular}{|c|c|c|c|c|c|c|c|}
\hline & $x$ & & & $x$ & & & \\
\hline Veriable & $\begin{array}{c}\text { Strongly } \\
\text { Agree }\end{array}$ & $\begin{array}{c}x \\
\text { Agree }\end{array}$ & $\begin{array}{c}x \\
\text { Disagree }\end{array}$ & $\begin{array}{l}\text { Strongly } \\
\text { Disagree }\end{array}$ & $\begin{array}{l}\text { Chi- } \\
\text { square }\end{array}$ & df & Prob \\
\hline
\end{tabular}

1) Students get along well with teachers (see Appendix I, IV).

\begin{tabular}{|c|c|c|c|c|c|c|c|}
\hline \multicolumn{8}{|l|}{ Gender } \\
\hline Mole & 3.1 & 66.4 & 26.7 & 3.9 & 8.57 & 3 & 0.04 \\
\hline fensle & 2.6 & 66.6 & 28.3 & 2.5 & & & \\
\hline \multicolumn{8}{|l|}{ Race } \\
\hline Asian/Pac Ist & 4.1 & 69.6 & 22.8 & 3.5 & 31.30 & 9 & 0.01 \\
\hline Hispanic & 4.2 & 66.1 & 26.9 & 2.8 & & & \\
\hline Black/Not Hisp & 2.4 & 57.0 & 35.6 & 5.0 & & & \\
\hline White/Not Hisp & 2.6 & 67.8 & 26.5 & 3.1 & & & \\
\hline \multicolumn{8}{|l|}{ SES } \\
\hline Q1=Low & 2.7 & 64.2 & 29.2 & 3.8 & 22.38 & 9 & 0.01 \\
\hline 02 & 2.4 & 65.7 & 28.8 & 3.1 & & & \\
\hline 03 & 2.5 & 67.9 & 25.7 & 3.9 & & & \\
\hline$Q 4=H i g h$ & 4.2 & 68.6 & 25.3 & 1.8 & & & \\
\hline
\end{tabular}


Table 6

Student Reported Classroom Climate Variables

Cross Tabulated with Gender, Race, and SES (NELS $\underline{N}=4,644$ )

(Continued)

\begin{tabular}{|c|c|c|c|c|c|c|c|}
\hline & $x$ & & & $\%$ & & & \\
\hline Veriable & $\begin{array}{l}\text { Strongly } \\
\text { Agree }\end{array}$ & $\begin{array}{c}x \\
\text { Agree }\end{array}$ & $\begin{array}{c}x \\
\text { Disagree }\end{array}$ & $\begin{array}{l}\text { Strongly } \\
\text { Disagree }\end{array}$ & $\begin{array}{l}\text { Chi- } \\
\text { square }\end{array}$ & $\underline{d f}$ & Prob \\
\hline
\end{tabular}

2) The teeching is good ot school (see Appendix 1, 2).

\begin{tabular}{|c|c|c|c|c|c|c|c|}
\hline \multicolumn{8}{|l|}{ Gender } \\
\hline Male & 10.4 & 65.3 & 18.6 & 5.6 & 20.25 & 3 & 0.01 \\
\hline Female & 7.7 & 69.8 & 18.7 & 3.8 & & & \\
\hline \multicolumn{8}{|l|}{ Race } \\
\hline Asian/Pac Isl & 9.4 & 67.1 & 20.0 & 3.5 & 14.62 & 9 & 0.10 \\
\hline Hispanic & 10.4 & 68.7 & 17.8 & 3.2 & & & \\
\hline Black/Not Hisp & 12.3 & 67.4 & 15.9 & 4.4 & & & \\
\hline White/Not Hisp & 8.5 & 67.3 & 19.1 & 5.1 & & & \\
\hline \multicolumn{8}{|l|}{ SES } \\
\hline $01=$ LOW & 10.1 & 70.0 & 15.7 & 4.2 & 20.68 & 9 & 0.02 \\
\hline Q2 & 8.9 & 65.8 & 20.2 & 5.1 & & & \\
\hline 03 & 7.4 & 67.4 & 19.7 & 5.6 & & & \\
\hline$Q_{4}=\mathrm{High}$ & 10.9 & 66.5 & 18.5 & 4.2 & & & \\
\hline
\end{tabular}

3) Teachers are interested in students (see Appendix $I, 3)$ ).

\begin{tabular}{|c|c|c|c|c|c|c|c|}
\hline \multicolumn{8}{|l|}{ Gender } \\
\hline Male & 9.5 & 59.3 & 25.5 & 5.6 & 4.45 & 3 & 0.22 \\
\hline Fermole & 8.8 & 61.7 & 25.0 & 4.5 & & & \\
\hline \multicolumn{8}{|l|}{ Race } \\
\hline Asian/Pac Isl & 10.1 & 65.7 & 19.5 & 4.7 & 13.69 & 9 & 0.13 \\
\hline Hisponic & 10.4 & 61.2 & 24.2 & 4.2 & & & \\
\hline Black/Not Hisp & 10.8 & 62.1 & 20.9 & 6.2 & & & \\
\hline White/Hot Hisp & 8.7 & 59.7 & 26.4 & 5.2 & & & \\
\hline \multicolumn{8}{|l|}{ SES } \\
\hline Q1=LOH & 9.9 & 60.7 & 24.1 & 5.3 & 16.73 & 9 & 0.05 \\
\hline 02 & 7.4 & 60.7 & 26.2 & 5.7 & & & \\
\hline 03 & 8.7 & 59.3 & 27.0 & 5.0 & & & \\
\hline$O_{4}=\mathrm{High}$ & 11.5 & 61.0 & 23.2 & 4.3 & & & \\
\hline
\end{tabular}


Table 6

student Reported Classroom climate Variables

Cross Tabulated with Gender, Race,

and SES (NELS $\underline{N}=4,644$ )

(Continued)

\begin{tabular}{ccccccc}
\hline & $x$ & & $x$ \\
Strongly & $x$ & $x$ & Strongly & Chi- \\
Agriable & Agree & Disogree & Disagree & square & df & Prob \\
\hline
\end{tabular}

6) When R works hard, teachers proise effart (see Appendix I, W).

\begin{tabular}{|c|c|c|c|c|c|c|c|}
\hline \multicolumn{8}{|l|}{ Gender } \\
\hline Mole & 7.2 & 43.1 & 41.3 & 8.4 & 7.38 & 3 & 0.06 \\
\hline Fenale & 6.0 & 44.4 & 42.8 & 6.8 & & & \\
\hline \multicolumn{8}{|l|}{ Race } \\
\hline Asian/Pac Isl & 9.9 & 50.9 & 32.7 & 6.4 & 60.39 & 9 & 0.01 \\
\hline Hispanic & 8.1 & 48.4 & 38.2 & 5.3 & & & \\
\hline Black/Not Hisp & 11.4 & 48.5 & 33.8 & 6.4 & & & \\
\hline White/Not Hisp & 5.5 & 41.8 & 44.4 & 8.3 & & & \\
\hline \multicolumn{8}{|l|}{ SES } \\
\hline $01=$ LOW & 7.1 & 47.7 & 37.4 & 7.9 & 35.25 & 9 & 0.01 \\
\hline 02 & 5.5 & 40.0 & 45.1 & 9.4 & & & \\
\hline 03 & 6.5 & 42.8 & 43.2 & 7.5 & & & \\
\hline$Q_{6}=\mathrm{High}$ & 7.9 & 45.4 & 41.6 & 5.2 & & & \\
\hline
\end{tabular}

5) In cless, often feel put doun by teachers (see Appendix I, \$5).

\begin{tabular}{|c|c|c|c|c|c|c|c|}
\hline \multicolumn{8}{|l|}{ Gender } \\
\hline Male & 4.3 & 17.4 & 59.5 & 18.8 & 3.05 & 3 & 0.38 \\
\hline Female & 3.3 & 18.1 & 60.0 & 18.5 & & & \\
\hline \multicolumn{8}{|l|}{ Race } \\
\hline Asian/Poc IsI & 2.9 & 18.7 & 59.1 & 19.3 & 56.71 & 9 & 0.01 \\
\hline Hispenic & 3.2 & 14.9 & 60.4 & 21.5 & & & \\
\hline Black/Hot Hisp & 4.4 & 14.5 & 59.1 & 30.0 & & & \\
\hline thite/Not Hisp & 4.0 & 18.7 & 60.8 & 16.6 & & & \\
\hline \multicolumn{8}{|l|}{ SES } \\
\hline $01=$ Los & 4.3 & 17.3 & 57.2 & 21.3 & 12.88 & 9 & 0.17 \\
\hline 02 & 3.1 & 17.5 & 61.4 & 17.9 & & & \\
\hline 03 & 4.6 & 18.0 & 59.9 & 17.5 & & & \\
\hline$Q 4=\mathrm{High}$ & 3.2 & 18.5 & 60.3 & 18.0 & & & \\
\hline
\end{tabular}


Table 6

Student Reported Classroom Climate Variables

Cross Tabulated with Gender, Race,

and SES (NELS $\mathrm{N}=4,644$ )

(Continued)

\begin{tabular}{|c|c|c|c|c|c|c|c|}
\hline & $x$ & & & $x$ & & & \\
\hline Variable & $\begin{array}{l}\text { Strongly } \\
\text { Agree }\end{array}$ & $\underset{\text { Agree }}{x}$ & $\begin{array}{c}x \\
\text { Disagree }\end{array}$ & $\begin{array}{l}\text { Strongly } \\
\text { Disagree }\end{array}$ & $\begin{array}{l}\text { Chi- } \\
\text { square }\end{array}$ & df & Prob \\
\hline
\end{tabular}

6) Often feel purt doun by students in cless (see Appendix 1, 6).

\begin{tabular}{|c|c|c|c|c|c|c|c|}
\hline \multicolumn{8}{|l|}{ Gender } \\
\hline Male & 3.9 & 16.5 & 57.7 & 22.0 & 6.57 & 3 & 0.09 \\
\hline Fenole & 4.5 & 18.7 & 57.1 & 19.8 & & & \\
\hline \multicolumn{8}{|l|}{ Race } \\
\hline Asian/Pac Isl & 2.9 & 15.9 & 55.3 & 25.9 & 51.25 & 9 & 0.01 \\
\hline Hispanic & 1.4 & 18.2 & 57.4 & 23.0 & & & \\
\hline Black/Not Hisp & 3.7 & 16.5 & 49.2 & 30.5 & & & \\
\hline White/Not Hisp & 4.8 & 17.6 & 58.7 & 18.9 & & & \\
\hline \multicolumn{8}{|l|}{$\underline{\text { SES }}$} \\
\hline $01=$ LOW & 4.8 & 18.3 & 55.3 & 21.6 & 9.86 & 9 & 0.36 \\
\hline 02 & 3.7 & 18.4 & 57.1 & 20.8 & & & \\
\hline 03 & 4.7 & 15.7 & 59.5 & 20.2 & & & \\
\hline $\mathrm{O}_{4}=\mathrm{H} \mathrm{igh}$ & 3.3 & 17.4 & 57.7 & 21.5 & & & \\
\hline
\end{tabular}

7) post teachers listen to $R$ (see Appendix $I, 7)$ ).

Gender

$\begin{array}{llllllll}\text { Male } & 5.8 & 56.2 & 30.9 & 7.0 & 8.63 & 3 & 0.04 \\ \text { Female } & 6.2 & 59.3 & 29.3 & 5.2 & & & \end{array}$

Rece

$\begin{array}{llllllll}\text { Asian/Pac Isl } & 4.7 & 62.0 & 28.1 & 5.3 & 40.45 & 9 & 0.01\end{array}$

Hispanic

$5.6 \quad 62.5$

25.6

6.3

Black/Not Hisp

11.0

59.0

23.1

6.3

Wite/Not Hisp

5.4

56.6

31.8

6.2

SES

\begin{tabular}{|c|c|c|c|c|c|c|}
\hline$Q 1=L O W$ & 6.1 & 59.5 & 28.2 & 6.2 & 8.93 & 9 \\
\hline 02 & 5.8 & 56.9 & 31.2 & 6.2 & & \\
\hline 03 & 6.2 & 54.9 & 32.5 & 6.3 & & \\
\hline$Q_{4}=\mathrm{High}$ & 6.0 & 60.0 & 28.2 & 5.9 & & \\
\hline
\end{tabular}


An examination of these data shows that a majority of the respondents regard their teachers positively with respect to teacher/student relationships, classroom climate, and general level of instructional ability. However, within a generally positive framework, there were some significantly difference response patterns based on gender, race, and SES. As a function of gender, boys were more likely to respond that "Students get along well with teachers," and that "The teaching is good at school," while girls responded more positively in response to "Most teachers listen to r."

Race produced several significant differences in response patterns. Interestingly, while Black students were more likely to disagree with the variable "students get along well with teachers," which suggests a negative response or tension from these students' perceptions, they were also more likely to strongly agree that their hard work was praised and they were listened to by their teachers, and disagree that they felt put down in the classroom by their teachers or other students. In response to the variable "When $R$ works hard, teachers praise effort," White students were more likely to disagree than Black, Asian, or Hispanic students.

The literature related to SES and school achievement suggested that low SES students may experience different, diminished opportunities when compared to students in a 
higher ses quartile. This is born out somewhat in these data, specifically in the more positive responses of students in the high sEs quartile. They were more likely to agree that students and teachers get along well, the teaching is good, teachers are interested in students, and that hard work earns teacher praise than students in the lower sEs quartiles.

\section{Climate Issues: Teachers'} Instructional style and Expertise

The examination of data regarding a teacher's instructional style and expertise indicated some interesting contradictions in the student perceptions of their teachers' abilities. The responses in this area overlapped repeatedly with student/teacher relations and classroom climate issues. Some key themes emerged in relation to the marginal achieving students' perceptions of how their teachers function and respond to them in the classroom.

A variety of delivery techniques surfaced as the positive feature of an instructor who was favored by the students. A teacher who showed a sense of style and freedom in her/his repertoire was seen as being more likely to encourage and appreciate these characteristics in the students themselves. Cooperative learning techniques or any group project configurations were emphasized positively, not so much for their instructional superiority as for the opportunities they provided to be with friends. 
The ability to explain material without being condescending and working to make sure the students really understood content was another area of focus. Teachers who had mastered a balance between "getting on our level" and "not talking down to us like we're babies" were viewed as a positive person in the school day. It was clear the students would be willing to work through content they did not particularly like, as long as it was presented in a way that showed the teacher was making the material accessible to them and offering a chance for success. Conversely, when this relational component was not evident with a specific teacher, even a subject that was positively regarded could just "slip," in the words of one participant, ". . . to just

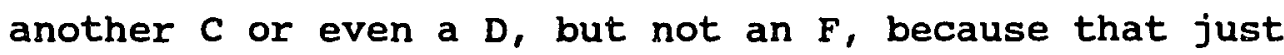
causes too many problems."

Teachers who were able to respond to students as individuals were viewed, not only as being fine professionals, but as a lifeline keeping students alive in a class. The personal connection between teachers and students was the overriding feature of the discussion about the interpersonal skills teachers demonstrated as part of their instructional capacity in the classroom. Mike, a sophomore, summarized such a relationship, which had evidence of both the positive and negative aspects to which students alluded in the discussion.

I started out working hard in math. I wasn't just one of the herd. Sometimes a teacher may find me 
interesting; I may find them interesting.

Sometimes a teacher will explore something with

you and maybe go further with you than with all

the rest of the class. Makes me think they see

something in me they don't see in someone else.

My math teacher lost interest in me when I bombed

on the tests. She doesn't do a very good job of

explaining to me, so I probably haven't been the

best student. I've brought it on myself, but

that's the point of gearing down.

According to the remarks made by the students, the more consistent a teacher was in establishing this connection

with a broad base of students, the more likely it was

received as being genuine and positive. A teacher had to be able to look past the exterior to the real person inside. Comments came from a variety of students to support this perspective:

Ms. M really cares about you. Kids come in to talk to her, even if they don't have class. She keeps things confidential. Ms. F finds the good in everybody, even if you smoke or do drugs.

she's always trying to get you to stop, but she'll always love you for who you are.

Mr. A is there if you need him. You're more than just a student ID number to him.

Conversely, teachers who were unable to establish this positive connection were viewed harshly. Inconsistencies were unforgivable to these students. Teachers who allowed students to become targets of other students in the class without putting a stop to that behavior were viewed negatively, even if the teacher did not participate. It was viewed as the teacher's job to protect all students, even from each other. 
Students were presented with the opportunity to evaluate their teachers' instructional styles from the perspective of negative characteristics. Teachers who talked too much received consistently negative remarks. Jerry, who described a pattern of teachers who:

-. . go on and on and only stop in enough time to give you the assignment for the next day, which you can't understand, because they haven't stopped talking long enough for you to ask questions. So you go home and try the best you can.

students indicated that this style of teaching was quite common.

Continuing in the examination of negative instructional traits, the subject of teacher preference surfaced as a critical feature in the marginal achievers' school perceptions. Teachers who were disorganized, lost papers, or made promises they did not keep were unanimously criticized, again with the sense this sort of thing happened a great deal. More than the particular item or statement, for the students, this presented evidence of a teacher's ability to respond differently to students. Some students received preferential treatment; some did not. The choice was always the teacher's to make. According to the students, and, perhaps, evidenced in the lack of student support for the statement "When the respondent works hard, teachers praise the effort," a strong feeling emerged that the students did not see themselves as being in the group that would get preferential treatment, however that 
preference manifested itself in the classroom. Small

episodes took on great significance in their eyes.

One time, I had this teacher who said he would change my seat to the front of the room, because I told him these two girls kept talking all the time, and I'm not so great in math. So I asked him to change me, but I wanted him to wait a few days, and maybe change a few people's seats so I wouldn't be the only one, because that would be really bad. Well, he must have forgotten or something, because I sat there for six weeks, and he never moved me. Finally, I got a new seat, because he got mad at everybody and made a new seating chart. I ended up in a worse spot than before, but I never bothered to even ask him to change me, because I knew he didn't care enough about me to even remember the first time. So I didn't bother. I got a $D$ from him, which was good, because I didn't have to take the class again.

David, a sophomore, concluded from this experience that teachers made decisions about students personally, they cared about them or did not care, and then acted accordingly. The critical feature seemed to be the acknowledgment that another student would have been treated differently and would have the seat changed promptly because of who $s /$ he was. That person would have been viewed by the middle achieving student as a member of the high-achieving, high profile group favored in the eyes of the teacher. In their own eyes, the middle achievers did not see themselves in that preferred class. Yet there did not appear to be any bitterness or anger directed toward the high achievers. The attitude was more one of acceptance--this is how school is. This presence of teacher preference or favoritism directed toward selected students was often a class where 
students said they would produce enough to pass and no more--the $C$ or $D$ level of achievement. Acting on the assumption they would never be one of the "favored ones," this situation was viewed as a place where the marginal group would be in the safe, middle ground of $c$, and occasionally D, work. Herein, the marginal achievers "knew their place," and acted with instincts developed in the previous ten years of school.

Climate Issues: Level of Interest in course content

Questions addressing class content were generally startup questions for the group sessions, since it was not an overly personal topic or one that would be too revealing for the students to discuss. As a rule, it was more difficult than anticipated to gain information about these topics, because the students were not in the habit of discussing their courses or the content in any sort of systematic way. Most had not given it much thought, and, they assured me repeatedly, they had never been asked. When presented with the general task of describing classes or content they liked or disliked, the conversation would drift quickly to the teachers who taught specific classes, rather than the content or the material.

There were no apparent patterns in the subjects the students likea or disliked. It cannot be said this group was more inclined to enjoy participatory classes such as art 
or physical education or classes such as math or computers. Statements made by the students seemed to cover the spectrum of classes: "I like math, art, band. Pretty much all of my classes except history. It's too boring." "I can't do math. I love lit. I love to read." "I hate math--it's always the same: take notes, do the assignments."

Some interesting concepts did begin to surface, however, in an exploration for a possible pattern in classes which were more appealing to students. First, there was apparent consensus that much of the work they were asked to do in their classes was uninteresting and irrelevant. Megan stated,

Almost everything $I$ do in school is completely boring and meaningless. Maybe if they asked me to do something halfway interesting, I'd be more involved, although I think I'd die of shock first.

Although the students were not always clear about what they considered to be a good curriculum, greater connection to their present lives and focused toward immediate use was viewed as both a dramatic difference as well as a great improvement over the current content.

As an example from her own experience, Megan offered her current English class.

I've always failed English. Doesn't mean I've always hated English, but I've always failed it. People who don't like to read aren't going to start because you give them a worksheet on a stupid story.

In his session, clarence added to this theme with his comment, "Please tell me why we have to read the stuff we 
read in American Lit? I don't think I'II ever read The

Scarlet Letter to my children as a bedtime story."

When I suggested there might be other reasons to struggle through a complex story, even though it would not be used for children's reading, clarence amended his feelings, but only slightly.

OK, I can see that when you're a junior in school they're not going to give you see spot Run. But there are lots of other things we could read that have to do with "now," and not two hundred years ago stuff. Why can't they just let "us" choose, sometimes? How well would "you" do when someone is always telling you what to read? But that wouldn't happen to you, because in real life, you get to choose, most of the time. Is it going to make us want to read "more" when most of the time we have no choices at all? You tell me how that works, because I'd sure like to know. I've been doing this for many years now, and it still makes no sense.

The level of interest in the subject matter of any given class can certainly be enhanced by the teacher. However, the final arbiter interest and involvement is each individual student. For these marginal achieving students, the level of interest and involvement was consistently quite low in most of the courses they were required to take. When questioned further, the students indicated their coursework was primarily "General" in nature, e.g., General Math, General Science, Regular English, etc. One participant summed up his point of view, representing that of others,

Maybe if they gave me the kind of classes like Advanced English or an honors class, maybe something goes on in there that's more interesting. But those kind of classes aren't 
meant for kids like me. I'm sort of a basic person, so I get the basic classes.

\section{Level of Expectation and}

Challenge

Teacher/student climate variables emphasized the importance of the relational component in the classroom as a factor in how students felt in a class and how hard they might work for a teacher. The final research question addressed the level of expectation and challenge inherent in the coursework itself and as presented by a specific teacher.

Four required classes were examined from the NELS survey sample. Math, English, history, and science were presented to students from three different perspectives:

1. How often did they work hard?

2. How often were they asked to show understanding?

3. How often did they feel challenged?

The student responses are summarized in Table 7 .

The responses to these three questions for each class illustrate an important link to a student's level of engagement and performance. If the level of expectation and challenge was too low, it could be hard to remain focused and the class might end up being boring, which was a common indication from the students. If the level of expectation and challenge was too high, the pressure could be too much for a student to handle. Either situation could cause a 
student to withdraw their efforts to a level of performance which would earn a C or D grade.

Table 7

Level of Expectation in Required classes

(NELS $\underline{N}=4,644$ )

\begin{tabular}{|c|c|c|c|}
\hline Variable & $q$ Never & \& Rarely & \& often \\
\hline \multicolumn{4}{|l|}{ Class=Math } \\
\hline $\begin{array}{l}\text { Show understanding } \\
\text { Work hard } \\
\text { Feel challenged }\end{array}$ & $\begin{array}{r}11.1 \\
6.1 \\
8.9\end{array}$ & $\begin{array}{l}29.4 \\
16.0 \\
17.6\end{array}$ & $\begin{array}{l}55.6 \\
74.0 \\
69.6\end{array}$ \\
\hline \multicolumn{4}{|l|}{ Class=English } \\
\hline $\begin{array}{l}\text { Show understanding } \\
\text { Work hard } \\
\text { Feel challenged }\end{array}$ & $\begin{array}{r}16.4 \\
5.6 \\
12.0\end{array}$ & $\begin{array}{l}35.4 \\
18.0 \\
29.4\end{array}$ & $\begin{array}{l}47.3 \\
75.4 \\
57.7\end{array}$ \\
\hline \multicolumn{4}{|l|}{ Class $=$ History } \\
\hline $\begin{array}{l}\text { Show understanding } \\
\text { Work hard } \\
\text { Feel challenged }\end{array}$ & $\begin{array}{r}14.7 \\
5.2 \\
8.3\end{array}$ & $\begin{array}{l}24.0 \\
13.5 \\
18.6\end{array}$ & $\begin{array}{l}29.3 \\
49.3 \\
41.2\end{array}$ \\
\hline \multicolumn{4}{|l|}{ Class=Science } \\
\hline $\begin{array}{l}\text { Show understanding } \\
\text { Work hard } \\
\text { Feel challenged }\end{array}$ & $\begin{array}{r}15.2 \\
5.0 \\
7.9\end{array}$ & $\begin{array}{l}32.4 \\
17.7 \\
19.6\end{array}$ & $\begin{array}{l}42.7 \\
67.8 \\
62.9\end{array}$ \\
\hline \multicolumn{4}{|c|}{$\begin{array}{l}\text { For the purpose of reporting, for each of the three } \\
\text { questions asked regarding level of expectation and challenge } \\
\text { felt in the individual classes, the choices less than once a } \\
\text { week and about once a week are reported as } 8 \text { Rarely, while a } \\
\text { few times a week and almost every day are reported as } \delta \\
\text { Often. }\end{array}$} \\
\hline
\end{tabular}

From these data, it appeared that a majority of the students believed they worked hard and felt challenged in their classes on a regular basis. The response choice "Show understanding" may have been interpreted as a weekly quiz or 
assignments turned in for credit. Respondents may not have been thinking about more subtle forms of checks.

The above information might be viewed as evidence of regular engagement, yet two other considerations became obvious. First, while the majority of the respondents reported a reasonably high level of expectation and challenge in the classes, if we combine the response percentages for those who report Never feeling challenged, working hard, etc., and those who report Rarely, anywhere from 20-50\% of the students claimed to be in classes where the level of expectation, and the accompanying need to produce at an acceptable standard was perceived as quite low. This would support the low levels of expectation and challenge the focus group students claimed were common features of their classes.

A second consideration was evident through examination of the level of expectation and challenge felt by the students and the grades they reported receiving in these same classes. In Table 8 , grades are summarized according to students who claimed to be earning mostly $A s$ and $B s$ and those who reported mostly Cs and Ds. It was not possible from the data to determine the level of the class (e.g., Introductory, Advanced, etc.). 
Table 8

Students' Self-Reported Grades in Required Classes* (NELS $\underline{N}=4,644$ )

\begin{tabular}{lcc}
\hline Class & o A-B & \& C-D \\
\hline Math & 17.4 & 78.3 \\
English & 18.2 & 81.7 \\
History & 14.0 & 68.3 \\
Science & 13.0 & 84.3 \\
\hline \#Responses for those not taking the course, missing \\
responses, and those in classes that were not graded \\
completed the percentages.
\end{tabular}

In all of the classes reported, less than 208 of the respondents claimed to be earning grades which suggested a high level of excellence, while $68 \%$ or higher were earning grades in the marginal achievement span. The apparent discrepancy between the efforts the students claimed to be making and the grades they earned in the end merits some examination. When asked to judge their own efforts and experiences, some of the students saw themselves as working hard and feeling challenged, etc., while other students perceived that a high level of engagement was rare for them. For those students who did see themselves as working hard and feeling challenged by the coursework, the resulting grades may have been received with a sense of disappointment, frustration, or, perhaps, routine acceptance. For those students who did not see themselves as working particularly hard, the resulting grades may have been seen as a match to their efforts, much like the student 
who claimed to ". . have brought it on myself." Regardless of the student's self-evaluation of performance, however, the academic results were similar. Whether they worked hard or not, only a small minority of the students claimed to be earning As or Bs, while the majority of the students, claimed to be earning Cs and Ds.

\section{School Characteristics}

Summary

The information collected from the School Characteristics section is summarized around four main points:

1. The size of a school, its location, and its SES were not variables which identified a specific profile of a school system or type of environment where marginal achieving students were more likely to be found. In the survey sample, students in the marginal achievement GPA span came from schools of all configurations.

2. Climate variables in a given classroom influenced a student's level of effort and production. Much of the coursework was perceived to be unrelated to the students' lives or to be of much interest. Therefore, student motivation was quite low. Teachers who were skilled in developing sincere personal relationships with the students were favored highly over a class situation where the students were treated impersonally or simply as one of a group, even if the class was a required subject. 
3. There was a conflicting relationship between the students' self-perceptions of their level of effort in a class and the grades they received. While many students felt the teacher may not always have recognized their efforts, they believed they were working hard and were challenged sufficiently. However, the primary grade level was $C$ or $D$, which indicated only a marginal level of achievement.

4. Finally, the concept of teacher preference or favoritism for one group over another surfaced as a significant finding. There was a specific perception held by the marginally achieving students that high achieving, high profile students were the favored or chosen group within a class, while the marginally achieving students neither received, nor did they seem to expect any special support or attention.

The lack of specific identifying characteristics, either of the students, themselves, or of the schools they attend, sustains the image of the marginal achiever as a student who could be anyone and found anywhere. However, emerging information of equal significance suggested a certain dynamic was occurring within the school between the students, who believed they were not in the "favored class" and geared down to a minimal level of effort, and school personnel (primarily, but not exclusively, teachers) who demonstrated in their daily behaviors there were favorites, 
or students other than the marginal achievers, who received more attention and assistance. This dynamic at least maintained the marginally achieving student's experiences, and may have played a part in initiating these experiences as well. The nature of these experiences was explored in section three.

\section{School Experiences}

The section about student characteristics described the marginal achiever in terms of individual characteristics, while the section related to school Characteristics shared information regarding those school setting and climate variables that provided a context for the student's achievement. School Experiences combines the two entities-the students and the school setting--to describe the nature of marginal achieving students' school experiences, which formed the core of the research question. What was it like to go to school and earn $C$ and $D$ grades? How did these students behave and what was the response to them in return?

1. What was the distribution of positive interactions in the school environment, including recognition of achievement (e.g., awards), participation in school activities, etc.?

2. What was the distribution of negative interactions in the school environment, including rule infractions, referrals, consequences, etc.? 
3. What were the self-reported student perceptions of their abilities as achievers?

4. What were the self-reported patterns in achievement over the student's lifetime?

To gain the broadest understanding possible of the marginal achieving student's school experiences, specific research questions for this segment addressed school interactions from both a positive and a negative perspective (RQ 1, 2). Within the established context of school achievement, the research questions focused on the students' own perceptions of their abilities as achievers--how did they evaluate their work now (RQ 3), and did they see any patterns in their level of performance and achievement? Was there ever a time when their profile was different (either better or worse) than at present (RQ 4)?

\section{Positive School Interactions}

Data indicate that the marginal achieving student does not experience positive school interactions on any sort of consistent basis. Regardless of gender, race, or SES, these students indicated a consistent absence of positive school recognition in a variety of standard school formats. From the NELS survey, the findings from nine diverse areas of student recognition are compiled in Table 9. 
Table 9

Positive School Interactions: Student

Recognition (NELS $\underline{N}=4,644$ )

Variable

\&oes Not Apply

Received a community service award

96.3

$R$ won an academic honor

93.9

$R$ elected officer of school class

Participated in voc./tech. competition

93.3

$R$ participated in a sci./math fair

92.8

Received recog. for good grades

91.5

Received recog. for writing an essay

91.4

Received recog. for good attendance

91.4

88.5

It appears that the schools in which these students operated did little to recognize and/or reward their efforts. A full $93.9 \%$ of the students claimed they had never received an award recognizing an academic achievement. While it may be true that the marginally achieving students do not perform at a level of excellence typically worthy of awards, effort or improvement in an academic area, positive citizenship, etc., are other areas of student performance that are often acknowledged for motivation, as well as recognition purposes. Over two thirds of the respondents, $66.3 \%$, claimed they had never won any sort of award at all. Only a modest $11.5 \%$ had won an award for something as simple as good attendance.

If these data reflect a lack of positive interaction from the school toward the student, there was a corresponding lack of involvement on the part of the 
students in school-sponsored activities. Here, too, the data supported the statement that the marginal achieving student did not interact, on a regular basis, in many positive school-sponsored activities. Percentages from a wide variety of activities are compiled in Table 10, giving evidence of this lack of engagement in school.

Table 10

Positive School Interaction: Activity Participation (NELS $\underline{N}=4,644$ )

Played baseball/softball at school

Played basketball at school

Played football at school

Played soccer at school*

Participated on swim team at school*

Played other team sport*

Played an individual sport

Participated in cheerleading

Participated on pom-pom, drill team*

Participated in school band, orchestra

Participated in school play or musical

Participated in student government

Participated in academic honor society

Participated in school yearbook, newspaper

Participated in school service clubs*

Participated in school academic clubs

Participated in school hobby clubs*

Participated in school FTA, FHA, FFA
85.5

82.4

82.3

93.0

96.7

87.0

80.1

95.1

96.3

80.8

90.7

96.7

99.2

94.2

92.2

78.1

93.3

87.5

For the purposes of reporting, responses indicating a school that did not offer an activity were combined with the response Did Not Participate. In all cases, schools without activities accounted for less than $10 \%$ except as noted (*).

Fewer than one out of every five marginally achieving students were involved in a school sponsored activity, with 
the interesting exception of participating in school academic clubs, such as Math club, Spanish club, etc. Beyond team sports, which usually require trying out and making the cuts to remain on a team, participating in service clubs, the school play, being a part of the newspaper staff, etc., are typical opportunities available for all students who wish to join. Even in these areas, the marginally achieving student did not show a high level of participation.

clearly, these students did not spend a great deal of time involved in a school program after their classes ended for the day. This confirmed the previous conclusion which suggested that the students left to be with friends, go to a job, or just go home. Once their required academic responsibilities were completed, these students gave little time to their school, even in the areas which could constitute a positive interaction.

\section{Negative School Interactions}

The vast majority of the marginally achieving students rarely engaged in any behavior requiring school disciplinary action. At many levels, from classroom rules, to more serious policy questions that could lead to disciplinary referrals or school administered consequences, the marginally achieving students avoided negative sanctions. From the NELS data, the percentages of student involvement 
in several levels of negative school interactions are summarized in Table 11 .

Table 11

Negative School Interactions

(NELS $N=4,644$ )

Variable

\&

8

Seldom sometimes often

\section{Class Readiness*}

How many $t$ imes:

* $R$ went to class w/o paper or pencil

$R$ went to class $w / 0$ books

$R$ went to class w/O HW done

87.4

92.4

73.5

44.0

20.4

52.7

82.5

89.3

99.2

95.1
12.6

7.6

25.5

Getting in Trouble**

$\star \star R$ got in trouble

$R$ cut/skip classes

$R$ was put on in-sch susp

$R$ was suspended out of $\mathrm{sch}$

$R$ was transferred for disc action

$R$ was arrested

$$
\begin{array}{r}
48.6 \\
62.1 \\
36.9 \\
16.7 \\
10.3 \\
.8 \\
4.5
\end{array}
$$

* For the purposes of reporting, response choices seldom and never were reported as Never, while often and usually were reported as often.

** For reporting purposes, response choices 1-2 Times and 3-6 Times were reported as Sometimes, while over 10 Times was reported as often.

In examining Table 11, "Trouble" and "being in trouble" may have constituted different things to different students. For some students, a verbal reminder to "Be Quiet" may have qualified as trouble, while another student may have felt s/he is not in trouble until a referral had been written 
demanding administrative action. The variable " $R$ got in trouble" reflected this ambiguity. The other items, however, were quite clear in meaning, and the responses indicated a profile of the marginally achieving student as a person who avoided getting into trouble. This finding corroborated with the image presented in the literature, for marginal achievers kept their part of the classroom bargain by being routinely prepared and in compliance with school rules.

\section{Student Abilities as}

Achievers

This section asked two main questions: What kind of a student are you? and how do you see your level of success? Many, like sophomore Casey, acknowledged a lack of motivation to work harder at their school work.

I'll work hard if I want to, if I like the class. I like my morning classes, but my afternoon classes I hate. We do poetry, and it's all tests, and she's hovering over you all the time, do this, do that. And she just wants you to do it for her, not for yourself, and she really doesn't put much into her classes. She just tells us to read and she never gives us class time. It doesn't make me want to work hard. I have a $c$ in that class, and $I$ have to get $C s$ and above to make my parents happy, and so I can drive. That's all I'm gonna get, because I'm not gonna put in extra effort. I'm not accomplishing anything. I could read the book myself.

Tina, a junior with a GPA of 1.90 , offered her self-assessment from the vantage point of having been at two schools: 
When I was at $S$ (other school), I was like, let's be bad! And if you got bad grades, it was cool. When I got here, I made some friends who were different, and it's kept me out of trouble. I want to get good grades, and I've started to think a lot about my future. That's what I go for now, raising $m y$ GPA. But I'm a real daydreamer. I'm not real good at hangin' in there.

This lack of motivation to work harder or achieve at consistently higher levels of excellence was acknowledged by the students as a feature that characterized their school performance. However, students framed this lack of effort in the larger context that, within certain parameters, minimal efforts could still lead to success, as measured by passing a given class. In terms of academics, these boundaries could be very broad, allowing for a range of student attitudes, some of which bordered on disdain. Greg, a junior, stated flatly, "I have never worked hard since I've been in school." currently in an alternative school program, Greg believed that he would have no trouble in passing his remaining classes and graduating on time. Another student, Robert, identified himself in less than flattering terms:

I'm a bad student. I like to distract others, sort of like, you know, a class clown. I think I probably annoy some teachers, but they know I'd never hurt anybody, so they leave me alone. I do what I have to do to get by, and I guess it must work, because I have never failed a class. It only gets hard at the end of the quarter, but then it's just for a few days, maybe a week, that I have to work hard.

Megan spotlighted a specific teacher as a good example of what school looks like to her: 
My teacher acts like a fourth grader. I bypass her, and do what I need to do to get by. I know exactly how many classes I can miss, how many days I have to participate, to get a passing grade.

Several students commented that they realized their lack of performance would have to change if they were in a different structure, e.g., working a job, a different school program such as college, etc. Mandy, a TAG student, stated that she knew she would have to change, but in a different environment, she would be more willing to change. "If you could challenge classes, challenge high school in general, I'd be in college, right now. Then I'd work harder."

This was an important point regarding the students' self-analysis of their work ethic. While they were clear their lack of effort would have to change under other, more rigorous circumstances, they returned continuously to the belief that their current academic standards would sustain them, and they would graduate with their class. A greater effort was not even necessary at this point, since, as Mark stated,

Ms. Summers, I don't think you realize that unless you're going to a big college somewhere, it's all pass/no pass. You don't have to work very hard in school, and you will still be able to do, basically, anything you want.

\section{Patterns in student}

Achievement

In trying to establish a larger context for these provocative responses, I raised the question of comparison by asking if there was ever a time when things were 
different, either for the better or worse, than right now. Only Jerry could describe how he had pulled his grades up from straight Fs to become eligible to play basketball. At this point, he was passing five classes with 3 Cs, 2 Ds, and a $B$ in PE. All of the other stories described some version of falling from a higher level of achievement to the present level of Cs and Ds. Two common themes in these scenarios were (a) the presence of some episode, from mild to significant, that caused the student's downfall, (b) coupled with a specific response from the school.

within this theme of disruptive events, the transition from middle school to high school was often a difficult time for these students. Clarence recalled, "In my first quarter as a freshman, I started strong. I really wanted to do well in my classes. But it was all the same, and I started slacking off almost immediately." Pete lasted a little longer--all the way through his first year. "I did well as a freshman. I just understood everything. I did what I was supposed to do, and I didn't fool around. This year, everything just got so much harder."

specific events in that first year had a powerful influence on the students. Two students recalled the impact of failing a class as freshman, and how the episodes changed them. For Tom, it was a higher level math class.

I flunked it, I know. I worked hard, but I just didn't get it, so they put me down. So I worked even harder to get back into the top track math, but they didn't put me up. I'm still in low math. 
I wonder why I even bothered. I'm still in low math. All that work didn't pay off.

For Tina, it was freshman PE, which she had failed in her previous school.

When I got here, they put me in a class with the younger kids. Do you know what that does to me? It's like I have a record, and I can't escape it, no matter what I do. How many times do you have to say you're sorry for stuff you did when you were a freshman, and I don't even remember most of it now, anyway.

More serious events proved to be extremely disruptive in the students' academic careers. Brandon was trying to build new school habits after returning from a recent 30-day rehabilitation program for drug and alcohol dependence. Megan lost almost a month of regular assignments when her ex-boyfriend tried to commit suicide, and she was spending a great deal of her time with him and his family. Divorce and moving from one school to another were cited as being reasons why students lost significant ground at school. Whatever the nature of the event, common to the stories was the way the students were treated when they returned to their old routines. Brandon stated, "Teachers remember you as a failure, and you get labelled forever," a response that received immediate affirmation from the group. He continued,

When you fall behind, you lose your study skills, and you don't know how to get caught up. It's hard to stay focused when you keep losing ground, and you know you're going to fail. 
Some students pointed to the school system as the main source of difficulty. "Don't ever expect help from the teachers to help you get caught up, either. When things go bad, you are on your own," stated Jerry, who spoke from the experience of having been a very poor student who was now experiencing some success in his classes. Pete, a sophomore, summarized the progression of events and feelings.

I have been a good student, and the teachers really liked me. I don't know, maybe I thought I could do the stuff without working very hard. Whatever happened, it all got a lot harder, and I really fell apart. Guess what? The teachers wrote me off. I guess they figured I had always taken care of myself, I could just $f$ ix myself without any help from them. I can't tell you how much it hurts when you find out they never really cared about you as a person, or they only cared when you were easy. Well, I've learned to keep a pretty low profile, now that I've messed up. No one expects anything from me now, so there's a lot less pressure. I don't need the spotlight. It's just not worth it to me, what you have to do and what you have to be to stay there.

Evidence of this isolation is supported by the NELS survey data which indicated that after returning from an absence, only $27.2 \%$ of the students claimed their teacher even asked where they had been. Strategies to help the students get caught up with the missing assignments, either with support from the teacher, other students, counselors, etc., were made available to these returning students less than $50 \%$ of the time. However, it was clear there were some good opportunities available outside of the school system. Megan summed up her experience in a matter-of-fact tone: 
Last year, I failed a lot of classes, because I didn't try. I turned 16 , and I realized I didn't want to drop out of school, but I'm so far behind, I can't take the classes I want. So I take psych classes at the college, because I can. I closed the doors here when $I$ was younger.

\section{Teacher Favoritism}

The question surfaced regarding which students, if any, would receive substantial help from the system after they had lost ground or at any point in their school careers. Appearing again was the concept of favored students, typically high-achievers, who were perceived by the marginal achievers as "chosen ones" within their school. It was in this discussion of favoritism within the classroom that the concept of gender inequities was most apparent.

For the purpose of establishing clear terms, the students defined "success" as passing a given class. They did not expect enough assistance through teacher favoritism to receive more than their usual grades, which meant a $c$ at best, or $\mathrm{a} D$ at worst. When asked if it was easier for girls to "skate" in a class, that is, to do the minimum amount of work and still pass based more on personality than product quality, the response was divided, with variations based on the gender makeup of the group. In Group A, the boys were adamant that girls had a decided edge in this unspoken class competition. They based their decision on a girl's outward appearance and her ability to "charm" a teacher. David related the following example: 
In Mr. H's class, he has his favorites. Those girls sit there and do nothing, and they pass. They just laugh at his stupid jokes, and he loves it. It makes me sick, but I'd do it, too, if I thought I could get away with it. It doesn't work that way for guys, though.

In Group B, Pete commented on a similar dynamic between the young, male teacher of one of his classes and a group of senior girls who thought the teacher was very attractive.

It's like they're his fan club. They sit there and stare at him all period. I have never seen him yell at them, or do anything that might make them not think he was so terrific. It's like he's afraid they won't love him any more. It's so disgusting to watch this every day, but it's sort of interesting, too. It's like television, I swear.

Girls in the all-girl group at site $A$ had two perspectives representing agreement with the general statement that girls had an easier time of it and disagreement on the basis that boys had their angles, too. The difference between boys and girls, said the girls, was the girls' superior level of maturity and understanding. According to Sharon,

Boys are naturally immature. They goof around too much. A teacher will put a name on them immediately, I don't like you, and they won't pass. Girls are quiet, and they can get by.

Tina added,

Boys could do it if they wanted to, they just don't want to. They have their macho attitudes. Girls can adjust their attitudes. Girls are just so much more subtle than boys. They are at least two years ahead. 
The system was not foolproof, however, and several

girls highlighted some of the inconsistencies. According to Mandy,

- . it depends on the girl. If she's rowdy and obnoxious, it's unlikely she'll pass, even if she tries to charm the teacher. But if she's calm and mellow, she'll have an easier time of passing.

Susan added that it depended on the gender of the teacher

as well. "Female teachers usually know what a girl is up to if they try to be too nice."

In the interview group from site $B$ (which included three boys and one girl), Angie defended her gender after hearing the typical responses from the boys in her group.

I have a different perspective, because I am a girl. But my history teacher is a football coach, and I see guys who can be the teacher's pet, too. There's an advantage there. The teacher wants the kid to get good grades so they can stay on the team.

Angie's remarks caused the boys to respond in kind. David said, "It's definitely an advantage, because the coach knows that person as an individual." Mark added, "She's got a real point. My study hall teacher is a coach, and if you're not a wrestler, you're squat to him." The apparent theme was that having some quality to help distinguish a person in the eyes of the teacher was seen as a definite advantage. If you were an athlete, an attractive girl, etc., you had an identity in a class which was perceived as having value. This was in contrast to the marginal 
achievers, who perceived themselves as having no value in the overall system.

\section{School Experiences Summary}

The School Experiences section produced some very provocative findings, which can be summarized according to five main points.

1. Data support the conclusion that the marginally achieving student was not regularly involved in most positive school interactions. For the most part, they did not receive positive recognition or awards from the school, and they did not remain on campus to participate in school-sponsored activities after their classes were finished for the day.

2. Marginally achieving students were not involved with minor rule infractions or major policy violations. Many indicated they were rarely, if ever, even late or unprepared for class. Only a very small percentage of the survey population had ever received any major consequences such as suspension.

3. The marginally achieving students in this study felt they were not working as hard as they could to realize their own potential. Under other, more rigorous circumstances, they knew they would probably have to work much harder to achieve success. However, there was a unanimous belief that the current performance level would be sufficient to carry the students through to graduation. 
4. When these students lost ground in their classwork, due either to absences or disruptive circumstances, they received minimal support in their attempts to recover and reestablish their previous routines. The lack of support was viewed by students as a discretionary decision made by the teacher. They believed another, favored student, usually a high achiever, would have received whatever support $s /$ he required.

5. Having a quality that distinguished a student positively in the eyes of the teacher was seen by the marginally achieving students as beneficial to secure good grades. Examples of such qualities could include being an athlete or physically attractive. While the marginal students viewed themselves as being as skilled as those people around them, they did not see themselves as being a part of the favored class of students, typically high achievers or high profile students. They did not believe they held to the same values as the school system, and they did not expect the support, privileges, or pressures associated with the high achiever position. One of the overriding images of the study was the unshakable student belief that their current performance levels in school would be sufficient to earn a diploma, graduate with their class, and move on to a productive future. The repeated statements of this belief brought parents into the equation. Parental support (and its 
influence on the performance of the marginal achieving student) was the basis of the fourth section of the research findings.

\section{Parent/Home Environment--Future Plans}

The final section of the research study examined the nature of the marginal achieving student's home situation, focusing on the level of parental influence in the student's school career. Four specific research questions are addressed in this section.

1. What were the student and parental expectations for the student's future schooling opportunities?

2. What were the dimensions of parental support of the student's school work?

3. What influence did these expectations and support behaviors have on the student's performance?

4. How did the students regard their future career opportunities?

We will first examine the level of educational expectations held by the primary family stakeholders, i.e., the student and the parents ( $R Q 1)$, and the support parents extended to help their students realize their school goals. What standards did the parents maintain for their children and what strategies did they use to help the students in relation to these expectations for school (RQ 2)? With this context established, what influence did those expectations 
have in terms of school performance (RQ 3)? Finally, the connection between a student's school career and future plans was explored ( $R Q 4$ ). Where do marginal achievers see themselves regarding future career choices?

\section{Student and Parent Expectations}

Marginally achieving students who were interviewed were confident that they would graduate with their class with a standard diploma. The NELS survey data upheld this claim, as noted in Table 12 .

Table 12

Student Post High School Educational

Expectations (NELS $\underline{N}=4,644$ )

Percentage

Less than H.S. grad

H.S. graduation only

$<2$ years trade school

.6

14.3

$2+$ years trade school

6.6

$<2$ years of college

12.7

$2 /$ more years college

5.2

Finish college

18.6

Master's degree

Ph.D., M.D.

28.7

6.8

6.4

These responses represented the students' expectations, gathered when they were sophomores in high school, or approximately 16 years old. Whether or not any of these young people will actually complete a four-year college program or attain an advanced degree is a question only time 
can answer. Most meaningful was the minimum standard which these students believed they could achieve. In oniy 39 cases out of 4,644 survey respondents did a student indicate s/he did not believe $s /$ he would finish high school. This was solid verification of these expectations by those students interviewed, who maintained throughout the sessions that their current level of performance would be sufficient for them to graduate on time and earn a diploma. The relationship between the students' level of post high school aspirations and their parents level of education was statistically significant $\left(X^{2}=548-19 ; \underline{\text { df }}=40 ; \underline{p}<=.01\right.$; see Appendix I, \#8).

Further exploration of the NELS data revealed that students perceived their parents' expectations for their post high school education to be consistent with their own level of aspirations. Students indicated they believed that both their mothers and fathers maintained the same expectation that, not only would their children graduate from high school, but there would be significant continuing opportunities after that (see Table 13).

students clearly believed that their parents held a high level of expectation regarding their educational career. Again, the emphasis on college and post-baccalaureate studies might have been more indicative of a high school student's imagination rather than a purposeful educational plan. However, the same minimum 
standard of graduation from high school was maintained whether the students were asked to respond according to what they believed or what their parents held as a basic educational expectation. In addition to the statistically significant pattern of responses in relation to the level of education a student's parents had achieved and parental post high school educational expectation (Father: $x^{2}=532.82$, df $=45 ; \underline{p}<.01 ;$ Mother: $\mathrm{X}^{2}=448.08$, df $=45 ; \underline{\mathrm{d}}<.01 ;$ see Appendix I, \#9) as the SES of the family increased, expectations for student education showed a corresponding increase (Father: $x^{2}=568.70$, df $=27$; $<.01$; Mother: $x^{2}$ $=465.07, \underline{\mathrm{df}}=27 ; \mathrm{p}<.01 ;$ see Appendix I, \#10).

\section{Table 13}

Parental Post High School Educational Expectations: Std. Responses

(NELS $N=4,644$ )

Response Choice

Less than H.S. grad Graduate from H.S. Vocational after H.S. Attend 2-yr college Attend 4-yr college Graduate from college Post-grad education Don't know Parent doesn't care Does not apply
\% Mother's Expectations
\& Father's Expectations 
These data supported the perspective that three of the major stakeholders in the marginally achieving student's life, both parents and the student her/himself, believed that the current academic performance and achievement profile of $C$ and $D$ level work would not only be sufficient to move the student forward toward graduation and a high school diploma, but that marginal high school performance did not act as a barrier to post high school educational opportunities. Many believed that marginally achieving high school students would pursue high aspiration educational options, with an emphasis on participation in a four-year college program.

\section{Parental Academic Support}

\section{Behaviors}

This research also explored the type and level of support students claimed their parents provided to sustain the stated level of expectation they had for school achievement for the students. The variable responses were arranged according to level of commitment or involvement performing each activity might require (see Table 14). The items began with the lowest level of involvement (e.g., having a discussion--presumably at home or some other convenient location), and increased to home structures created to support the student's school career, such as checking homework. Finally, high-involvement parent 
activities that took place at school (e.g., attending meetings, etc.) were listed.

Table 14

Parental Support Activities in the student's School Career: Std. Responses

(NELS)

\begin{tabular}{|c|c|c|c|}
\hline Variable & $\stackrel{8}{8}$ & $\stackrel{q}{\text { sometimes }}$ & $\stackrel{q}{q}$ \\
\hline $\begin{array}{l}\text { Discussed school activities } \\
\text { Discussed things studied in school } \\
\text { Discussed grades } \\
\text { Discussed transferring schools } \\
\text { Discussed prep for sAT/ACT } \\
\text { Discussed going to college } \\
\text { Parents check homework } \\
\text { Parents help with homework } \\
\text { Special privileges for good grades } \\
\text { Limit privileges for poor grades } \\
\text { Parents attend school meetings } \\
\text { Parent phone teacher or counselor } \\
\text { Parents attend school event } \\
\text { Parents act as school volunteer }\end{array}$ & $\begin{array}{r}18.2 \\
14.7 \\
42.5 \\
6.3 \\
5.4 \\
28.7 \\
23.0 \\
8.5 \\
18.0 \\
23.9 \\
10.0 \\
15.4 \\
26.3 \\
5.3\end{array}$ & $\begin{array}{l}55.5 \\
61.7 \\
48.9 \\
22.5 \\
31.0 \\
51.8 \\
31.0 \\
37.2 \\
36.8 \\
32.6 \\
43.1 \\
41.8 \\
20.9 \\
13.5\end{array}$ & $\begin{array}{l}26.4 \\
23.6 \\
7.6 \\
71.2 \\
63.6 \\
19.5 \\
46.0 \\
54.2 \\
45.2 \\
43.6 \\
53.4 \\
39.7 \\
50.7 \\
78.2\end{array}$ \\
\hline
\end{tabular}

For the purposes of reporting, responses were condensed. sometimes and once or Twice were reported as $\%$ sometimes. Often and More than Twice were reported as often. Missing responses complete the percentages.

While it was not clear from the data exactly what the nature of the "discussions" might have been, it appears that what a student had learned in school, how s/he was doing in current classes, etc., were topics of conversation between students and parents. The data also indicated that discussing college opportunities was another consistent subject. However, preparing for the SATs or the ACTs, a 
typical planning step for the college-bound, was not regarded as a regular a subject of parent-to-student conversation. This pattern might imply that most of the students were not planning to attend colleges that required those tests, or, as sophomores, that such a conversation was a bit premature. However, a general discussion about future educational options seemed to be a standard feature in the marginally achieving student's home environment.

Beyond discussion of post-secondary plans, Table 14 indicates that the level of parental involvement declines sharply. In terms of checking and/or helping with homework, and structuring home rules to support the student's school career and study obligations, there was a split between homes that provided such an environment and those that did not. Most pronounced was the reduced parental participation or involvement in support activities that occurred at the school, such as attending school meetings or events, even when those events could be of a sport or entertainment nature. Parent initiated phone calls to school personnel, for positive or negative reasons, did not occur on any regular basis.

While there was a relatively high level of parental expectation for education progress as perceived by the student respondents, there was a diminished level of parental involvement in the students' careers, either as demonstrated in at-home support behaviors or in higher 
commitment, school-based activities. It was therefore important to explore the nature of this particular aspect of the parent/student relationship as it related to school achievement. Specifically, how did parental expectations function in the academic performance of the marginal achieving high school student?

The Nature of Parental Influence for the Marginal Achieving student

According to the focus group participants, parental expectation, even at the lowest levels of verbal commitment and involvement, played a critical, yet complicated role in their levels of achievement and performance. While a complex set of factors may have combined to keep these students out of the ranks of the high track achievers, parental expectation may be one of, if not the key feature in understanding how the marginal achiever remained successfully afloat in the secondary system, rather than fall a notch further to being at-risk of not graduating. It was apparent that their parents' level of expectation had a profound influence on the students' levels of performance and achievement. There were many ways that parents supported the expectations that their children would indeed complete high school. A parent could be very involved in a student's progress but not attend school meetings. As Susan said, "My dad is a big part of my motivation. He's half of me. Parents have a lot of influence." 
The anecdotes regarding parental involvement and how this factored into the students' experiences sorted into two categories: The first category concerned parental behaviors and responses that conveyed a general level of expectation. The second category, which centered on the effectiveness or ineffectiveness (as perceived by the students) of the strategies used by parents to motivate student performance, was defined for this group. Some significant patterns surfaced as the students described this component of parental influence in their lives.

Having a basic understanding of their parents' level of expectation proved to be very powerful motivation for these students to attend school and pass most, if not all, of their classes. Jerry stated, "Every day, my parents say, 'Do good in school.' If I said I was dropping out, they'd make me go. They only care about two things: curfew and me graduating." Brandon added,

My parents (father and stepmother) have high expectations. If I dropped out, I'd get kicked out of the house, and my father would be very disappointed. Bottom line, it's their house, so I go to school.

Finally, Robert suggested, "My parents would take me to jail and leave me there to teach me a lesson if I ever said I was dropping out."

For Peter, the perception of their expectations was tied to a mutual understanding between himself and his parents. 
I get along with my parents. We treat each other with respect. They don't play a big role in helping me get homework done, but they'd be very disappointed if I dropped out. There's a big sense of commitment. I couldn't face them, I don't think I could live with myself for hurting them so much.

Clearly, parental expectation was a powerful component in the students' home environment. However, it is important to specify that while the sense of parental expectation seemed to provide sufficient motivation to pass a class, there was little evidence that their parents expected the students to achieve consistently at levels above a $C$ grade.

For Janey, the expectation of Cs was accepted by both of her parents and Janey herself.

In school, they know I could get As if I applied myself. They insist I get Cs. Last year, I did get $a$, but I was doing my hardest, and I got good comments, so they didn't do anything.

For Peter and Mark, the level of expectation was about the same. Peter said, "My dad knows it's hard for me to get As. I'm a middle student, so he expects me to get at least middle grades."

Mark's perspective was based on his parents behaviors that supported his $\mathrm{C}$ work.

I have an older brother at Lewis and clark. He's the brain, but I felt pressure to measure up. But in my freshman year, my parents sat me down and encouraged me to look at alternatives to make me a better person. I have just never been able to function in a regular school, but I'm committed to school. If I get Cs, they're fine. Less than Cs, they'd probably talk to me. 
Jacob's comments, perhaps, best summarized this student perception:

My parents were very disappointed in my freshman year. 'We know you can do better than that.' They hear but they don't listen. The classes are harder, and they don't realize that. But they don't ground me. As long as I make it through high school, they don't care.

To accommodate their expectations, parents had, in fact, applied a variety of the common strategies (see Table 14), with varying degrees of success in the student response. For some students, the influence of the routine parental discussions related to school was extremely motivating. Tina compared her school achievement with this involvement and without it.

My dad was always working and didn't pay much attention. Mom did when I was in grade school, but when I got to high school, she didn't bother. She's out of the picture now. My dad realizes I was neglected, and he's doing everything he can. He's excited for me, and he asks me how I'm doing. That's pushing me a lot.

Tight structure of privileges was another common option for parents to exercise as a motivator. According to Sharon, "My parents are $100 \%$ of my motivation. My brother has been grounded all year for bad grades. They control my social life." Although her parents had not included grounding in her experiences, Traci made the intriguing comment, "If my parents had grounded me when I was younger, I'd probably respect them more for trying to help me." Angie's parents resorted to sending her to a psychologist who specialized in working with troubled 
students. "All my parents wanted from me was Cs, but they sent me to a psychologist to see why I hated school so much, and why I wouldn't put in the effort to earn better grades." This strategy produced the desired effect of motivating Angie to pass her classes with mostly $C$ and $D$ grades.

Sometimes, parental influence produced results that reflected more harm than good. According to Megan, her father's efforts to motivate her were fruitless.

He's ex-military, and he tries to be compassionate, but it doesn't work. He makes a lot of empty threats, but it's so stupid, because I know he'li never carry them out. I do what I want.

For Tony, the inconsistency of his father's actions was frustrating and counterproductive to his efforts. "My dad is cool when the grades are good. As soon as he sees a bad grade, he says, 'you're grounded!' That does nothing, because I just get back at him by doing even worse." Rather than risk the punishment at his last report card, Tony used a strategy of his own. "I lied to him about my grades, so I didn't have to put up with it. He never checked, and I figured he wouldn't. It's just too hard to work for As." Traci's perspective of her parents' influence showed an important shift in focus from her parents to herself.

My parents don't have much to say. I have a job (25 hours/week). I kind of work toward that. I want a diploma. I know so many people who got their GEDs. It's not the same. I don't know what I want to do, but I'm not throwing 11 years away. My parents think of me as responsible. It's pretty much up to me now. 
As a junior, Traci's viewpoint reflected an evolution from the kind of extrinsic influence parents applied to an intrinsic level of student motivation, tied to the application of current school performance to future career benefits. Once that link was established in their minds, students began the process of transcending parental influence and achieving for their parents' sake, toward working for their personal satisfaction and future goals. As secondary students, the reality of a career beyond high school was close enough to be an influence on their current performance levels as they began to create plans for the future.

\section{Future Career opportunities}

The marginally achieving students who participated in this study were fairly goal oriented as they considered their futures. Their plans reflected a mix of uncertainty about the present and the future and an attempt to sort out interests, skills, and options. Representing one teen extreme, opportunities to mow lawns at a funeral parlor (because it is quiet and no one will complain), going to Australia to search for cute guys, and being a high pick in the NBA draft were suggested as career plans.

on the more serious side, real estate school, training to be an EMT, the forestry program at the local community college, law enforcement, and physical therapy courses were described as choices well within reach in terms of GPA and 
the availability and affordability of local programming options. Students had sufficient information from older siblings or friends to be somewhat knowledgeable about the requirements for entrance into these programs, and, from their perspective, they had a complete understanding of what it would take to be successful in the programs, as well. The confidence factor was unanimously high for all of the participants that success in college after a marginal high school career was completely feasible. The students felt they had a clear understanding that the work would be harder and the need to apply more productive study behaviors toward their classes would be evident. There was no indication from any of the students that these performance and achievement adjustments could not or would not be made easily and gladly. Personal abilities did not appear to a concern to the students.

However, finances surfaced as a consideration that was directly pertinent to the students' current level of expectations regarding their future educational opportunities and held corresponding implications for their current levels of performance and achievement. Susan, who is interested in physical therapy, has a job at a local sports clinic and would like to pursue health services as a career cption. Her financial circumstances have limited her post-secondary educational choices, which has limited her current academic performance as well. 
My parents have told me that college is out of the picture, unless it's Mt. Hood. So my grades only have to be good enough to get into their programs, which is like about a 2.5 or something. I can do that easily. I would need to work harder for osu or $U$ of 0 , but there's no money for that, so why bother? I do the best I can in my classes, but I have a lot of other interests right now.

Kevin, a junior, intended to enter the forestry program, also at Mt. Hood Community College.

After that, I can transfer to osu or wherever they have a program and get my four-year degree. My parents said I have to earn the money to go away to school, but they can swing a local school for the first two years. So I am working hard enough now to get into the program. I concentrate my efforts in science and math, and $I$ do the absolute minimum in everything else to pass the class so I don't have to take it again. My parents told me as long as I get into the program, how $I$ do it is my business. As long as I satisfy the entrance requirements, no one can say $s * * *$ about it.

\section{Parent/Home Environment--}

Future Plans Summary

The focus of this section differed somewhat from the

previous three in that it examined an aspect of the marginal achieving student's profile and experiences other than the student her/himself. Here, the expectations, philosophies, and strategies of the parents, as perceived by the students, were studied. The findings from this section were summarized according to five main points.

1. Both parents and students maintained a solid belief the students would pass their classes and graduate on time with a standard diploma. This belief, together with a sense of responsibility to parents, was cited repeatedly by 
students as a key reason why they had no intention of dropping out or considering leaving school prior to graduation.

2. While the level of expectation to pass classes was clearly established clearly, there was further evidence to suggest the parental expectations of these students did not exceed consistent student achievement at a c level. As long as the students were successful in moving forward in the system, as demonstrated by passing classes and receiving credit, students as well as parents believed this to be acceptable. Passing courses seemed to be the critical variable in this understanding.

3. Student and parents expected that the current level of academic performance would be sufficient, not only to finish high school, but also to link up to educational opportunities after high school, with an emphasis on four-year college programs. The higher the SES and level of parental education, the greater the expectation of significant post high school participation in an educational program, usually college.

4. Parent/student discussions about school were the most common form of support. Consistent verbal reinforcement of expectations was a powerful motivator to the students. Other behaviors (such as school contact or on-site participation) were less frequent forms of parental involvement. 
5. Student participants expected that their current academic performance and achievement levels were well-suited to a variety of future career options. The reduced level of GPA requirements at many community colleges matched the practical concerns of the parental ability to finance a college education, making the local post secondary choices more plausible than other college or university options that carried more rigorous entrance requirements.

\section{Data Summary}

What are the characteristics of marginal achieving secondary students, and what is the nature of their high school experience?

\section{Student Characteristics}

One of the primary research goals of this study was to describe the characteristics of marginally achieving high school students who attend school and earn mostly $C$ and $D$ grades. After a substantive qualitative and quantitative research effort, there is no evidence to suggest that specific demographic characteristics can be used to identify these students. The portion of the student population that fell into the GPA range had broad representation on the basis of a variety of factors. Specifically, marginality is not a clear function of gender, race, SES, or any other single variable that was included in this study. The students involved in this study came from what appeared to 
be stable home environments, with the majority of the students living in a two parent family structure.

The students in this study did not see themselves as being "lost" or "marginal." On the contrary, most of the students indicated a high level of personal self-esteem and faith in their abilities. The believed they were meeting the expectations held for them at school at an adequate level of achievement. However, despite this positive self-assessment, these students did not demonstrate high levels of engagement or achievement in their schoolwork or after school activities. Social activities such as talking on the phone or driving around with friends were emphasized, rather than more academic activities such as using a computer or reading for pleasure. For some students, working at a part time job provided an opportunity for increased performance expectations which the students met easily and willingly.

\section{School Characteristics}

There was no indication that any specific set characteristics that were attributed to school was more likely to foster marginality than another. Urban versus rural location, big school versus small school enrollment, or SES did not produce any significant differences in the phenomenon of marginality. Any student, in any type of school can be in the range of the marginal achiever. 
Classroom climate factors did influence the level of effort and achievement for these students. While much of the curriculum was seen as being too unrelated to their lives to be motivating, the students felt that a teacher's instructional style had a profound effect on how they felt about a given class and how hard they worked. Teachers who were able to develop specific personal relationships with students were viewed as being favored highly over teachers who treated them impersonally or as if they were simply part of the crowd. It is important to note, however, that whether or not the students were in classes where they felt they were working hard and being challenged, the predominant grades earned were Cs and Ds.

Perhaps the most significant climate issue to emerge in the School Characteristics segment was the concept of teacher favoritism. The marginal achieving students believed that their teachers favored the high-profile, high achieving students and focused their instructional efforts on that group. Students in middle group did not seek or expect any special attention from their teachers.

\section{School Experiences}

Marginally achieving students were not involved in many positive school interactions. They had not earned awards or recognition for any school association such as academics, citizenship, attendance, etc., nor did they remain on campus to participate in school sports or activities. Still, from 
a management perspective, the students showed no evidence of negative behaviors at any level. They were compliant with most of the typical classroom policies, including coming to class on time and being prepared.

There was clear validation of the image of these students as being "in the middle" of low and high track achievement standards. There were no data to support any inclination of these students to slip to a level where they would be at-risk of dropping out and not completing high school. On the contrary, these students believed they would be successful in completing secondary school with a standard diploma along with their graduating class. However, they were aware they were not making as strong an academic effort as they could, and under other circumstances, they would have to perform at higher levels of achievement and excellence. This adjustment was one the students felt could be made easily.

Continuing with the concept of teacher favoritism, when the marginal achieving students fell behind in school work, they believed they received minimal teacher support to help them reestablish themselves in the class. They believed a high-achieving student in the same situation of returning to school after an absence of any duration would have received ample assistance in understanding and completing missing assignments, etc. Having a quality to distinguish a student in the teacher's eyes was viewed as a very positive 
situation. Examples of these qualities could include being an athlete, being an attractive female, etc. The marginal achieving students did not see themselves as having any of those qualities, nor did they believe their teachers saw them as having those qualities. They believed they occupied a place of lower value in the school system.

\section{Parent/Home Environment--} Future Plans

While there was clear acknowledgment that their performance levels were marginal, students believed their current achievement levels would be sufficient to enable them to pass their classes and graduate with a standard diploma. The emphasis on passing a class is significant. According to the students' reports, they felt their parents expected them to work hard enough to earn Cs and Ds, since that would earn the credit. However, the students did not feel their parents expected them to work harder or earn higher grades on any consistent basis.

Further, the students reported that their parents expectations matched their own for post-secondary educational options. The predominant expectation for these marginally achieving students was they would complete high school and go on to a variety of educational opportunities, with the emphasis on attending a four-year college program. This was especially true for high SES students and students whose parents had a higher level of education. To support 
these expectations, the students reported their parents used a variety of behaviors. The most powerful support came from regular parent/student discussions about school. Parent involvement in school-based activities such as attending meetings or volunteering showed far less parent participation.

These expectations for post-secondary education matched a variety of career options selected by the students. Many of them were aware of local community college and university requirements for program entrance. Finances were a significant factor in influencing a student's future career plans as well as current academic performance. Since students were unable to afford tuition at a major college, local community colleges were a more viable option. The reduced financial burden was matched, in most cases, by reduced expectations for a student's GPA. This factor caused many of the students to acknowledge their current academic performance as being marginal yet sufficient to satisfy the entrance requirements for many community college programs.

After they had gained entrance to one of these programs, the students claimed they would begin to work harder, either for success in that program or for the ability to transfer to a more rigorous program at another college or university. However, while they were still in high school, the students believed their current performance 
levels met their expectations, as well as those of their parents and teachers.

\section{Summary}

The purpose of this research study was to take an initial step in bridging the gap of understanding about this phenomenon of marginality by seeking information from the students themselves. Through a blend of qualitative and quantitative research techniques, distinctive details became available about the types of students who exist "in the middle" and how they perceive their particular experiences in high school. The results of this research have significant implications, both for the practitioners who serve these students as they proceed through secondary school, as well as those educators who are engaged in the larger work of reshaping school policies and systems to better meet the challenges of educating for the $21 \mathrm{st}$ century. The findings of this study, and the implications for secondary education, are discussed in Chapter $v$. 
CHAPTER V

DISCUSSION, CONCLUSIONS, LIMITATIONS, SIGNIFICANCE, AND RECOMMENDATIONS FOR FURTHER RESEARCH

Introduction

This chapter discusses the results of the research study and present conclusions drawn from the analysis of the data. The limitations of the study are shared in addition to the significance of its contribution to secondary education and recommendations for future research.

\section{Discussion of Results}

The objective of this research study was to examine the marginally achieving secondary school population of students whose cumulative GPAs were in the range of 1.5 to 2.5 , to describe the specific characteristics of these students as individuals and the general nature of their high school experiences. Although marginally achieving students have been acknowledged in the literature as being a standard segment of a secondary school's population, these students are described primarily by exclusion from the other levels of achievers, i.e., they are not in the top track of high profile, high achieving students bound for college, and they are not in the low track of students at-risk of not 
completing their work for a high school diploma and dropping out of school. The marginally achieving student is described typically as the one most likely to get lost in the system, because they are ". . . the middle-of-everything kid, the unspecial kind of kid" (Powell et al., 1985, p. 173), the sort of student most in danger of not being served effectively by the educational system in which s/he exists.

While many school stakeholders such as teachers, administrators, parents, and the students themselves acknowledged that these middle-achieving students existed in large quantities within a school and were generally overlooked and poorly served in the system, there was little specific information regarding what features characterized these students as individuals or described the nature of their experiences as they moved through four years of high school. The purpose of this study was to provide some definition and understanding of the characteristics and experiences of this student population.

Information describing the marginally achieving student group is critical in light of a national school reform agenda focused on increasing the level and quality of achievement and skill students can master and bring forth into the workplace. Nationwide, educational organizations are grappling with the implications of a growing perspective that, more than any other time in history, the economic success of our country depends on increasing dramatically 
the caliber of skills and capacities our nation's high school graduates possess as they move from high school into the workforce.

Recently, a four-part television series entitled Challenge to America (Smith, 1994) examined the differences between American systems for business and industry, levels of productivity, and education, and comparable systems in Germany and Japan. Moderator Hedrick Smith made the following statement:

The Germans and Japanese push students pretty equally, keeping them all well motivated as they move into high school. The American system of tracking works well for the brightest and most affluent. They get pushed to the hilt, and pointed toward the world's best universities. But a lot of American kids get the message they're not meant for school, and so they stop trying. So while America leads at the top, it also leads at the bottom, with huge numbers of dropouts. But what about the majority, the average kids, the mid-kids, that 70 f who won't finish college, the backbone of our future workforce? Preparing the mid-kids for high-tech jobs is the key to a high standard of living in the 21st century. So how are we doing?

If a part of the national educational objective is to increase the performance of the workforce, and marginally achieving students represent a substantial portion of that future population, then such an undertaking demands as much clarity about the characteristics, experiences, and needs of these students as can be provided to ensure the best fit of programs and service options. Yet a focus on marginally achieving students has been conspicuously absent in the literature. This portion of the student population has been 
poorly defined for too long. Without specific knowledge of who these students are and how they perceive their experiences in high school, it is difficult to envision how restructured systems will provide a better match to their educational needs and further them in securing the skills and abilities they will need for a successful, productive future in the 21 st century.

To provide such a focus on the marginally achieving secondary student, this study included a quantitative analysis of the responses of a sample group of 4,644 sophomores in the grade range of 1.5-2.5 GPA drawn from the National Education Longitudinal study (NELS) • student responses to approximately 165 variables were sorted into four categories for examination: student Characteristics, School Characteristics, School Experiences, and Parent/Home Environment--Future Plans.

There was sufficient evidence from current literature to suggest certain students had different, diminished educational experiences by virtue of certain demographic characteristics such as gender (Chapman, 1988; Delamont, 1990; Gough, 1976; Reis, 1991; Sadker \& Sadker, 1982; Stitt, 1988), race (National Institute of Education, 1977; Hare, 1987; Haw, 1991; Schofield, 1989; Simms, \& Contreras, 1980), and SES (Hauser, 1971; Meier, Stewart, \& England, 1989; Weis, 1988). These variables were highlighted in the study 
to explore how these features were factored into the phenomenon of marginality, if at all.

These data were combined with the interviews from five focus groups of local high school sophomores and juniors, totaling 22 students. The interviews were conducted in May, 1993, and sorted according to the same four categories of inquiry as the NELS data. The combination of descriptive data targeted the characteristics and experiences of marginally achieving secondary students and produced the following eight major findings:

1. No demographic variables used in this study, including gender, race, or SES, could be identified as significant correlates of the marginal achieving secondary student. Two-parent family structures were reported by 79.48 of the sample respondents, and generally positive feelings of self-esteem and faith in their abilities were reported by more than $90 \%$ of the students. While they did not typically participate in high-engagement activities after school, some students did work at part-time jobs and accepted easily their performance expectations.

2. No demographic characteristics used in this study could be identified as descriptors of any school structure more likely to foster marginality. However, "climate" issues specifically related to curriculum and instruction had an important impact on the students and their level of performance. While the academic material was often too 
irrelevant to be motivating to the students, teachers who were able to establish a personal bond with the students were preferred over teachers who were viewed as favoring other, high achieving or high-profile students.

3. At school, marginally achieving students were not particularly visible in their school's system of rewards or sanctions. They did not earn awards or recognition in any of the typical categories of school acknowledgment such as academics, attendance, or citizenship. They were compliant with policies regarding school and classroom rules and expectations.

4. Although student grades reflected only mediocre achievement, there was strong support for the statement that these students had no intentions of dropping out of school. The students believed their parents held the same expectation that they would at least graduate from high school with a diploma.

5. Marginally achieving students saw themselves as having little value within the school organization. They believed high achieving or high profile students were more valued by their teachers as evidenced by their perceptions of the increased allocation of teacher time and attention.

6. Even though they were earning primarily $C s$ and Ds in their high school coursework, the students maintained they would have little trouble being successful in a college program, and most intended to pursue either two or four year 
programs after graduation from high school. They reported that their parents held the same beliefs. There was a significant relationship between a family's SES or the educational level of the parents and the expectation that students would pursue post-secondary educational options. Increases in SES or educational level led to increases in the level of post-secondary schooling students were expected to attain.

7. The students reported that the primary parental academic support behavior was student/parent discussions about school. Beyond this level of discussion, students indicated their parents did not routinely participate in activities to support students' academic efforts, such as helping with homework or communicating with teachers. Students claimed their parents acted as though they did not expect them to earn grades higher than $C$ or $D$, and, in some cases, this was a stated expectation. The primary focus for the students was on passing each class on the way to securing a diploma.

8. The students acknowledged that their GPA standings were too low for many college or university systems, but were acceptable for entrance into community college programs. Future plans and career expectations were considered as the students matched their academic progress to program availability, cost, and entrance requirements. However, attendance in college, specifically in a four-year 
program, at some point in their educational careers was the expectation of the majority of the students.

These eight findings form the basis of the conclusions discussed in the following segment. Following the established format of the four categories of inquiry, student Characteristics, school Characteristics, school Experiences, and Parent/Home Environment--Future Plans, the conclusions have been sorted according to the same areas and will be addressed in that order.

\section{Conclusions}

\section{Student Characteristics}

While the lack of specific demographic variables may fail to create the level of definition of marginal achieving students that was sought originally in this study, several important conclusions can be drawn from the data. The literature refers to these students as "lost" and "invisible," which seems to convey a sense of student weakness or frailty. The students did not see themselves this way. They saw themselves as being as capable and worthy of those around them, and they felt good about who they are.

Framed in this generally positive self-perception, marginal achievement can be viewed as a path these students walked as they made their way through senior high school. It is important to note the choice was between high 
achievement and middle achievement. Low achievement, or slipping down to a level where passing classes was in jeopardy, was not a consideration for these students. on the other hand, high achievement represented a level of effort, focus, and commitment these students were not willing to make toward their schoolwork at this time in their lives. Marginal achievement represented a path through safe, middle ground toward their acknowledged goal of earning the high school diploma.

\section{School Characteristics}

similar to the lack of defining variables for the students, there were no specific variables, such as geographic location or enrollment size, to define a certain school environment that fostered marginality. However, the school climate issues that surfaced were critical in the understanding of this phenomenon. The students did not see themselves as being invisible or lost when they were asked to assess their own abilities. However, they did see themselves as being less valued in the larger school system, particularly when it came to relationships with teachers.

The school work they were asked to complete was often seen as irrelevant and did not inspire the students to work any harder than necessary to pass a given class. In addition to this lack of motivation as reflected in the content, the students saw themselves as having less value within the school system than their high-profile, 
high-achieving peers, which further deflated their

willingness to work any harder than they felt was required to pass a class. They did not expect any sort of positive recognition or any of the assistance that was routinely afforded to the high achieving students.

These students believed that school was geared toward meeting the needs of the high-achieving students and not their needs. Consequently, the holding power of the school was fairly weak for them. When their compulsory obligation to attend school was over at the end of each day, these students either went home or left to go to jobs where they felt they had a role, responsibility, and value.

\section{School Experiences}

"The bargain" (Sedlak et al., 1986) was endorsed in both the quantitative and qualitative portions of the study. The marginal achievers followed the path of least resistance by attending school almost every day, staying out of trouble, and producing enough work to pass their classes. Although they were not challenged to achieve at higher levels of excellence, neither were they detained on their march through high school toward a diploma.

For these students, their path represented a credible avenue to the principle outcome, which was the attainment of the high school diploma. Further, in contrast to their high achieving peers, the marginally achieving student was under less pressure and had more time and energy to channel toward 
other activities besides schoolwork. There was no limelight or school recognition for them, but they accepted the lack of public approval as a price to be paid for a relatively easy route to the diploma.

The power of that diploma cannot be overemphasized. From the study, there was no evidence to suggest that the students would fail to get the diploma. However, the emphasis was clearly on attainment rather than quality of their work. At this time in their school careers, the students did not see the issue of higher standards or increased quality as being a required part of the process in attaining the diploma.

\section{Parent/Home Environment--} Future Plans

All of the evidence gathered regarding student perceptions of their parents' expectations for their schooling and their future options supported the notion of attainment of the diploma as the critical measure of success. Students reported their parents did not behave as if they expected them to achieve at higher levels of excellence. Passing classes with Cs and Ds was acceptable, although perhaps not desirable, as long as progress toward a diploma was maintained. When they described their future plans, the students believed that their current level of performance would not inhibit credible educational options after graduation. This added further support for the 
student perspective that their path would enable them to connect to a variety of educational and career options, and their lives would not "dead end" after high school.

From the data collected in this study, it was evident that the students regarded marginal achievement, $C$ and $D$ level work, as a credible path to attaining the high school diploma, and they perceived the behaviors of their teachers and their parents as supporting them at that level of achievement, but no higher. As one junior boy stated, "If getting a $D$ was such a problem for the teachers, then why can you still get $a$ D and get credit? If they really didn't want you to get Ds, then they shouldn't let Ds be ok." The students accepted their position in the system as one of low value but also low stress. The end for them was still a diploma, and the end justified the means.

\section{Limitations to the study}

There are three main limitations to the study that need to be addressed. First, by using student data as the sole source of information, some questions are raised. It is impossible to be certain the data reported in the survey or in the focus groups is completely accurate, although this is probably a concern with many data-collection techniques. However, in the case of asking students to self-assess their status as marginally achievers, or to acknowledge the discrepancies between their performance and that of their 
high achieving peers, some "face-saving" responses may have been introduced, either consciously or unconsciously. This uncertainty prompts a key question: When the perspectives of other constituencies, such as teachers and parents, are introduced into the study, how might the overall understanding of marginality change? While it is certainly appropriate to focus on students as a primary stakeholder in the study, without the inclusion of these other viewpoints, this can only be acknowledged as a first step, rather than an exhaustive study of a complex subject.

A second limitation arose from the size of the participant pool for the focus groups, which were smaller and fewer in number than was originally intended. Focus groups reach a point of saturation when the researcher can accurately predict the general nature of the participants' responses (D. L. Morgan, personal communication, April 19, 1994). This state was, in fact, reached with the number of students and the number of groups included in this study, However, larger numbers of students might have enabled greater flexibility in arranging students into specific group configurations according to "break characteristics" (Knodel, 1993, p. 39) such as gender or race, which might have produced different responses related to some of the key demographic variables in the study. Also, more groups representing a wider range of school classifications or other geographic locations might have contributed to 
increased generalizability. This would have necessitated a study on a much larger scope than was feasible at this time. The final limitation to the study reflects concerns about having one specific researcher conduct the focus groups. I am a white, female assistant principal. students may have been reacting to me, or not reacting, in a particular fashion based on race, gender or job title. Morgan and Krueger (1993) assert that it is not always necessary, and in some cases it is not desirable, to have a moderator with highly developed, professional skills in leading focus groups. However, they continue, it is false to suggest

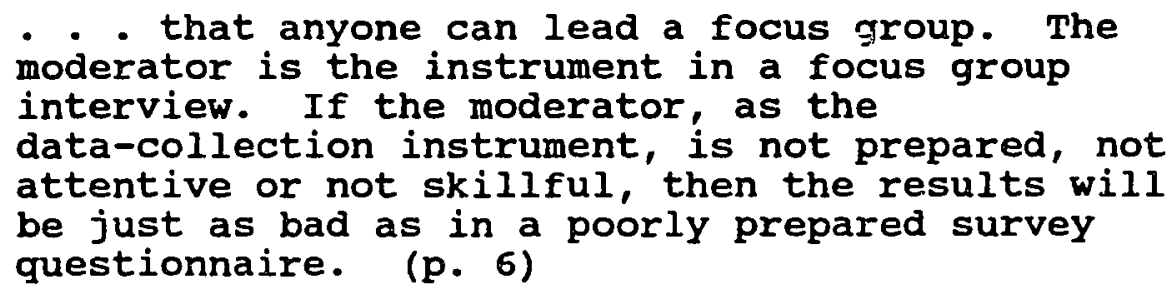

Since there were no other options available for the students, it is impossible to know if the students would have responded differently to someone else in the facilitator role, or to know if the responses as they stand in this study represent the richest, most accurate data available from the student perspective about marginal achievement. 


\section{Significance to Educational Leadership}

The results of this study are particularly beneficial in two areas in the field of educational leadership: client/student identification and educational reform issues. First, this study begins to define for practitioners the characteristics and experiences of marginal achieving students by gathering information from those very students. The literature cited to describe these students reflects the practice of attempting to describe a student population or phenomenon on the basis of the experiences or perceptions of selected individuals, usually, adult school personnel.

This study represents the exploration of individual student perspectives in combination with quantitative data gathered according to sound research practice. Using the national database of information in conjunction with the context data from the local focus groups moves the results of this study toward the generalizability that is a desirable feature of any research. Readers of this study will undoubtedly recognize the descriptions of those marginally achieving students who walk in the halls of their own schools, regardless of public or private status, size of enrollment, or geographic location. Recognition is a critical first step if changes are to be made to increase the level of value, expectation, and quality in the experiences of the marginally achieving student. 
Also, although its student focus has been cited as a limitation of the study, that same feature gives a voice to these students, often the most overlooked stakeholders of all. Routinely, school decisions are made, policies are set, and programs are created without input from the students for whom the work is intended. In the case of the marginally achieving student, this reflects the exclusion from school consideration and resource allocation they have come to expect. Still, a student perspective is critical if the needs of this population are to be addressed in a substantive, positive manner.

with the student perspective as its primary focus, the results of this study will give practitioners a greater awareness of the characteristics and experiences for the marginally achieving students and how those students perceive many of the opportunities made available to them in a secondary program. This information becomes an important filter in the processes of policy formation and action, as well as program design, at the secondary level.

A second area of educational practice that will benefit from this study is the reform effort based on the components of Oregon's Educational Act for the 21st Century, or HB 3565 (1991). These findings give practitioners some important factors to consider as increased investment is made in school restructuring, specifically, efforts related to the secondary level. 
Briefly, HB 3565, passed by the oregon legislature in 1991, represents a blueprint to restructure Oregon's educational systems to produce graduates who are "able to connect learning to know with learning to do . . . [and can demonstrate] mastery of learning outcomes which will meet world class standards" (Oregon Department of Education, 1993, p. 2) by the year 2010. While many features of the bill have been called into question, the basic tenets of the secondary portion of the bill represent a shift from an educational system based on seat time and the accumulation of courses taken over four years to a system that will routinely call upon students to demonstrate that they have, in fact, learned the principles of the core subject areas (math, science, language, etc.) and can apply those learnings to real-life problem solving situations around them at a much higher level of performance and excellence than the current system demands.

With the increased understanding of the characteristics and experiences of the marginally achieving student that this study provides, the implications of the bill can be considered for this portion of the population. There is nothing to suggest this segment of the student population could not be successful when the standards of achievement are raised. In fact, there are indicators to the contrary, including the students' own acknowledgment that they are not 
working up to their potential and would work much harder under other circumstances.

Also, recalling the high value these students placed on attaining a diploma, as long as the change in standards did not alter their perception that the value of the diploma is worth the work, there is no evidence to support the belief they would value the diploma any less because they had to work harder to get it. If a part of the reform effort is an attempt to restore credibility to the diploma, thus increasing its value, the knowledge that the marginally achieving student is already very focused on attaining the diploma could lead to the desired situation of the students increasing their level of performance to reach the new established standard for attainment.

However, while this may appear to be a positive match between the intentions of the bill and the goals of the marginally achieving student, it would be a critical error to underestimate the magnitude of the discrepancy that exists currently between the level of performance anticipated in the reform movement, as evidenced in performance-based work and assessment opportunities, senior projects, etc., and the current level of performance and expectation exhibited in the experiences of marginal achieving students. This discrepancy must be addressed from the standpoints of behavior and expectation. 
While HB 3565 (1991) is designed to restructure educational opportunities for all students, for the marginally achieving student, this bill represents a quantum leap in performance expectations. Historically, these students have made a successful showing in high school primarily on the basis of attendance and compliance rather than academic performance. HB 3565 has targeted this very scenario as one that is no longer acceptable if students intend to earn a diploma and move into the job market as productive, employable citizens. Put simply, these marginally achieving students will no longer be able to "do school" the way they have always done it.

While there is nothing to suggest that these students would not be able to achieve at higher levels of performance and excellence, there is a great deal to suggest that such a change will be extremely complicated due to the pervasive nature of marginality. The work of retraining these students to exhibit different academic behaviors may fall short of the desired level of success if they are not simultaneously taught to hold different expectations for themselves and for the systems in which they function.

However, such a change will require that serious attention be paid to the people who participate in that system along with the students, specifically teachers and parents. The following seven-point proposal incorporates the key learnings from this study and addresses both the 
need to increase the level of professional awareness regarding the characteristics and experiences of marginally achieving students and the need to bring about key changes in the secondary instructional model to better serve these students.

\section{Point \#1: Communicate}

\section{Findings}

Increasing the level of awareness regarding the marginally achieving student is a critical first step in bringing about a positive change. Due, in part, to the lack of clarity regarding this population, teachers and other school professionals may or may not have acknowledged them as being "casualties" of the current secondary educational system. Sharing the findings of this study with school staff members, site councils, school boards, and community members would begin to build a foundation of knowledge regarding these students. Stakeholders need to be made aware that the current level of academic quality for these students is probably much lower than most people realize and no longer can remain an acceptable standard in today's changing marketplace.

\section{Point \#2: offer Data}

Collection options to Teachers

For teachers and other school personnel, data collection and analysis techniques, such as those made popular by Kerman and Martin (1980) through TESA (Teacher 
Expectations and Student Achievement) and GESA (Gender Expectations and Student Achievement)--are tools to help practitioners increase their understanding of personal patterns for their instructional behaviors in the classroom. These techniques include teacher identification of students they perceive to be high, low, and middle achievers, followed by an objective scoring of how often the teacher calls on each student, responds with praise or criticizes a student, how much wait time is given to allow a student to think about an answer, etc. Some people may be unconsciously placing students in the classroom or selecting students for participation following patterns that have become second nature, and they need objective data to help them unravel the features of those patterns and begin replacing them with new, more inclusive behaviors. By individualizing this understanding of how each teacher plays a role in "the bargain" that defines a key aspect of marginality, and by exchanging some of the current curricular and instructional practice with techniques that counter the marginal scenario, a basis for understanding and support for these "invisible" students can be built.

\section{Point \#3: Staff Development}

in student Engagement

Techniques

Increased levels of awareness and concern can lead to a commitment for change, but from that commitment must come the modification of the current instructional service model 
if marginally achieving students are to experience an increase in the quality of their educational opportunities. Staff development opportunities must be made routinely available for teachers to learn new techniques to increase the level of student engagement in their classes.

From the research focus groups, it was clear that the students responded to good teaching techniques and relevant, motivational material. Many of the concepts described in HB 3565 (1991) describe the type of classroom setting that would be highly invitational and engaging to the marginal achieving student. As outlined in the bill, the principles of the Certificate of Initial Mastery are based upon applying core learnings to real-life situations, a scenario the students claimed was exactly what was missing in much of the current work they were required to cover. In addition to the real-life application, opportunities to work with student colleagues on tasks that were based on performance or "doing," rather than exclusively pencil and paper oriented tasks that valued "remembering," represented a rigorous challenge these students felt would be motivating and educational.

Examples of this type of instructional orientation needed to increase student engagement and achievement are becoming more evident in many school districts in oregon as the work of moving toward becoming 21 st Century schools continues. In Alsea High School, for example, students work 
in teams with representatives from the Department of Fish and Wildlife and the Forestry Service to study the area surrounding their school. Core content instruction in language arts, math, social studies, science, etc., is based upon concurrent studies of water currents, fish and river plant life, the economic structure of the area, conservation practices, etc. By participating in tasks that apply academic concepts to the world around them, students may find the relevance and motivation the focus group participants claimed would increase their level of engagement and performance.

At Gresham High School, students in the Freshman Focus program of Language Arts and Science conduct community-based research studies on topics of their choice including sexual harassment, teen alcohol and drug use, career expectations, etc. Their findings are presented to audiences of their peers or at selected community sites such as local middle school classrooms. This permits critical opportunities for increased levels of student engagement and the demonstration of learning in a real world setting.

\section{Point \#4: Staff Development}

in student Assessment

strategies

Another area that has important implications for the marginal achieving student is student assessment. Current reform efforts related to student assessment have led teachers to examine not only what work is assessed but how 
such data are collected and valued. Rather than traditional evaluation models featuring the exclusive use of pencil and paper/objective tests focusing on information recall, new techniques create a more authentic or performance-based setting for students to demonstrate and apply what they have learned.

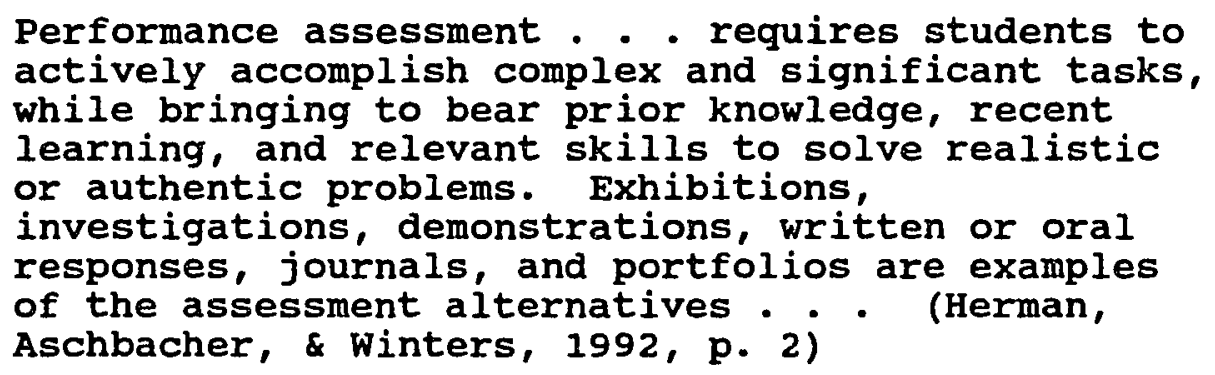

Such techniques may have a very powerful, positive impact on the academic achievement patterns of marginal achieving students, for at least two reasons:

First, all strategies that enable teachers to respond to the work of individual students stand to decrease the opportunities for students to be able to merely attend without achieving; to progress without producing. Students will have less opportunity to fade out of the spotlight at regular assessment points through the year. As an example, at Cottage Grove High School, students can earn a Certificate of Initial Mastery (CIM) only after they have presented their collected work samples from a student portfolio to a CIM board consisting of teachers, parents, and community members for approximately one half hour. Although this represents a tremendous resource commitment to 
the $200+$ students who will be presenting, this change in behavior on the part of the cottage Grove school community conveys the message that every student is valued and that performance of certain tasks is now the measure of school success.

second, assessment strategies that enable all students to become valued participants in the acknowledgment and examination of student performance will help to break the cycle of reduced expectations that pervades the phenomenon of marginality. Student self-assessment models or inciusion in group process are examples of powerful techniques that may serve to develop within the marginally achieving population the belief that they are valued as individual learners and within the classroom community.

For instance, at Milwaukie High School, freshmen and sophomore students are assigned to a resource class that meets every other day. The classes are small in number and focus on helping students to be noticed in the larger system. Work in this program is not graded, and students share academic progress information with teachers and peers who respond with praise, advice, etc., depending on the student need. By emphasizing the process of communicating about school matters, and de-emphasizing the evaluative aspect in a safe, collaborative environment, students can begin to identify their strengths and areas for growth in the academic setting. 
The Cottage Grove and Milwaukie High School examples represent another key feature of some of the alternative assessment strategies that are becoming more prevalent as the concepts of authentic work and assessment are translated into current practice. By incorporating participants outside of the school into the process of teaching and learning, whether those participants are other students, other teachers, community members, etc., a critical external check is introduced into the system. This need to report out to other stakeholders may serve to increase the awareness, productivity, and accountability of all of the participants. If it is true that it will be much more difficult for marginally achieving students to "hide" in the school system, so it may be for marginal teachers who will no longer be able to simply close the door and do as they please.

Point \#5: Staff Development in the creation of Assessment Rubrics

All strategies that include the establishment of rubrics to teach students about standards of excellence and gradations of quality (Marzano, Pickering, Whisler, Kendall, Mayeski, \& Paynter, 1993) will further assist in changing the patterns for a population whose levels of expectation and performance have been uniformly low.

Rubrics are sets of criteria that describe levels of performance or understanding. Rubrics provide students with expectations about what will be 
assessed as well as standards that need to be met. Rubrics provide "road signs"--information about where they are in relation to where they need to be. (pp. 13)

For the first time, many marginally achieving students will be introduced to the notion that there are levels of quality that apply to the work they produce that have little, if anything, to do with the fact that they attended school on a regular basis or that they were pleasant in class. The establishment of scoring rubrics will help students to see what level of quality is expected of them, and what level of quality will no longer be acceptable. By producing these rubrics at the beginning of a project, students can begin to work toward the new, higher level of expectations.

As an illustration, at Centennial High School, the development of a Senior Project (Barrett, 1991) has caused the staff to "work backwards" into their curriculum to see what skills and what experiences students need at the freshmen, sophomore, and junior levels to enable them to reach the level of quality expected in the culminating activity (McDonald, Smith, Turner, Finney, \& Barton, 1993) that is a requirement for high school graduation. Students are working with teacher and student-developed rubrics, from their initial projects in the ninth grade through the final demonstration as seniors, to increase familiarity with the increased expectations demanded in their work. They are experiencing regularly that 608 accuracy of a subject 
knowledge test just is not sufficient to pass a class any more.

\section{Point \#6: Communicate} with Parents

Such communication and retraining of teachers will take time and a concerted effort if the undertaking to reform oregon's school system is to reach its goals. If HB 3565 (1991) is successful in raising performance and achievement expectations to a higher level, there are certain implications for the parents of the marginal achieving students, and the results of this study should be communicated to them, as well.

As this study has indicated, marginally achieving students did not see their parents holding higher expectations than the completion of high school with a diploma. Along with their children, it seemed the parents had developed a set of expectations that reflected their knowledge of what it would take for a student to move through the system to that goal. As long as the students passed their classes, there was a clear message that $C$ and $D$ level work would be tolerated. If this scenario is no longer be acceptable, parents will need to be apprised of the increase in standards along with a rationale for the change. Although this study represents part of such a rationale for change, it may be more difficult to convince parents who see a guaranteed path to a diploma for their 
children become more challenging at the same time it becomes more credible.

\section{Point \#7: Communicate}

\section{with students}

Finally, it is imperative we change the ways in which we communicate with the students who attend our schools. One of the key findings of this study is that marginally achieving students were so accustomed to being left out of the communication flow, they no longer expected to be asked anything of significance related to school.

The suggestions for increasing the expectations and standards reflected in the current reform movement represent significant changes for all students, including the marginally achieving population. However, this student group is comfortable with a student/school relationship that requires little effort on their part and yet still results in a diploma.

The current reform efforts represent a major change, or the negotiation of a whole new student/school bargain. students must be brought into the dialogue as soon and as often as possible. student surveys or informal focus groups can be used to communicate and gather student opinions or ideas about the workings of their school. Forums through leadership classes are another vehicle for students to gain a voice, as well as an arena to develop avenues to gather and value student input. 
Communication efforts of this nature reflect the key findings of this research. Increased awareness of the experiences and needs of the marginally achieving student is a part of the evidence that significant secondary school reform is needed. No student should be able to graduate with a standard diploma representing time spent rather than principles learned and applied, and no student should be able to leave high school without having had significant experiences in placing her/his skills and interests into the wider framework of the world beyond high school.

However, the philosophy of reform does not have to be grounded in "job training" for marginally achieving students. The critical issue is the consistent enhancement of the quality of their experiences, so they can begin to see their value within their school organization and the benefits of their increased participation. communication with teachers, parents, and students must occur if the reform efforts are to be effective in increasing standards for all students. For marginally achieving students, this examination of expectations and practice is essential if the patterns of marginality are to change.

\section{Recommendations for Further Research}

Future researchers would do well to consider using the parent and teacher survey information available in the NELS database to examine the perspectives of these other 
constituencies in addition to those of the students, as investigated in this study. By using the same database, cross-tabulations could be employed to discover any connections between the responses of the students and those of the other respondents. The inclusion of these data would represent an important expansion by providing an important check of the student perspective described in this study. Also, the focus group methodology could be replicated to include school personnel and parents. As in this study, that anecdotal information could be combined with the quantitative data to provide a rich view of the perspectives of those stakeholders. In combination with the student perspective, such information would form a substantive description and analysis of a complex population.

The data from the focus groups included in this study provided a critical source of contextual information. If any replication is to be undertaken, focus groups in a variety of geographical locations would address the issue of representation to a greater extent than was feasible in this study. At the same time, group facilitators who were not affiliated with the school sites might prove to be beneficial to the quality of the material, since group participants would have no associations which might influence their responses. 
Summary

This study was undertaken to describe a student population that had been largely undefined in the overall secondary school system by examining the responses of the students themselves. Marginally achieving students had created a special niche for themselves by adopting the expectations and behaviors of "onlookers" rather than "participants" in high school. They watched the greatest share of the opportunities, teacher time, support, and recognition go to the high-achieving, high-profile student group, in which they had no part. For the marginal achiever, as long as they attended school on a regular basis, made no trouble for their teachers, and submitted work of passable quality, they would receive a high school diploma. Upon receipt of the diploma, they could move on to the portion of their lives where they could make choices that reflected their talents and ambitions, choices that did not seem to be available to them in the high school setting. If reform efforts in oregon are to match the goal of increased engagement and achievement for all students, it is necessary to match those restructuring efforts to the needs of the student populations served in our schools. This research study has begun the process of describing marginally achieving secondary students to provide the sort of descriptive information practitioners require to ensure 
the best fit of policies, program designs, and instructional methodologies for the clients they serve. 
References

American Association of School Administrators. (1991). America 2000: Where school leaders stand. Arlington, VA: Author.

Barrett, A. (1991, May 30). Students make a final quest for knowledge. The oregonian, p. 1 .

Bidwell, C. E. (1965). The school as a formal organization. In J. E. March (Ed.), The handbook of organizations (pp. 972-1,022). Chicago: Rand McNally.

Boyer, E. (1983). High school: A report on secondary education in America. New York: Harper and Row, Publishers.

Butler-Por, N. (1987). Underachievers in school: Issues and intervention. New York: John wiley and Sons, Ltd.

Chapman, A. (1988). The difference it makes: A resource book on gender for educators. Boston: National Association of Independent Schools.

Cray-Andrews, M. (1989). School failure: Whose loss? Preventing School Failure, 34(1), 35-40.

Cusick, P. A. (1973). Inside high school: The student's world. New York: Holt, Rhinehart, Winston.

Cusick, P. A. (1983). The egalitarian ideal and the American high school. New York: Longman, Inc.

Delamont, S. (1990). Sex roles and the school (2nd ed.). New York: Routledge.

Glasser, w. (1990). The quality school: Managing students without coercion (2nd ed.). New York: Harper Perennial.

Goodlad, J. I. (1984). A place called school: Prospects for the future. New York: McGraw-Hill Book Company.

Goodlad, J. I., \& Keating, P. (Eds.). (1990). Access to knowledge: An agenda for our nation's schools. New York: College Entrance Examination Board. 
Gough, P. (1976). Sexism: New issue in American education. Bloomington: The Phi Delta Kappa Educational Foundation.

Hampel, R. L. (1986). The last little citadel: American high schools since 1940. Boston: Houghton Mifflin Company

Hare, B. R. (1987). Structural inequality and the endangered status of black youth. Journal of Negro Education, 86(1), 100-10.

Hauser, R. M. (1971). Socioeconomic background and educational performance. Washington, DC: American Sociological Association.

Haw, K. F. (1991). Interactions of gender and race: $A$ problem for teachers? A review of emerging literature. Educational Research, 33(1), 12-21.

Herman, J. L., Aschbacher, P. R., \& Winters, L. (1992). A practical quide to alternative assessment. Alexandria, VA: The Regents of the University of California.

Herriott, R. E., \& St. John, N. H. (1966). Social class and the urban school: The impact of pupil background on teachers and principals. New York: John Wiley and Sons, Inc.

Johnston, W. B. (1987). Workforce 2000: Work and workers for the twenty-first century. Indianapolis: U.S. Department of Labor, Hudson Institute.

Judson, G. (1992, December). Lost in the middle. The New York Times-Special Edition, p. 1.

Kerman, S., \& Martin, M. (1980). TESA: Teacher expectations and student achievement. Bloomington, IN : Phi Delta Kappa.

Knodel, John. (1993). The design and analysis of focus group studies: A practical approach. In D. L. Morgan (Ed.), Successful focus groups: Advancing the state of the art (pp. 35-50). Newbury Park: Sage Publications.

Krueger, R. A. (1988). Focus groups: A practical guide for applied research. Newbury Park: Sage Publications.

Lightfoot, S. L. (1983) . The good high school: Portraits of character and culture. New York: Basic Books, Inc. 
Magaziner, I. (1990). America's choice: High skills or low wages! Executive Summary. Rochester, NY: National Center on Education and the Economy.

Marzano, R. J., Pickering, D., \& McTighe, J. (1993). Assessing student outcomes. Aurora, CO: McREL Institute.

Marzano, R. J., Pickering, D. J., Whisler, J. S., Kendall, J. S., Mayeski, F., \& Paynter, D. E. (1993). Authentic assessment. Aurora, CO: MCREL Institute.

McDonald, J. P., Smith, S., Turner, D., Finney, M., \& Barton, E. (1993). Graduation by exhibition: Assessing genuine achievement. Providence, RI: Brown University.

McNeil, L. M. (1988) - Contradictions of control: School structure and school knowledge. New York: Routledge.

Meier, K. J., Stewart, J., Jr., \& England, R. E. (1989). Race, class, and education: The politics of second-generation discrimination. Madison: The University of Wisconsin Press.

Morgan, D. I. (1988). Focus groups as qualitative research. Newbury Park: Sage Publications.

Morgan, D. L. \& Krueger, R. A. (1993). When to use focus groups and why. In D. L. Morgan (Ed.), Successful focus groups: Advancing the state of the art (pp. 3-19). Newbury Park: Sage Publications.

National Center on Education and the Economy. (1990). America's choice: High skills or low wages! The report of the commission on the skills of the American workforce. Rochester, NY: Author.

National Commission on Excellence in Education. (1983) . A national at risk: The imperative for educational reform (S6059-S6065). Washington, DC: U.S. Department of Education.

National Council of La Raza. (1992). State of Hispanic America 1991: An overview. Washington, DC: Author.

National Institute of Education. (1977). Desegregation and the education concerns of the Hispanic communityconference report. Washington, DC: Author.

Oakes, J. (1985). Keeping track: How schools structure inequality. New Haven: Yale University Press. 
O'Neil, J. (1992). On tracking and individual differences: A conversation with Jeannie Oakes. Educational Leadership, 50(2), 18-21.

Oregon Department of Education. (1993). Schools for the 2lst century. Salem: Author.

Oregon Educational Act for 21 st Century Schools, HB 3565. (1991).

Parish, J. G., \& Parish, T. S. (1989). Helping underachievers succeed. Reading Improvement, 26(1), pp. 71-78.

Parnell, Dale. (1985). The neglected majority. Washington, DC: Community College Press.

Perrone, V. (1985). Portraits of high schools. Lawrenceville: Princeton University Press

Powell, A. G., Farrar, E., \& Cohen, D. K. (1985). The shopping mall high school: Winners and losers in the educational marketplace. Boston: Houghton Mifflin Company.

Reich, R. B. (1990, Summer). New economic realities. What's next: A newsletter of emerging issues and trends, 12, pp. 1-2.

Reis, S. M. (1991). The need for clarification in research designed to examine gender differences in achievement and accomplishment. Roeper Review, 13(4), 193-198.

Sadker, M. P., \& Sadker, D. M. (1982). Sex equity handbook for schools. New York: Longman.

Salamon, I. M. (1991). Overview: Why human capital? Why now? In D. W. Hornbeck \& L. M. Salamon (Eds.), Human and America's future: An economic strategy for the 90's (pp. 1-39). Baltimore: John's Hopkins University Press.

Schofield, J. W. (1989). Black and white in school: Trust, tension, or tolerance? New York: Teachers College Press.

Sedlak, M. W., Wheeler, C. W., Pullin, D. C., \& Cusick, P. A. (1986). Selling students short: Classroom bargains and academic reform in the American high school. New York: Teachers College Press. 
Simms, R. L., \& Contreras, G. (Eds.) . (1980). Racism and sexism: Responding to the challenge. Washington, DC: National Council for the Social studies.

Sinclair, R. L., \& Ghory, w. J. (1987). Reaching marginal students: A primary concern for school renewal. Chicago: Mccutchan Publishing Corporation.

Sizer, T. R. (1964). Secondary schools at the turn of the century. New Haven: Yale University Press.

sizer, T. R. (1984). Horace's compromise: The dilemma of the American high school. Boston: Houghton Mifflin Company.

Sizer, T. R. (1992). Horace's school: Redesigning the American high school. Boston: Houghton Mifflin Company.

Smith, H. (Producer-Director). (1994). Challenge to America. Washington, DC: Hedrick Smith Productions and WETA.

stitt, B. A. (1988). Building gender fairness in schools. Carbondale: Southern Illinois University Press.

Weis, L. (Ed.). (1988). Class, race, and gender in American education. Albany: State University of New York Press.

Wolfie, J. A. (1991). Underachieving gifted males: Are we missing the boat? Roeper Review, 13(4), 181-184. 
APPENDIX A

LETTER TO DR. KATTERLE 
March 15, 1993

To: Dr. Zeno Katterle

From: Aeylin K. Summers

Re: Doctoral Research Request

Dr. Katterle:

This letter is a formal request for permission to conduct the student interview portion of my doctoral study in the Barlow-Gresham School District. The following information addresses three areas of concern: benefits to the school district, student protocol issues, and procedures.

Benefits to the school district

The centering research question of this study is: What are the characteristics of marginal achieving secondary students, and what is the nature of their school experiences? The purpose of this study is to gather more precise information regarding the student achievement profiles of "middle track" students -typically students who earn $C^{\prime} s$ and $D^{\prime} s$. We know a great deal about high and low achievers. However, despite the fact that some iiterature suggests middle track achievers represent 50-70\% of a typical high school, we do not have a clear perspective regarding what types of students are in this portion of the total population.

As school professionals, if we knew more about which types of students ended up in the middle track, and if we understood more about the nature of their school experiences, we would have a better opportunity to shape on-going school restructuring efforts to meet the needs of these students with the intent to increase their level of engagement and achievement.

Qualitative information will be gathered through school site focus group interviews with high school sophomores who are middle track achievers. For this study, students who are in a GPA range of 1.25-2.00 will be selected from the focus groups. Part of the interview guide will include questions regarding how these students feel schools would need to be in order for them to truly engage, which is important data to be considered by anyone who is involved in the work of making schools more engaging and more effective for students. All of this information will be made available to school district personnel. 


\section{Student Protocol Issues}

Students appropriate for this study will be identified through the counseling departments of each high school. students will be invited to participate with a letter sent home to their parent/guardian. This letter will include a parent and a student permission form, which must be examined by the Portland state University Human Subjects Research Review Committee. Students who are able to participate in the study will be guaranteed complete anonymity. They will be interviewed at their home school site in groups of about 5-6 students, which should lessen some of their anxieties and make them feel more comfortable with the research setting. Students will be given opportunities to respond to questions regarding their school experiences and how they think schools need to change. All student information will be reported with coded names, and the school district will not be identified. The group interviews should take approximately one hour per session.

\section{Procedures}

1. An application to the Human Subjects Committee must be completed and advanced before any actual interviewing can begin. This particular study represents little, if any, risk to the students.

2. Upon advancement by the university committee, I will be able to contact the counseling departments of the two schools to identify pools of potential interview candidates (students in the $1.25-2.00$ GPA range).

3. After a pool of approximately 75 students has been identified at each school, I will mail the letters and permission slips home to the students. This packet will include a statement that all students included in the pool may not need to be interviewed.

4. Interview groups and times will be arranged. At this time, 2:05-3:00 after school each day during a one week time period appears to be the best research timeframe. This will minimize disruption to the instructional day for both students and teachers. I hope to have everything in place to conduct these interviews during the last two weeks of April, 1993.

5. Respond with thank you letters to all students and parents who were available to participate and to those who are actually involved in the focus groups.

I believe this information will be extremely useful to school district personnel at all levels, and I will make the 
findings available. I would appreciate the opportunity to work in the Barlow-Gresham School District, and I will comply with any procedural requests or address any concerns you may have. Jim Carlile is a member of my dissertation committee, and he may have additional suggestions which would improve the quality of this work. Please do not hesitate to contact me if you need any further information. Thank you, Dr. Katterle, for your time and consideration.

Respectfully,

Aeylin summers 
APPENDIX B

\section{LETTER TO PRINCIPALS}


March 22, 1993

To: Principals Linda Jessell and John Miner, Gresham and Barlow High Schools

From: Aeylin K. Summers

RE: Doctoral Research Request

Ms. Jessell and Mr. Miner:

This is a formal letter to request permission to conduct the student interview portion of my doctoral study at Gresham and Sam Barlow High Schools. I have secured permission from Dr. Zeno Katterle already. My purposes with this letter are to a) provide some basic background data regarding the research study, b) outline the protocol for the study, and c) request permission to interview students in both high schools.

a) The centering research question of this study is: what are the characteristics of marginal achieving secondary students, and what is the nature of their school experiences? The purpose of this study is to gather more precise information regarding the student achievement profile of a "middle track" student- typically a student who earns Cs and Ds. We know a great deal about high and low track achievers. However, despite the fact that some literature suggests middle track achievers represent 50-70\% of a typical high school, we do not have a clear perspective regarding what types of students are in this portion of the total population.

As school professionals, if we knew more about which types of students ended up in the middle track, and if we understood more about what school has been like for them, we would have a better opportunity to consider on-going school restructuring efforts in light of this information. For example, are middle track students more accurately described as at-risk students with some extra component(s) (e.g. personality traits, home or school environmental factors) that keep her/him engaged, even at a marginal level, rather than force the student to drop out? If so, what are those components, and can they be emphasized, supported, expanded, etc.? Are middle track achievers more oriented toward high track capability yet they lack some critical component(s)? Again, what are these components, and how can this information be used to advantage?

b) Students appropriate for this study will be identified through the counseling departments of each high school. 
Students will be invited to participate with a letter sent home to their parent/guardian. This letter will include a parent and a student permission form, which must be examined and approved by the Human Subjects Research Review Committee at Portland state University. Students who are able to participate will be guaranteed complete anonymity. They will be interviewed at their home site in groups of about 5-6 students, which should lessen some of their anxieties and make them feel more comfortable in the research setting. students will be given opportunities to respond to questions regarding their school experiences and how they think schools need to change. All student information will be reported with coded names, and the school district will not be identified. The group interviews should take approximately one hour per session after school.

c) I would appreciate the opportunity to conduct the interviews with students at Gresham and Barlow High schools. I do not think the process will be overly intrusive or disruptive to the school day. Also, the information will be made available to the faculty of both schools for further consideration. If you have an questions or concerns, please do not hesitate to contact me at \#666-8033 (W) or \#282-3818 (H).

sincerely,

Aeylin K. Summers 
APPENDIX C

CONSENT LETTER AND PERMISSION FORM 
Research Project-April-kaye 1993

To: Parents/guardians of selected sophomore and junior students

From: Aeylin Summers

I am an assistant principal at Gresham High School, and I am a graduate student at Portland state University. I am working currently on the research component of my doctorate in Educational Administration. To complete this research, I will be interviewing approximately 25 high school students at each of the Gresham and Barlow High school sites. students selected for the interviews will be sophomores and juniors with mid-range GPA's. The purpose of the interviews will be to get information from these students regarding their school experiences and what schools would have to be like for them to be motivated to achieve at higher levels of engagement and excellence. This data about schools will be made available to all district personnel.

Here are some key points about the study:

*All student information will remain completely anonymous. Names will be coded and school names will not be mentioned. *All information will be kept confidential by the investigator, and the students will be asked to keep the discussion confidential, as well.

* There are no physical, mental, or emotional risks to the students at all.

$\star$ All interviews will take place in a group setting of about 5-6 students.

*Interviews will be conducted at the home school site. *Interviews will take about an hour at lunch time.

*All students who are willing to participate may not be interviewed.

I cannot interview any student without a signed parent/ guardian and a student permission form on file. If you consent to having your child participate, please complete the permission sijp and have your child return it to the contact person at each site. Thank you very much for your cooperation. I am looking forward to the study and interviewing the students. 
parent/Guardian and student consent Form

I, agree to have my child take part in this research project on mid-range GPA high school students. I understand that the study involves being a part of a group of students who, for about one hour, will be asked some questions about their school experiences. Ms. Aeylin summers has informed me that the purpose of the study is to gain information about how schools would have to change to motivate middle achieving students. My child may not receive any direct benefit from taking part in this study, however, the study may help to increase knowledge that will help others in the future.

Ms. Summers has offered to answer any questions I may have about the study and what my child is expected to do. She has promised that all information given will be kept confidential to the extent permitted by law, and that the names of all people in the study will be kept confidential by the researcher. I understand that my child does not have to take part in this study, my child can withdraw from the study, and that this will not affect any of her/his grades or relationship with Gresham or Barlow High school in any way.

\section{Parent/Guardian and student consent}

I have read and understand the above information and agree to have my child take part in this study.

I have read and undexstand the above information and agree to take part in this study. Please complete the reverse side.

\section{student Signature}

Date

If you have any concerns or questions about this study, please contact the Chair of the Human Subjects Research Review Committee, office of Grants and Contracts, 105 Neuberger Hall, Portland State University, (503) 725-3417. 
APPENDIX D

STUDENT INTERVIEW INFORMATION SHEET 


\section{Student Information Sheet}

Please fill out the information on this sheet. Thanks! Gender Age Year in School

Where are you from originally?

How long have you gone to this school?

Have you ever gone to another high school? If yes, where?

Tell me about the people in your family? How many, what number are you, etc.

Do you participate in any after school sports or activities? If yes, please list them.

List some of the things you like about school.

List some of the things you dislike about school.

Do you have a job outside of school? If yes, where and how many hours a week do you work? 
APPENDIX E

STUDENT FOCUS GROUP QUESTIONS 


\section{Focus Guide-student Interview Questions}

Research Question: What are the characteristics of marginal achieving secondary students, and what is the nature of their school experiences?

\section{Btudent Demographic/Background Data (On card)}

Gender? Age?

Where from originally? Where do you live now? Years in area?

Family Information (number of siblings, birth order)

Years/months at this school?

Extra-curricular activities in which you participate?

\section{Curriculum}

"We're going to talk for a while about school, and we're going to think about it in two parts- first the classes and the coursework, then the teachers. Let's start by thinking about classes you have taken."

Which classes have you enjoyed the most? (Specify level-i.e. Algebra 2)

What are the characteristics of classes you have enjoyed?

Which classes have you enjoyed the least?

What are the characteristics of classes you have enjoyed the least?

Which are some of the most memorable classes you have taken? Why were they memorable?

Which are the classes where you believe you learned the most material that you will remember?

Which classes covered material that will be important to you for the rest of your life?

Describe how material is presented in some of your current classes.

\section{Instruction}

"Now, let's think about the teachers in these classes. You might have one particular teacher in mind, or you may have a few in mind, and you can talk about things these people have in common."

What are some of the characteristics of teachers whose classes you have enjoyed? Describe a particular teacher (no names).

Describe what a teacher does in a class you enjoyed.

What are some of the characteristics of teachers whose classes you have not enjoyed? Describe a particular teacher ( no names).

Describe what a teacher does in a class you did not enjoy. 
What are some of the characteristics of teachers where you learned a lot of the material? Describe a teacher (no names).

Describe what a teacher does in a class where you learned a lot.

Personal 8chool Experiences

"No matter which class or which teacher you have, you are always the student. Think about yourself as a student."

Describe yourself as a student. What has school been like for you, in general?

Was there ever a time when you experienced a great deal of success in school? Describe that experience or time.

Was there ever a time when you did much worse in school? Describe that time or experience.

What was your level of success last year, compared to this year (e.g. "I'm doing about the same, a little better, worse, etc."

How do you account for this?

Is your level of success what you expected of yourself?

Are you satisfied with your level of success? Are you a marginal student?

Are you working as hard as you could in school?

could you work harder at school than you are currently working?

What would make you work harder at your school work?

How do you decide how much work to do in a given class?

In which of your classes, if any, do you put in your best effort (i.e. pay attention, do all of the assignments, ask questions, stay prepared, etc.)?

How do you account for your effort in this class?

What would make you put in this kind of effort in every class?

$(* \star$ Focus $=$ school? parents? self? teachers? $)$

School Environment

"Now, I want you to think about school, in general, not one particular class or teacher."

Besides go to classes, what do you do at school (e.g. see friends, play sports)?

What do you look forward to the most? What is your favorite part of the school day? Why?

What do you look forward to the least? What is your least favorite part of the school day? Why?

Do you feel like you are a part of your school? How do you fit in to your school?

Who are some of the people at school you believe you could ask for help with school work or school-related issues (Problems? Schedules?)

How often do you seek help from these people? 
What accounts for how often you seek help from these people?

How often do you get sent to the principal's or assistant principal's office for disciplinary meetings?

Typically, why would you be sent?

Do you make appointments to see your counselor? How often do you see her/him? Why would you go?

Do you think your teachers like you? Why or why not?

Do you ever talk to your teachers about non-school subjects? Why or why not?

If yes, what do you talk about?

Do you believe your teachers care about you as a person? Why or why not?

How do teachers act when they care about you? When they don't?

Home Environment

What do you do after school?

How many waking hours are you at home every day after school?

Do you talk to your parent/guardian about school? How often?

What kinds of items do you discuss about school?

Do you seek help from your parent/guardian regarding school and school issues? Why or why not?

What kinds of things do your parents/guardians say about school?

Do you plan to graduate from high school?

How important is it to you to graduate with your class?

Do you have plans for yourself after high school? Describe your plans.

How much influence do your parents/guardians have over your future plans?

How much influence do sisters, brothers, or other family members have over your school decisions? Describe this influence.

\section{Future/Projection Questions}

"I'm going to ask you some questions about stuff you may never have even thought about. I want to hear about how you see your future."

Do you have any future plans right now? College? Job?

Would you be ready to graduate at the end of this (sophomore) year?

If you were going to receive a certificate at the end of tenth grade that says you are ready to choose a career path, would you know what to choose to study?

can you see as benefits to this idea (choose at the end of tenth)? What? 
What do you think of these ideas? Do you think they would make you work harder or make a greater effort in school?

-longer school day/year?

-shorter school day/year?

-couldn't get a work permit without a diploma?

-employers advertised a higher wage for high school graduates

-fewer subjects to study every day? more block scheduling?

-more choices of electives?

-more extra-curricular opportunities all year long?

-system where you couldn't earn less than a c? (If

lower grade, get an Incomplete till the grade $=$ at

least a $c$ or better)

-system where you needed to show/demonstrate what you knew, sometimes with paper/pencil test, sometimes with projects?

-system where you took classes related to a career/job?

-system where you took classes part-time at the high

school, part-time at a community college or university?

-system where you went to school part-time and worked part-time?

Describe what you think school would have to be like for you to want to come to school and where you would work pretty hard at your schoolwork.

Segments=curriculum, instruction, school environment

What else do you think would help you to make a big effort and work hard in school? Is there anything else that school people could do? Parents? 
APPENDIX F

NELS QUESTIONNAIRE--1988 FOLLOW-UP 


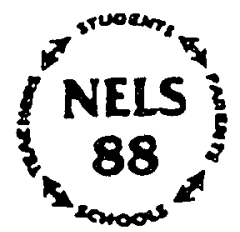

\author{
NATIONAL EDUCATION \\ LONGITUDINAL STUDY

\title{
STUDENT QUESTIONNAIRE
}

\author{
Prepared for: U.S. Department of Education \\ National Conter for Equcation Statistics \\ By: NORC. A Socid Science Resaren Conter \\ Univervity of Cricepo
}

\section{USES OF THE DATA}

The data from the survey will be used by educators and by federal and state policy makers to address important issues facing the nation's schools: educational standards, curriculum tracking, dropping out of school, the education of the disadvantaged, the needs of language minority students, incentives for attracting students to the study of science and mathematics. and the features of effective schools.

\section{CONFIDENTLALITY}

As a matter of policy, the National Center for Education Statistics is concemed with protecting the privacy of individuals who perticipate in voluntary surveys. We want to let you know that:

1. Section 406 of the General Education Provisions Act (20-USC 12210-1) and Public Law 100-297 allow us to ask you the questions in this questionnaire.

2. We are asking you these questions in order to gather information about what happens to students as they move through high school and make decisions about what they are going to do after high school.

3. You may skip any questions you do not wish to answer, however, we hope that you answer as many questions as you can.

4. Your responses will be combined with those of other students, and the answers you give will never be identified as yours.

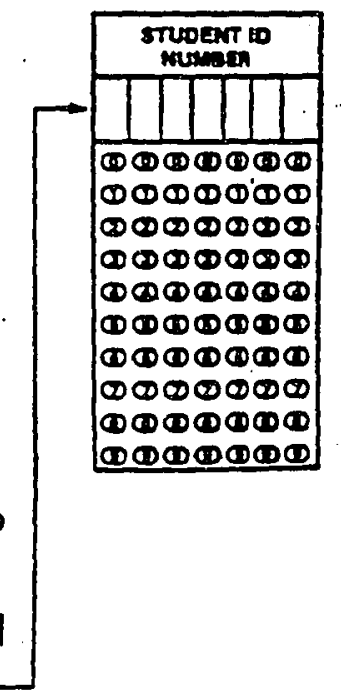


The public reporting burden for collection of inis information is estimated to average throe hours (180 minutes). including one hour for the questionnaire. one and one-hall hours for the Cognitive Test, and up to one-half hour for distsibuting materials and giving instructions. Send comments regarding this collection of information, or any other aspect of this collection of information, to: U.S. Department of Education, Information Management and Compliance Division. Washington. D.C. $20202-4651$ and to the Office of Management and Budget. Papenwork Reduction Project. Washington. D.C. 20503.

Tha Satf-Description Questionnaire is copyriptred by Herbert Marsh and used by permission. No reproduction of the Setf-Description Questionnaire mry be mada withour permission of the owner.

The purpose of this survey is to collect information that will allow teachers and educators to better understand students' various exporiences in high school.

This questionnaire is not a test. We hope you will answer each question truthfully, because we need your answer. You may skip any question you do not wish to answer.

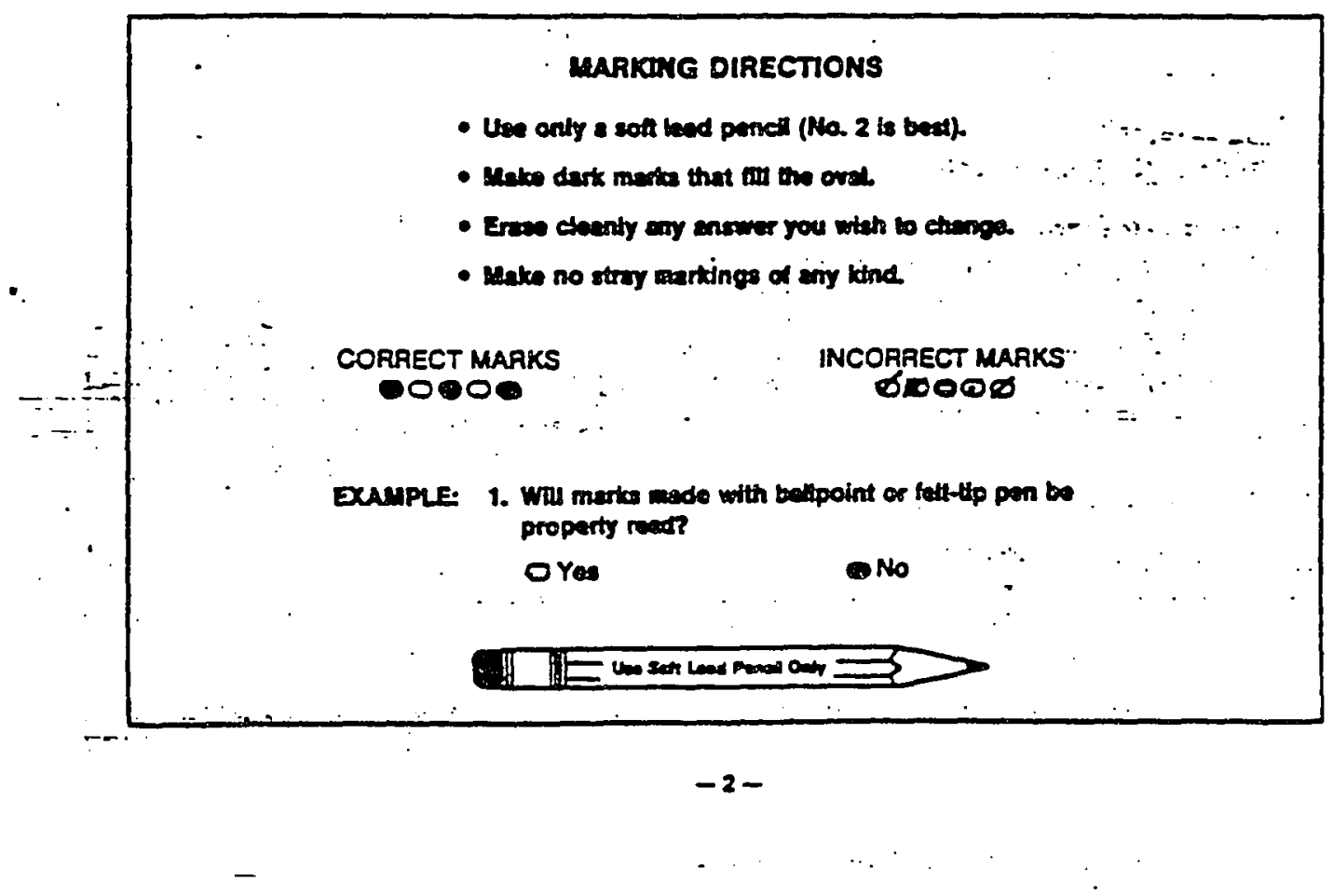




\section{GENERAL INSTRUCTIONS}

\section{PLEASE READ EACH QUESTION CAREFULLY.}

It is important that you follow the directions for responding to each kind of question. These are:

E.

A. (MARK ONE)

What is the color of your eyes?

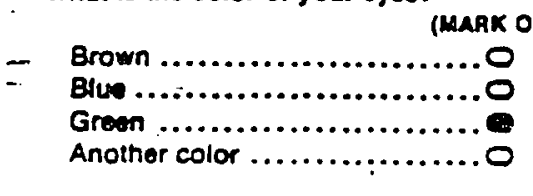

(MAAK ONE)

D. (MARK ALL THAT APPLY

Lest weok, did you do any of the following?

Sea a play

(MAAK ALL TMAT NOMLY)

Go to a movi ..................

Attend a sporting event

\section{C. (MARK ONE ON EACH UNE)}

Do you plan to do any of the following next weak?

(RAAR ONE ON EACH LNAS

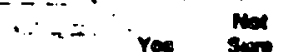

a. Visit a relstive

You

b. Go to a musaum.......................

c. Study at a triend's house ............. .0

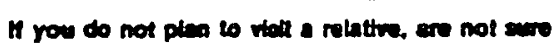

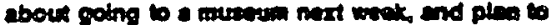

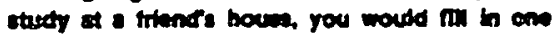
itan on eech lire as thom

D. (OUESTION WITH A SKIPZ

2 Do you est sweet toode?

(MAAK OND)

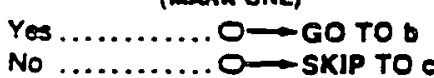

b. Do you bruth your terth after anting swert loode?

(Manx Ond)

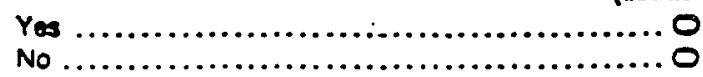

c. Lant weete did you do any of the followtng?

(MARK AL THAT APPLY)

See a play ................................

Go to a movio .................................

Attend a sporting owart . 


\section{PART 1 - ADDRESS INFORMATION}

1. Phase prtht yous mane, addrese, and bephone mumber.

0

* name.

Last
ADORESS:

Aooress

Contrinued:

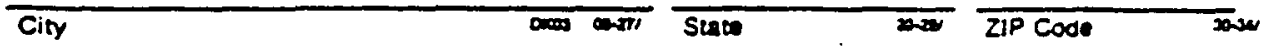

$\cdot$

$\frac{1}{\text { Arae Code Tolephone Number }}$

WHEN WE SAY PARENT(S), MOTHER, OR FATHER, AMSWER FOR THE PARENT/GUAADLAN OR STEPPAAENT WTTH MHOL YOU LVE.

$$
\div \div
$$

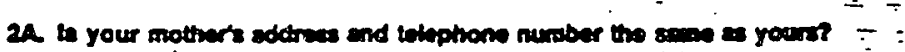

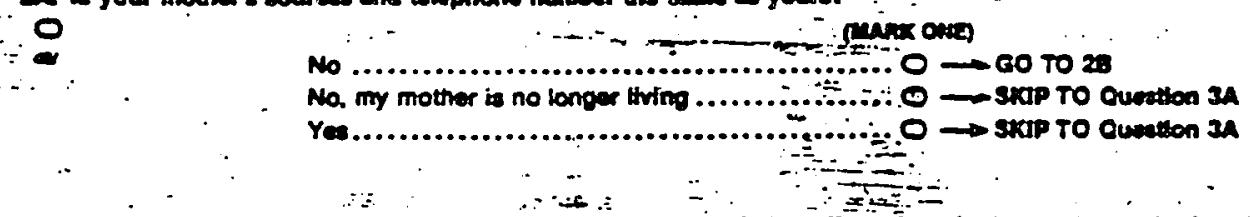

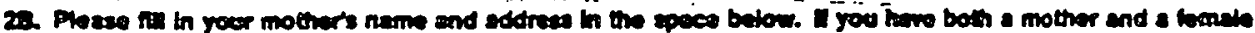
O guerdien, with in the narse of the an whom you twe with most of the trim.

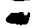

NAME:

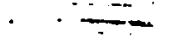

$-\cdots+2=$

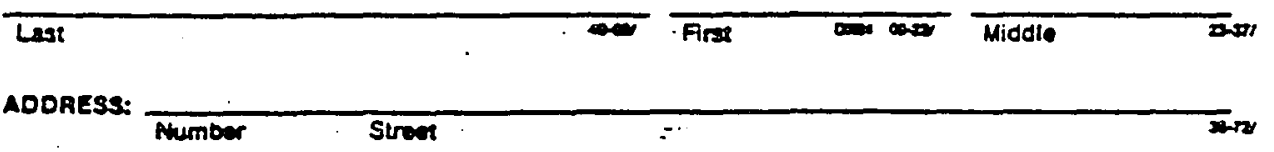

ADDRES3

CONTTNUבR:

$\cdots+-\cdots$

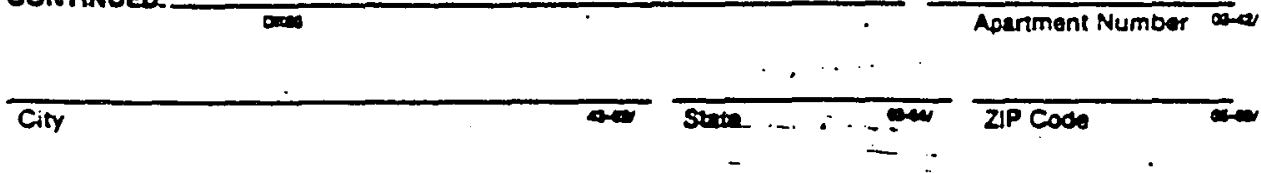

Texephoke: $\frac{1}{\text { Area Code Telophone Number }}$

the dow not have

cimpion 


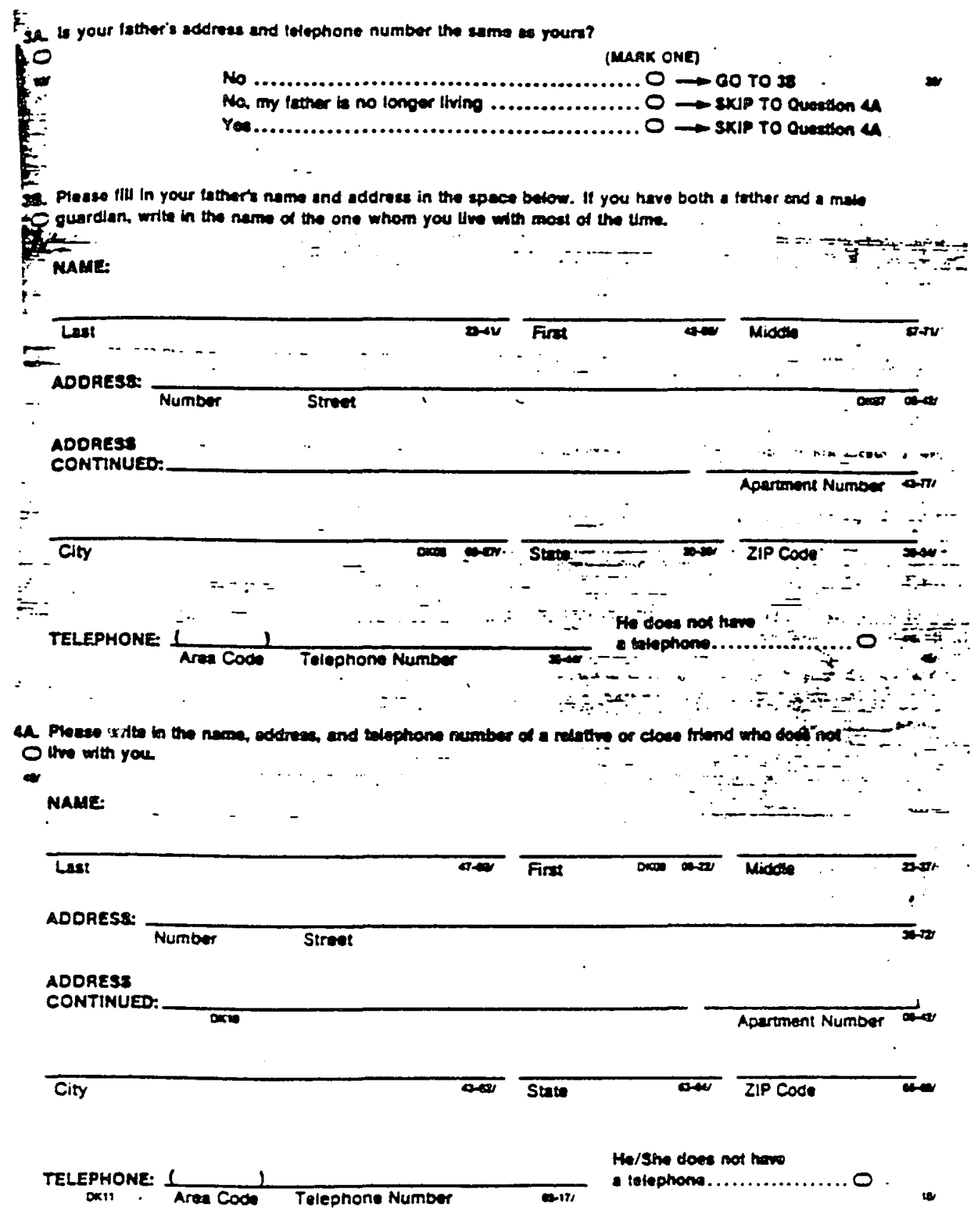


48. What is your matationstip to this person?

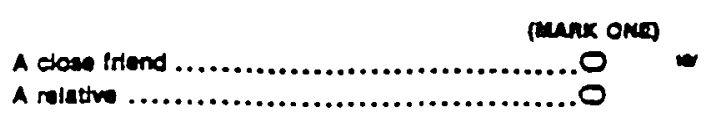

5. What grade aro you In?

$=$

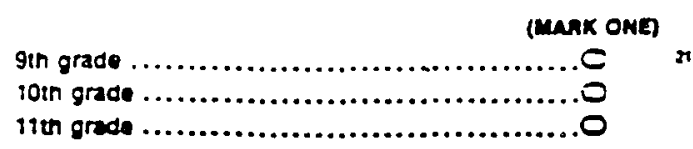

64. What schood will you be atending in 12un grade?

0

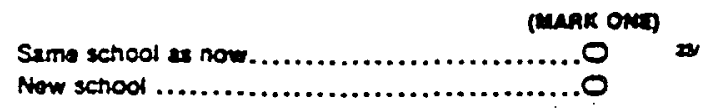

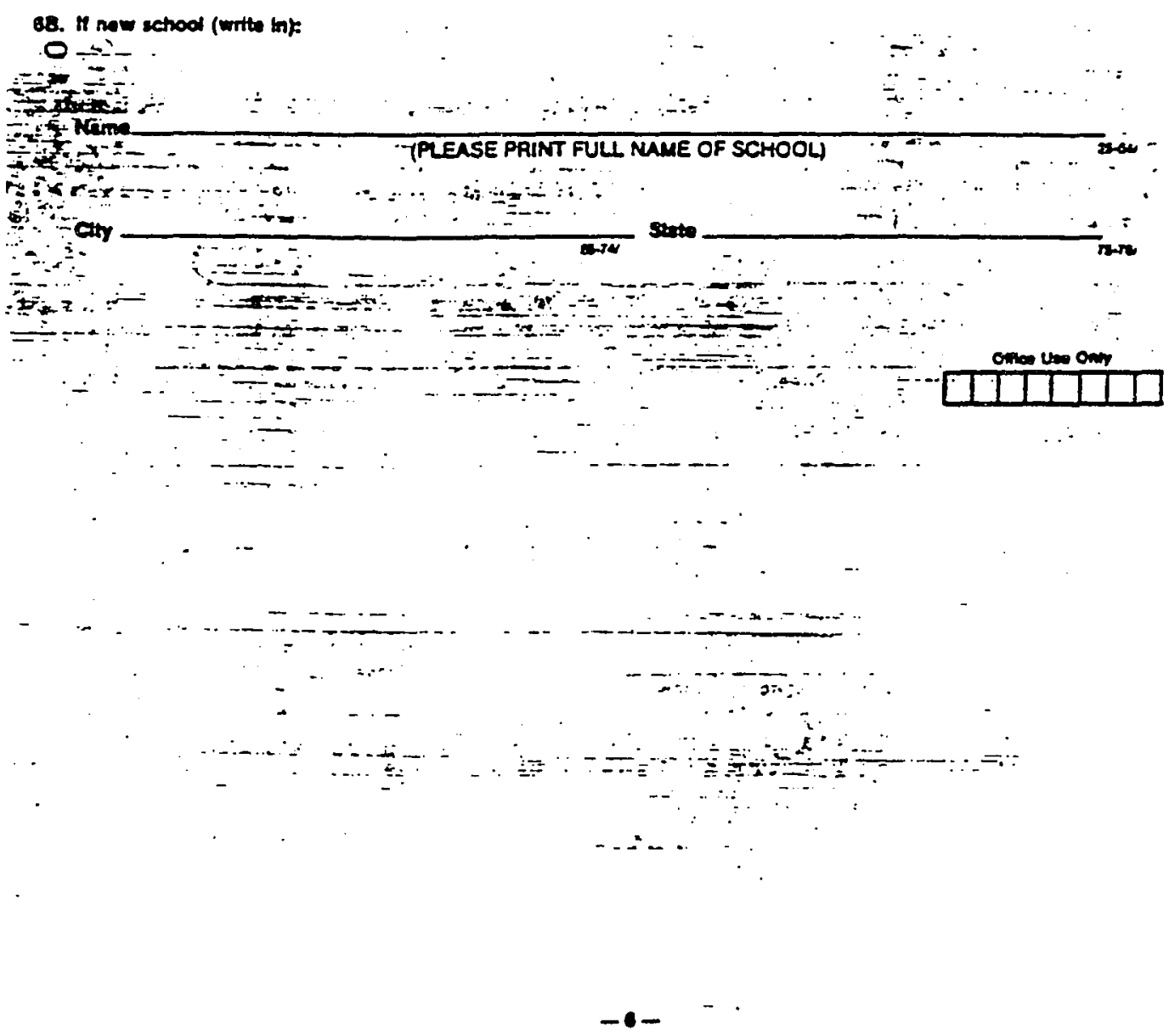




\section{PART 2 - YOUR SCHOOL EXPERIENCES AND ACTIVITIES}

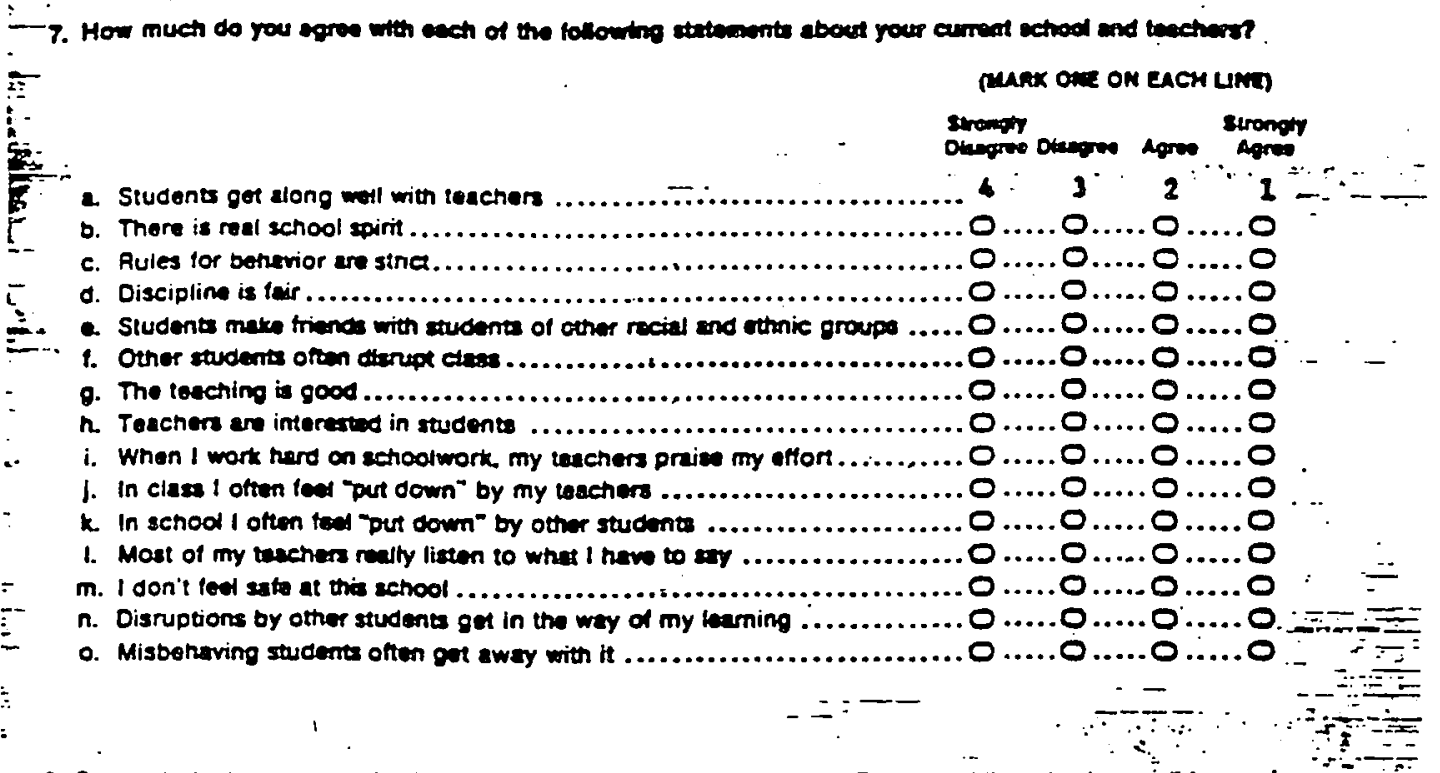

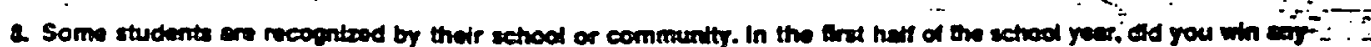

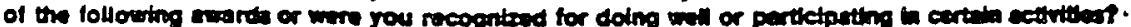

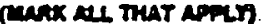
a. I have not won any wards or recoived recogrition.......................... I
b. Elocted officer of a shool clase $\ldots$
c. Won an academic honor ............................................ I

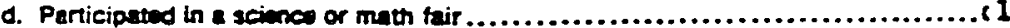
e. Received special recognition for good attendance.......................... I
f. Received special recognition for good grades or honor roll ..................... I
g. Received special recognition for writing an exesy or poem ................... I

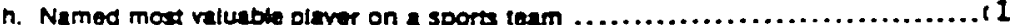
i. Recoived a commumity sorvice award $\ldots \ldots \ldots \ldots \ldots \ldots \ldots \ldots \ldots \ldots \ldots \ldots \ldots \ldots \ldots$ i 1

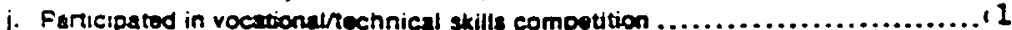

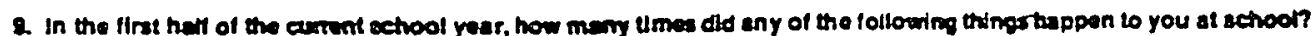

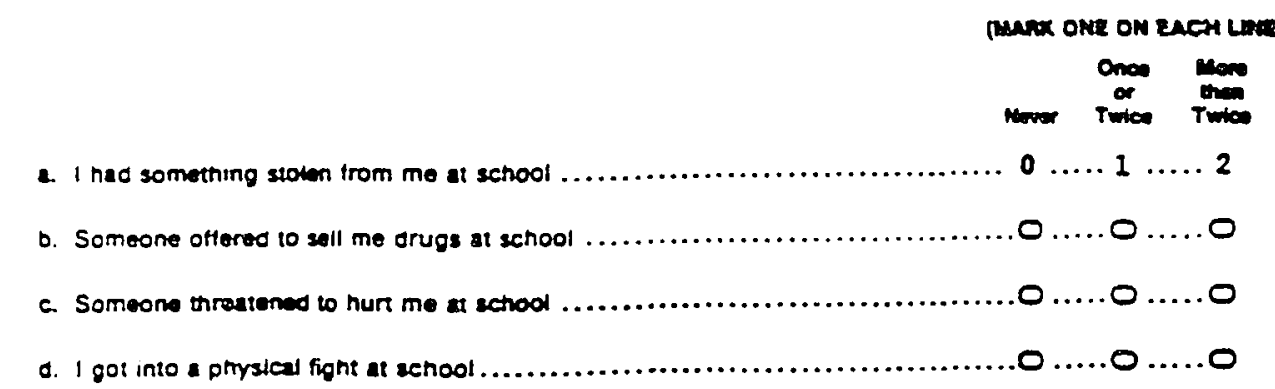




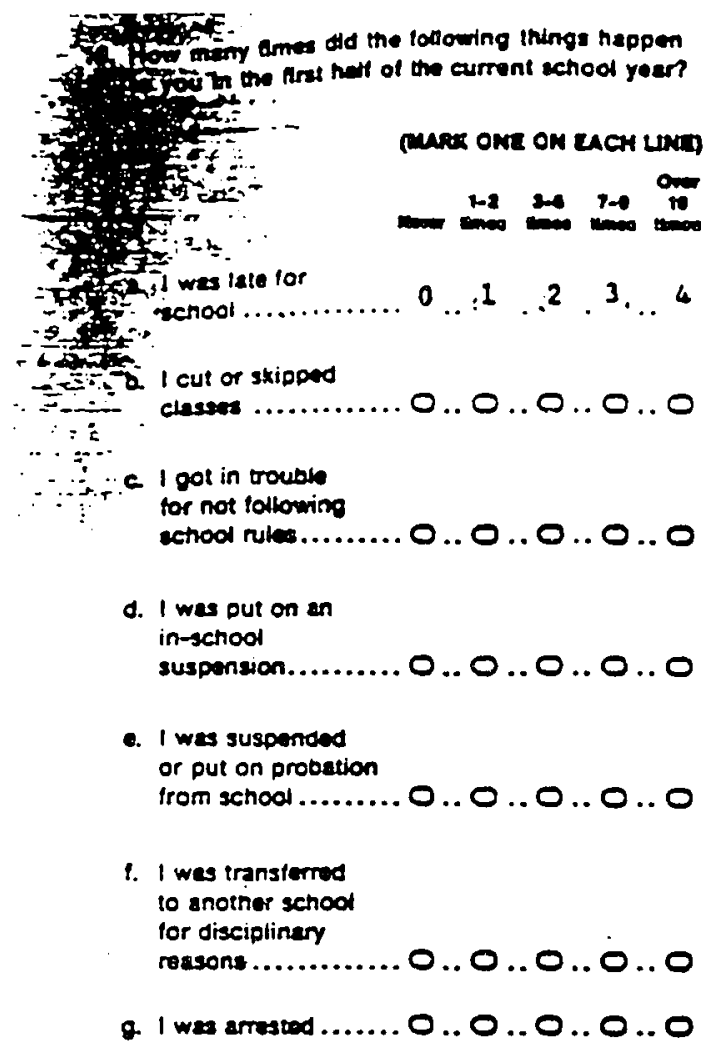

11. Do you foed it th -OK tor yoe to ...

- marx one on each UNA)

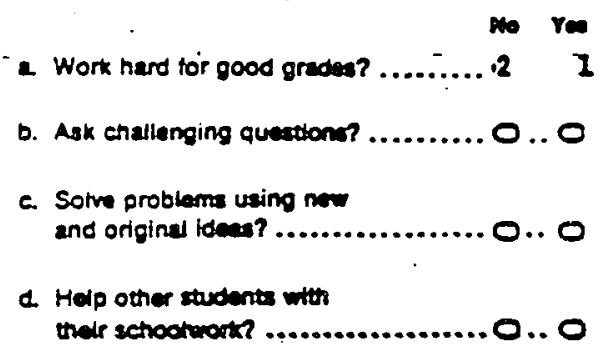

12. How often do you fow II is "OK" lor you to...

(MAAX ONE ON UCH UNE)

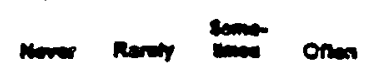

2. Be late for schoor?.......4 $4 \quad 2 \quad 1$

b. Cut a couple of classes? ......

c. Skip school tor i whow dey?..... $0 . . . .0 \ldots . . . . .6$

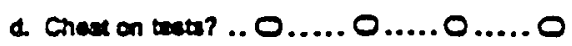

-. Copy someone utse's homowork? . $0 . . . .0 \ldots . .0 \ldots . .0$

8. Get into physical fights? ..........................

2. Botong 10 gangs? .........०....०....०....०

h. Make racist remetos? ........ $0 . . . .0 \ldots . . . . .0$

i. Menes soxiet momerket ........ $0 . . . .0 \ldots . . . . . .0$

- 1. steed batonginge

from xhoot. a ster

. dent or a bechert $0 . . . .0 .0 . . .0 . . . .0$

k. Destroy or damage

$\because \ldots$ school property $.0 \ldots . . .0 \ldots . .0 \ldots . .0$ $\therefore$

-2. Smate on sechood

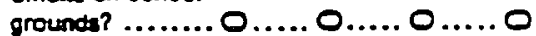

m. Onnk stcohol during xctool doy $0 . . . .0 \ldots . .0 . . .0$

n. Use inoger arups durng schoor den $0 . . . .0 \ldots . .0 \ldots . .0$

a. Brtion wepons to seroor ....... 0..... $0 . . . .0 . . .0$

p. Aoun texchers physicaly? ....... $0 . . . . \circ \ldots . . \circ \ldots . .0$

a. Talk back to

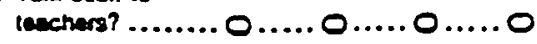

r. Disobery ectiod rubet?

.


13. In the first heff of the current schoot yoar. sbout = how many doys wore you suent trom school - for any remon?

$$
8
$$

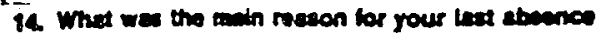
troes sechoar?

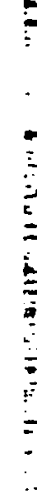$$
\begin{aligned}
& 5 \\
& - \\
& \vdots \\
& \vdots \\
& \vdots \\
& \vdots \\
& \vdots \\
& \vdots \\
& \vdots \\
& \vdots \\
& \vdots \\
& \vdots
\end{aligned}
$$

I hed to care for a momber

of my family or clowe triend

max ons

I was sick .................... $\ldots 12$

I didn't fest tike going to school ............ . 4

I wes worried about my safory

going to or in school ...................... s

I had to get a job to hap my fanlly ........ 16

I had problem with a teactier or

other adult in schood $. \ldots \ldots \ldots \ldots \ldots \ldots . .7$

I hed problems with anothor sudemt

- - or group of students......................

I wented to spand time with $\mathrm{my}$

friends wo ere not in sechool ...............9

I wean' prepared for a but or

ctess essigrment ..........................10

1 couldn't keep up with my setiod work .... II

I fett I didn't beiong at achool ............ 12

I don't remember....................... 13

15. Which of the following happened on your teat absence from sctioon?

MARX ONE ON EACF LING

$$
\text { is res Dont }
$$

a. The school did not

do anything ..............2 1

b. Sommone trom school called my hom .......... $0 . . . .0 . . . .0$

c. Sompone trom sechod visited my nom .

d. The school sent a letter to my norre ....... $\odot \ldots . . \odot \ldots . . \varnothing$

e. The senool mede mo soe a counsetor.
16. Whan you com bect to school stter your last absence. which of the following heppened.

(wax M mat ann

- My tachers hadped me cusch up on

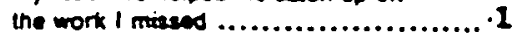

$b$. Other students halped me catch up on the work I missed .................... I

c. Someone else halped me ................... 1

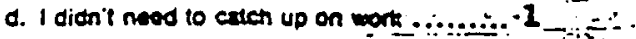

- When I cem bect to schoot a tescher :-

wes mod at me or put mo down in ctase .... 1

1. A tencher. counsalor. or other sctutt in the sechool suked in where l'a been ........ il

Q. I fell banind ................................. . 4

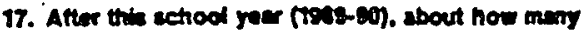

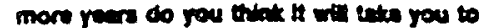
graduete from high sction?

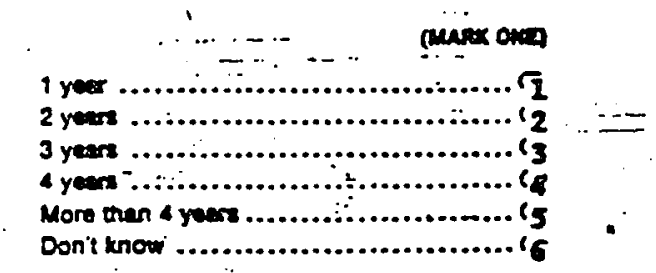

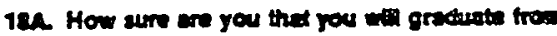
0 high schoon?

(2haras ond

Very sure I wont gradule ................ I

I probebly won't graduate................ Q

I'll probubly graduat ..................

very sure i"ll gradust .................... of

128. How ure ene you thet rou will go on for further edveation atter jou bive high sechod?

(WAAR ONG)

Very sure I wonit go .................. \&

I probably worit go..................... 3

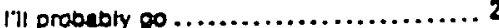

very sure lil go ..................... I 
For esen torm you were enrolled in school, did you ...

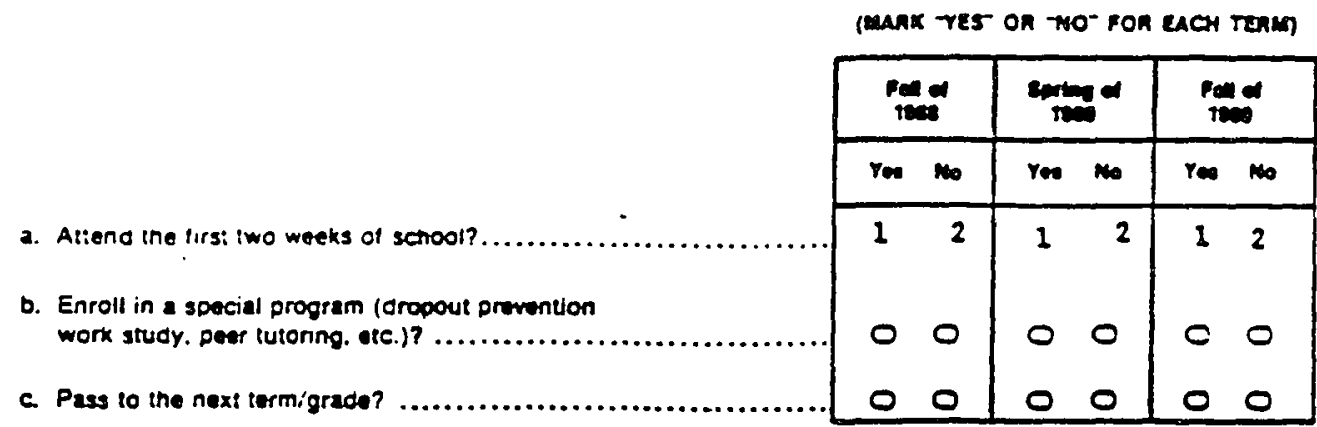

22. Which of the following best dascribos yous prent progran?

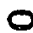

(mancone

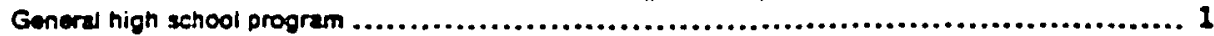

College prep. academic. or specialized scademic (xeh as Science or Math) ......................2

Vocuttonal. technical. or business and carer

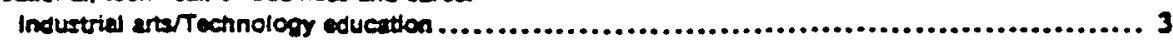

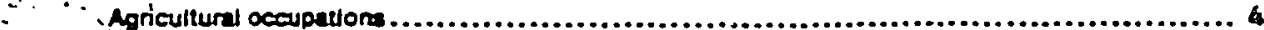

Business or office occupadions .......................................................

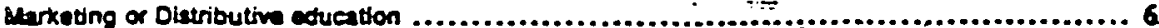

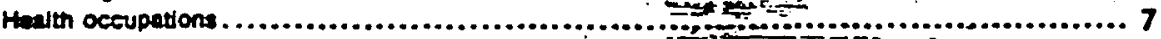

Home economics occuptions .....................

Coraumer end homemeling educeston .............

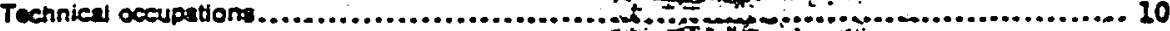

Trade or industrial occupations ....................

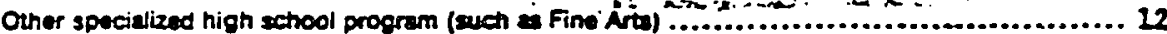

Other ........................................................................... 13

I dont know ......................................................................14

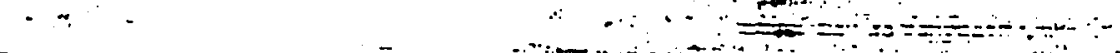

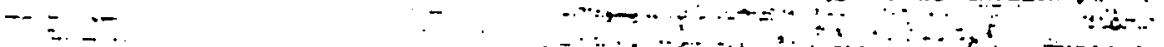

21. What is the main reacon you so taiting the following wablecter?

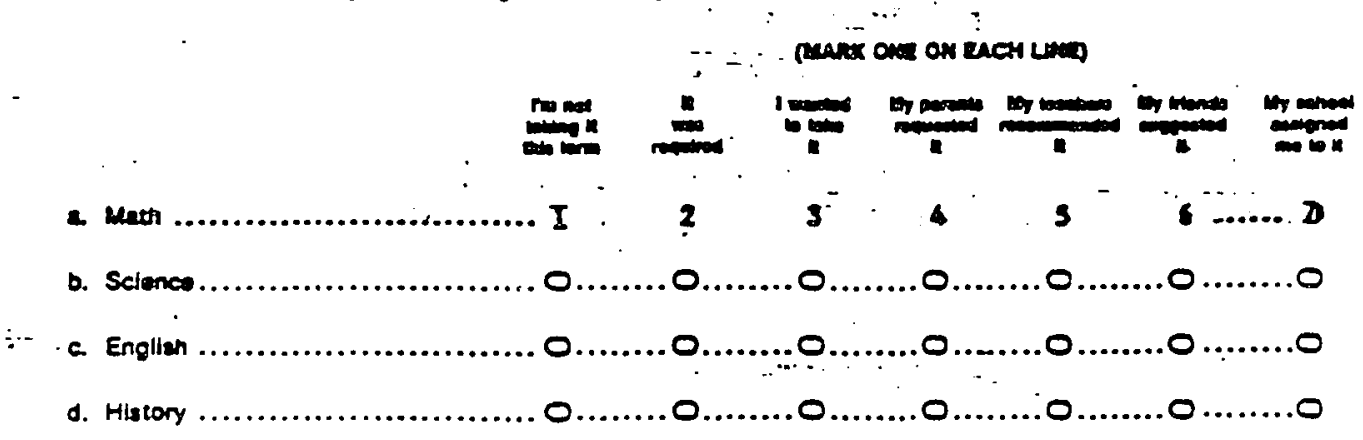




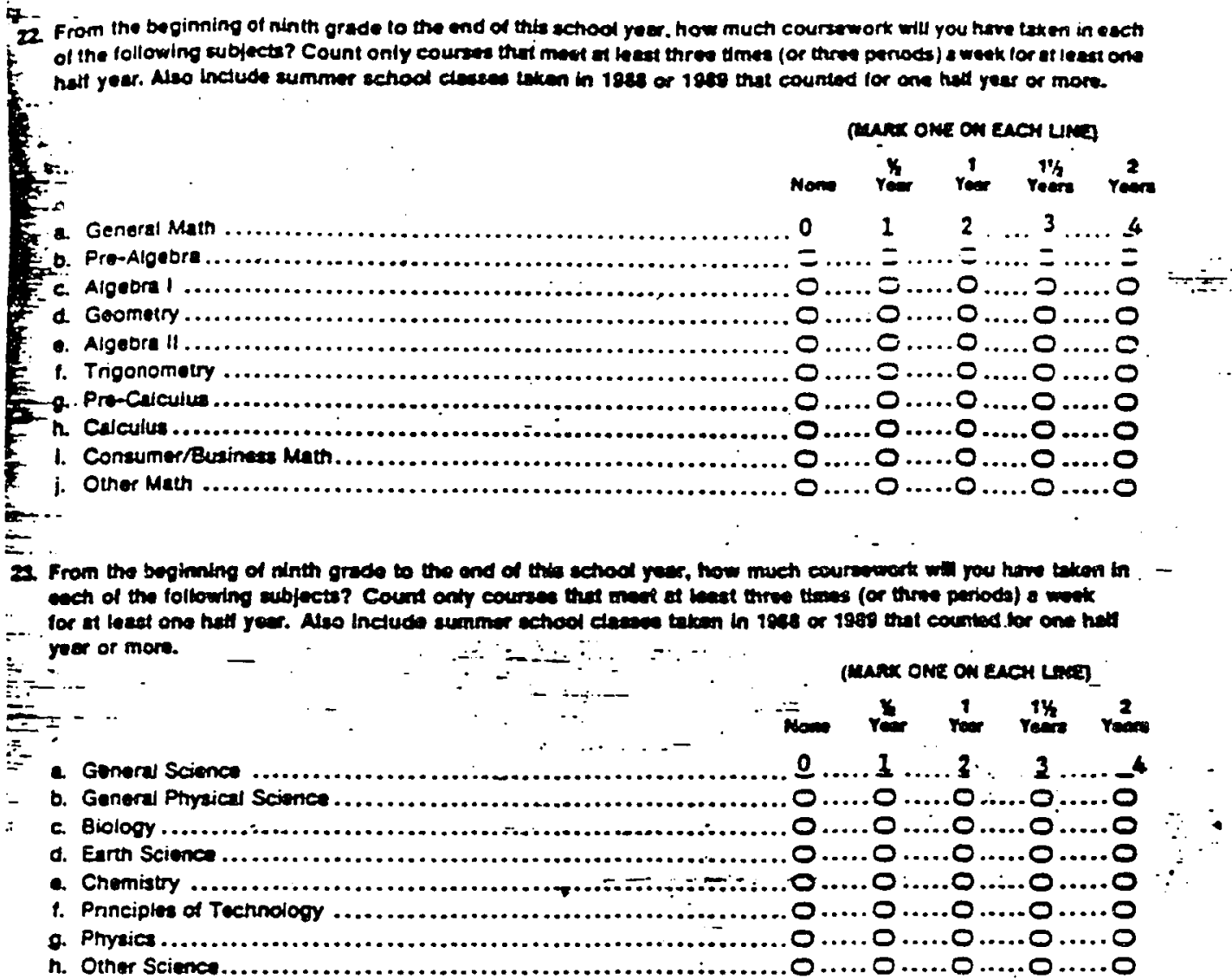

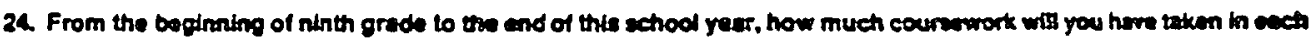

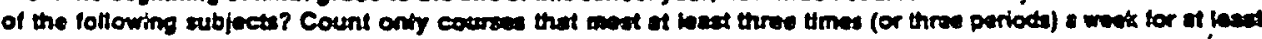
one hal yest. Aleo includs summer school cournes baken in 1989 or 1989 thet counted for ons hatf yeer or more.

(MAR ONE ON ENCH LINE)

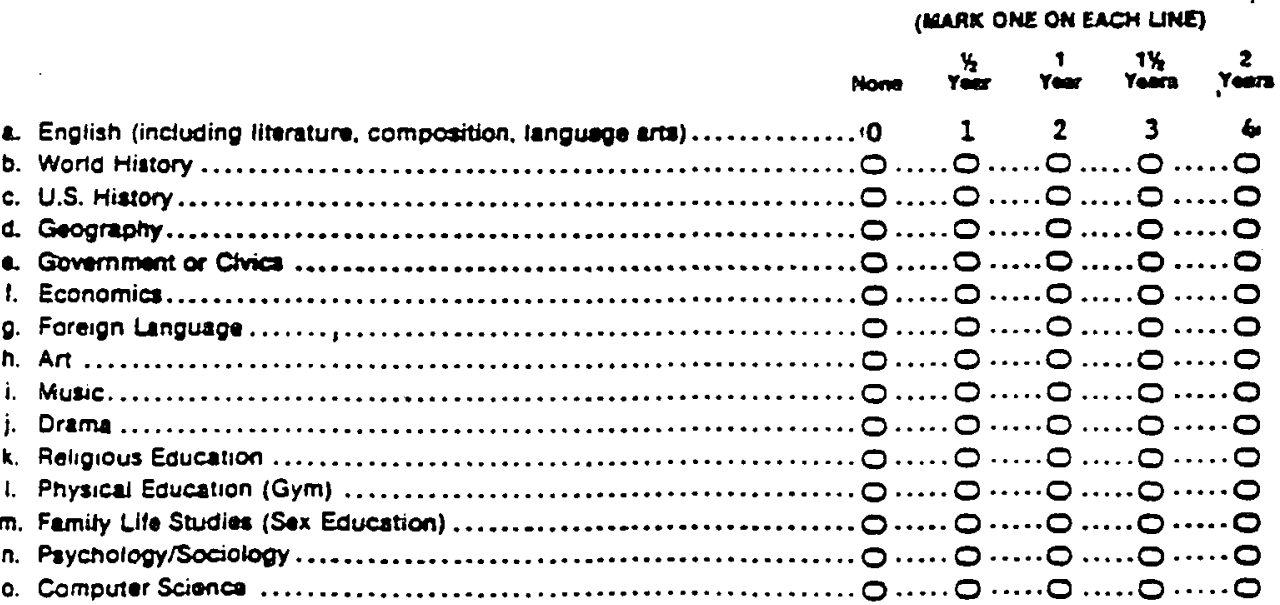


25. From the bagkning of nintw grade to the end of this achood year. how much coursemork will you have taken in each of the following subjects? Count ordy courses that mext at least three thes (or three penode) a week for at least one

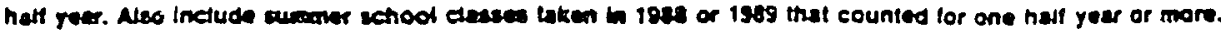

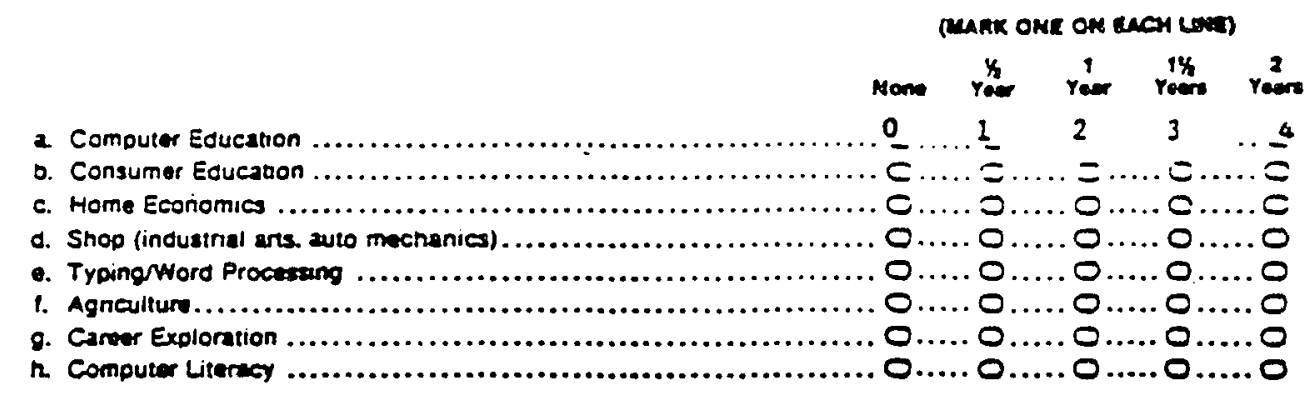

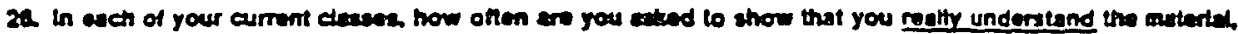
ruther then furt ghe en enewer?

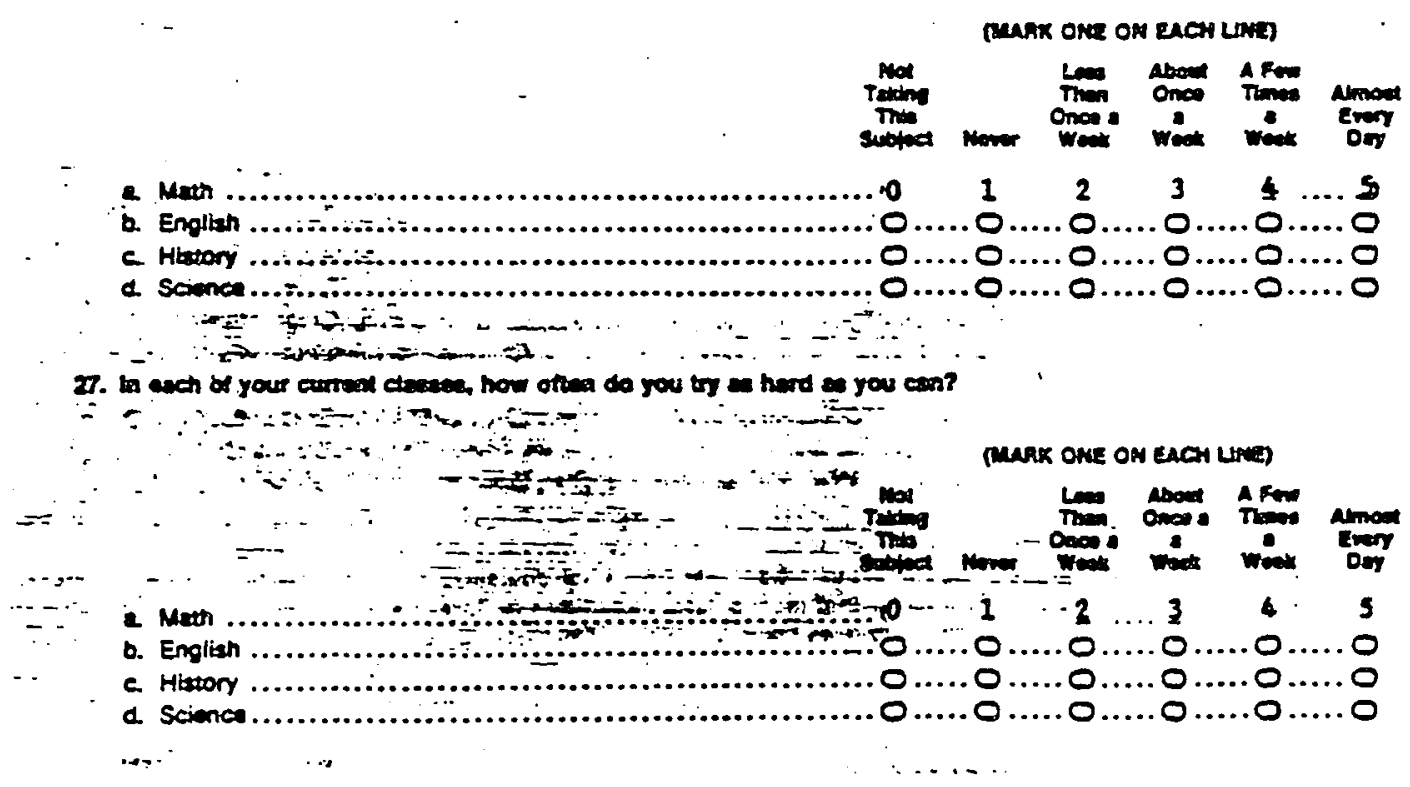

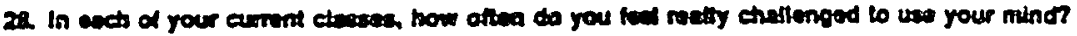

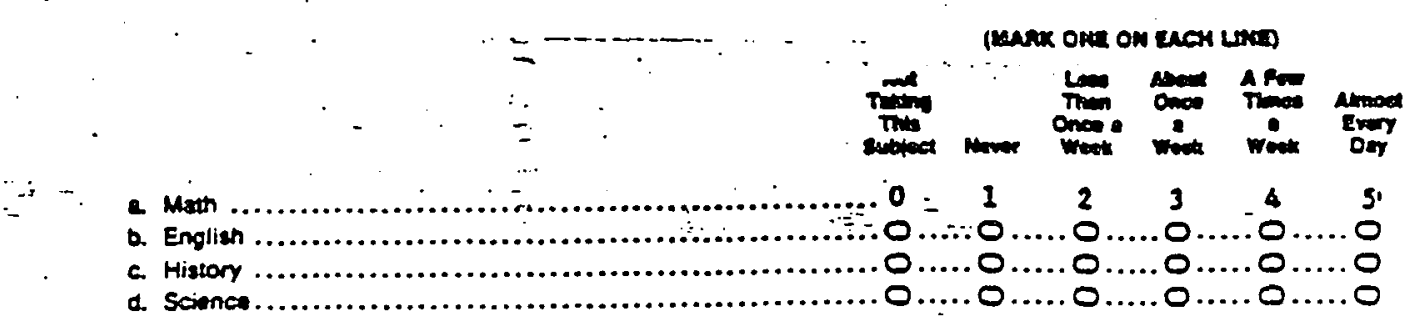


29. In your most recent of current SCIENCE chasere how often de/did rou ...

(IF YOU hAVE nOT TAKEN A SCIENCE CLASS, DARKEN THE OVAL AND SKIP TO QUESTION 31.)

Mive not rot taken a science clase

$0 \rightarrow \infty 0$ TO Qumena $x$

manx oxe on erch unat

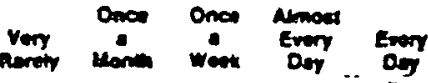

a. Review the work trom the previous day? 1......3.....3..........3...

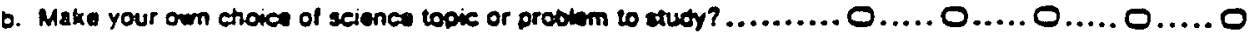

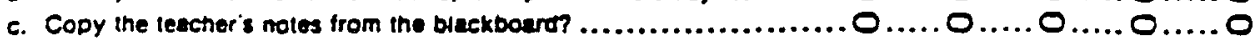

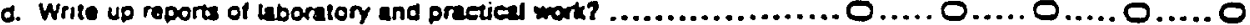

- Use a book or other wntten instructions that show you how to 00 .

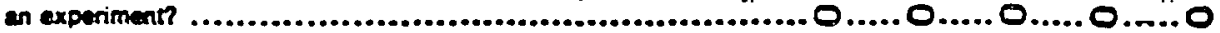

f. Make up your own problems and wort out your own methods is

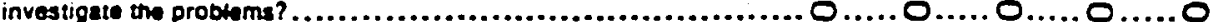

๑. Design end conduct experiments or project on your own .......... $. \ldots . .0 \ldots . .0 \ldots . .0 \ldots . .0$

h. Use computers to wite up experimom or reports? ................. $. \ldots . .0 \ldots \ldots . . \ldots .0 \ldots . .0$

- i. Use computers for collecting and/or andyzing dala? ............... $. \ldots . . . \ldots . . . .0 \ldots . .0$

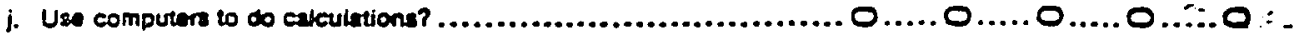

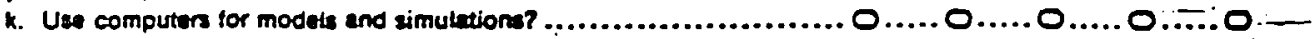

1. Listen to the teacher lecture? ................................ $. \ldots . .0 \ldots . .0 \ldots . .0 \ldots \ldots, 0 ; .$.

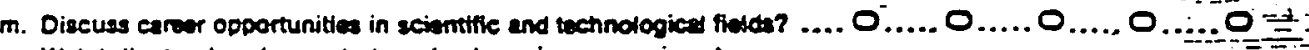

n. Waten the unctier demonatute or lead you in an experiment... . or systematic obsemation?................................... $. \ldots . . . .0, \ldots .8$.

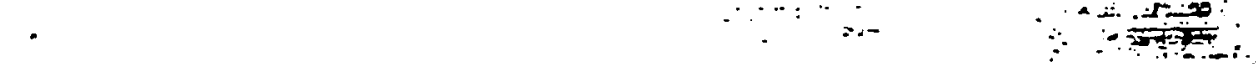

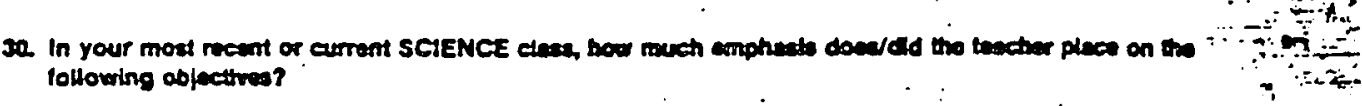

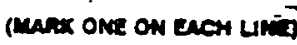

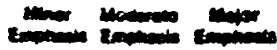

a. Increasing your interes in science ...............................

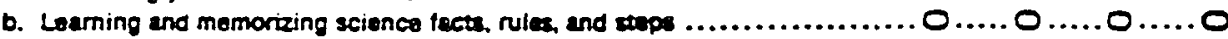

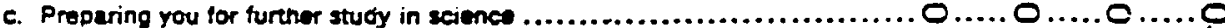

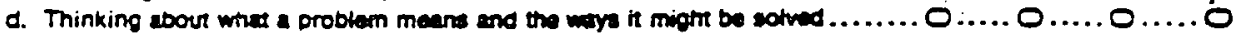

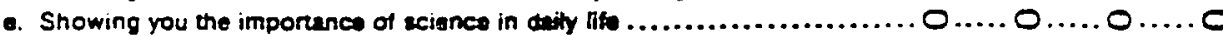

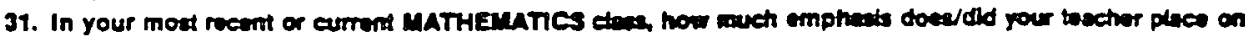
each of the tollowing objoctres? (IF YOU HAVE NOT TAKEN A MATHEMATCS CLASS, DARKEN THE OVAL AND SKIP TO OUESTION 34 )

Have not yet taken a mathematics clas.

$0 \rightarrow$ co TO Ountion $x$

(MARX ONE ON EACH LANE)

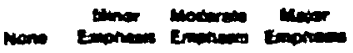

a. Increasing your interest in mathematies ............................. 0.21

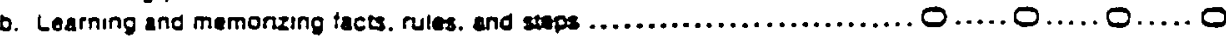

c. Proparıng you tor turther study in math $\ldots \ldots \ldots \ldots \ldots \ldots \ldots \ldots \ldots \ldots \ldots \ldots \ldots \ldots . \ldots \ldots, \ldots \ldots, \ldots \ldots, 0$

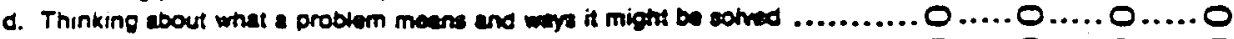

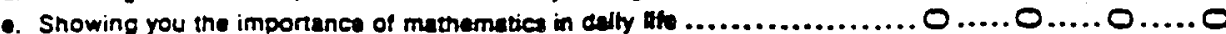


32. In your moat recent or curront MATH dast. how often do/did you...

(MARK ONE ON EACM LNE)

2. Roview the work from

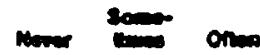
the provious day? ..... \& $\quad 2 \quad 3$

b. Use Dooks other than text books? .......... $=\ldots . . \ldots .=$

c. Copy the reacher's noles from the backbourd? .. $0 \ldots \ldots \circ \ldots . .0$

d. Do story problems or probierm-solving acivities? ........... $. \ldots . \varnothing \ldots .$.

- Use computers?...... $0 . . . .0 \ldots . .$.

1. Uea handeron materiat or modeta? ...........,...., $0 \ldots . .0$

9. Use calculators? ...... $\odot \ldots . . . \quad \ldots . . \varnothing$

h. Participate in studentled discussions?....... $. . . .0 \ldots . .0$

i. Explain your work to the class oraly? ...... $0 \ldots \ldots \circ \ldots \ldots 0$

32. In your moxt recent or current vocatioksh course, how buch enptrals ald/does you inecher plece on the following oblectrines? -

- Have not bian a woctional course

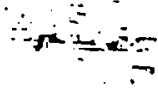

(MARK ONE ON EACM UAD

- Teaching you

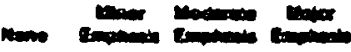

- ikills rou cen $-\ldots$

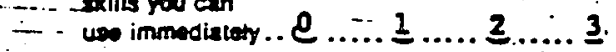

b. Teaching you tacts, rules. and stups $=-$

c. Helping you underseand how scientific ideses and mathematica are uad in work. .

a. Thinting about whe a probiem mines and the wers it mignt be sotred

- Helping you to understand

mathematica

and scientufe

idoce by halping

you to manipulat

prysical obiect

(toots. machines.

lob equidmint)
34. Here you mer been in any of the following kinde of courses or programs in high school?

\section{max ow on thon ling}

Nor $r$

2. Remedial English Isomelimes called basuc or assen(ia)t.

b. Remedial Methematics (sometimes called besic or essentud).

c. Bllingual or bicuttural progran ............................

d. Englien as a Second Lenguege program ..............................

e. Advanced plecernint progran ..... O .....

1. Special progrem for the educationally handicepped ........

8. Special program for the phytically handicapped.

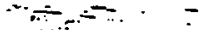

n. Dropout ormation program .......

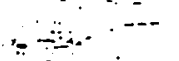$$
-\because \because \therefore
$$

35. Hawe you nectived hroration on the following toples in your arriat ectoon?

- $\quad \therefore \because-1$

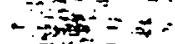

RUAK OATE ON EACH UNG $-1: \because$

and $-\because$

2. Famity llte or $\operatorname{sx}$ ectucertion.......2 2

b. ADS ctucition .

c. Acohol or drug abue education... 0 ..... O 


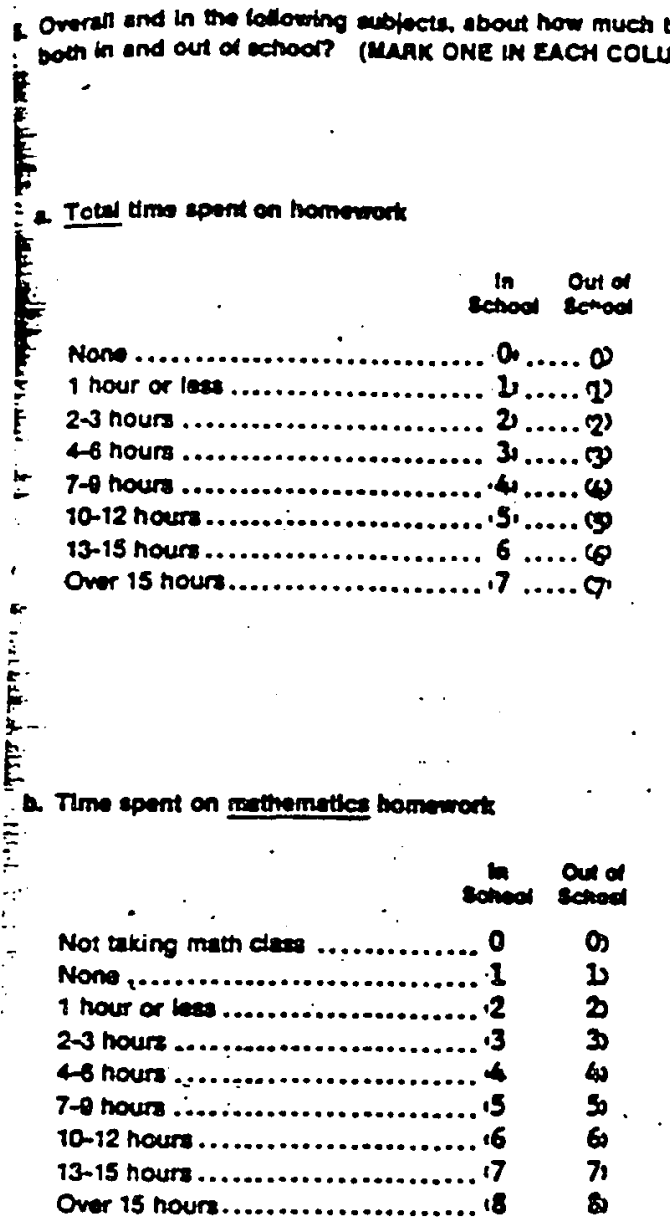

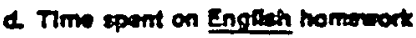

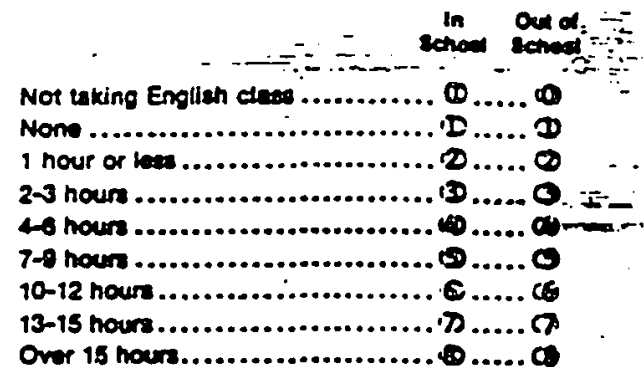

Over 18 hours.....................6.....

c. Thme apent on edence homemort

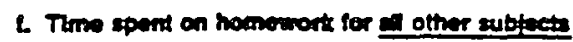

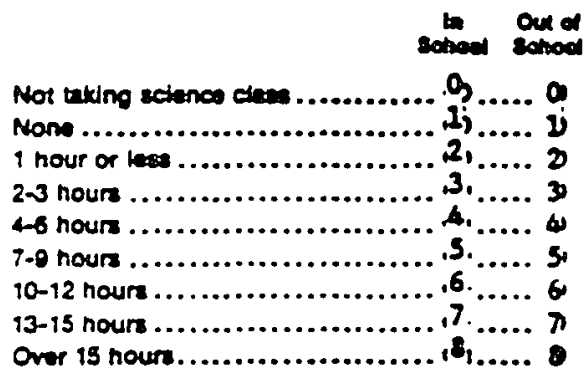

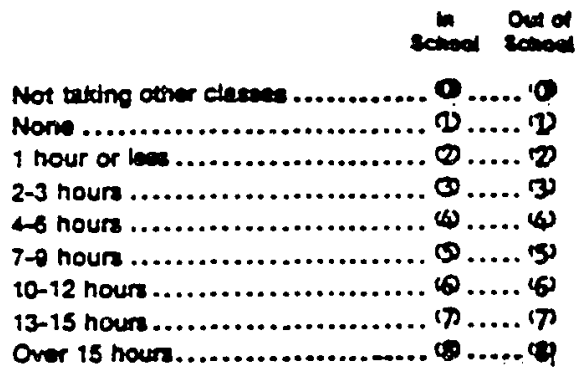


37. In a typical day. How muny clase pertoda do you spend in a study haut?

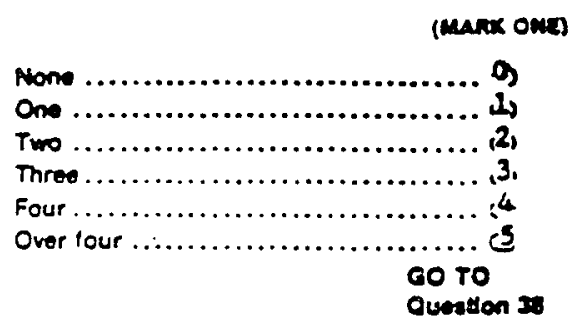

32. How importent ere good gredes to you?

(MAnK ONe)

Not imporent ......................... it

Sommwa inportant ................. o

Important ............................ 31

Very important ......................

GO TO Quention Is

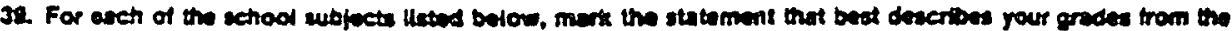
$O$ beolnning of nian grede unath now.

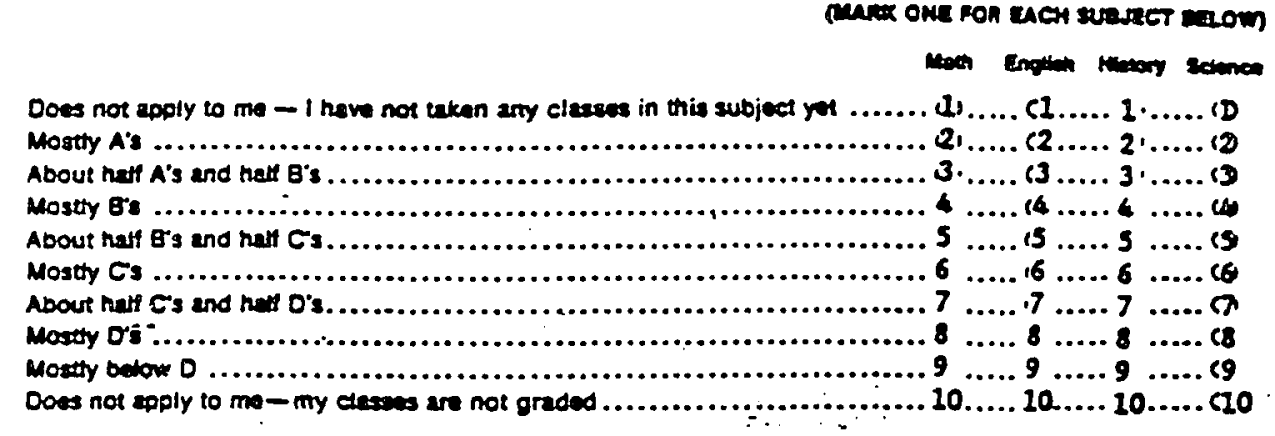

WAKE SUAE THAT YOU HAVE ONEN ONE ANSWTA FOA EACH SUEJECT ABOVE

4a. How oftun do you coms to claed WTHOUT these thinge?
4. Prnell or paper ..
b. Boola

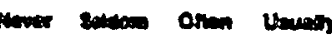
c. Your hom
(s) $\therefore 3$, 2
c. Your hommork dons
. $. . . .0 . . . .0 \ldots 0$

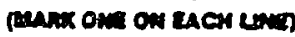

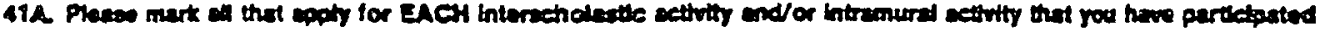
in THis sCHOOL YeNR.

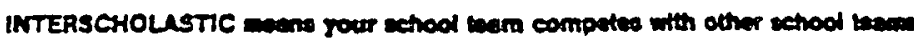
SCHOOL INTRALURAL ment the them aro whth your own school

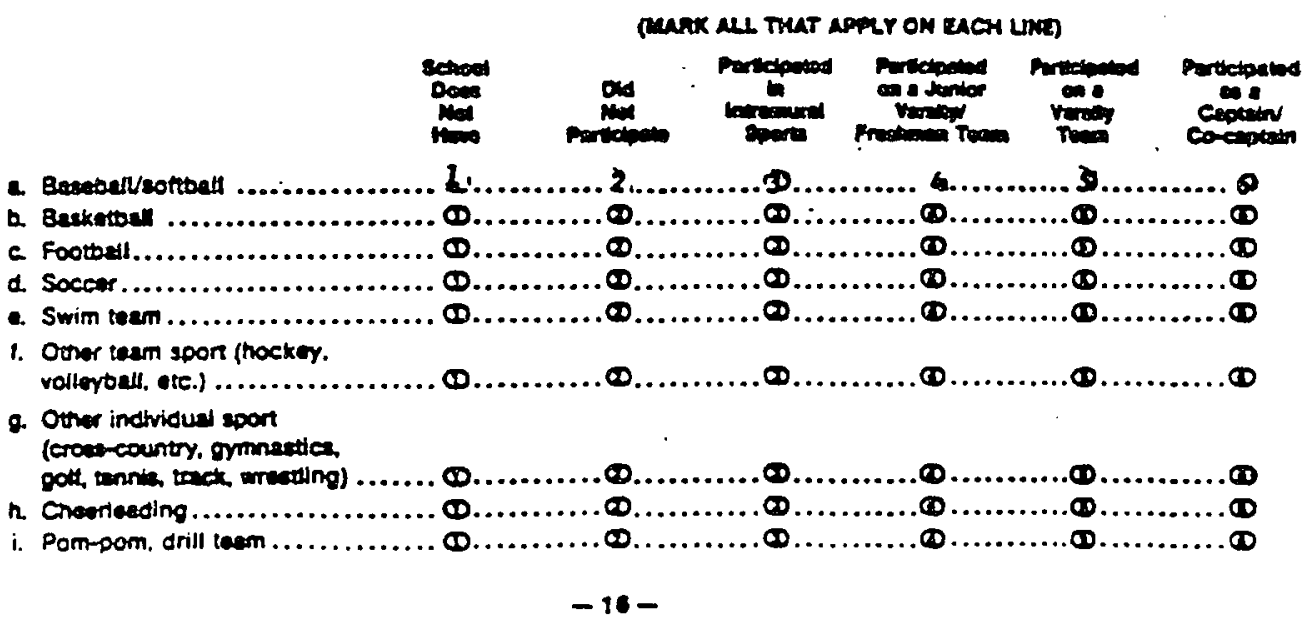




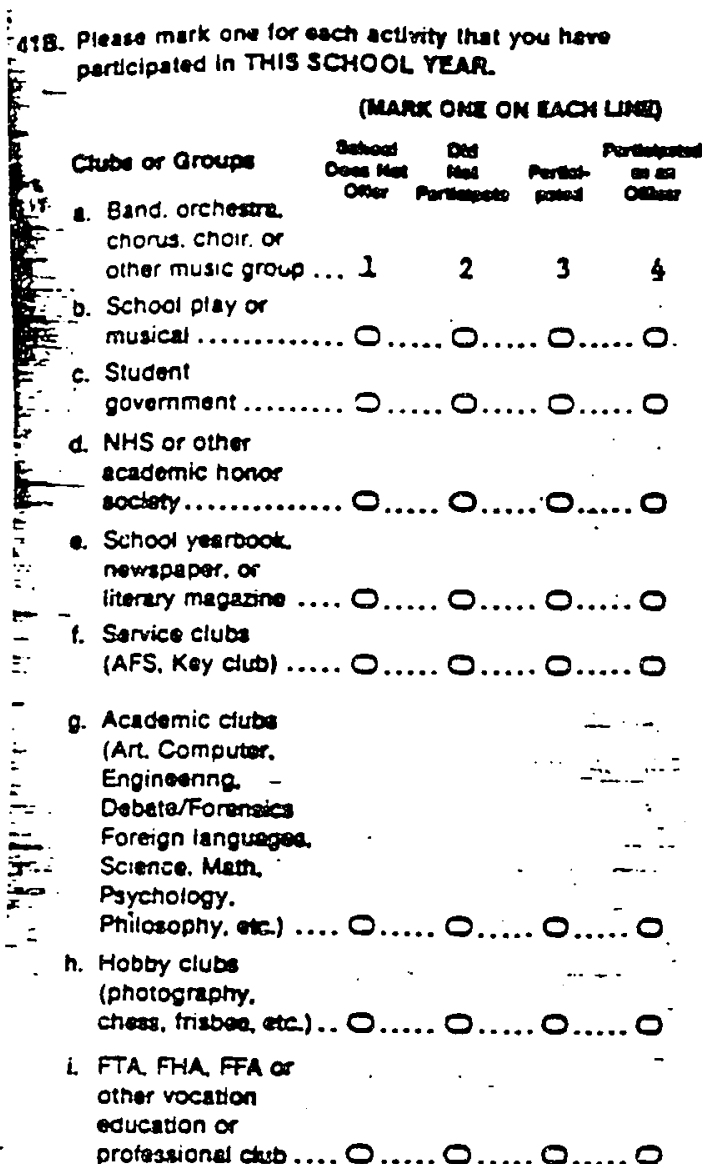

42 In a typical mat how much rotal tim do roo apond on all SCroOL-SPONSORED extrecurricular actutties?

mancons

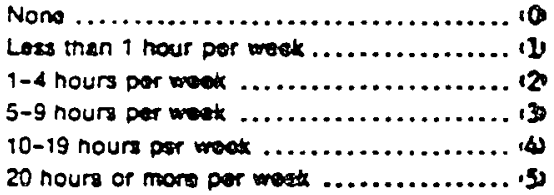

43. How much adorisend reading to you do cach wrots on your ow outude of school - nol h connection with echootwort? (Do not cownt any schoot-assignod reading)

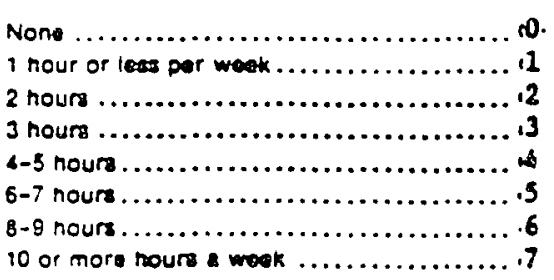

4h. How often do you spend tume on the following ecoville outside of sehoor

mave one on ench ung

2. Visiting with

triencs at a

loca nangout ...... $1 \quad 2 \quad 3 \ldots$ 4

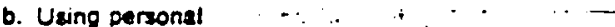
computers ........ ०.... O.... $0 . . . .0$

c. Working on noobies arts. or cratu on my own ... O..... $0 . . . .0 . . . .0$

d. Rescting tor plessure ........... $0 . . . .0 \ldots . .0 \ldots .0$

- Going to the park. gym. besch, or poot ...... $0 . . . .0 \ldots . . .0 \ldots . .0$

1. Pieying oull or other sport: with triends ....... $\odot . . . . \odot . . . . \odot \ldots . . \varnothing$

Q. Attending youth groupe or racroationst programs ... $0 . . . .0 . . .0^{-} \ldots . .0$

h. Voluntering or partorming community service .. $0 . . . .0 \ldots . . .0 \ldots . .0$

L Driving or riding. . . ....... around (Jiono

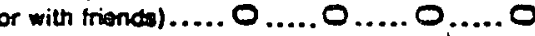

1. Talteing with frlends on the totephone ... $0 \ldots . . . \ldots .0 \ldots$.

$k$ Talking or doing things with your mothet or tather.... $0 \ldots . . . . .0 . . .0$

1. Talking or doing things with other

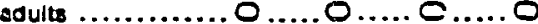

m. Taking classes: music, ar. lenguage. dance....๑ ....๑ ....... .0

n. Taxing sporta lessont

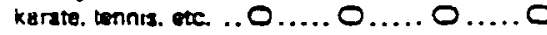

o. Artending religious acuivises

45. During the sechod yeer, how momy hour a day do you USUALLY waten NV or towotapos? ANSWER BOTH A AND B BZOW.

(MAAK ONE) (MARK ONE)

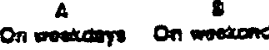

Don't wateh TV ............ 0 ......... 0

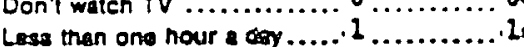

$1-2$ nowre $\ldots . . . \ldots \ldots \ldots \ldots .2 \ldots . . .2$

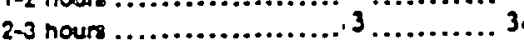

3-4 nours .........................4

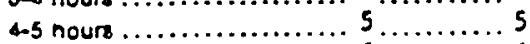

Oyor $s$ noure a dey .........6.6....6 6 


\section{PART 3 - YOUR PLANS FOR THE FUTURE}

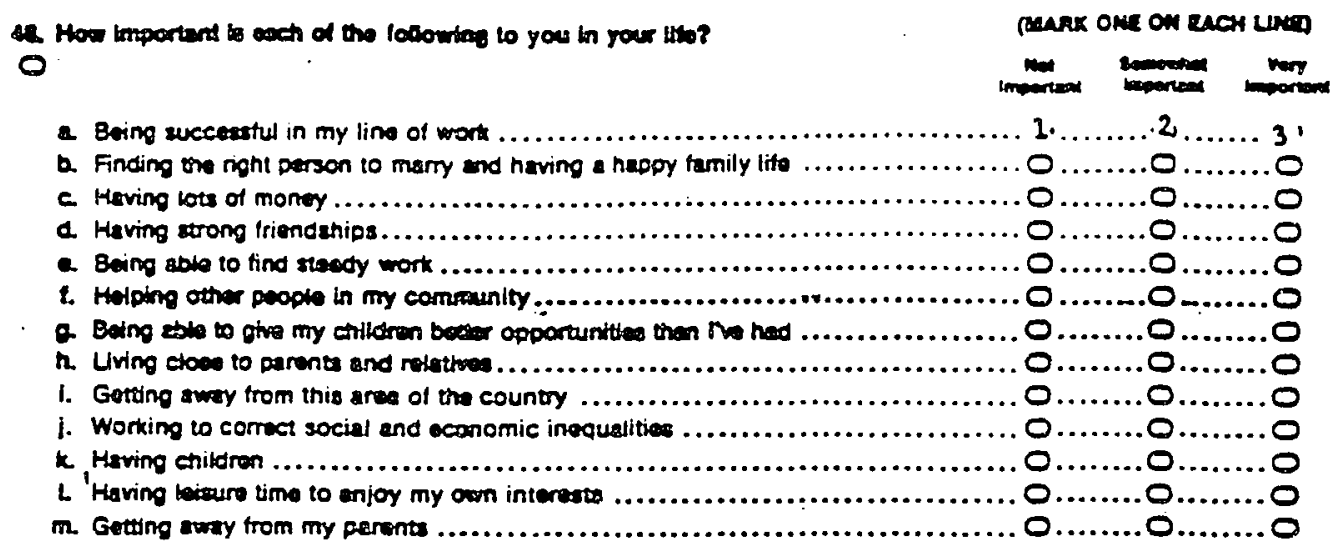

47. Whet do the following people think th the mod importint thing for you to do righ after figh sctoot?

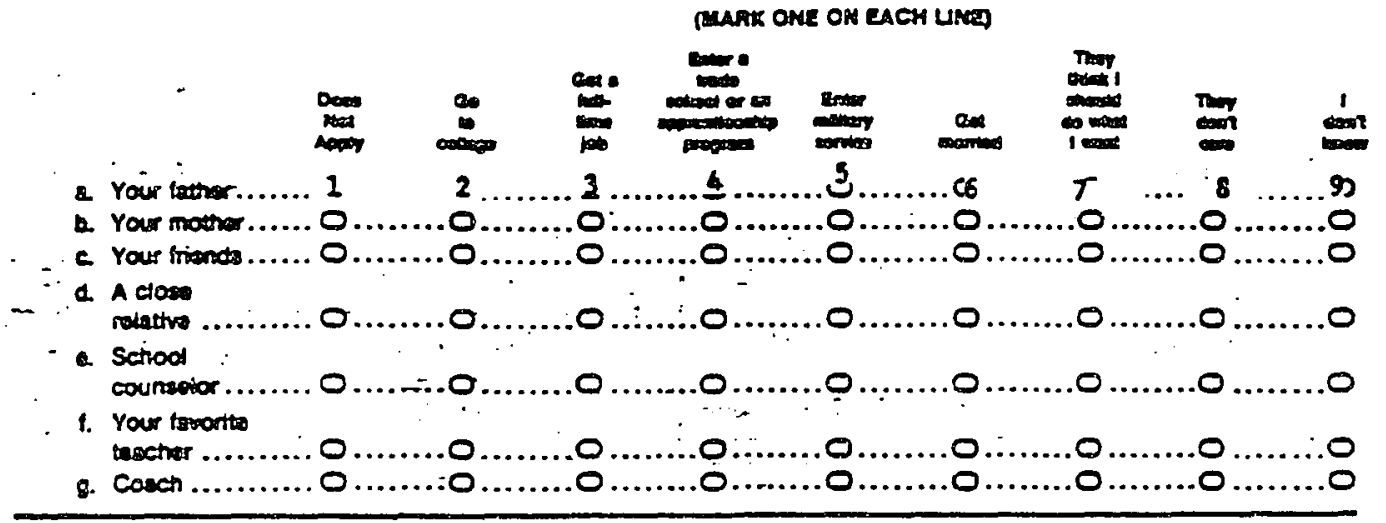

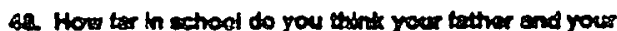
mother wou to go? (BE SUPE TO ANSWE? BOTH A AFD B BELOW FOR PERSONS WTTH WHOH YOU UVE OR WTTH WHOE YOU HAVE REGULAR CONTACT.)

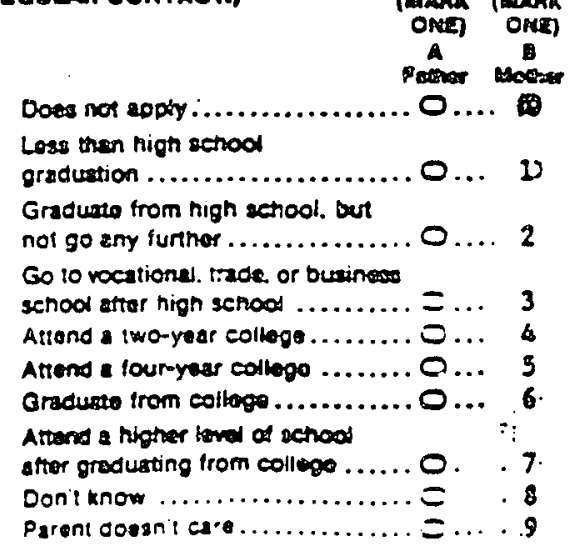

4. As thinges stand now, how ter th echoes do you O think you will got?

Loss than high school grectustion ....... (I)

Migh senool graduation onty ............

Vocational, trede. or bustnoses sctood after high sechoot:

...Lees than two years .................. 3,

Two years or more ............... 43

College program:

Less inan two years of collega ....... is

Two or more years of college

Iincluding two-year cegreal......... i6

Finiah college (tour- or five-

yas degreol .....................

Aastar's degres or aqutratara ........

Ph.Q.. M.O.. or other adisnced

protessional dogres ................ 9 


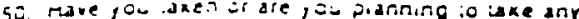
of the lollowing lests in the next two years?

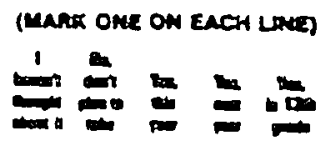

a. Pre-SAT tast $1 . .2 \cdot .3 \ldots 4 . .5$

b. College Board (SAT) Scholestic Aptitude

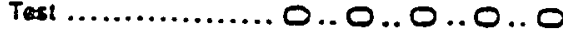

c. (ACT) Ameriegn College Testing test .... . . . .. .. $0 . .0$

d. Advanced Placament (AP) test ....... O.. .. 0..0..

e. Armod Servicas

Vocational Aptitude Batzery (ASVAB) ..... O.. ○.. O.. O..

f. Proliminary American College Testing Test (PACT)

B1. Do you plan 10 go 10 college after you grachuobe from high schoon

(maRk oprs?

No. don't plan to go to colloge .............. t) - 8xip TO Quostion 85

Yes. Noht atter high school ...............'? -

Yes, after ctaying out of sechood

tor on year............................

Yes- anter staylng out of sechood

for over a year

Don't know ...............................

52. How tmportart is each of the folowing in chooding a colloge you plan to ettend?

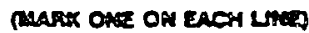

a. College expenase

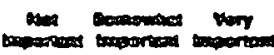
(tuition. books. room end board) a 23

b. Availability of finerceses aid such as a school laan. scholarghip. or grant.

c. Availability of specific courses or curriculum

d. Reputation of the catere in atnletx program ......... $. \ldots . . . \varnothing \ldots . .0$

a. Social the at the colloge ...... $0 . . . .0 \ldots . . .0$

1. Abte to the at home and attend the collega ......๑ $\bigcirc . . . \varnothing \ldots . \varnothing$

9. Abte to live away trom noma ....

i. A low came onvronment ..... $0 . . . . \varnothing \ldots . . \varnothing$

j. Job or employment plecement rocord of - colloge graduates.

k. Reputition of calloge in aceoemic programs .......

1. Easy acmession stanceras .... $\varnothing \ldots . . \varnothing \ldots . \varnothing$
53. which al the criegories jeio zimers cokesi io $O$ dercribing the job or occupetion thet you expect or plen to have rlght atter hoh echool and when roo ere 30 years odo? Eren te you are not bere. math your batt guese.

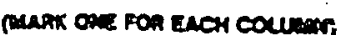

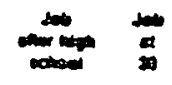

CLERICAL such as bank teller. Dookkeeper. secretary. troist. mait comor. licket agent b d....1-

CRAFTSMAN such as beker. automobile mechanc. maching panter. plumber. toteptione

instler, cerpenter ................21....2 2

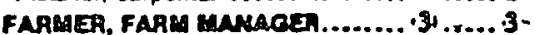
HOMEMAKER OR MOUSEWIFE OraY ........................ \& ....\&

LABORER such construction worker, car watwer. canitary morker, farm laborer $0 . \cdots \sigma^{2}$ MAMAGER, AOAIAISTRATOR such as seles manaper, office mansegr school administrutor, buyer, $\quad$ resteurant maneger, governmert officdal

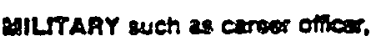
entiatod man or woman in the Amod forces .....................7.....

OPERATTV such most cuter. crombles, mectine operacer, netdo taxicab. bie or inces ditrer

PAOFESSIONAL wuch as eccompan anthet registered rurres. engineses llbrerian. writer. eccid wortor. actor. actreses. untert. politicion. but not including school tout ...9 1....9)

PROFESSIONAL uch a clorgiman.

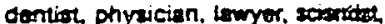
colloge tascher .......................10

PAOPRIETOR OA OWNER whe Ownor of a small businesan, contretor recturant owner .................11....11

PAOTECTIVE SERVICE such 0 defective. Dolice officer or gued. sherift, fire fignter ............. $12 \ldots .12$

SALES such as satesporson.

actertising of insurenco sgent. real erate broker ................ 13....13

SCHOOL TEACHER such \& evementary or socondary ..........14...14

SERVICE such as barber. besuticion. practical nurse. privat housenotd worker. panitor waiter .......... 25 ... 15

TECHNICAL such as dratteman medical or demal toctnicien, computar programmor ............. 16....16

nOT PLANNIAG TO WORK.......17.... 17

OTHER ................... 18... 18

DONT KNOW .............. 29... 19 


\section{PART 4 - LANGUAGE USE}

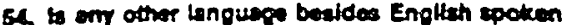
in rour home?

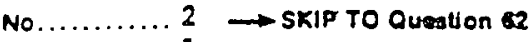

ge. What other lenguege is spoken In your home?

$\operatorname{manx} 0 \cos$

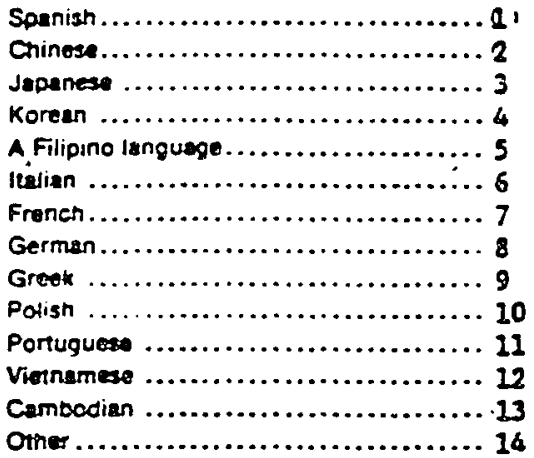

$-{ }^{-}$

55A. to the your natter banguge (the flrst lenguoge you lewed whea you were is chad?

$$
\begin{aligned}
& \text { No ........... 2 } 2 \rightarrow \text { SFap TO Question } 58 \\
& \text { Yes ........... I } \rightarrow \text { CO TO Oustion } 558 \\
& \text { - - } \quad \ldots \div \div=
\end{aligned}
$$

558. How wen to you do the following?

(MARK ONE ON EACH UNAT)

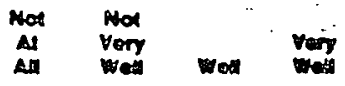

a. Understand your native language... 14 $3 \quad 3 \quad 2 \quad 1$

b. Sposk your nstive languege ... $. \ldots \ldots \circ \ldots . . . \ldots \circ$

c. Aead yout nattu languega... $0 \ldots . . . . .0 . . .00$

d. Wrtte your

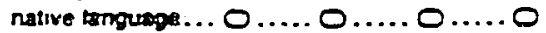

50. How often do you spark to your parents in Engitah soout your homswort or other school work?

Doos not appty - don't

(MARK ONE)

Ialk sbout homewcth

1

Never in Enction ..............

Somatima in Englien ............... 3

About $1 / 2$ the time in English .......

Always or most of the ume in Engish .... 5
57. How woll do you do the following?

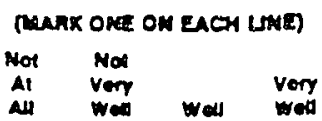

2. Undersiand spoken English ... (4 3 . 321

b. Speak English .... $0 \ldots \ldots 0 \ldots .0 \ldots . .0$

c. Read Englian..... $0 \ldots . . .0 \ldots ., \ldots .0$

d. Wrtte Englian..... $0 \ldots . .0 \ldots . . . . .0$

52. Stree the beginning of the ninth grede, hew you rocotrod spocted hetp in raoding, writing, or paraing Englleh?

\section{(MARK ONC)}

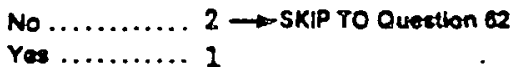

52. the spected halp in the form of...

(EAAK NL THAT APPL)

2. Individual (onorto-ono) tutoring? ........... d)

b. A small group? ......................... d

C. A large group other than you

rogular clase? ........................... (1)

c. English as acond Lenguspe? ............ (1)

e. Bilingual oducation?.................... (1)

w. How often did you work on the following in these -. clanes or actrittion?

$\therefore \quad$ -

8. Listaning to nover onom English tapes

b. Improving English

sposking skills $\ldots \odot \ldots \ldots \circ \ldots \ldots, \ldots \ldots 0$

- c. Reading English.. $0 \ldots . .0 \ldots . .0 \ldots .0$

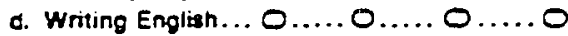

- Other activities ... $0 \ldots . .0 \ldots . .0 \ldots . .0$

61. Do you think your Englien atis hove improved in the following creas a resust of there special clasers or ostivitios?

(MARK ONE ON EACH LNE)

AN som Crost

a. Understending spokion English .......... $0 \quad 1 \ldots 2$

1. Speaking Engltan ......... $0 \ldots . .0 \ldots . .0$

c. Reading English ......... $\odot \ldots . . \odot \ldots . \bigcirc$

a Writing English........... $=\ldots . . \ldots=$ 


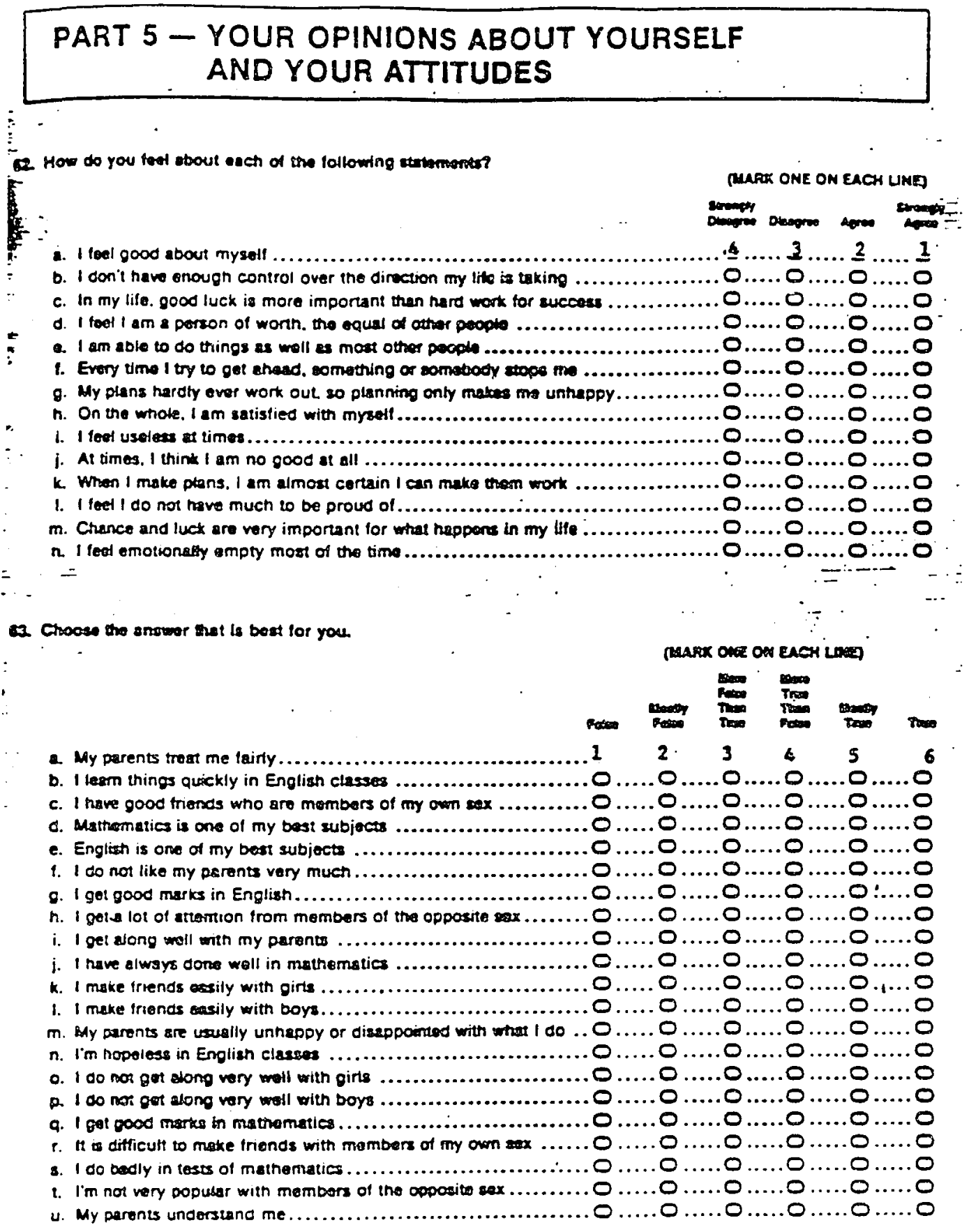


64. Think abcul how you see your future. What are the chences that...

(MAGK ONE ON EACH LUNE)

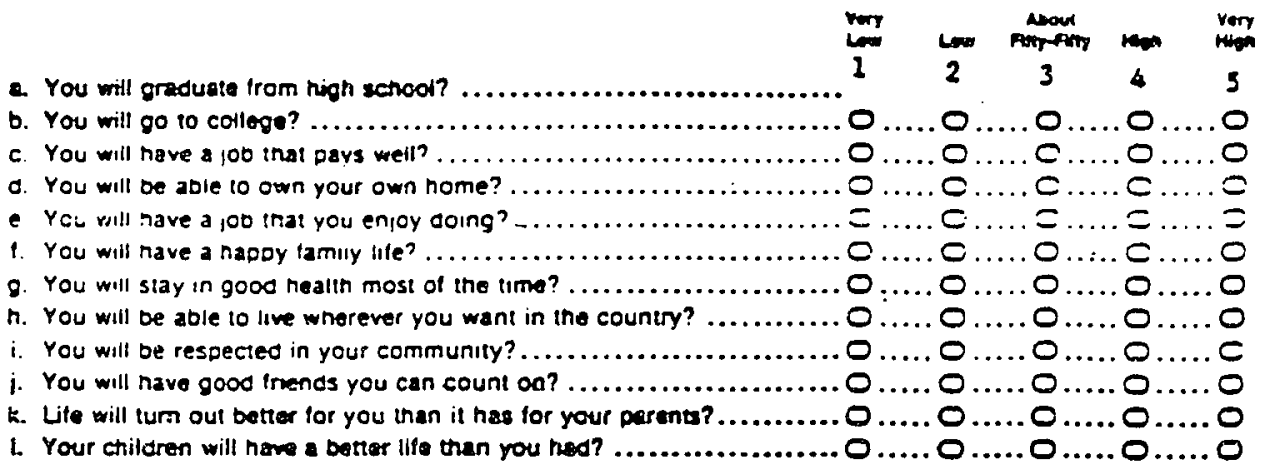

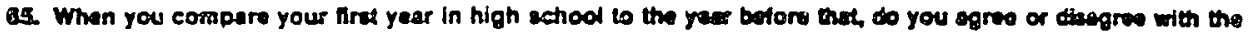
following statemente?

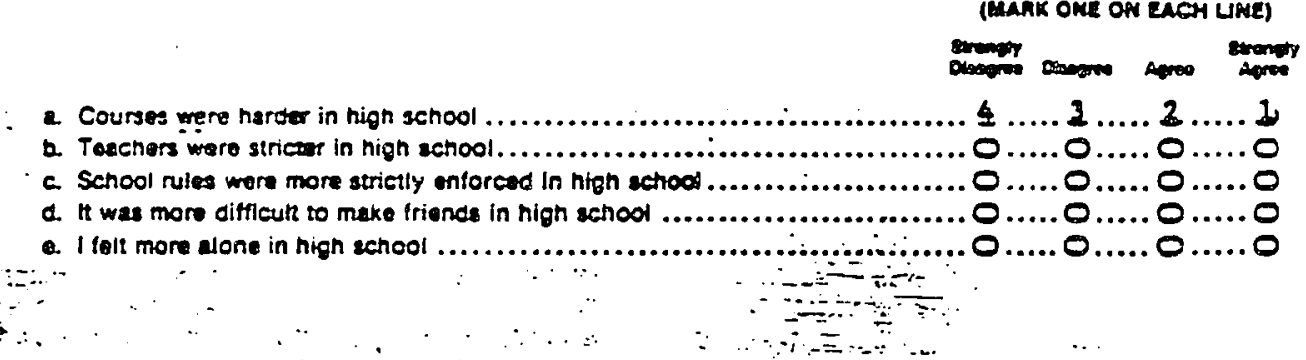

64. Do you agros with the following statements about why you go to seched?

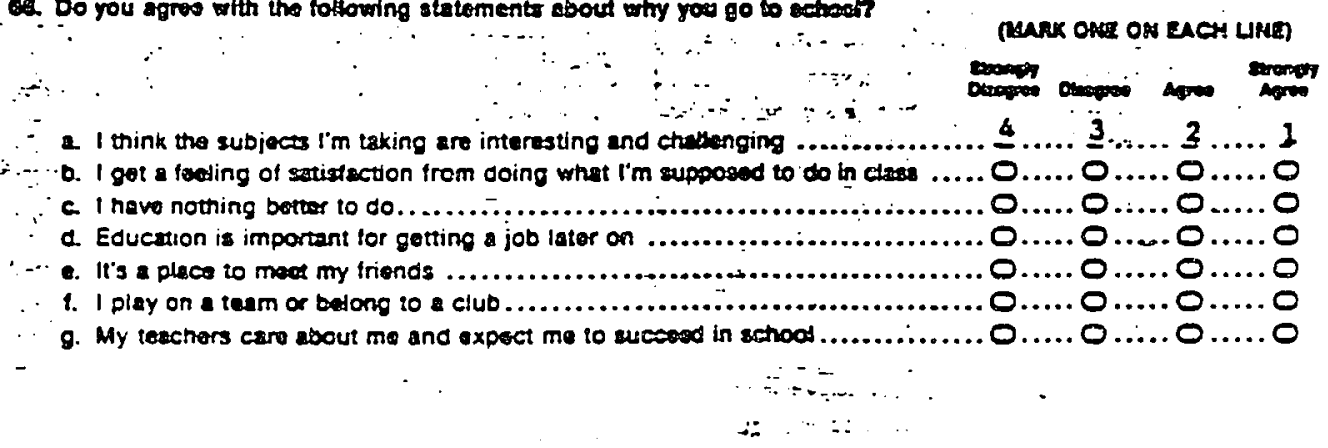

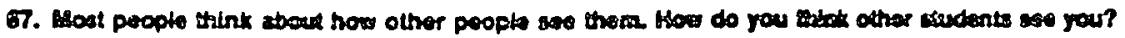

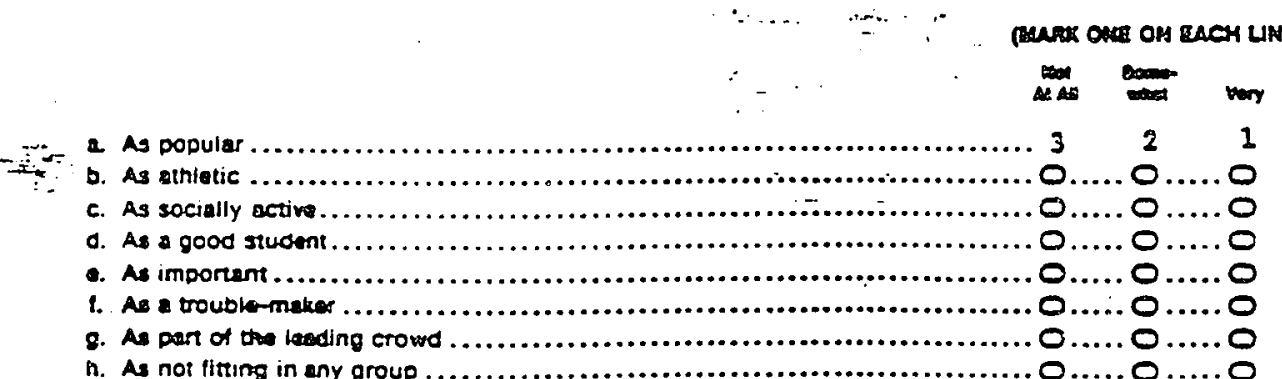


THE FOLLOWING QUESTIONS ARE IMPORTANT TO UNDERSTAND HOW YOUA FRIENDSHIPS RELATE TO YOUR LIFE.

F.

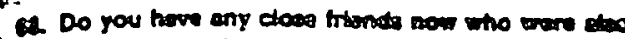

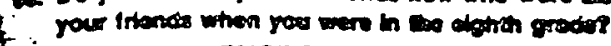

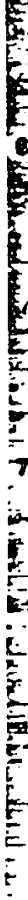
No $\ldots \ldots \ldots \ldots 2$

Yes $\ldots \ldots \ldots \ldots 1$

Alogerthor, how many of your choe fribus how dropped out of echool without gredunting?

(Do not hiclude those who have transfirred to another sechool.)

None of them

(warex ONas

Som of them ...........................1

Most of them .............................

All of them $\ldots \ldots \ldots \ldots \ldots \ldots \ldots \ldots \ldots \ldots$,

2. Among the friends you heng out with how importin to to to...

a Aund claseses ropularty? 40 nerer

b. Sindy 12

c. Pioy sports?

O.... $0 . .$.

. c. Get good grades? ........... $0 . . . .0 . . . .0$

e. Be popular/woltiked by students? ............... $0 . . . .0 \ldots . .0$

1. Finiwh tigh schoot?......... $0 . . . .0 . . . .0$

9. How atendy boytriand/girtiriend?

h. Ba willing to perty. get wilo?:

i. Continue thair esucetion past high schoor?

j. Participats in ratigious activitios? .

k. Do community work or voluntoer?

1. Haw a steady job?

n...... ......

7. Of at the poople you know personety, yourd or soluth think about the person pou admitre the moet. How would you decertse thit person?

\section{This parsons}

(Bear als THaT aOptr)

a Is popular.

b. Inomet $\ldots \ldots \ldots \ldots \ldots \ldots \ldots \ldots \ldots \ldots \ldots \ldots$ I

c. Dresses woil..$\ldots \ldots \ldots \ldots \ldots \ldots \ldots \ldots \ldots \ldots \ldots$. 1

d. Is intelligent............................ I

- Understends ma......................... I

f. Drrves a nice car ........................ 1.

o. Hes an importent job ....................... I

h. Makes a lot of monay ....................... 1

i. to pood at spors ......................2....... I

i. Thinks about important things

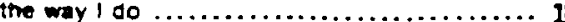

k. I do not semire anyono - Exip to Qwation 73 . 11
72 What is your relationship to that person and wat to hat of hare oge?

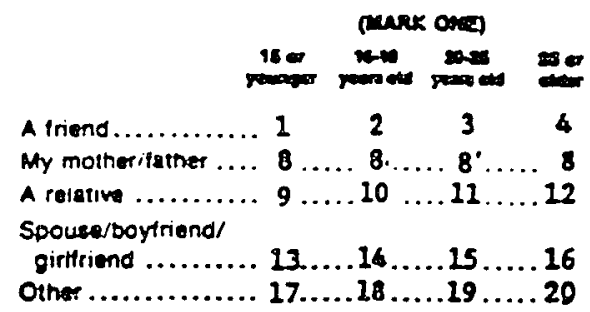

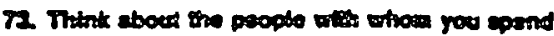

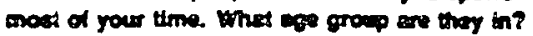

(WARX ALL THAT APPLn
a. 13 or younger. 1
b. 14-15 vars oid........................... I
c. 16-17 years ad.......................... 1
c. 18-18 years odd........................... 1
e. 20-21 yours oto........................... I
f. $22-25$ years oid............................ 1
o. 20 and older ......................... I

QUESTIONS 74-7E UKE ALL TrES IA THUS QUESTOMNALE ARE VOUNTART. WE HOPE YOU WRL

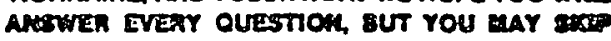
AHY QUSSTION YOU DO mot WEA TO ANGWE. THE FOLLOWNG QUESTIOAS ARE IMPORTANT TO UNDERSTANO HOW YOUR RELATONSHLS ARATR TO YOUR OTHEA IN-SCHOOL AND OUT OF SCHOOL ERERIENCES

74. Do you thint if to tmportend to be mentiod botore horing soxulal Iniencocurou?

(anax ON

Not important $\ldots \ldots \ldots \ldots \ldots \ldots \ldots \ldots \ldots \ldots$.

Very important ........................ 3

75. Would you conaider hasting a child if you borent mantod?

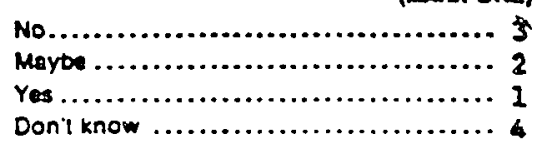

72. Do you have eny childeren of your own?

No. 1 don't ............................ 3

No. but 1 am expecting one............? 2

Yos. $100 \ldots \ldots \ldots \ldots \ldots \ldots \ldots \ldots \ldots \ldots 1$ 
OUESTIONS $T$ THROUGH 80 ARE VOLUNTARY. WE HOPE YOU WILL ANSWER EVERY QUESTION. BUT YOU MAY SKIP ANY QUESTION YOU DO NOT WISH TO ARSWER.

77. How many cigerattes do you usually smake in a doy?

and opes

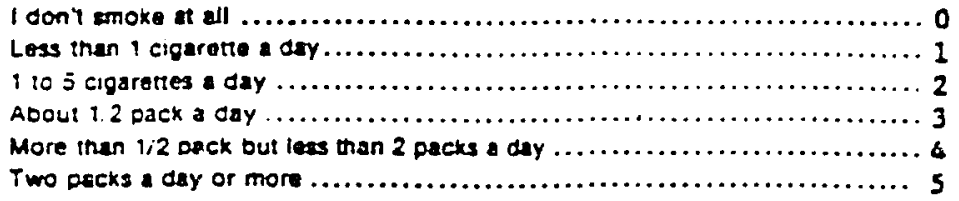

MEXT WE WANT TO ASK YOU ABOUT ORINKING ALCOHOUC BEVERAGES INCLUDING BeER, WIME, WINE COOLERS, AND LIOUOR.

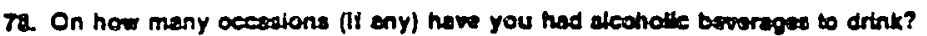

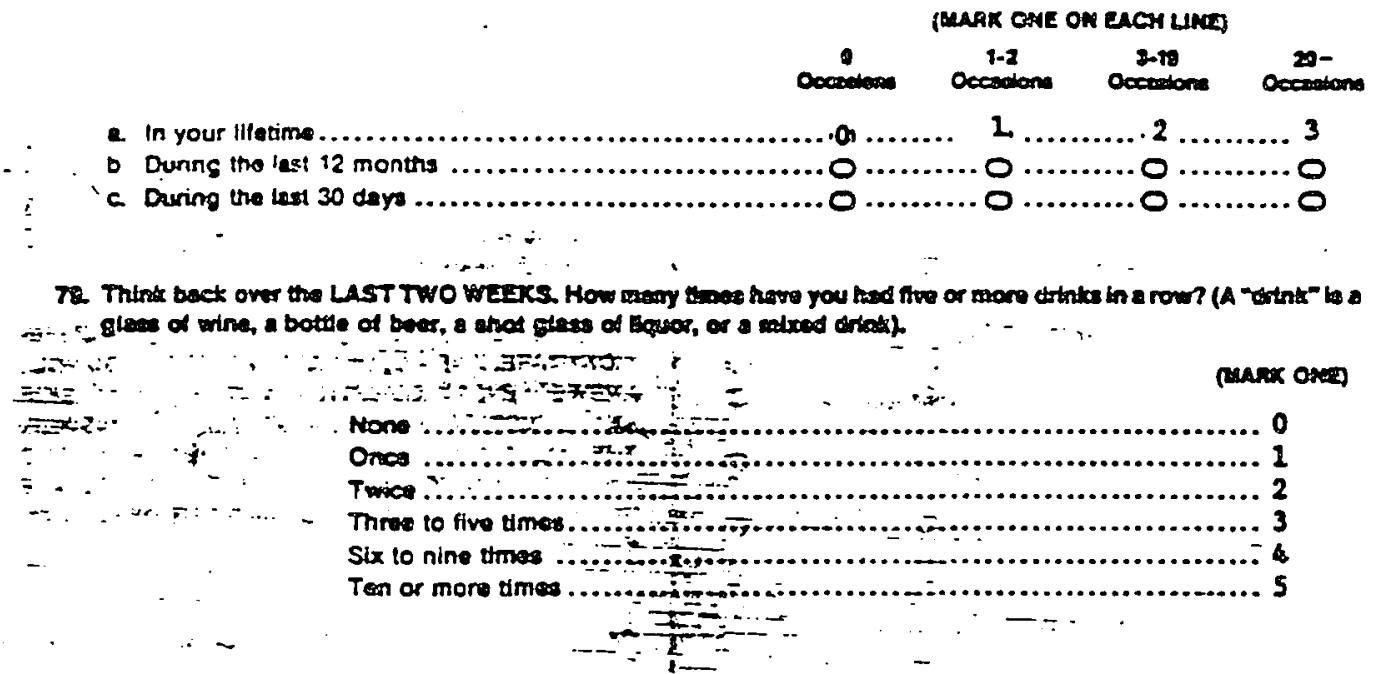

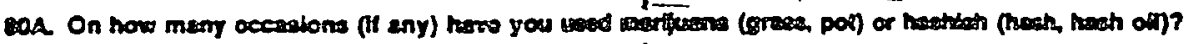
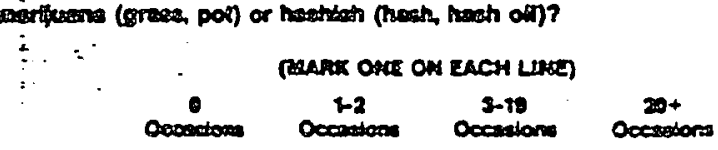
a. In your thetime.
0
$.1 \ldots \ldots .2$
$2 \ldots \ldots \ldots 3$
b. During the last 12 monthe

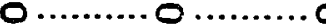
c. During the last 30 day
6
O

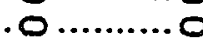

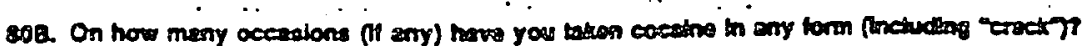

$$
\begin{aligned}
& -+-i \\
& \therefore+i
\end{aligned}
$$

(MAFx ONe ON BACN UPE)

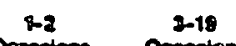

Ocoevitan

$20-$

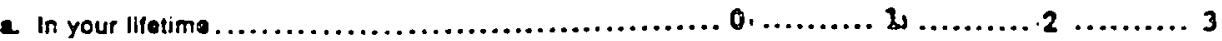

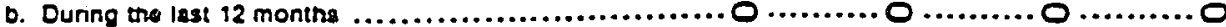

c. Durtng the last 30 day .............................. 


\section{PART 6 - BACKGROUND INFORMATION}

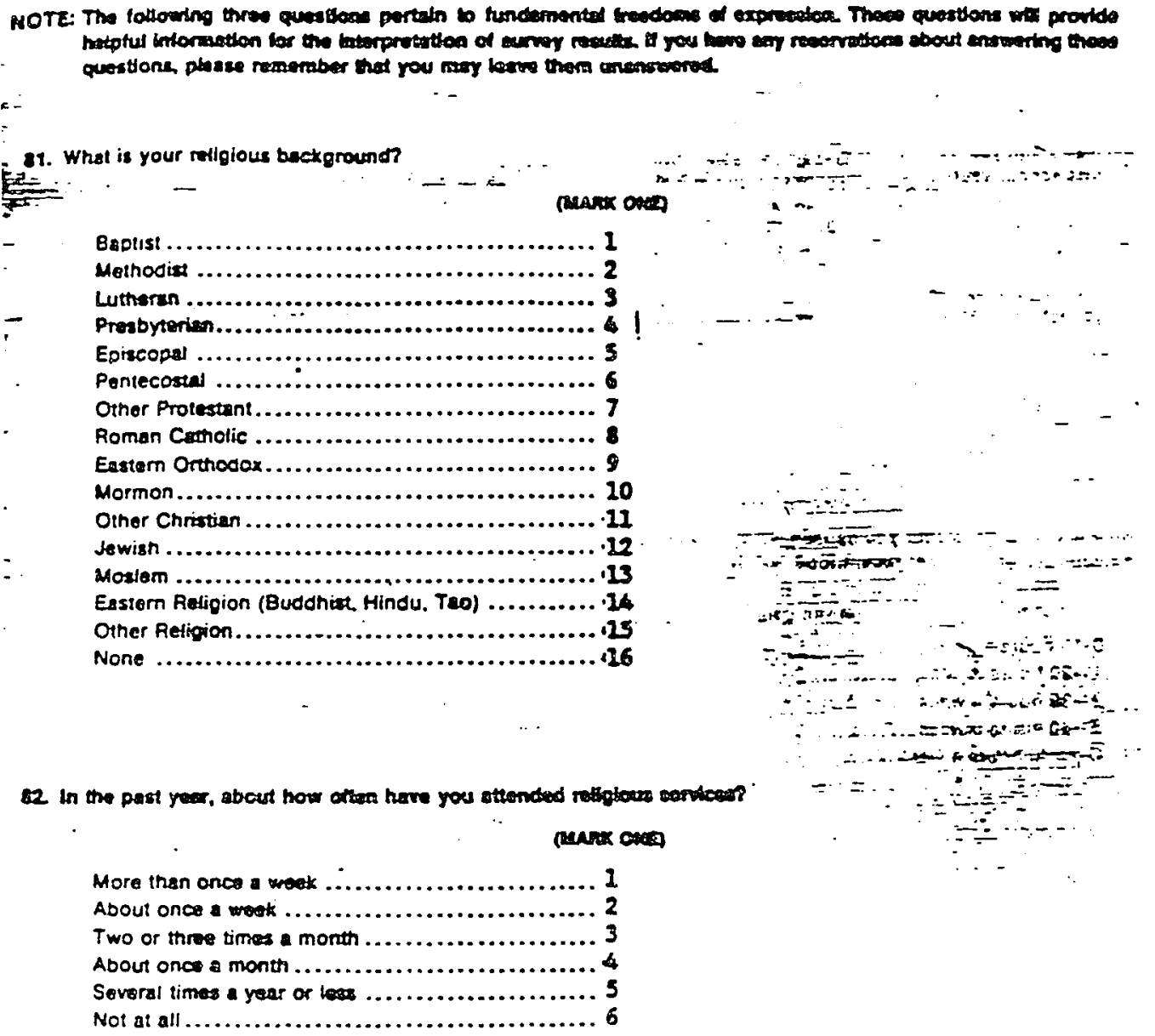

23. Do you think of yourneff an a malous person?

(enapor 0ow

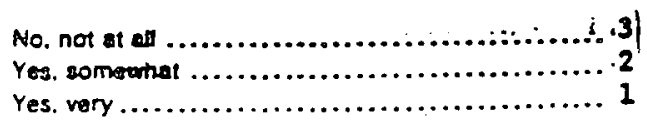




\section{PART 7 - MONEY AND WORK}

24. Are you curnenty empleyed or bere you wer been omployed?

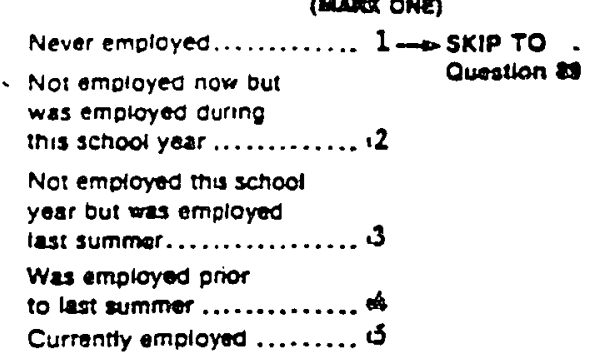

85. How mamy hours do/dd you usunty work a woet on your current or most rween fob?

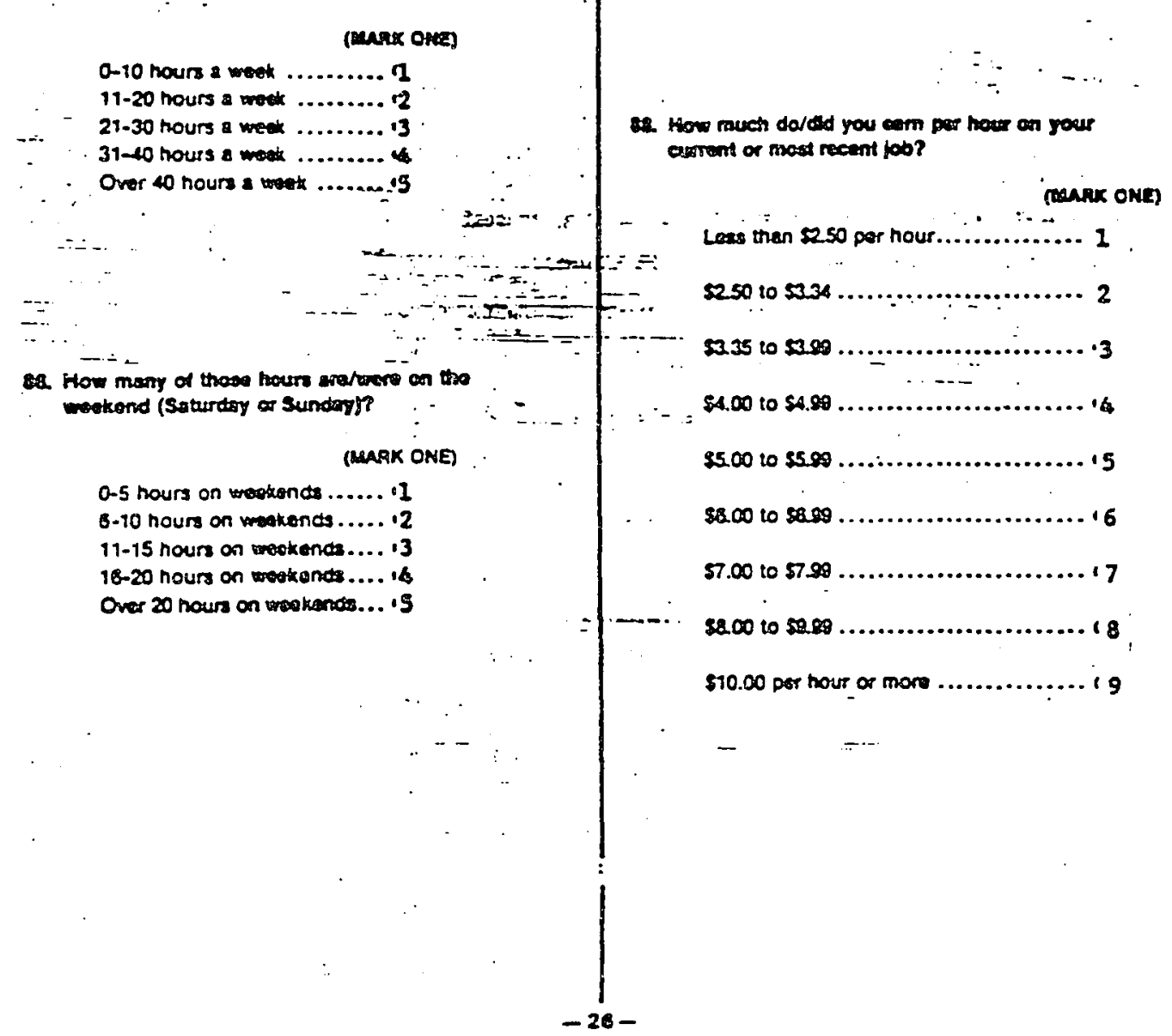

77. What kind of want dodad you do ka pay on your

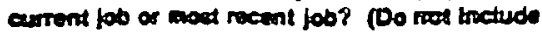
wort sround your own house. I more then ons kdnd of work. choose the on thet peid you the most per nour.)

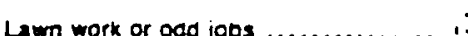

Fast 1000 morker ......................

Water or watress ..................., 3

Nowspape route ................... is

Babyutter or child care ................ is

Comp coundor or the guand ........... 6

Farm worker ...................... 7

Factory worker ......................

Manued laborer ....................... 9

Store Clark, salesperson ............... 10

House cloaning ....................... II

Construction work .................. 12

Otfice or clerical worker ........ 13

Hospital or hecith worker .............. 14

Hospital or herith worker .............. 14

25

How much da/ald you cam por hour an your cromt or most recent lob? 


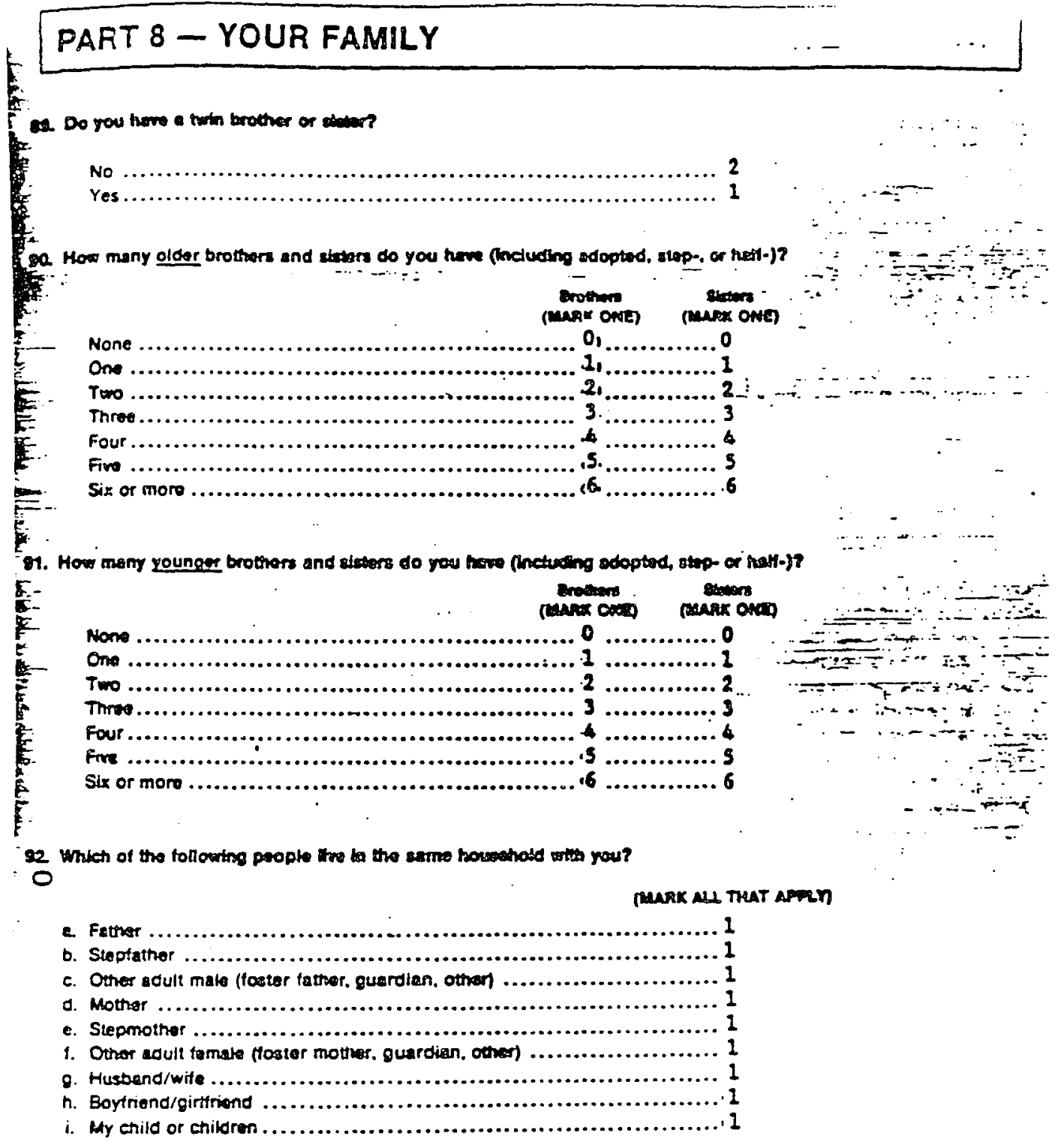

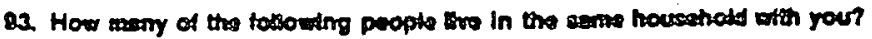
0

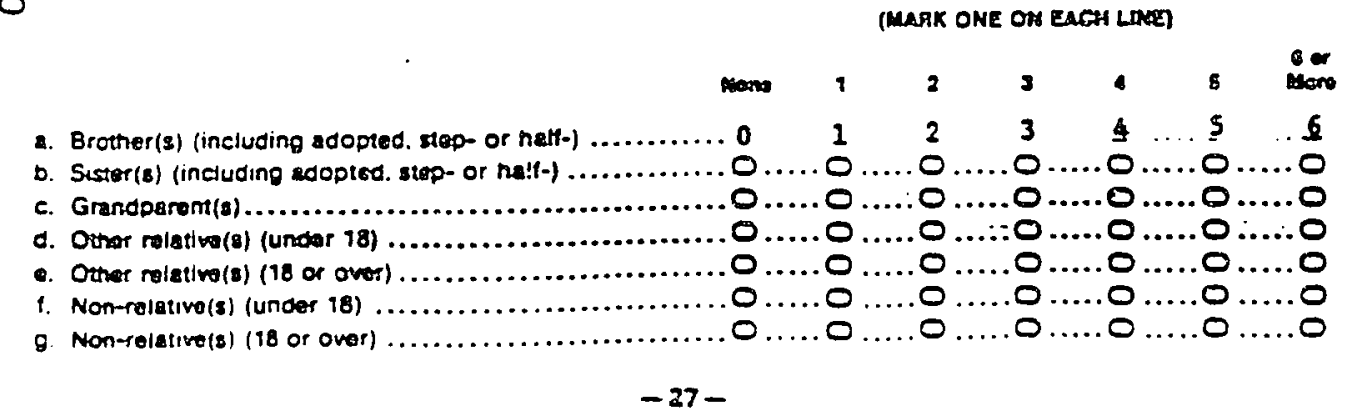


84. How many of your brothers end staters fincluding odopted. step-. or haft-) kett high school betora gradusting?

(MARK ONE)

I don't hum any brothers or stecese

None are in nigh echool yot.

None ket sehool.

One lett school.

Two or more left school 1

2 3

25. Do you betralt of tate care of your own chlld. younger brothers or sictors of other relative?

(MAax ONe)

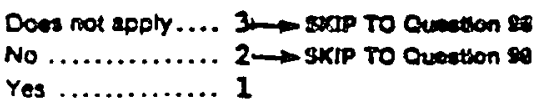

Yes $\ldots . . \ldots \ldots \ldots 1$

26. On the unege, how many hours per dy are you respondate for vietr care?

(manx one)

Less than s hour ........................ 1

More than T. lese then 3 hours ............. 2

More than 3, less than 5 hours ............. 3

More then 5. logs then 7 hours ............ \&

More then 7, leas than 10 nours ............ 5

Mato than 10 hours a day ...............6 6

87. In a typted month, how many achool doye do you

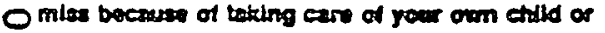
your browers and siaters?

(tenaK ONA)

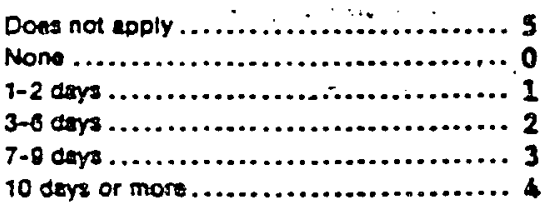

28. is there anyon in your tamily with whow you ten't get along?

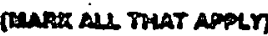

a. I got dong with an the poopto th my tamtin... I

b. Father ................................. I

c. Othar mala guardian (stoptather of foster fatner) .......................... .1

a. Mother ............................. 1

- Other female guardian (rtepmother or toztar mother) ....................... 1

1. Erother(s) (Including stap- or hash-) ....... I

g. Steter(s) (Including top-or halk) .......... II

n. Grandperental. ......................... I

I. Other rolattre(s) (children or colults)....... I
09. Lots of thinge happen in familien thet may afiect $C$ young people. In the last 2 reare have any of the following happened to your ianily?

(WNRK ALI THaT AFMY

2. My famity moved to a new home .......... 1

b. Ore of my parents got mamed........... I

c. Afy parents got divorced or separated ...... I

o. My mother last her job ................. I

. Wy tather lost nis job ................... I

f. My mother stanted to work .............. I

g. My tather started to work ................. 1

h. I beceme seriousty ill or dienbled........... I

L. Wy tather died $\ldots \ldots \ldots \ldots \ldots \ldots \ldots \ldots \ldots \ldots \ldots$ I

1. My mother diod ......................... I

t. A dowe relativo dled ......................... I

One of m inmented preginant ............................ 1

One of my brothers or these

dropped out of shoct ..................... 1

. n. My tamily weot on wotfere ................ I

a. My tamily went of whars ............... I

1. Ahy tamity atayed on unethere tho 1

Q. A tamity member bocame sorlosedy Hi or diasblec ........................ 1

r. Hy family was homales for : poriod of tima ........................... I

¿ \& None sopty .............................. I 


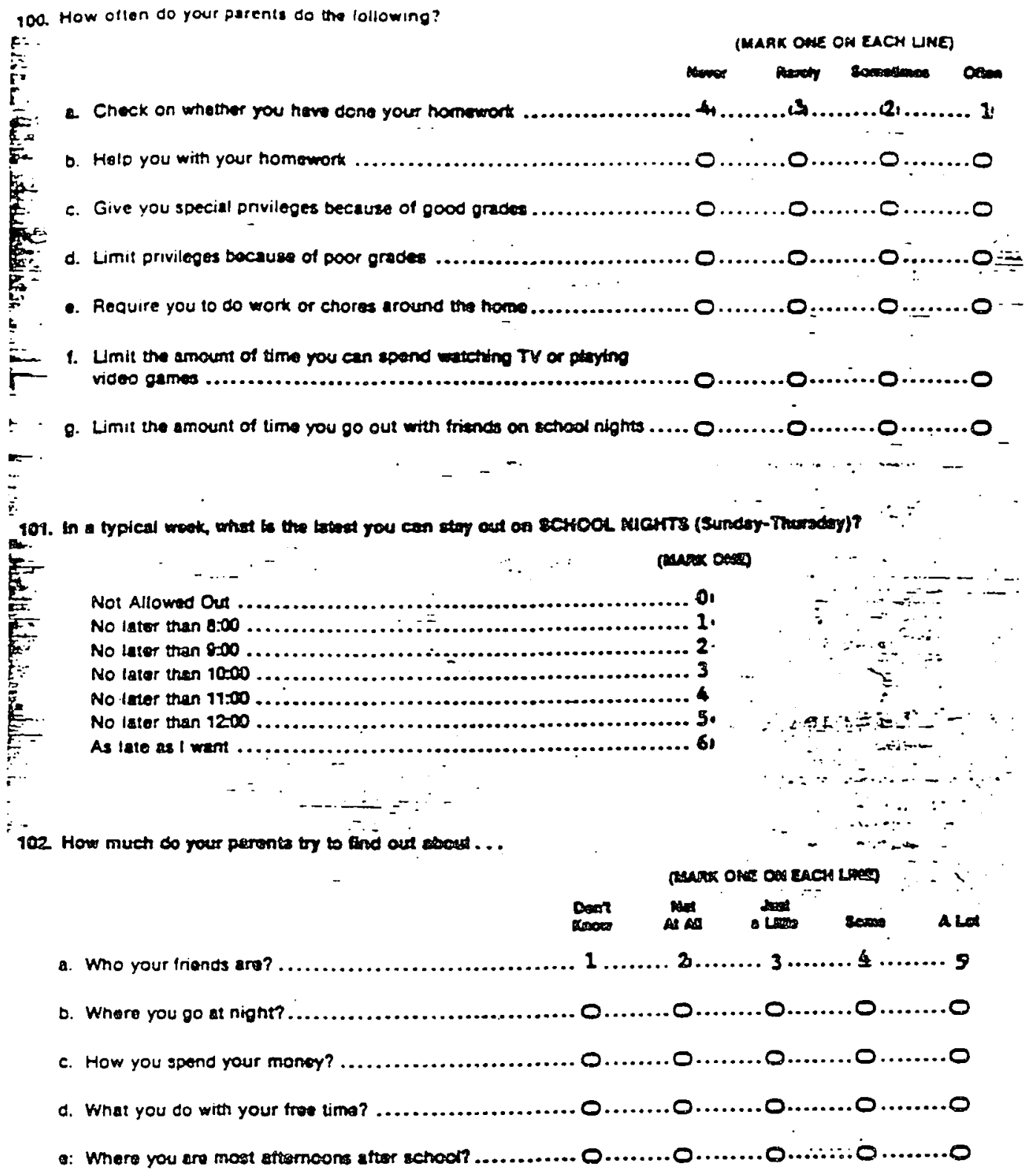

103. Do your perents know the porents of your chosed ectood tronda?

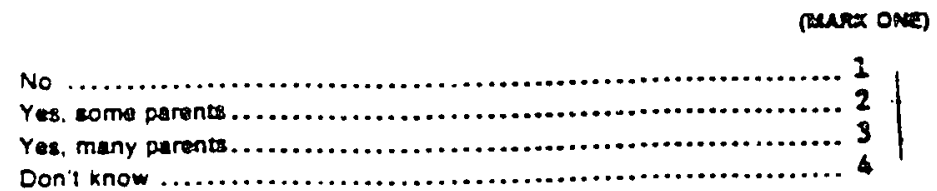


104. In your tamty. who mates most of the decisiom on sach of the following topica?

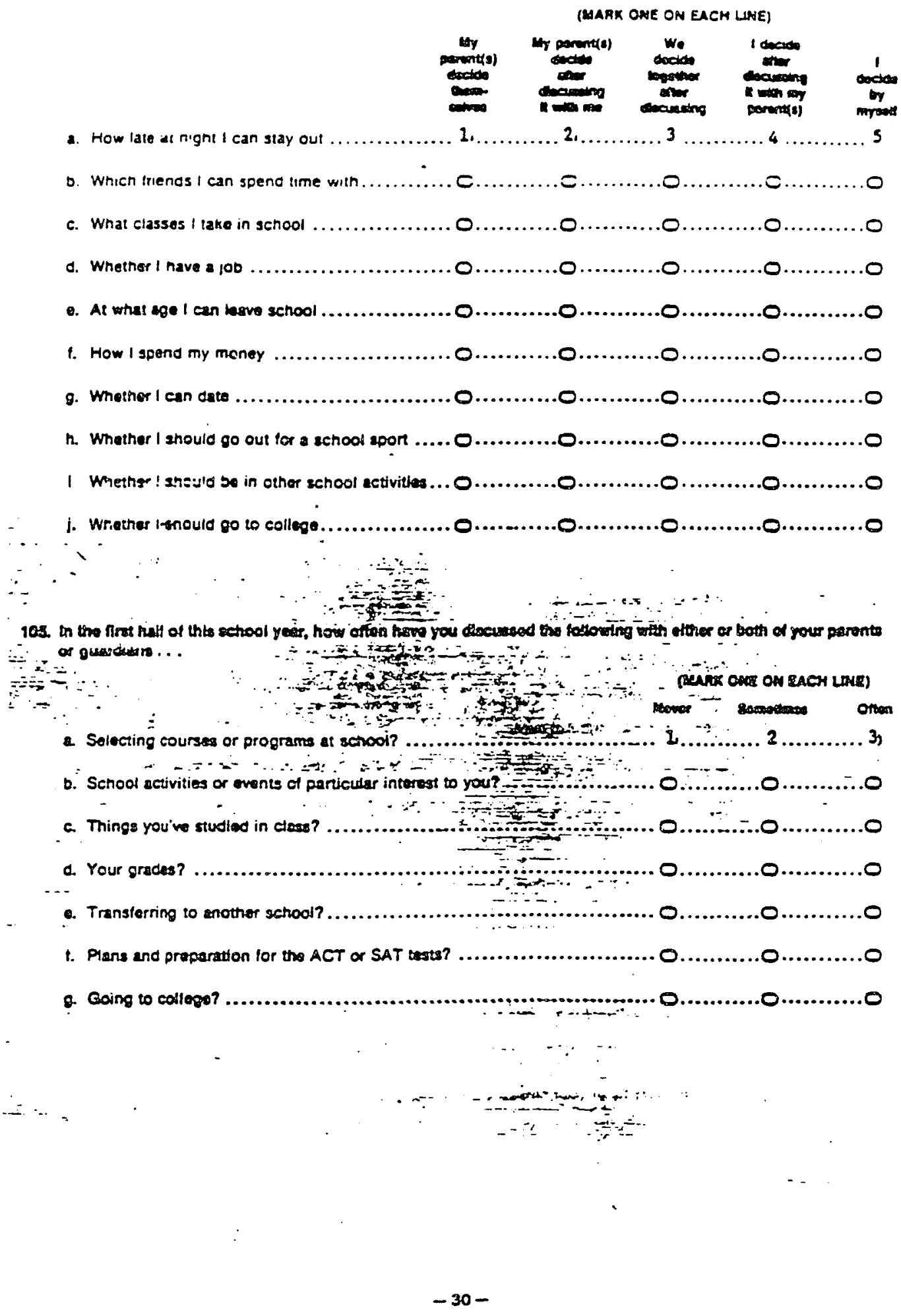




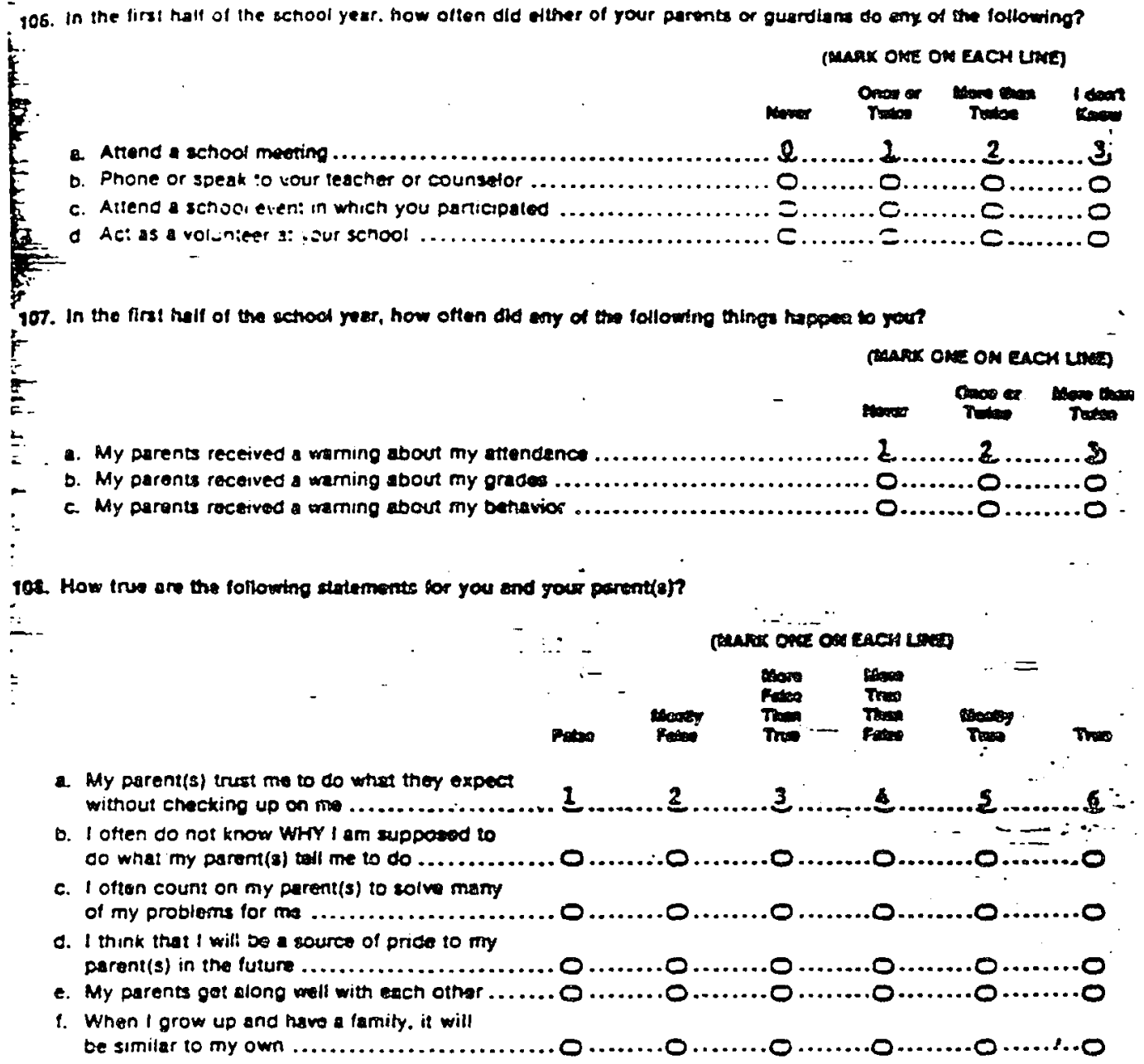

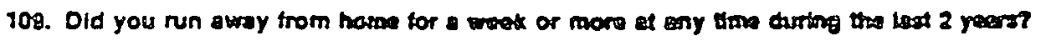

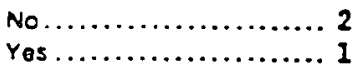

\begin{tabular}{|c|c|c|c|c|c|c|c|}
\hline \multicolumn{8}{|c|}{ Plomen fil in today'a date: } \\
\hline \multicolumn{2}{|c|}{ MONTH } & \multicolumn{5}{|c|}{ DAY } & TEAA \\
\hline$\varnothing \operatorname{san}$ & Q duly & (D) & $\Phi$ & $\infty$ & (1) & (3) & \\
\hline$O$ F.b & O Aug & $\infty$ & $\infty$ & (4) & $\infty$ & 6 & 01900 \\
\hline$O$ mar & $O$ Seo & $\infty$ & D & (1) & $\infty$ & $\infty$ & 010000 \\
\hline OApr & ○ oct & (3) & 6 & 0 & $\infty$ & 9 & O 1891 \\
\hline Omy & C Nov & $\infty$ & $\infty$ & $\infty$ & $\infty$ & $\infty$ & \\
\hline$\varnothing$ June & Q Dec & 0 & a & (1) & $\theta$ & $\infty$ & \\
\hline
\end{tabular}


APPENDIX G

NELS CATEGORIES 
Figure 1.3: NELS:88 base year key questionnaire items related to educational policy in education research

1 Surial capital/Parent involvement/

Commenumity moolvement

\section{ISSUES}

Active parental involvement, school policies

and enviroment related to parental

involvement. parental choice in school, parental

networks and interactions

\section{STUDENT}

34 Education level of parents

37 Patent participation at school

SCHOOL

3) iest results provided to parents

45 nvallable extracurncular activities

4 School climate and policy enforcement
Equity/Access/Choice

\section{SSUES}

Academic programs, school climate, admissions practices, relationship between elementary

school experiences and secondary education

access, SES and ethnicity, teaching quality and
practices. A.P., honors, and remedial classes,

student choices

\section{STUDENT}

20 Language use

31 A.D Race, ethnicity

57.59 School climate

66 Advanced courses

68 Gifted/talented programs.

SCHOOL

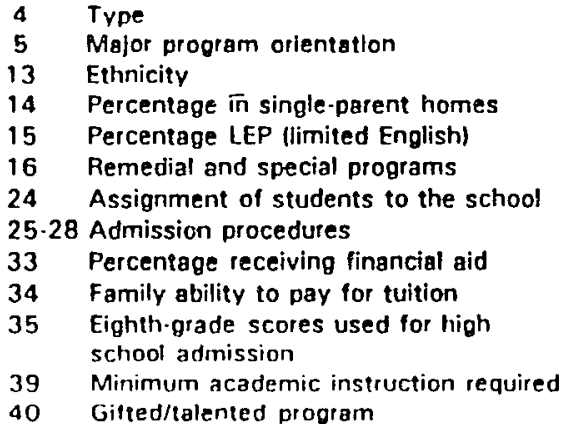

III. School effectiveness

\section{ISSUES}

Influence on outcomes of size of school: studen body ethnicity and SES level; school type and affiliation; school climate, and staff and curricular attributes

\section{STUDENT}

Cognitive test scores

81 Self-reported grades

\section{SCHOOL}

$\begin{array}{cl}2 & \text { School enroliment } \\ 6 & \text { Length of school year } \\ 10 & \text { Nominated tenth grade } \\ 11 & \text { Average daily attendance } \\ 12 & \text { Drop-out, migration rate } \\ 17 & \text { Number of full-time teachers } \\ 18 & \text { Schood structure for instruction } \\ 19 & \text { Teacher base salary } \\ 21 & \text { Teacher degree level } \\ 38 & \text { Retention reasons } \\ 45 & \text { Billingual classes } \\ 47 & \text { School climate } \\ 48 & \text { School policies } \\ 49 & \text { Discipline and other problems }\end{array}$


Figure 1-3 (cont.): NELS:88 base year key questionnaire items related to educational policy in education research

1 Social capital/Parent involvement/ Community involvement

\section{PARENT}

30 Parent education level

15 Parent request to retain child in school $54.56 \mathrm{Par}$. involvement in course selections School contact with parent about child Parent contact with school about child Parent participation in school organizations

61 Outsıde community activities with child

62 Parenl knowledge of child's friends and their parents

63 Non school activities of child

66 Parein time talk.ng with child about school

67 Talk with child about high school plans Talk with child about PSE plans

Parent time helping child with homework Parent involvement with financial aid and scholarships

TEACHER

III 2 f Probleins with school policies as reiated 10 student. community. and parent. drugs weapons, assault, robbery. vandalism. etc

III. 30 teachet time spent communicating with parents

III 31 How many students' parents does teacher talk to

\section{Equity/Access/Choice}

\section{PARENT}

10 Race/ethnicity

34.80 SES level

38 Child's attendance at pre-school

48 Child's participation in special programs

52 Child in piftedtalented prograt

70 Computer in home

82 Money for educational expenses

84 Money earmarked for student's PSE

22 Language spoken at home
TEACHER

1.11 Teacher perception of student as a language minority student

1.12 Teacher perception of student as LEP

II.16 Teaching practices in the classioom

II-17. Teaching methods in the classroom for

29 specific subjects

III.4 Years of teaching experience

III-6 Type of teaching certificate

III-19 Amount of in-service education

III.21 Instruct in gifted/talented program

III. 27 Holding a second job

1II. 30 Time spent outside school hours on activities such as planning classes. correcting papers, courdinating curriculum, etc.

III-32 Percentage of students using computer for instructional material
III. School effectiveness

\section{PARENT}

34,80 SES level

57 School contact with parent

74 Parent opinion of school's ellectiveness

75 Parent satisfaction with school curriculum

76 Parent opinion of child's schooling future 
Figure 1.4: NELS:88 first follow-up key questionnaire items related to educational policy in education research

Equity/Access/Choice

ISSUES

Arademic programs, school climate. adimissinis practices. SES and Pthwroty. equal teaching quality and martices, A P and honors reuress ipmental classes. student chorces

\section{STUDENT}

in Attend start/pass each term

20) HS program

$18 A$

19 Certainty will

20 HS program

46 Important things in life

49 Educational expectalions

53 Occupational expectations

92.93 Who else lives in house

97 Absences because babysit

99 Major family events

SCHOOL

11 HS program enrollment

2425 Days to be truant, D-out

\% Students LM or LEP

* Teachers

Fimucity of teachers

45 is Teachers assigned ESL:

cenified

Admission practices

SCHOOL

1.4

Schoot size, type

HS program enrollment

$\%$ Receive special services

$$
\text { * Teachers }
$$

Ethnicity of teachers

45-46 T tachers assigned ESL: certified

Admission practices

Use homogenous grouping

Who alfects stud. placernen

Coursework requirements

Math/sci. courses offered

* AP courses offered

Have D-out prevent. program

Why studs. in $D$-out program

Math/sci courses offered

AP courses offered

Have D out prevent. program 76
III. Tracking dynamics

and correlates

\section{ISSUES}

Coursetaking, grouping decision making, cognitive growth.

differential assigne gre.

out, achieversent, atitudes, socia

out, achievement, attitudes, social
relations, coliege and employment relations, college

STUDENT

53 Educational expectations

Occupational expectations

18A Certainty will graduate

19 Attend start/pass each term

20 HS program

46 Important things in life

49 Educational expectations

Occupational expectations

203 Have anv children of own

92.93 Who else lives in house

97 Absences because babysit

99 SCHOOL

\section{SCHOOL}

11 HS program enrollment

\% Students LM or LEP

24-25 Days to be truant. D-out

29 \% Students LM or LEP

\% Receive special services $30 \quad \%$ Receive special services

Admission practices

\# Teachers

Teachers assigned ESL

$\begin{array}{lrl}\text { Who affects stud. placement } 61 & \text { Use homogenous grouping } \\ \text { Math/sci. courses offered } & 75 & \text { Math/sci. courses offered } \\ & 82 & \text { Have D.out prevent. program } \\ & 84 & \text { Why studs. in D.out program }\end{array}$

$\begin{array}{lrl}\text { Who affects stud. placement } 61 & \text { Use homogenous grouping } \\ \text { Math/sci. courses offered } & 75 & \text { Math/sci. courses offered } \\ & 82 & \text { Have D.out prevent. program } \\ & 84 & \text { Why studs. in D.out program }\end{array}$

$\begin{array}{lrl}\text { Who affects stud. placement } 61 & \text { Use homogenous grouping } \\ \text { Math/sci. courses offered } & 75 & \text { Math/sci. courses offered } \\ & 82 & \text { Have D.out prevent. program } \\ & 84 & \text { Why studs. in D.out program }\end{array}$ 
Figure 1.4 (cont.): NELS:88 first follow-up key questionnaire items related to educational policy in education research

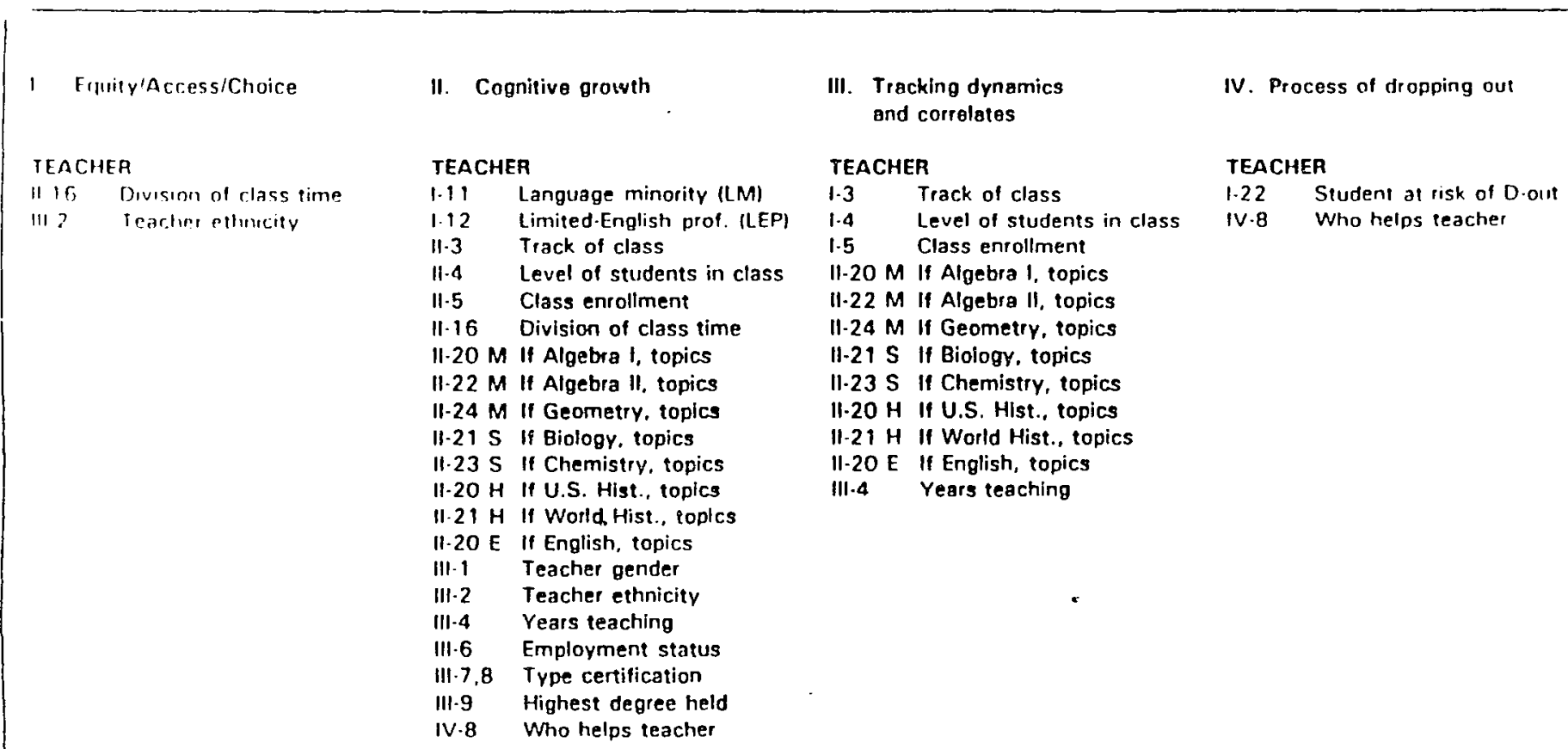


Figure 1.4 (cont.): NELS:88 first follow-up key questionnaire items related to educational policy in education research

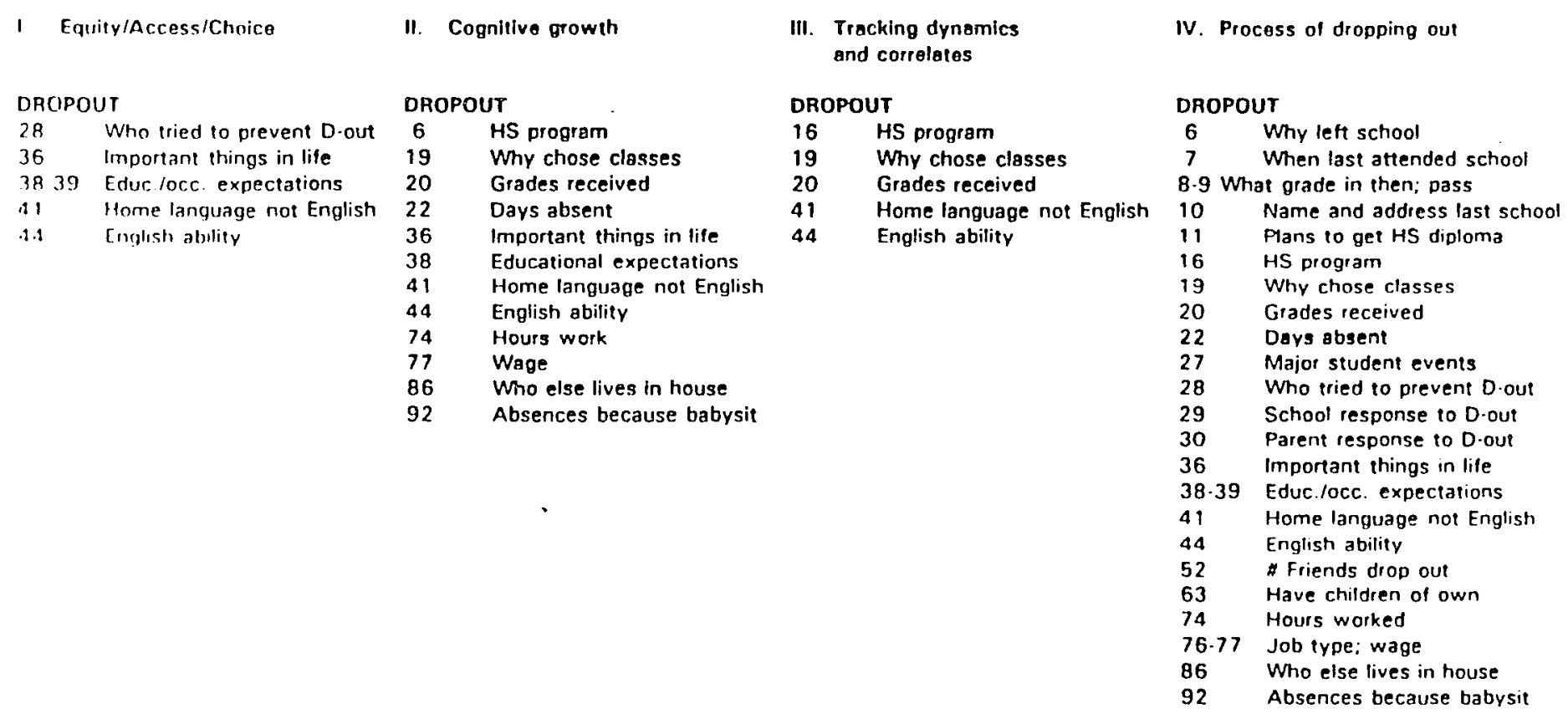


Figure 1.4 (cont.): NELS:88 first follow-up key questionnaire items related to educational policy in education research

$\checkmark$ Transition parterns from 8 th to 10 th grade

\section{ISSUES}

Movement across private/public school sectors, farmily migration, track placement. differences in experience of school environment. school size. mnial clumate and organzational ethos of school

\section{STUDENT}

19 Artend start/pass each term

20 HS program

\section{SCHOOL}

$54 \quad$ Admission practices

\section{Schoot effoctiveness}

\section{ISSUES}

School size. SES level, school sector.

school climate, principal and teacher

autonomy, staff job satisfaction, textbooks.

curricular offerings, teacher quality.

student performance and growth, student persistence and school-leaving

\section{STUDENT}

18A Certainty will graduate

19 Attend start/pass each term

39 Sell-reported grades

$49^{\circ}$ Educational expectations

\section{SCHOOL}

1.4 School size, type

11 HS program enrollment

24.25 Days to be truant, D-out

$29 \%$ Students LM or LEP

30 \% Receive special services

* Teachers

Ethricity of teachers

45.46 Teachers assigned ESL; certified

54 Admission practices

Use homogenous grouping

Who affects stud, placement

Coursework requirements

Math/sci. courses offered

- AP courses offered

Have D-out prevent. program

Why stud. in D-out program
VII. Parental and community involvement

\section{ISSUES}

Active parental involvemene, school policies and attitudes related to parental involvement.

parental choice in school, parental networks and

interactions, student performance, remain

in school

\section{STUDENT}

13 Days absent

99 Major family events

\section{SCHOOL}

84 Why studs. in D.out program 
Figure 1.4 (cont.): NELS:88 first follow-up key questionnaire ltems related to educational policy in education research

$\checkmark$ Transition patterns from 8th to 10th grade

TEACHER

DROPOUT

10 Last school

Plans for HS diploma
VI. School offectiveness

TEACHER

II-20 M If Algebra I, topics

II.22 M If Algebra II, topice

II.24 M If Geometry, topics

II-21 S If Biology, topics

1-23 s if Chemistry, topics

11-23 S If Chemistry, topic

11.20 H in U.S. Hist., lopics

I.-21 H in World Hist, copics

$11.20 \mathrm{E}$ If English, topics

III.6 Employment status

III.7.8 Type cerification

III-9 Highest degree held

IV-8 Who helps teacher

\section{DROPOUT}

19 Why choose classes

29 - Schoot response to D-out

38 Educational expectations

44 English language proficlency
VII. Perental and community

$$
\text { involvemont }
$$

\section{TEACHER}

\section{DROPOUT}

30 Parent response to D-out

41 Home language not English

Who else llves in houge 
Figure 1.6: Documentation available for use with NELS:88 base year data files

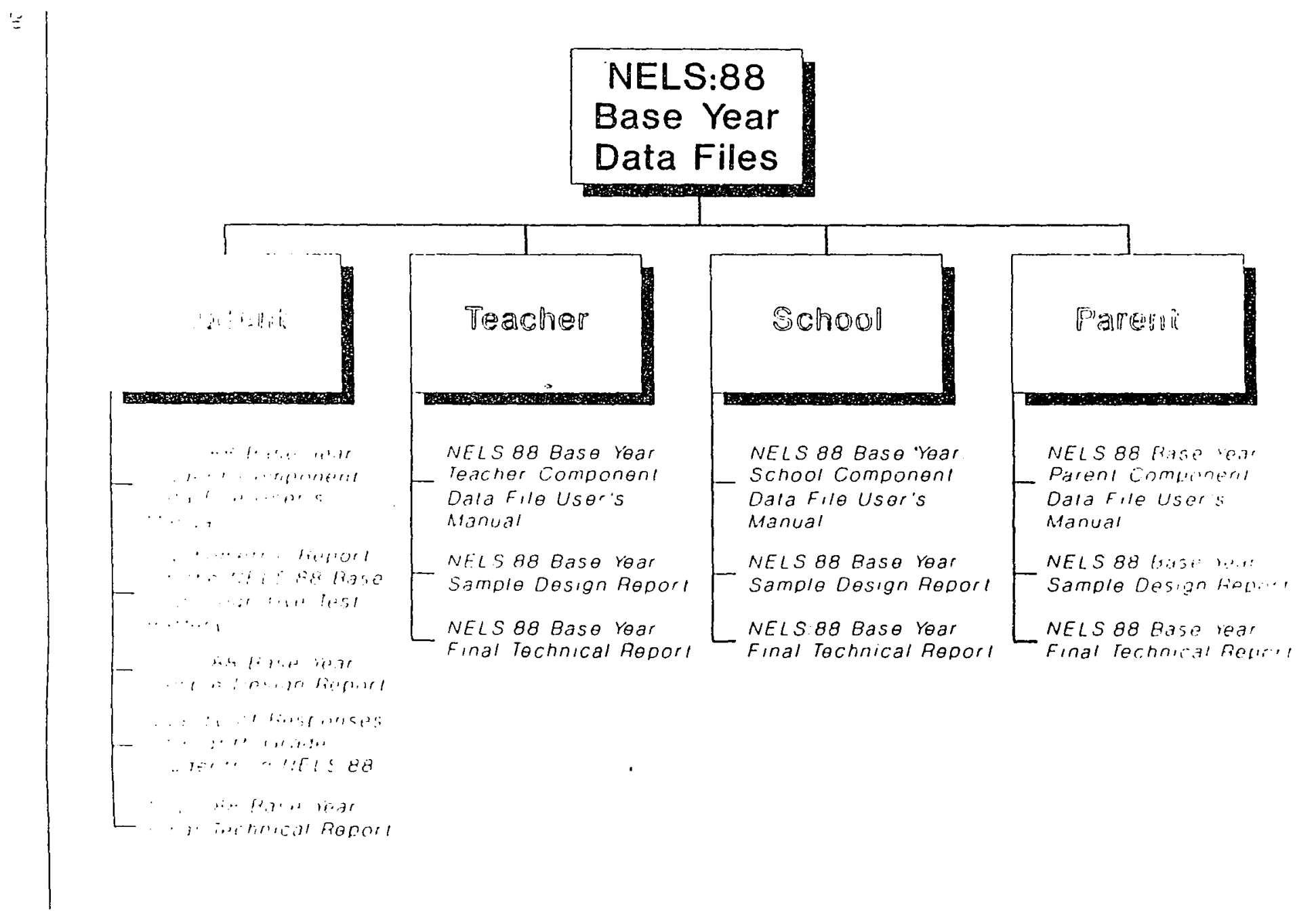


Figure 1.4 (cont.): NELS:88 first follow-up key questionnaire items related to educational policy in education research

$\checkmark$ Transition potterns

trom 8 ih to 10 th grade

ISSUES

Movement across private/public school sectors,

tamily inigration,tlack placement, differences

in experience of school environment, school

size. moral climate and organzational ethos

of sichool

\section{STUDENT}

19 Attend start/pass each term

20 HS program

SCHOOL

54 Adimission practices
VI. School effectiveness

\section{ISSUES}

School size, SES level, school sector school climate, principal and teacher autonomy. staff job satisfaction, textbooks. curricular offerings, leacher quality. student performance and growth, student persistence and schoolleaving

\section{STUDENT}

18A Certainty will graduate

19 Artend start/pass each term

39 Self-reported grades

49 Educational expectations

\section{SCHOOL}

1.4 School size. type

11 HS program enrollment

24.25 Days to be truant. D.out

\% Students LM or LEP

30 \% Receive special services

- Teachers

Ethnicity of teachers

45.46 Teachers assigned ESL: certified

54 Admission practices

61 Use homogenous grouping

70 Who affects stud. placement

$75 \mathrm{Math} / \mathrm{scl}$. courses olferod

76 AP courses offered

82 Have D-out prevent. program

84 Why stud. in D-out prograrn
VII. Parental and community involvement

ISSUES

Active parental involvement, school policies and attitudes related to parental involvement.

parental choice in school, parental networks and interactions, student performance, remain

In school

STUDENT

13 Days absent

99 Major family events

\section{SCHOOL}

84 Why studs. in D.out program 
Figure 1.4 (cont.): NELS:88 first follow-up key questionnaire items related to educational policy in education research

\begin{tabular}{|c|c|c|}
\hline $\begin{array}{l}\text { V. Transition patterns } \\
\text { from } 8 \text { th to } 10 \text { th grade }\end{array}$ & VI. School offectiveness & $\begin{array}{l}\text { VII. Porented end community } \\
\text { involvement }\end{array}$ \\
\hline TEACHER & 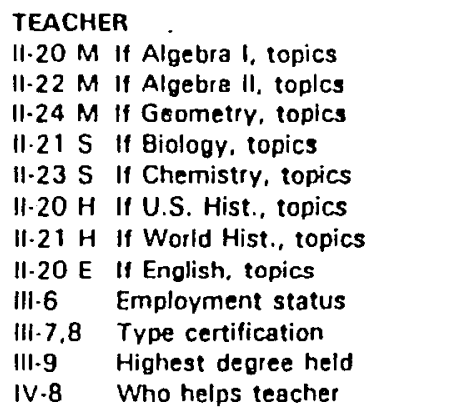 & TEACHER \\
\hline OROPOUT & DROPOUT & DROPOUT \\
\hline $\begin{array}{ll}10 & \text { Last school } \\
11 & \text { Plans for HS diploma }\end{array}$ & $\begin{array}{ll}19 & \text { Why choose classes } \\
29 & \text { School response to D-out } \\
38 & \text { Educational expectations } \\
44 & \text { English language proficiency }\end{array}$ & $\begin{array}{ll}30 & \text { Parent response } 100 \text {.out } \\
41 & \text { Home language not English } \\
86 & \text { Who else lives in house }\end{array}$ \\
\hline
\end{tabular}


Figure 2-9: Content areas in NELS:88 base year questionnaires

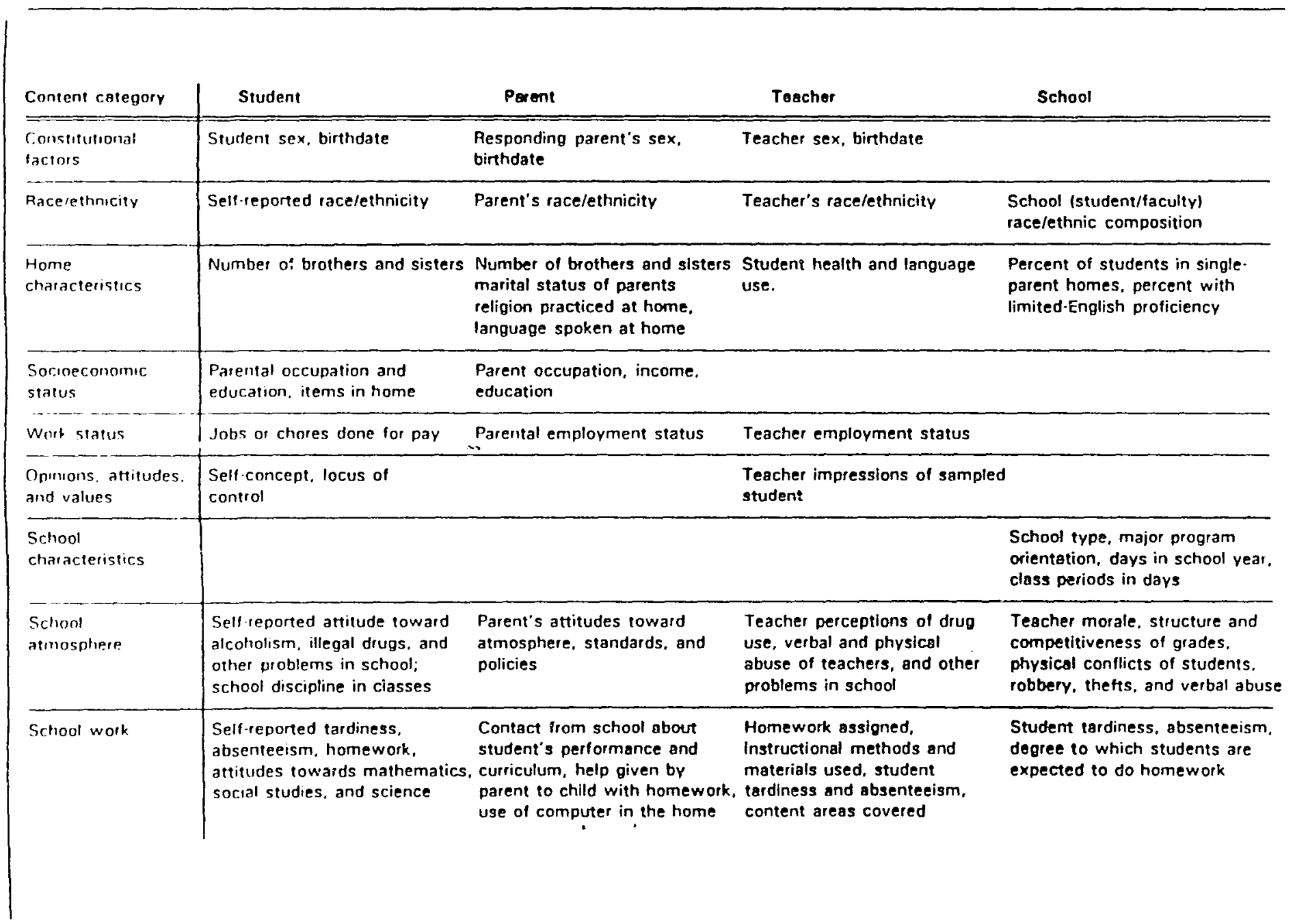


Figure 2-1 (cont.): Content areas in NELS:88 base year questionnaires

\begin{tabular}{|c|c|c|c|c|}
\hline Content category & Student & Parent. & Teacher & School \\
\hline Srhonl performance & $\begin{array}{l}\text { Self-reported grades. } \\
\text { performance on NELS:88 } \\
\text { cognitive test battery }\end{array}$ & $\begin{array}{l}\text { Parental expectations for } \\
\text { child's grades }\end{array}$ & $\begin{array}{l}\text { Teacher impression of student } \\
\text { achievement }\end{array}$ & \\
\hline Gundance & $\begin{array}{l}\text { Siudent reported availability } \\
\text { of counseling (for education } \\
\text { plans. jobs, careers, drus } \\
\text { abuse. etc.) given by school } \\
\text { employee. adult relative. } \\
\text { or friend }\end{array}$ & $\begin{array}{l}\text { Parent talks at home with child } \\
\text { about school, high school plans, } \\
\text { or homework }\end{array}$ & & $\begin{array}{l}\text { Availability of guidance } \\
\text { counseling for students in } \\
\text { school }\end{array}$ \\
\hline Sperial prog̣ams & $\begin{array}{l}\text { Participation in special } \\
\text { programs le g., gifted and } \\
\text { talented, special education. } \\
\text { bilingual. or ESL) }\end{array}$ & $\begin{array}{l}\text { Physical and mental limitations } \\
\text { of students, special services } \\
\text { rendered (e.g., for gitted and } \\
\text { Palented student) }\end{array}$ & $\begin{array}{l}\text { Teacher involvement and } \\
\text { satisfaction with gifted and } \\
\text { talented programs }\end{array}$ & $\begin{array}{l}\text { Special services le.g. gitted } \\
\text { and talented programs) }\end{array}$ \\
\hline $\begin{array}{l}\text { Alfer sritool } \\
\text { supervision }\end{array}$ & Parental supervision & $\begin{array}{l}\text { Parental supervision, after- } \\
\text { school childcare arrangements }\end{array}$ & - & \\
\hline $\begin{array}{l}\text { Irvolvement with } \\
\text { community }\end{array}$ & $\begin{array}{l}\text { Family life, cultural experience, } \\
\text { participation in neighborhood } \\
\text { programs }\end{array}$ & $\begin{array}{l}\text { Family life, activities in } \\
\text { communily le.g.. borrows } \\
\text { books from library, ottends } \\
\text { concerts, museums. } \\
\text { participates in community- } \\
\text { bosed groups }\end{array}$ & & \\
\hline $\begin{array}{l}\text { Alter sthool } \\
\text { acturities }\end{array}$ & $\begin{array}{l}\text { Extra-curricular activities, } \\
\text { outside school classes and } \\
\text { clubs }\end{array}$ & $\begin{array}{l}\text { Student enrollment in outside } \\
\text { school clubs }\end{array}$ & & \\
\hline $\begin{array}{l}\text { life goals. } \\
\text { erfucavional and } \\
\text { orcicunational }\end{array}$ & $\begin{array}{l}\text { Student and parent } \\
\text { expectations of how far in } \\
\text { school student will advance. } \\
\text { student's desired occupation }\end{array}$ & $\begin{array}{l}\text { Parental expectations of } \\
\text { educational attainment of child }\end{array}$ & & \\
\hline finanrial assistance & & $\begin{array}{l}\text { Proposed financial aid for luture } \\
\text { education }\end{array}$ & & $\begin{array}{l}\text { Percent of students receiving } \\
\text { aid in school }\end{array}$ \\
\hline
\end{tabular}


-.......

\begin{tabular}{|c|c|c|c|c|}
\hline & & & \multicolumn{2}{|l|}{ Teacher sex, birthdate } \\
\hline & & & Teacher race/ethnicity & $\begin{array}{l}\text { School Istudent' } \\
\text { faculty) race/ethnic } \\
\text { composition }\end{array}$ \\
\hline & $\begin{array}{l}\text { Others in household, number } \\
\text { of brothers and sisters. } \\
\text { own child, religion, } \\
\text { language use }\end{array}$ & $\begin{array}{l}\text { Others in household, number } \\
\text { of brothers and sisters. } \\
\text { own child, religion. } \\
\text { language use }\end{array}$ & $\begin{array}{l}\text { Student language use and } \\
\text { health }\end{array}$ & $\begin{array}{l}\text { Percent of students in single- } \\
\text { parent homes, percent with } \\
\text { percent with limited English } \\
\text { English proficiency }\end{array}$ \\
\hline \multirow[t]{2}{*}{ nds } & $\begin{array}{l}\text { Family relationships and } \\
\text { events, parental school } \\
\text { involvement, attributes of } \\
\text { friends }\end{array}$ & $\begin{array}{l}\text { Family relationships and } \\
\text { events, parental school } \\
\text { involvement, attributes of } \\
\text { friends }\end{array}$ & Parental school involvement & Parental school involvement \\
\hline & $\begin{array}{l}\text { Work status, type. hours. } \\
\text { and pay }\end{array}$ & $\begin{array}{l}\text { Work status. type, hours, } \\
\text { and pay }\end{array}$ & $\begin{array}{l}\text { Teacher work status, outside } \\
\text { work }\end{array}$ & $\begin{array}{l}\text { Teschel pay, degrees, work } \\
\text { status, and certification }\end{array}$ \\
\hline \multirow[t]{2}{*}{ jes. } & $\begin{array}{l}\text { Self-concept, locus of } \\
\text { control }\end{array}$ & $\begin{array}{l}\text { Self-concept. locus of } \\
\text { control }\end{array}$ & $\begin{array}{l}\text { Teacher impressions of } \\
\text { student }\end{array}$ & \\
\hline & & & & $\begin{array}{l}\text { School type, structure, grades, } \\
\text { locale, couises and programs. } \\
\text { departments, periods, days }\end{array}$ \\
\hline \multirow[t]{2}{*}{ here } & $\begin{array}{l}\text { School climate, problems in } \\
\text { school. level of discipline }\end{array}$ & $\begin{array}{l}\text { School climate, problems in } \\
\text { school, level of discipline }\end{array}$ & $\begin{array}{l}\text { Schoof climate, problems in } \\
\text { decision-making processes. } \\
\text { satisfaction with teaching }\end{array}$ & $\begin{array}{l}\text { Probiems in school, disciplinary } \\
\text { actions taken, teacher morale. } \\
\text { grading }\end{array}$ \\
\hline & $\begin{array}{l}\text { Program, coursework, } \\
\text { homework, teacher } \\
\text { mactices, self.reported } \\
\text { tardiness, absenteeism, } \\
\text { suspension, and arresis }\end{array}$ & $\begin{array}{l}\text { Program, coursework, } \\
\text { homework, tescher } \\
\text { practices, self-reported } \\
\text { tardiness, absenteeism, } \\
\text { suspension; ond arrests }\end{array}$ & $\begin{array}{l}\text { Instructional methods and } \\
\text { materials, content areas } \\
\text { covered, track of class. } \\
\text { homework, tardiness. } \\
\text { absenteeism }\end{array}$ & $\begin{array}{l}\text { Track composition, student } \\
\text { tardiness and absenteeism }\end{array}$ \\
\hline
\end{tabular}


Figure 2.2 (cont.): Content areas in NELS:88 first follow-up questionnaires

\begin{tabular}{|c|c|c|c|c|}
\hline Content category & Student & Dropout & Tezcher & School \\
\hline Srhool performance & $\begin{array}{l}\text { Self-reported grades, NELS } \\
\text { cognitive test scores }\end{array}$ & $\begin{array}{l}\text { Self-reported grades, NELS } \\
\text { cognitive test scores }\end{array}$ & Student achievement & \\
\hline Special programs & $\begin{array}{l}\text { Participation in special } \\
\text { programs }\end{array}$ & $\begin{array}{l}\text { Participation in special } \\
\text { programs }\end{array}$ & & $\begin{array}{l}\text { Programs offered, level of } \\
\text { participation }\end{array}$ \\
\hline $\begin{array}{l}\text { After school } \\
\text { activities }\end{array}$ & $\begin{array}{l}\text { Participation in school-related } \\
\text { and non-school-related } \\
\text { activities }\end{array}$ & $\begin{array}{l}\text { Participation in school-related } \\
\text { and non-school-related } \\
\text { activities, sctivities since left }\end{array}$ & & \\
\hline $\begin{array}{l}\text { Life goals. } \\
\text { educational and } \\
\text { occupational }\end{array}$ & $\begin{array}{l}\text { Educational and occupational } \\
\text { expectations and preparation, } \\
\text { others' expectations. } \\
\text { important things in life }\end{array}$ & $\begin{array}{l}\text { Educational and occupational } \\
\text { expectations and preparation, } \\
\text { others' expectations, } \\
\text { mportant things in life, why } \\
\text { left school }\end{array}$ & & \\
\hline
\end{tabular}


Figure 3-1: Longltudinal sample design of NELS:88

\begin{tabular}{c} 
BY \\
1988 \\
arade 8 \\
\hline
\end{tabular}

$\left[\begin{array}{c}\text { select oin } \\ 0,000 \text { entoole }\end{array}\right]$

seieci inillai

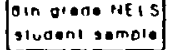<smiles></smiles>

varily allotbliliy tor ay

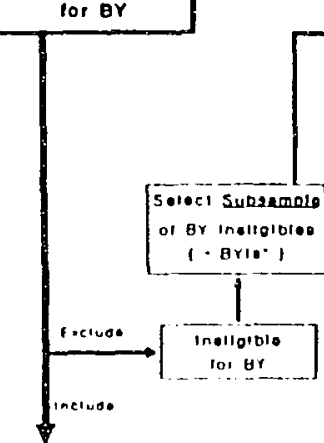

$[$ atis $\sin 0.0000$

asmole memoer.

11

FInol Pels $A \theta$

Aasa rest

conoul
conglidina

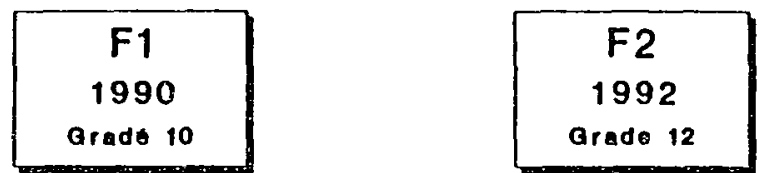

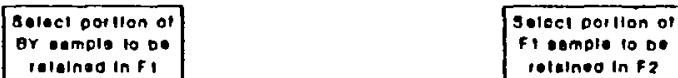

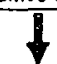

Fresneon ino 81

colained camplo

(Coloci F 2 ,

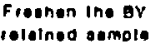

nolleo in tain gied

I Celect FI,

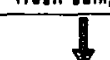

vorily oltglolilly

tor fi

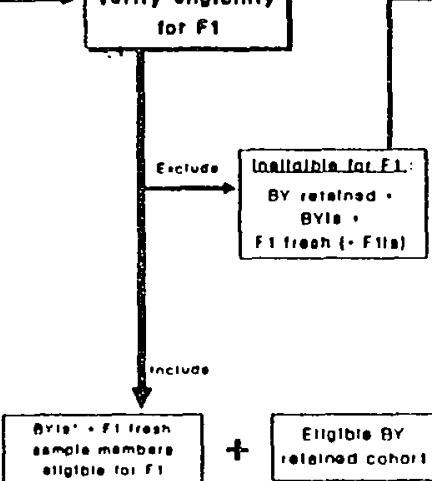

II

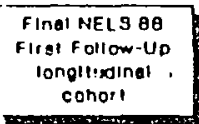

Fist follow $U_{0}$

conor

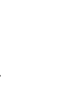

- Verlly allolbilliy

lor $F 2$ 
Figure 4-1: First follow-up data colloction phese diagram

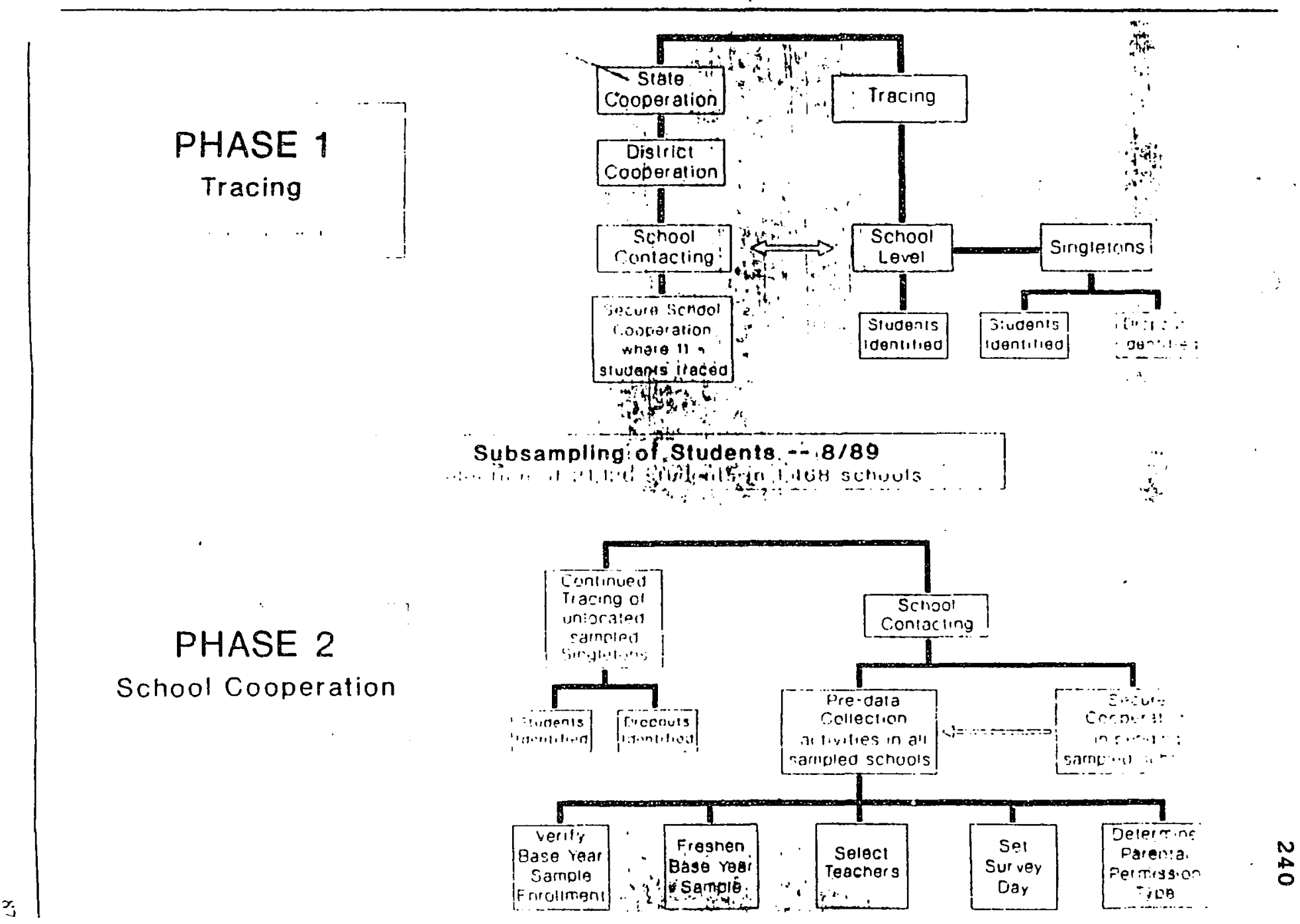


Figure 4-1 (cont.): First follow-up data collection phase diagram

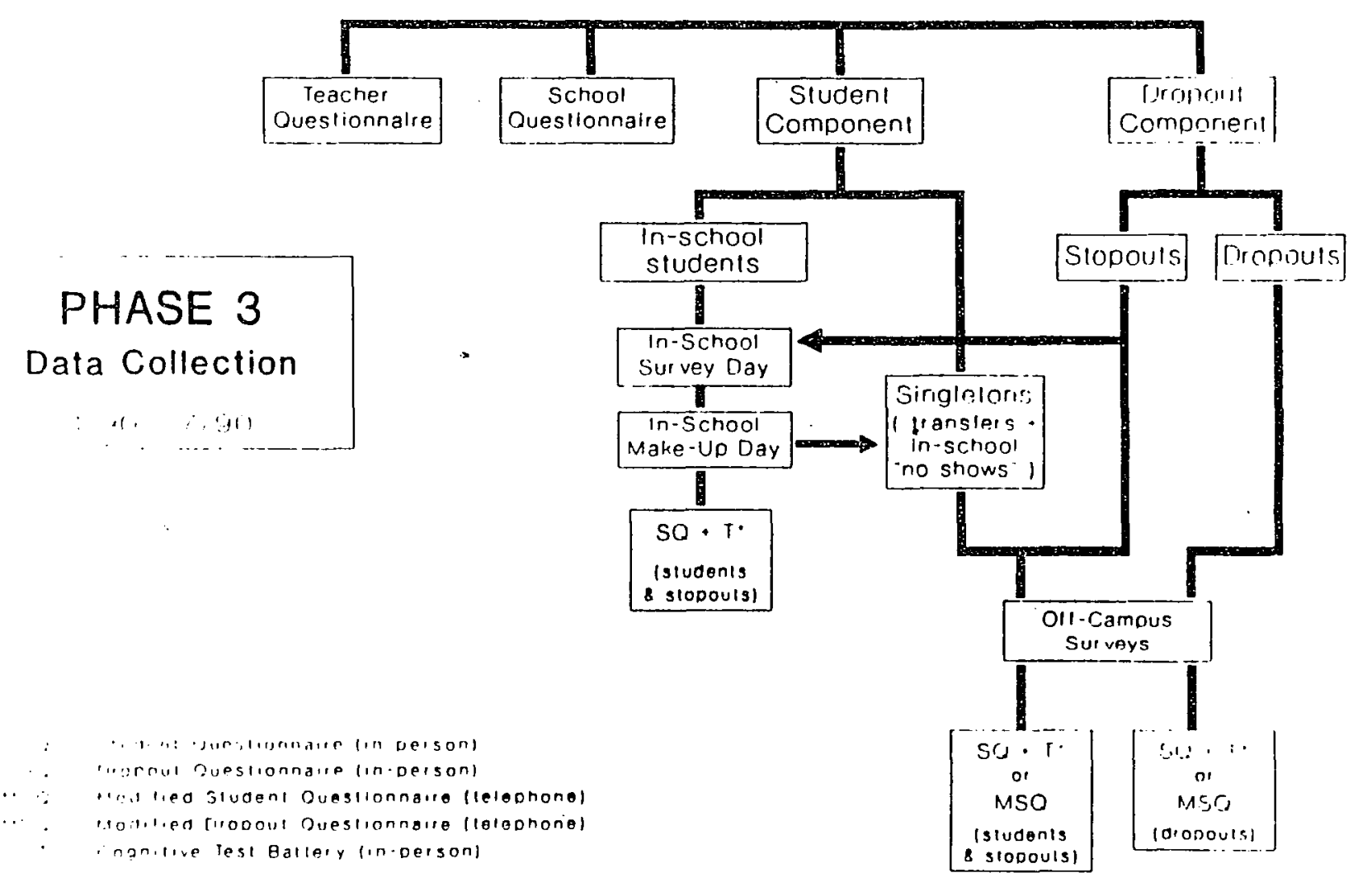


Figure 4-1 (cont.): First follow-up data collection phase dlagram

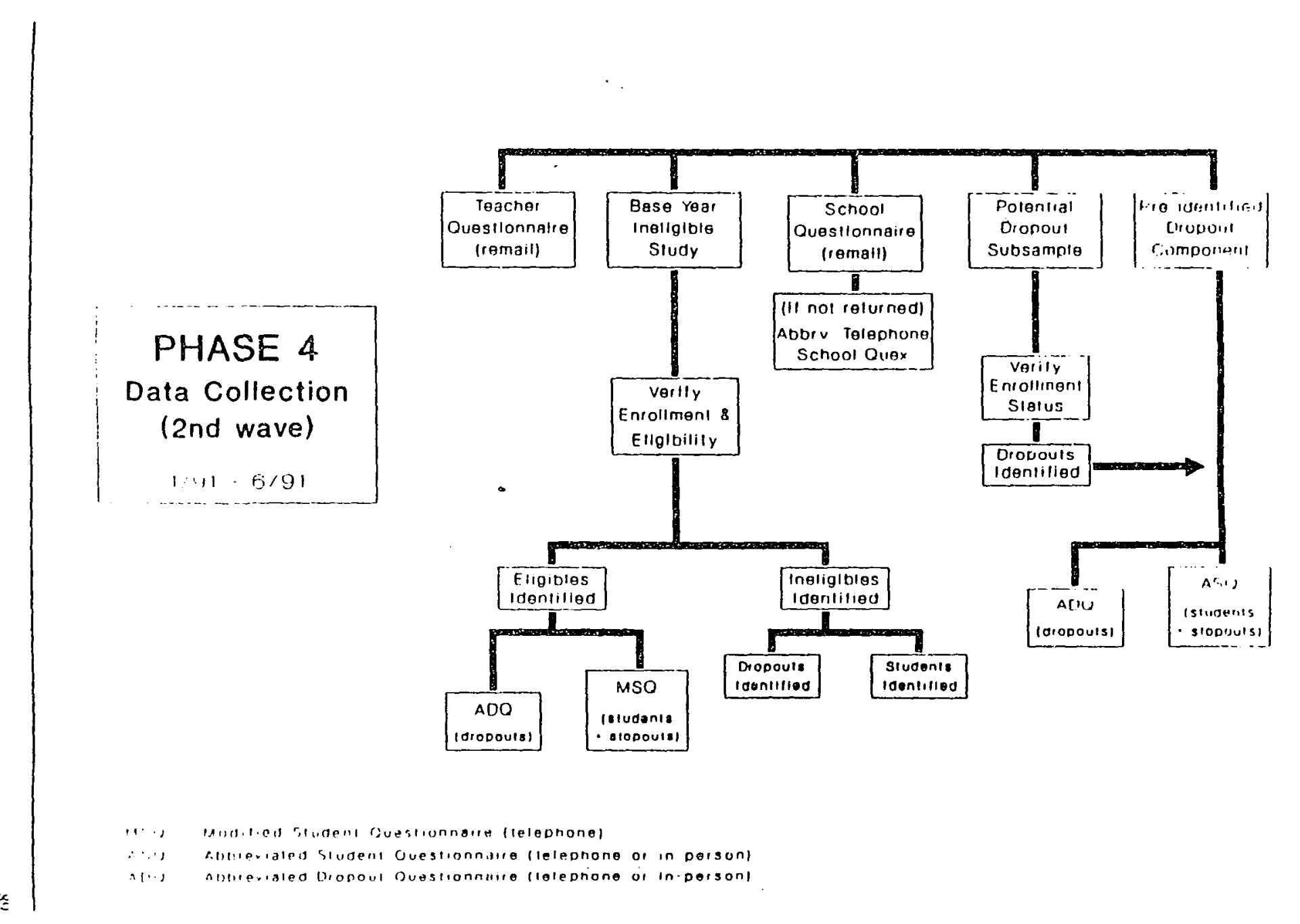


Figure 7-1: Guide to date Fle Inkege for NELS:B8 base year and first follow-up

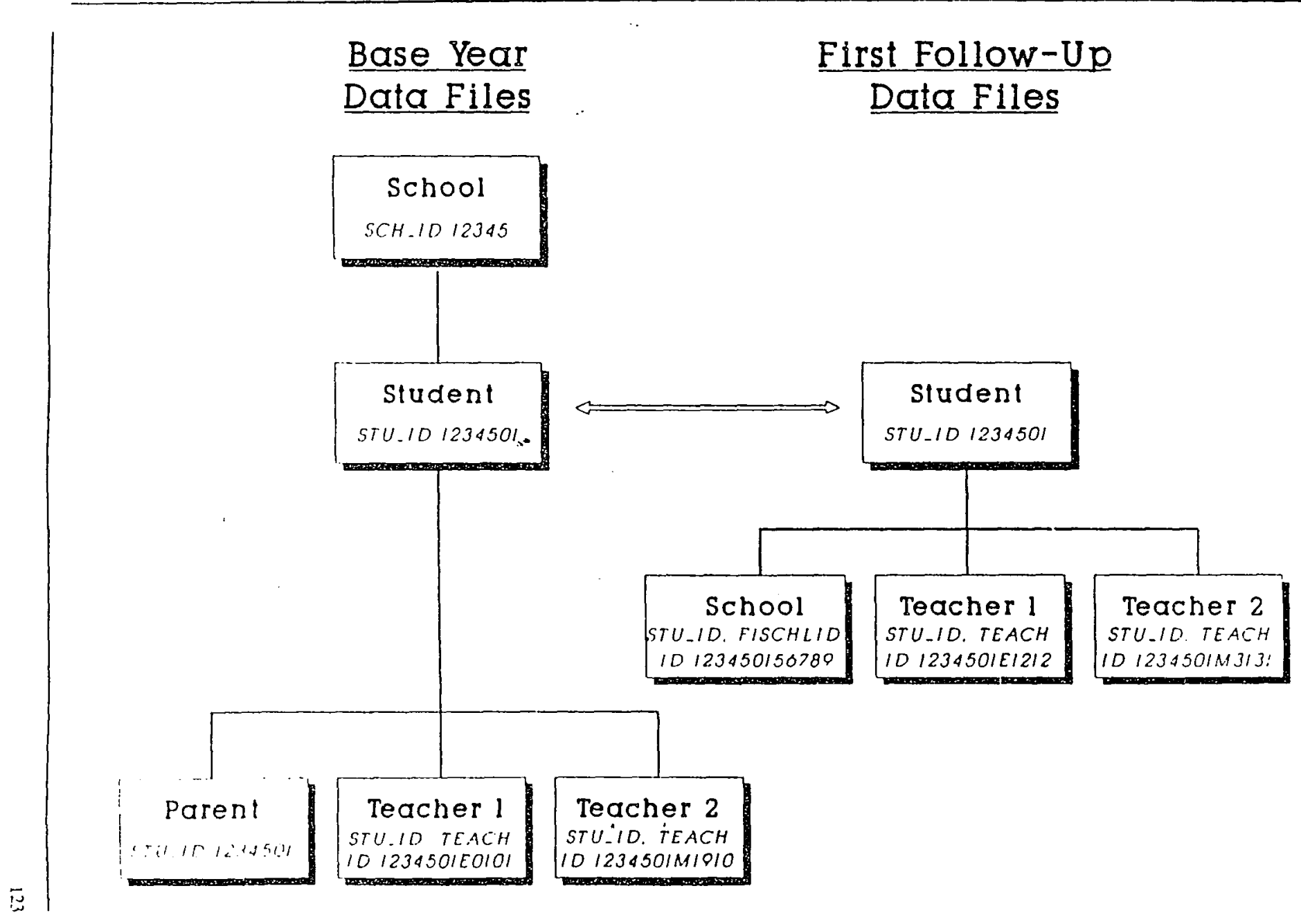


Br.Fl:Suden Compunem Data File User's Manual

Longitudinal and Housebold Studies Branch (LHSB) NELS:88 Publications

\section{RELEASED ANALYSIS REPQRTS.}

Hafner. A.; Ingels, S.J.; Schneider, B.; and Stevenson, D.L. A Profile of the American Eighth Grader, June 1990; NCES 90-458.

Hoachlander, E.G. A Profile of Schools Attended by Eighth Graders in 1988, September 1991; NCES 91-129.

Bradby, D. Language Characteristics and Academic Achievement: A Look at Asian and Hispanic Eighth Graders in NELS:88, February 1992.

\section{RELEASED E.D. TABULATIONS.}

Rasinski, K.A.; and West, J. NELS:88: Eighth Graders' Reports of Cousses Taken During the 1988 Academic Year by Selected Student Chamaeristics, July 1990; NCES 90-459.

Rock, D.A.; Pollack, J.M.; and Hafner, A. The Tested Achievement of the National Education Longirudinal Study of 1988 Eighth Grade Class, April 1991; NCES 91-460.

\section{RELEASED USER'S MANUALSTECHMNCAL REPORTS.}

Ingels, S.J.; Abraham, S.; Rasinski, K.A.; Karr, R.; Spencer, B.D.; Frankel, M.R.; Owings, J.A. NELS:88 Base Year Data Flle User's Manuals:

PARENT COMPONENT: March 1990 ; NCES $90-466$

SCHOOL COMPONENT: March $1990 ;$ NCES $90-482$

TEACHER COMPONENT: March 1990; NCES $90-484$

STUDENT COMPONENT: March 1990; NCES 90-464*

Spencer, B.D.; Frankel, M.R.; Ingels, S.J.; Rasinski, K.A.; and Tourangeau, R. NELS:88 Base Year Sample Design Repon, August 1990; NCES 90-463.

Rock, D.A.; and Pollack, J.M. Psychometric Repon for the NELS:88 Base Year Test Bantery. April 1991, NCES 91.468 .

Kaufman. P.; Rasinskı. K.A.; Lee, R.; and West, J. Quality of Responses of Eighth-Grade Students to the NELS:88 Base Year Questionnaire. September 1991; NCES 91-487.

* contains a codebook with frequency distributions for the full $(24,599) 1988$ participating cross-secuonal sample 
BY.F l:Student Component

Data File User's Manual

Ingels, S.J.; Rasinski, K.A.; Frankel, M.R.; Spencer, B.D.; and Buckley, P.B. NELS:88 Base Year Final Technical Report, 1990; Chicago: NORC.

\section{FORTHCOMING LHSB NELS:88 REPORTS/E.D. TABULATIONS/USER'S MANUALS.}

Ingels, S.J.; Scot, L.A.; Lindmark, J.T., Frankel, M.R.; Myers, S.L.; and Wu, S. NELS:88 First Follow-Up Data File User's Manuals:

STUDENT COMPONENT February 1992; NCES 92-030

SCHOOL COMPONENT March 1992

DROPOUT COMPONENT April 1992

TEACHER COMPONENT May 1992

A Profile of American Eighth Grade Math and Science Instruction: NBIS:88 Teachers, Schools, and Students (Estimated Release April 1992).

NELS:88 Base Year Parent Descriptive Report (Estimated Release April 1992).

Portrait of the At-Risk Eighth Grader (Estimated Release May 1992).

NELS:88 Thansition Pattems Experienced by Students as They Move fross Eighth Grade to Terith Grade (Estimated Release Decenber 1992).

NELS:88 First Follow-Up Student Profile: descriptive summary of the American tenth-grader. (Estimated Release April 1992).

NELS:88 First Follow-Up Final Technical Report (includes base year ineligibles survey report) (June 1992).

Comparison of NELS:88 1990 Sophomores and FS\&B 1980 Sophomores. (Estimated Release December 1992).

NELS:88 First Follow-Up Dropout Descriptive Repon (Estimated Release September 1992). 
FFS \# DOQ * BYS \# HS\&B \#

\begin{tabular}{|c|c|c|c|c|}
\hline $12 \mathrm{~m}$ & $14 m$ & -- & -. & Feel it is OK to drink alcohol during the school day \\
\hline $12 \pi$ & $14 n$ & -- & -- & Feel it is OK to use illegal drugs during the school day \\
\hline 120 & 140 & -- & -- & Feel it is OK to bring weapons to school \\
\hline $12 p$ & $14 p$ & -. & -- & Feel it is OK to abuse teachers physically \\
\hline $12 q$ & $14 \mathrm{q}$ & -- & -- & Feel it is OK to talk back to teachers \\
\hline $12 \mathrm{r}$ & $14 r$ & .. & -- & Feel it is OK to disobey school rules \\
\hline 13 & 22 & - & .. & Days absent last semester \\
\hline 14 & 23 & -- & -- & Main reason for my last absence \\
\hline $15 \mathrm{a}$ & $24 a$ & - & -. & On my last absence the school did not do anything \\
\hline $15 b$ & $24 b$ & - & -- & On my last absence someone from school called my home \\
\hline $15 c$ & $24 c$ & -. & - & On my last absence someone from school visited my home \\
\hline $15 d$ & $24 d$ & -. & -- & On my last absence the school sent a letter to my home \\
\hline $15 \mathrm{e}$ & $24 e$ & - & - & On my last absence the school made me see a counselor \\
\hline $16 a$ & $25 \mathrm{a}$ & - & - & When I returned my teachers helped me catch up \\
\hline $16 b$ & $25 \mathrm{~b}$ & - & - & When I returned other students helped me catch up \\
\hline $16 c$ & $25 c$ & - & -- & When I returned someone else helped me \\
\hline $16 \mathrm{~d}$ & $25 d$ & -- & - & When I returned I didn't need to catch up \\
\hline $16 e$ & $25 \mathrm{e}$ & - & - & When I returned a teacher was mad at me or put me down \\
\hline $16 f$ & $25 f$ & -- & - & When I returned an adult in the school asked where I'd been \\
\hline $16 \mathrm{~g}$ & $25 g$ & - & -- & When I returned I fell behind \\
\hline $18 \mathrm{~A}$ & - & 46 & $3^{*}$ & How sure I am that I will graduate from high school \\
\hline $18 \mathrm{~B}$ & -- & 47 & - & How sure I am that I will go on for further education after HS \\
\hline 20 & 16 & 49 & 1 & High school program \\
\hline $26 \mathrm{a}$ & $18 \mathrm{a}$ & -- & - & How often challenged to use mind in math \\
\hline $26 b$ & $18 \mathrm{~b}$ & - & -- & How often challenged to use mind in English \\
\hline $26 c$ & $18 \mathrm{c}$ & -- & - & How often challenged to use mind in history \\
\hline $26 d$ & $18 \mathrm{~d}$ & -- & -- & How often challenged to use mind in science \\
\hline $34 \mathrm{a}$ & -- & -- & $13 a$ & Ever been in remedial English \\
\hline $34 b$ & -- & -- & $13 b$ & Ever been in remedial mathematics \\
\hline $34 c$ & -- & -- & $13 \mathrm{e}$ & Ever been in a bilingual or bicultural program \\
\hline $34 i$ & -- & -- & $13 \mathrm{~h}$ & Ever been in a program for the emotional!y handicapped \\
\hline $34 \mathrm{~g}$ & -. & -- & $13 i$ & Ever been in a program for the physically handicapped \\
\hline $36 b$ & -- & $79 \mathrm{a}$ & - & Time spent each week on math homework \\
\hline $36 c$ & -- & $79 b$ & -- & Time spent each week on science homework \\
\hline $36 d$ & -. & $79 c$ & -- & Time spent each week on English homework \\
\hline $36 \mathrm{e}$ & -- & $79 d$ & - & Time spent each week on social studies homework \\
\hline $36 f$ & -. & $79 \mathrm{e}$ & -- & Time spent on homework each week for all other subjects \\
\hline 39 & $-\cdot$ & $81^{\circ}$ & -- & Grades in specific subject areas \\
\hline $40 \mathrm{a}$ & .. & $78 \mathrm{a}$ & $16 a$ & How ofien come to class without pencil or paper \\
\hline $40 b$ & -- & $78 b$ & 166 & How ofien come to class without books \\
\hline $40 c$ & -. & $78 \mathrm{c}$ & $16 \mathrm{c}$ & How ofien come to class without homework done \\
\hline
\end{tabular}


FFS \# DOQ * BYS \# HS\&.B \#

\begin{tabular}{|c|c|c|c|c|}
\hline $41 \mathrm{Aa}-\mathrm{g}$ & -. & $82 b, c^{\circ}$ & $34 a^{\circ}$ & Participation in spors \\
\hline $4 ! \mathrm{Ah}$ & -. & $82 d^{\circ}$ & $34 b^{\circ}$ & Paricipation in cheerleading \\
\hline $4 ! \mathrm{Ba}$ & & $82 \mathrm{e}, \mathrm{f}^{*}$ & $34 d, e^{\circ}$ & Participation in band, orchestra, chorus, or other music group \\
\hline $41 \mathrm{Bc}$ & -- & $825^{\circ}$ & -- & Participation in student government \\
\hline $41 \mathrm{Bd}$ & -- & $820^{\circ}$ & 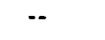 & Parricipation in academic honor sociery \\
\hline $41 \mathrm{Be}$ & -- & $82 p . q^{\circ}$ & - & Paricipation in school yearbook or newspaper \\
\hline $41 \mathrm{Bg}$ & -- & $82 h-m$ & $34 g^{*}$ & Paricipation in academic clubs \\
\hline $41 \mathrm{Bh}$ & - & -- & $34 f$ & Paricipation in hobby clubs \\
\hline $41 \mathrm{Bi}$ & -- & $82 u^{\circ}$ & $34 \mathrm{~h}^{\circ}$ & Participation in vocational education or professional clubs \\
\hline 43 & -- & 80 & -- & Additional reading each week \\
\hline $44 a$ & $34 a$ & - & $47 \mathrm{a}$ & How often visit with friends at a local hangout \\
\hline $44 b$ & $34 b$ & - & - & How often use personal computers \\
\hline $44 c$ & $34 c$ & - & - & How often work on hobbies, arts, or crafts \\
\hline $44 d$ & $34 d$ & - & $47 \mathrm{~b}$ & How often read for pleasure \\
\hline $44 e$ & $34 \mathrm{e}$ & - & - & How often go to park, gym, beach, or pool \\
\hline $44 f$ & $34 f$ & - & - & How often play ball or other sports with friends \\
\hline $44 \mathrm{~g}$ & $34 \mathrm{~g}$ & - & - & How often attend youth groups or recreational programs \\
\hline $44 \mathrm{~h}$ & $34 \mathrm{~h}$ & - & - & How often volunteer or perform community service \\
\hline $44 i$ & $34 i$ & - & 47d & How often drive or ride around \\
\hline $44 j$ & $34 j$ & - & $47 e$ & How often talk with friends on the telephone \\
\hline $44 k$ & $34 \mathrm{k}$ & - & - & How often talk or do things with mother or father \\
\hline 441 & 341 & - & -- & How often talk or do things with other aduits \\
\hline $44 m$ & $34 m$ & - & - & How often take classes: music, ant, language, dance \\
\hline $44 n$ & $34 n$ & - & -- & How often take sports lessons: Karate, tennis, etc. \\
\hline 440 & $34 p$ & - & - & How often attend religious activities \\
\hline 45A & $35 \mathrm{~A}$ & $42 \mathrm{~A}$ & 48 & Hours watch TV on weekdays \\
\hline 45B & $35 \mathrm{~B}$ & $42 B$ & - & Hours watch TV on weekends \\
\hline $46 a$ & $36 \mathrm{a}$ & - & $61 \mathrm{a}$ & Important in my life to be successful in my line of work \\
\hline $46 \mathrm{~b}$ & $36 b$ & - & $61 b$ & Important in my life to find the right person to marry \\
\hline $46 c$ & $36 c$ & - & $61 \mathrm{c}$ & Important in my life to have lots of money \\
\hline $46 d$ & $36 d$ & - & $61 d$ & Important in my life to have strong friendships \\
\hline $46 \mathrm{e}$ & $36 \mathrm{e}$ & - & $61 \mathrm{e}$ & Important in my life to be able to find steady work \\
\hline $46 f$ & $36 f$ & - & -- & Important in my life to help others in my community \\
\hline $46 \mathrm{~g}$ & $36 \mathrm{~g}$ & - & $61 \mathrm{~g}$ & Important in my life to give my children better opportunities \\
\hline $46 \mathrm{~h}$ & $36 \mathrm{~h}$ & - & $6 \ln$ & Imporant in my life to live close to my parents \\
\hline $46 i$ & $36 i$ & - & $6 l i$ & Important in my life to get away from this area \\
\hline $46 j$ & $36 \mathrm{j}$ & -- & $61 j$ & Important in my life to work to correct inequalities \\
\hline $46 k$ & $36 k$ & -- & $61 k$ & Important in my life to have children \\
\hline $46 !$ & 361 & .. & 611 & Important in my life to have leisure time to enjoy interests \\
\hline $46 \mathrm{~m}$ & $36 \mathrm{~m}$ & -- & $-\cdot$ & Imporant in my life to get away from my parents \\
\hline $47 \mathrm{a}$ & -. & -- & $50 \mathrm{a}$ & What father thinks! should do after high school \\
\hline
\end{tabular}

\footnotetext{
- Question is not identical across survev instruments, but mav be made comparabie by collapsing response categories
} 
Br.Fl:Srudent Component

Dala File User's Manual

Question Number Question Wording

\section{FFS \# DOQ \# BYS \# HS\&B \#}

\begin{tabular}{|c|c|c|c|c|}
\hline $47 \mathrm{~b}$ & -- & -- & $50 \mathrm{~b}$ & What mother thinks I should do after high school \\
\hline $47 \mathrm{e}$ & -- & .. & $50 c$ & What counselor thinks I should do after high school \\
\hline $47 f$ & -- & -. & SOd & What teacher thinks I should do after high school \\
\hline 48A & $37 \mathrm{~A}$ & $48 \mathrm{~A}$ & -. & How far in school father wants me to go \\
\hline $48 \mathrm{~B}$ & 37B & $48 \mathrm{~B}$ & 70 & How far in school mother wants me to go \\
\hline 49 & 38 & 45 & 69 & How far in school I think I will get \\
\hline 51 & - & -- & 112 & Plan to go to college when graduate; how soon \\
\hline 53 & 39 & 52 & 68 & Job category expect or plan to be in at age 30 \\
\hline 54 & 41 & 21 & - & Any language other than English spoken at home \\
\hline $55^{1}$ & 42 & 18,22 & $11.15^{2}$ & What other language is spoken in home \\
\hline $55 \mathrm{~A}$ & $42 \mathrm{~A}$ & - & -- & Whether it is my native language \\
\hline $55 \mathrm{Ba}$ & $42 \mathrm{Ba}$ & - & - & How well understand native language \\
\hline $55 \mathrm{Bb}$ & $42 \mathrm{Bb}$ & - & - & How well speak native language \\
\hline $55 \mathrm{Bc}$ & $42 B C$ & - & -- & How well read native language \\
\hline 55Bd & 42Bd & -- & - & How well write native language \\
\hline $57 \mathrm{a}$ & $44 a$ & $27 a$ & $19 a^{2}$ & How well understand English \\
\hline $57 \mathrm{~b}$ & $44 b$ & $27 \mathrm{~b}$ & $19 b$ & How well speak English \\
\hline $57 \mathrm{c}$ & $44 c$ & $27 \mathrm{c}$ & $19 \mathrm{c}$ & How well read English \\
\hline $57 d$ & $44 d$ & 27d & $19 d$ & How well write English \\
\hline 58 & 45 & - & - & Received special help in reading, writing, or speaking English \\
\hline $62 a$ & $46 a$ & $44 a$ & $62 \mathrm{a}$ & I feel good about myself \\
\hline $62 b$ & $46 \mathrm{~b}$ & $44 b$ & - & I don't have enough control over the direction of my life \\
\hline $62 c$ & $46 c$ & $44 c$ & $62 \mathrm{~b}$ & In my life, good luck is more important than hard work \\
\hline $62 d$ & $46 d$ & $44 d$ & $62 \mathrm{c}$ & I feel I am a person of worth, the equal of other people \\
\hline $62 \mathrm{e}$ & $46 e$ & $44 e$ & $62 d$ & I am able to do things as well as most other people \\
\hline $62 f$ & 468 & $44 f$ & $62 e$ & When I try to get ahead, somebody or something stops me \\
\hline $62 \mathrm{~g}$ & $46 g$ & $44 \mathrm{~g}$ & $62 f$ & My plans hardly ever work out; planning makes me unhappy \\
\hline $62 \mathrm{~h}$ & $46 \mathrm{~h}$ & $44 h$ & $62 \mathrm{~h}$ & On the whole, I am satisfied with myself \\
\hline $62 \mathrm{i}$ & $46 i$ & $44 i$ & - & I feel useless at times \\
\hline $62 \mathrm{j}$ & $46 j$ & $44 j$ & $62 \mathrm{j}$ & At times I think I am no good at all \\
\hline $62 k$ & $46 k$ & $44 k$ & $62 k$ & I am almost certain I can make my plans work \\
\hline 621 & 461 & 441 & 621 & I feel I do not have much to be proud of \\
\hline $62 \mathrm{~m}$ & $46 m$ & $44 m$ & -- & Chance and luck are very important in my life \\
\hline $62 n$ & $46 n$ & - & -- & I foel emotionally empty most of the tirxe \\
\hline $63 a$ & $47 a$ & - & -- & My parents treat me fairly \\
\hline $63 \mathrm{~b}$ & $47 \mathrm{~b}$ & - & - & I learn things quickly in English classes \\
\hline $63 c$ & $47 \mathrm{c}$ & -- & - & I have good friends who are members of my own sex \\
\hline
\end{tabular}

Questions 55 and $55 \mathrm{~A}$ should be combined in order to achieve comparability with language items in HS\&B and NELS: 88 base year. If the answer to $55 \mathrm{~A}^{\circ}$ is $^{-} \mathrm{Yes}^{*}$. then question 55 would be comparable to HS\& $B$ items 11 and 15 , and NELS: 88 base vear 0.18 and 22 . If the answer to $0.55 A$ is "No", then 0.55 can only be compared to HS\&B 0.15 and NELS:88 base vear 0.22 .

2 Questions 11, 15, and 19 are not trom the main HS\&B Sophomore Questionaire, but from the Student tdentification Pages 


\section{Question Number Question Wording}

\section{FFS \# DOQ \# BYS \# HS\&B \#}

\begin{tabular}{|c|c|c|c|c|}
\hline $63 d$ & $47 d$ & - & -- & Mathematics is one of my best subjects \\
\hline $63 \mathrm{e}$ & $47 \mathrm{e}$ & -- & -- & English is one of my best subjects \\
\hline $63 f$ & $47 f$ & -- & -- & I do not like my parents very much \\
\hline $63 g$ & $47 g$ & -- & $-\cdot$ & I get good marks in English \\
\hline $63 \mathrm{~h}$ & $47 \mathrm{~h}$ & -- & -- & I get a lot of attention from members of the opposite sex \\
\hline $63 i$ & $47 i$ & - & -- & I get along well with my parents \\
\hline $63 \mathrm{j}$ & $47 j$ & $\cdots$ & - & I have always done well in mathematics \\
\hline $63 k$ & $47 \mathrm{k}$ & - & - & I make friends easily with girls \\
\hline 631 & 471 & - & - & I make friends easily with boys \\
\hline $63 \mathrm{~m}$ & $47 m$ & - & - & My parents are unhappy or disappointed with what I do \\
\hline $63 n$ & $47 n$ & - & - & I'm hopeless in English classes \\
\hline 630 & 470 & - & - & I do not get along very well with girls \\
\hline $63 p$ & $47 p$ & - & - & I do not get along very well with boys \\
\hline $63 q$ & $47 q$ & - & - & I get good marks in mathematics \\
\hline $63 r$ & $47 r$ & - & - & It is difficult to make friends with members of my own sex \\
\hline $63 \mathrm{~s}$ & $47 \mathrm{~s}$ & - & - & I do badly in tests of mathematics \\
\hline $63 t$ & $47 t$ & - & - & I'm not very popular with members of the opposite sex \\
\hline $63 u$ & $47 u$ & - & - & My parents understand me \\
\hline $64 a$ & $48 \mathrm{a}$ & - & - & Chances will gradsuate from high school \\
\hline $64 b$ & $48 b$ & - & - & Chances will go to college \\
\hline $64 c$ & $48 c$ & - & - & Chances will have a job that pays well \\
\hline $64 d$ & $48 \mathrm{~d}$ & - & - & Chances will be able to own home \\
\hline $64 e$ & $48 \mathrm{e}$ & - & - & Chances will have an enjoyable job \\
\hline $64 f$ & $48 \mathrm{f}$ & - & - & Chances will have a happy family life \\
\hline $64 \mathrm{~g}$ & $48 \mathrm{~g}$ & - & - & Chances will stay in good health most of the time \\
\hline $64 \mathrm{~h}$ & $48 \mathrm{~h}$ & - & - & Chances will be able to live wherever want in country \\
\hline $64 \mathrm{i}$ & $48 \mathrm{i}$ & - & - & Chances will be respected in the community \\
\hline $64 \mathrm{j}$ & $48 j$ & - & - & Chances will have good friends \\
\hline $64 k$ & $48 \mathrm{k}$ & - & - & Chances life will turn out better than it has for parents \\
\hline 641 & 481 & - & - & Chances children will have a berter life \\
\hline $67 a$ & - & $56 a$ & $53 a$ & Other students see me as popular \\
\hline $67 \mathrm{~b}$ & -- & $56 \mathrm{~b}$ & 53b & Other students see me as athletic \\
\hline $67 c$ & - & - & $53 c$ & Other students see me as socially active \\
\hline $67 d$ & - & $56 c$ & $53 \mathrm{~d}$ & Other students see me as a good student \\
\hline $67 \mathrm{e}$ & - & $56 d$ & $53 \mathrm{e}$ & Other students see me as imporant \\
\hline $67 f$ & - & $56 e$ & $53 f$ & Other students see me as a trouble-maker \\
\hline $67 \mathrm{~g}$ & - & - & $53 \mathrm{~g}$ & Other students see me as part of the leading crowd \\
\hline 69 & 52 & - & - & How many close friends have dropped out of school \\
\hline $70 \mathrm{a}$ & $53 \mathrm{a}$ & - & -- & Important to close friends to attend classes regularly \\
\hline $70 \mathrm{~b}$ & $53 \mathrm{~b}$ & - & -. & Imporant to close friends to study \\
\hline $70 \mathrm{c}$ & $53 \mathrm{c}$ & - & -- & Important to close friends to play sports \\
\hline $70 d$ & $53 d$ & - & -- & Important to close friends to get good grades \\
\hline $70 \mathrm{e}$ & $53 \mathrm{e}$ & -. & -- & important to close friends to be popular \\
\hline $70 f$ & $53 f$ & - & -- & Imponant to close friends to finish high school \\
\hline $70 \mathrm{~g}$ & $53 \mathrm{~g}$ & .. & -- & important to close friends to have a steady boy/girlfriend \\
\hline
\end{tabular}


BY.Fl.Stualent Component

Dara Filc Liser's Manual

Question Number Question Wording

\section{FFS \# DOQ \# BYS \# HS\&B \#}

\begin{tabular}{|c|c|c|c|c|}
\hline $70 \mathrm{~h}$ & $53 \mathrm{~h}$ & -- & -- & Imporiant to close friends to be willing to party. get wild \\
\hline $70 i$ & $53 i$ & -- & -- & Important to close friends to continue their education \\
\hline $70 \mathrm{j}$ & $53 \mathrm{j}$ & -- & -- & Important to close friends to participate in religious activities \\
\hline $70 \mathrm{k}$ & $53 k$ & -- & -- & Imporant to close friends to do community work, volunteer \\
\hline 701 & 531 & - & -- & Important to close friends to have as steady job \\
\hline $71 a$ & $59 a$ & -- & -- & Person admire most is popular \\
\hline $7 ! b$ & $59 \mathrm{~b}$ & -- & -- & Person admire most is honest \\
\hline $71 \mathrm{c}$ & $59 \mathrm{c}$ & - & -- & Person admire most dresses well \\
\hline $71 d$ & $59 \mathrm{~d}$ & -- & -- & Person admire most is intelligent \\
\hline $71 \mathrm{e}$ & $59 \mathrm{e}$ & - & -- & Person admire most understands me \\
\hline $71 f$ & $59 f$ & -- & -- & Person admire most drives a nice car \\
\hline $7 \lg$ & $59 \mathrm{~g}$ & - & - & Person admire most has an important job \\
\hline $7 \mathrm{lh}$ & $59 \mathrm{~h}$ & - & - & Person admire most makes a lot of money \\
\hline $7 \mathrm{Ii}$ & $59 \mathrm{i}$ & - & - & Person admire most is good at sports \\
\hline $71 \mathrm{j}$ & $59 \mathrm{j}$ & - & - & Person admire most thinks about important things like I do \\
\hline $71 \mathrm{k}$ & $59 k$ & - & - & I do not admire anyone \\
\hline 72 & 60 & - & -- & Relationship to person admire most \\
\hline 73 & 58 & - & -- & Age groups of friends \\
\hline 74 & 61 & - & - & Important to be married before having sex \\
\hline 75 & 62 & - & 81 & Consider having a child if not married \\
\hline 76 & 63 & -- & -- & Have children of own \\
\hline 77 & 66 & 43 & $\cdots$ & Cigarettes smoked daily \\
\hline $78 \mathrm{a}$ & $67 a$ & - & - & Occasions drank alcoholic beverages in lifetime \\
\hline $78 b$ & $67 b$ & - & - & Occasions drank alcoholic beverages in the last year \\
\hline $78 c$ & $67 \mathrm{c}$ & - & -- & Occasions drank alcoholic beverages in the last month \\
\hline 79 & 68 & - & -- & Times had five or more drinks in a row in the last two weeks \\
\hline $80 \mathrm{Aa}$ & $69 \mathrm{Aa}$ & - & -- & Occasions used marijuana in lifetime \\
\hline $80 \mathrm{Ab}$ & $69 \mathrm{Ab}$ & - & - & Occasions used marijuana in the last year \\
\hline $80 \mathrm{AC}$ & $69 \mathrm{AC}$ & - & - & Occasions used marijuana in the last month \\
\hline $80 \mathrm{Ba}$ & $69 \mathrm{Ba}$ & - & -- & Occasions used cocaine in lifetime \\
\hline $80 \mathrm{Bb}$ & $69 \mathrm{Bb}$ & - & -- & Occasions used cocaine in the last year \\
\hline $80 \mathrm{Bc}$ & $69 \mathrm{BC}$ & - & -- & Occasions used cocaine in the lase month \\
\hline 81 & 70 & -- & 92 & Religious background \\
\hline 82 & 71 & - & 93 & How often attended religious services in the past year \\
\hline 83 & 72 & -- & 94 & Think of self as religious person \\
\hline 84 & 73 & -- & -- & Currentiy or ever employed \\
\hline 85 & 74 & $53^{\circ}$ & - & Hours worked per week \\
\hline 86 & 75 & -- & -- & How many hours worked are on the weekend \\
\hline 87 & 76 & 54 & 27 & Kind of work \\
\hline 88 & 77 & -- & .. & Earnings per hour \\
\hline 89 & 8.3 & -. & 98 & Have a iwin \\
\hline 90 & 84 & 33 & $97 a, h$ & Number of older brothers and sisters \\
\hline
\end{tabular}

Question is not idenica! across survey instruments. but may be made comparable by collapsing response categories. 
BY.Fl:Student Component Dara File User's Manual

\section{Question Number}

Question Wording

\section{FFS \# DOQ \# BYS \# HS\&B \#}

\begin{tabular}{|c|c|c|c|c|}
\hline 91 & 85 & -- & $97 d, e$ & Number of younger brothers and sisters \\
\hline $92 \mathrm{a}$ & $86 a$ & $8 \mathrm{a}$ & $36 \mathrm{~b}$ & Father lives in the same household with me \\
\hline $92 b, c$ & $86 b, c$ & $8 b$ & $36 c$ & Other adult male (stepfather) lives in the same household with me \\
\hline $92 d$ & $86 d$ & $8 \mathrm{c}$ & $36 d$ & Mother lives in the same household with me \\
\hline $92 \mathrm{e}, \mathrm{f}$ & $86 e, f$ & $8 d$ & $36 \mathrm{e}$ & Other adult female (stepmother) lives in same household with me \\
\hline $92 \mathrm{~g}$ & $86 \mathrm{~g}$ & - & $36 \mathrm{~h}$ & Husband/wife lives in the same household with me \\
\hline $92 \mathrm{~h}$ & $86 \mathrm{~h}$ & -- & - & Boy/girlfriend lives in the same household with me \\
\hline $92 i$ & $86 i$ & -. & $36 \mathbf{i}$ & My child or children live in the same household with me \\
\hline $93 a, b$ & $87 a, b$ & $8 e^{\cdot}$ & $36 f$ & Number of brothers/sisters living in the same household with me \\
\hline $93 \mathrm{c}$ & $87 \mathrm{c}$ & $8 \mathrm{~g}^{\circ}$ & $36 g^{*}$ & Number of grandparents living in same household with me \\
\hline $93 d, e$ & $87 d, e$ & $8 \mathrm{~h}^{\circ}$ & $36 \mathrm{j}^{\circ}$ & Number of other relatives living in same household \\
\hline $93 f, g$ & $87 f, g$ & $8 i^{\circ}$ & $36 \mathrm{k}^{\circ}$ & Number of non-relatives living in same household \\
\hline 94 & 89 & - & - & How many brothers and sisters lef school before graduating \\
\hline 95 & 90 & - & - & Babysit own child, younger siblings, or other relatives \\
\hline 96 & 91 & - & - & Hours per day responsible for their care \\
\hline 97 & 92 & - & - & Days of school missed per month because babysitting \\
\hline 988 & $93 \mathrm{~A}$ & - & - & I get ajong with all of the people in my family \\
\hline $98 \mathrm{~b}$ & $93 B$ & -- & - & I don't get along with my father \\
\hline $98 c$ & $93 c$ & -- & - & I don't get along with another male guardian \\
\hline $98 d$ & 93d & - & - & I don't get along with my mother \\
\hline $98 \mathrm{e}$ & $93 e$ & - & - & I don't get along with another female guardian \\
\hline $98 f$ & $93 f$ & - & - & I don't get along with my brother(s) \\
\hline $98 \mathrm{~g}$ & $9 \hat{j g}$ & - & - & I don't get along with my sister(s) \\
\hline $98 \mathrm{~h}$ & $93 \mathrm{~h}$ & - & - & I don't get along with my grandparent(s) \\
\hline $98 i$ & $93 \mathrm{i}$ & - & - & I don't get along with other relative(s) \\
\hline $99 a$ & $94 a$ & -- & - & My fanily moved to a new home \\
\hline $99 b$ & $94 c$ & - & -- & One of my parents got married \\
\hline $99 c$ & $94 b$ & -- & -- & My parents got divorced or separated \\
\hline $99 \mathrm{~d}$ & $94 d$ & -- & - & My mother lost her job \\
\hline $99 \mathrm{e}$ & $94 \mathrm{e}$ & -- & - & My father lost his job \\
\hline $99 f$ & $94 f$ & -- & -- & My mother started to work \\
\hline $99 \mathrm{~g}$ & $94 \mathrm{~g}$ & -- & - & My father stanted to work \\
\hline $99 \mathrm{~h}$ & $94 \mathrm{~h}$ & $-\cdot$ & -- & I became seriously ill or disabled \\
\hline $99 i$ & $94 i$ & -- & -. & My father died \\
\hline $99 j$ & $94 j$ & -- & -- & My mother died \\
\hline $99 k$ & $94 k$ & -- & -- & A close relative died \\
\hline 991 & 941 & -- & - & One of my unmarried sisters got pregnant \\
\hline $99 m$ & $94 m$ & -- & -. & One of my brothers or sisters dropped out of school \\
\hline $99 n$ & $94 n$ & -. & -- & My family went on welfare \\
\hline 990 & 940 & -. & -- & My family went off welfare \\
\hline $99 p$ & $94 \mathrm{p}$ & -. & -- & My family stayed on welfare \\
\hline $99 q$ & $94 \mathrm{q}$ & -. &.- & A family member became sernously ill or disabled \\
\hline
\end{tabular}

- Question is not identical across survey instruments. but may be made comparable by collapsing response categories 
Br.Fl:Sndent Compencm

Data Filc User's Mamual

Question Number Question Wording

\section{FFS \# DOQ \# BYS \# HS\&B \#}

\begin{tabular}{|c|c|c|c|c|}
\hline $99 r$ & $94 r$ & -- & .. & My family was homeless for a period of ume \\
\hline $99 \mathrm{~s}$ & $94 \mathrm{~s}$ & -- & -- & None apply \\
\hline $100 \mathrm{a}$ & -- & $38 \mathrm{a}$ & -- & How often parents check on whether have done homework \\
\hline $100 \mathrm{e}$ & -. & $38 b$ & -- & How often parents require work or chores around the home \\
\hline $100 \mathrm{f}$ & -- & $38 \mathrm{c}$ & $-\cdot$ & How often parents limit the time spent watching TV \\
\hline $100 \mathrm{~g}$ & - & $38 \mathrm{~d}$ & -- & How often parents limit the time with friends on school nights \\
\hline $102 a$ & $95 \mathrm{a}$ & -- & -- & How much my parents try to find out who my friends are \\
\hline $102 b$ & $95 b$ & -. & $-\cdot$ & How much my parents try to find out where 1 go at night \\
\hline $102 c$ & $95 \mathrm{c}$ & $-\cdot$ & - & How much my parents try to find out how I spend my money \\
\hline $102 d$ & $95 d$ & -- & -- & How much my parents try to find out what I do with my time \\
\hline 103 & 96 & -- & $-\bullet$ & My parents know the parents of my closest friends \\
\hline $104 a$ & $98 \mathrm{a}$ & -- & - & Who decides how late at night I can stay out \\
\hline $104 b$ & $98 b$ & -- & -- & Who decides which friends I can spend time with \\
\hline $104 c$ & $98 \mathrm{~g}$ & -- & - & Who decides what classes I take in school \\
\hline $104 d$ & $98 \mathrm{c}$ & -- & -- & Who decides whether I have a job \\
\hline $104 \mathrm{e}$ & $98 d$ & - & - & Who decides at what age I can leave school \\
\hline $104 f$ & $98 \mathrm{e}$ & - & - & Who decides how I spend my money \\
\hline $104 \mathrm{~g}$ & $98 f$ & -- & -- & Who decides whether I can date \\
\hline $107 a$ & -- & $55 \mathrm{c}$ & - & How often parents received a warning about my attendance \\
\hline 1070 & -- & $55 d$ & -- & How often parents received a warning about my gredes \\
\hline $107 c$ & - & $55 \mathrm{e}$ & -- & How often parents received a warning about my behavior \\
\hline $108 a$ & $99 a$ & $39 a^{*}$ & -. & My parents trust me to do what they expect \\
\hline $108 \mathrm{~b}$ & 996 & $39 b^{\circ}$ & -- & I do not know WHY I am supposed to do what they tell me \\
\hline $108 c$ & $99 c$ & $39 c^{\circ}$ & -- & I often count on my parents to solve problems for me \\
\hline $108 \mathrm{~d}$ & $99 d$ & -- & - & I think I will be a source of pride to my parents in the future \\
\hline $108 \mathrm{e}$ & $99 \mathrm{e}$ & -- & -- & My parents get along well with each other \\
\hline $108 f$ & $99 f$ & -- & $-\cdot$ & When I grow up I will have a family similar to my own \\
\hline 109 & 100 & -- & -- & Ran away from home for a week or longer last two years \\
\hline ADDla & ADDla & - & -. & Occasions used LSD in lifetime \\
\hline ADDIb & ADDIb & -- & -- & Occasions used LSD in the last year \\
\hline ADDlc & ADDic & -- & -- & Occasions used LSD in the last month \\
\hline $\mathrm{ADD} 2 \mathrm{a}$ & $\mathrm{ADD} 2 \mathrm{a}$ & -- & -- & Occasions used amphetamines in lifetime \\
\hline $\mathrm{ADD} 2 \mathrm{~b}$ & $\mathrm{ADD} 2 \mathrm{~b}$ &.- & -- & Occasions used amphetamines in the last year \\
\hline$A D D 2 c$ & $\mathrm{ADD} 2 \mathrm{c}$ & -- & -- & Occasions used amphetamines in the last month \\
\hline ADD3a & ADD3a & -- & -- & Someone I know stanted using illegal drugs \\
\hline$A D D 3 b$ & ADD3b & -- & - & Someone offered to sell me illegal drugs \\
\hline$A D D 3 c$ & $\operatorname{ADD} 3 \mathrm{c}$ & .. & -- & A member of my family used illegal drugs \\
\hline$A D D 3 d$ & ADD3d & -- & -- & A member of my family was in a rehabilitarion program \\
\hline
\end{tabular}

- Ouestion is not identical across survey insiruments but inay be made comparable by collapsing response categones 
Table 1. Summary of NELS:88 Populations, Samples, Level of Analyses, Sample Identification Flags, and Weights

\section{Population of Interest \\ Longitudinal Cohort (Panel): The \\ population of 1988 \\ eighth graders two \\ years later.}

Eight grade cross. section: The

population of all

students enrolled

in the eighth grade

in 1988.

\section{Sample and Sample}

$\underline{\mathbf{N}}$

Base year retained sample members

who completed

both a base year

and first follow-up

questionnaire.

$N=17.424$. Note:

undercoverage 3

bias: $5 \%$ of

potential base year

sample excluded.

\section{Base year selected}

sample members

who participated in

the base year.

$N=24.599$. Note:

undercoverage

bias: $5 \%$ of

potential base year

sample excluded.

\section{Level of Angirsis}

Cross-wave,

longitudinal level

of analysis.

\section{Cross-sectional}

level of analysis

\section{Sample ID Flag}

Solect the panel

\section{(FIPANFLG $=1$ ).}

\section{Use the base year \\ student data file \\ and select for}

BYOFLG $=1$

\section{Weight}

Use the panel

weight

(FIPNLWT)
Use the base yea questionnaire

weight (BYOWT). 
Table 1. (cont.) Summary of NELS:88 Populations, Samples, Level of Aaalyses, Sample Identification Flags, and Weights

\begin{tabular}{|c|c|c|c|c|}
\hline $\begin{array}{l}\text { Population of } \\
\text { Interest }\end{array}$ & $\begin{array}{l}\text { Sample and Sample } \\
\underline{N}\end{array}$ & Level of Analysis & Sample ID Flag & Weight \\
\hline $\begin{array}{l}\text { Tenth grade cross- } \\
\text { section: The } \\
\text { population of all } \\
\text { siudents enrolled in } \\
\text { the tenth grade in } \\
1990 \text {. }\end{array}$ & $\begin{array}{l}\text { Representative } \\
\text { sample of students } \\
\text { enrolled in tenth } \\
\text { grade in the spring } \\
\text { term of } 1990 \text {. } \\
\mathrm{N}=17.544 \text {. } \\
\text { Includes freshened } \\
\text { students and } \\
\text { excludes dropouts } \\
\text { and out-of- } \\
\text { sequence sample } \\
\text { members. }\end{array}$ & $\begin{array}{l}\text { Cross-sectional } \\
\text { analysis: Trend } \\
\text { analyses with } \\
\text { HS\&B } 1980 \\
\text { sophomores and } \\
\text { F1 } 1990 \\
\text { sophomores. }\end{array}$ & $\begin{array}{l}\text { Select for } \\
\text { F1QFLG }=1 \text { and } \\
\text { F1SEOFLG }=0\end{array}$ & $\begin{array}{l}\text { Use the first } \\
\text { lollow-up } \\
\text { questionnaire } \\
\text { weight (F1OWT). }\end{array}$ \\
\hline $\begin{array}{l}\text { First follow-up } \\
\text { cross-section: The } \\
\text { populatlon of all } \\
\text { first follow-up } \\
\text { eligible persons } \\
\text { who were elther in } \\
\text { the elghth grade } \\
\text { durng the } 1987 \text {. } \\
1988 \text { school year } \\
\text { or were in the } \\
\text { tenth grade during } \\
\text { the } 1989-1990 \\
\text { school year. }\end{array}$ & $\begin{array}{l}\text { All first follow-up } \\
1990 \text { sample } \\
\text { members: } \\
\text { combines } 1988- \\
\text { eligible eighth- } \\
\text { grade cohort and } \\
1990 \text { tenth-grade } \\
\text { freshened sample. } \\
\mathrm{N}=19.264 \text {. }\end{array}$ & . & $\begin{array}{l}\text { Select for } \\
\text { FISTAT }=0\end{array}$ & $\begin{array}{l}\text { Use the first } \\
\text { follow-up } \\
\text { questionnaire } \\
\text { weight (F) QWT). }\end{array}$ \\
\hline
\end{tabular}


Questions appearing in first follow-up abbreviated questionnaires

\begin{tabular}{|c|c|c|c|c|c|}
\hline & STUDENT & & DROPOUT & & NEW STUDENT SUPPTEMENT \\
\hline 84 & $\begin{array}{l}\text { Respondent's most recent employment } \\
\text { status }\end{array}$ & 63 & Does respondent have children & 17 & $\begin{array}{l}\text { Degree of respondent's English } \\
\text { proficlency }\end{array}$ \\
\hline 85 & $\begin{array}{l}\text { Number of hours worked per week at } \\
\text { current or most recent job }\end{array}$ & 73 & $\begin{array}{l}\text { Respondent's most recemt employment } \\
\text { status }\end{array}$ & 20 & $\begin{array}{l}\text { Educutional attainment of respondent's } \\
\text { parems }\end{array}$ \\
\hline 88 & $\begin{array}{l}\text { Respondent's hourly salary at current } \\
\text { of most recent job }\end{array}$ & 74 & $\begin{array}{l}\text { Number of hours worked par week at } \\
\text { current job }\end{array}$ & 22 & Was respondent ever held back \\
\hline \multirow[t]{2}{*}{92.93} & $\begin{array}{l}\text { Other people livino in respondent's } \\
\text { household }\end{array}$ & 77 & $\begin{array}{l}\text { Respondent's hourly salery at current } \\
\text { of most recent job }\end{array}$ & & \\
\hline & & 86-87 & $\begin{array}{l}\text { Other people living ho respondent's } \\
\text { household }\end{array}$ & & \\
\hline
\end{tabular}


APPENDIX G

NELS VARIABLES 
NELS Variables

TABLE 1: Student Demographics/Background Variables

Student Demographics

Gender

Race

SES

$R$ lives with father/mother
Personality/Self Assessment

Locus of control

$R$ feels good about Self

$R$ doesn't have enough control over life

$R$ feels s/he is a person of worth

$R$ is able to do things as well as others

$R$ is satisfied with self

$R$ feels useless at times

$R$ doesn't have much to be proud of

Non-School Activities

How often respondent:

visits hangout

plays ball, sports

uses P/C

talks on the phone

drives/rides around

TABLE 2: School Demographics/ School Climate Variables

Student-Teacher Relations

Students get along well w/teachers

Teachers are interested in students

When $\mathrm{R}$ works hard, teachers praise
School Demographics

Urbanicity of school

Entire school

enrollment

Region of the country

\section{Level of Expectations-Core Classes}

How often $R$ 1) is asked to show understanding; 2) works hard; and 3)feels challenged in math, English, history, and science 
TABLE 3: Personal School Experiences/ Future Plans Variables

School Recognition

$\mathrm{R}$ has not won any awards

$R$ elected officer of school class

$R$ won an academic honor

$R$ participated in science/math fair

$R$ received recognition for good grades

work

School Achievement Attitudes

Participation

OK to work hard for good grades

How many years to graduate

$R$ sure will graduate from HS

R sure further ed after $H S$

How important are good grades

Absentee Policy

When absent

-school called home -school sent letter teacher helped R
Negative Behavior Patterns

How many times R:

-was late for class

-skipped a class

-got in trouble

- was suspended

-went to class w/o

\section{School Sports/Activity}

R played school team/ individual sport

$R$ participated in:

-school band/orch

-school play

-school

-yearbook/newspaper

-school hobby/acad

club

TABLE 4: Home/ Parent Environment Variables

\section{Parent Expectations}

\section{Support}

How far in sch. dad/mom wants $R$ to go

Parents' highest ed level
Parent Strategies-Academic

How often parents check/help w/ HW

Special privileges for good grades

Parents limit privileges for poor grades

Parents limit time with friends 
Parents' School Involvement How often parents:

-attend sch. meetings

-phone teachers

-attend sch. event

-received acad.warning
Parent-Student School

Involvement

How often parents:

-discuss school courses w/ stds.

-discuss grades w/ students

-discuss plans for college

-discuss preparation for

SAT/ACT 
APPENDIX I

STATISTICAL DATA/

FREQUENCIES 


\section{Appendix 1: $\quad$ Students get along well with teachers: as a function of gender, race, and SES.}

EISEX COMPOSITE SEX by FIS7A STUDENTS GET ALONG WELL WITH TEACHERS

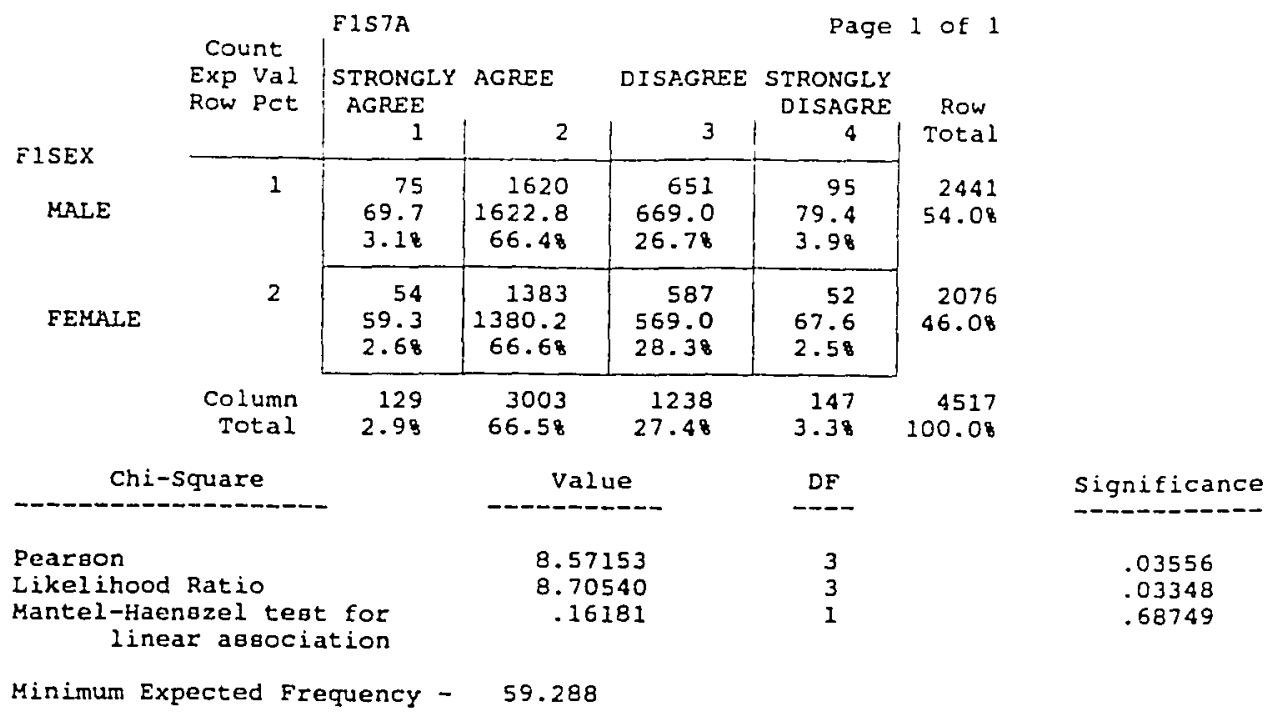

Number of Misaing Observations: 127

FIRACE COMPOSITE RACE bY FISTA STUDENTS GET ALONG WELL WITH TEACHERS

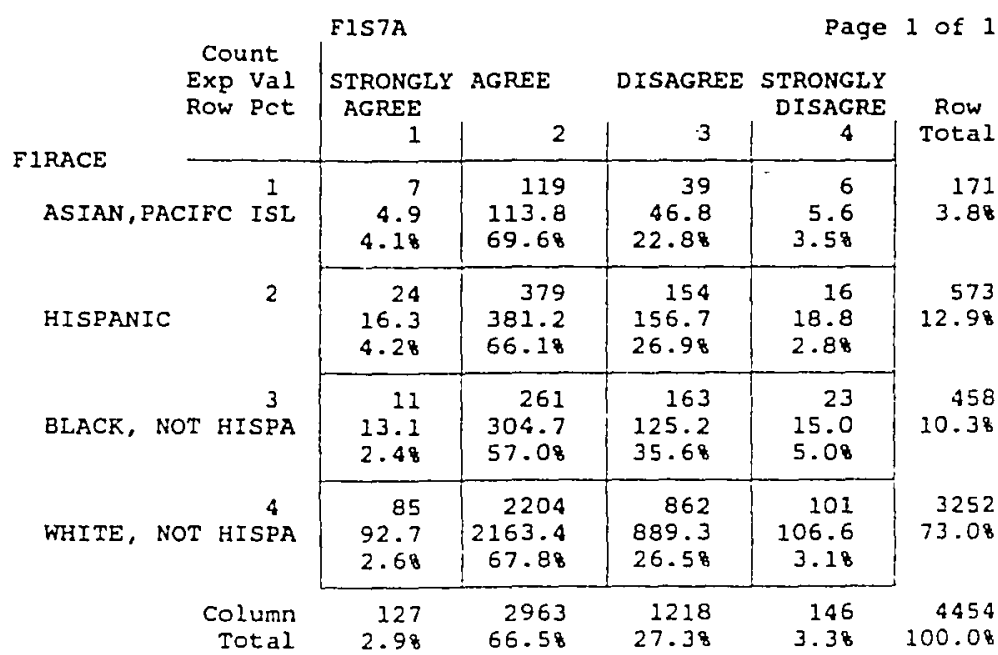

\begin{tabular}{|c|c|c|c|}
\hline Chi-Square & Value & DF & Significanc \\
\hline Pearson & 31.30318 & 9 & .00026 \\
\hline Likelihood Ratio & 29.60129 & 9 & .00051 \\
\hline $\begin{array}{r}\text { Mantel-Haengzel tegt for } \\
\text { linear association }\end{array}$ & .01012 & 1 & .91988 \\
\hline
\end{tabular}


LSESQ SOCIO-ECONOMIC QUARTILE

bY FISTA STUDENTS GET ALONG WELL WITH TEACHERS

\begin{tabular}{|c|c|c|c|c|c|c|}
\hline & $\begin{array}{l}\text { Count } \\
\text { Exp VaI } \\
\text { Row PCt }\end{array}$ & $\begin{array}{l}\text { ElSTA } \\
\text { STRONGLY } \\
\text { AGREE } \\
1\end{array}$ & AGREE & DISAGRI & $\begin{array}{c}\text { STRONGLY } \\
\text { DISAGRE } \\
4\end{array}$ & $\begin{array}{l}\text { Row } \\
\text { Total }\end{array}$ \\
\hline QUARTILE & I LOW ${ }^{1}$ & $\begin{array}{r}31 \\
32.2 \\
2.78\end{array}$ & $\begin{array}{r}725 \\
750.6 \\
64.28\end{array}$ & $\begin{array}{r}330 \\
309.4 \\
29.28\end{array}$ & $\begin{array}{r}43 \\
36.7 \\
3.88\end{array}$ & $\begin{array}{r}1229 \\
25.08\end{array}$ \\
\hline QUARTILE & 2 & $\begin{array}{r}31 \\
37.3 \\
2.48\end{array}$ & $\begin{array}{r}859 \\
868.9 \\
65.78\end{array}$ & $\begin{array}{r}376 \\
358.2 \\
28.88\end{array}$ & $\begin{array}{r}41 \\
42.5 \\
3.18\end{array}$ & $\begin{array}{r}1307 \\
28.98\end{array}$ \\
\hline QUARTILE & 3 & $\begin{array}{r}30 \\
34.5 \\
2.58\end{array}$ & $\begin{array}{r}821 \\
803.8 \\
67.98\end{array}$ & $\begin{array}{r}311 \\
331.4 \\
25.78\end{array}$ & $\begin{array}{r}47 \\
39.3 \\
3.98\end{array}$ & $\begin{array}{r}1209 \\
26.88\end{array}$ \\
\hline QUARTILE & 4 HIGH & $\begin{array}{r}37 \\
24.9 \\
4.28\end{array}$ & $\begin{array}{r}598 \\
579.7 \\
68.68\end{array}$ & $\begin{array}{r}221 \\
239.0 \\
25.38\end{array}$ & $\begin{array}{r}16 \\
28.4 \\
1.88\end{array}$ & $\begin{array}{r}872 \\
19.38\end{array}$ \\
\hline & $\begin{array}{r}\text { Column } \\
\text { Total }\end{array}$ & $\begin{array}{r}129 \\
2.98\end{array}$ & $\begin{array}{r}3003 \\
66.58\end{array}$ & $\begin{array}{r}1238 \\
27.48\end{array}$ & $\begin{array}{r}147 \\
3.38\end{array}$ & $\begin{array}{r}4517 \\
100.08\end{array}$ \\
\hline
\end{tabular}

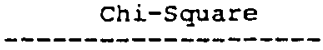

pearson

Iikelihood Ratio

Mantel-Haenszel test for

linear association

Minimum Expected Frequency -
DF

9
9
1

\subsection{3}

22.60606

12.20259

24.903
Significarıce

.00773

.00714

.00048 


\section{Appendix 2: $\quad$ The teaching is good at school: as a function} of gender, race, and SES.

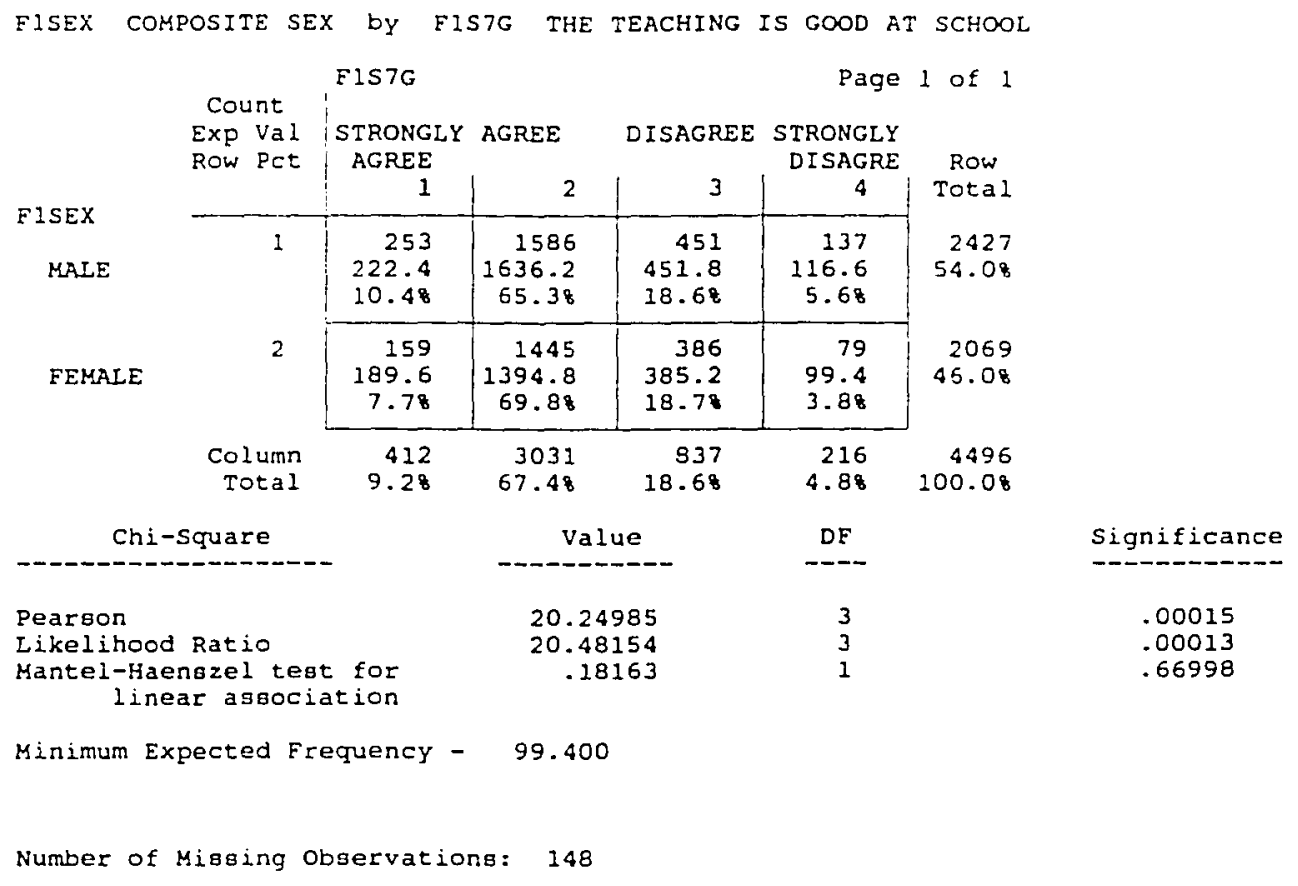




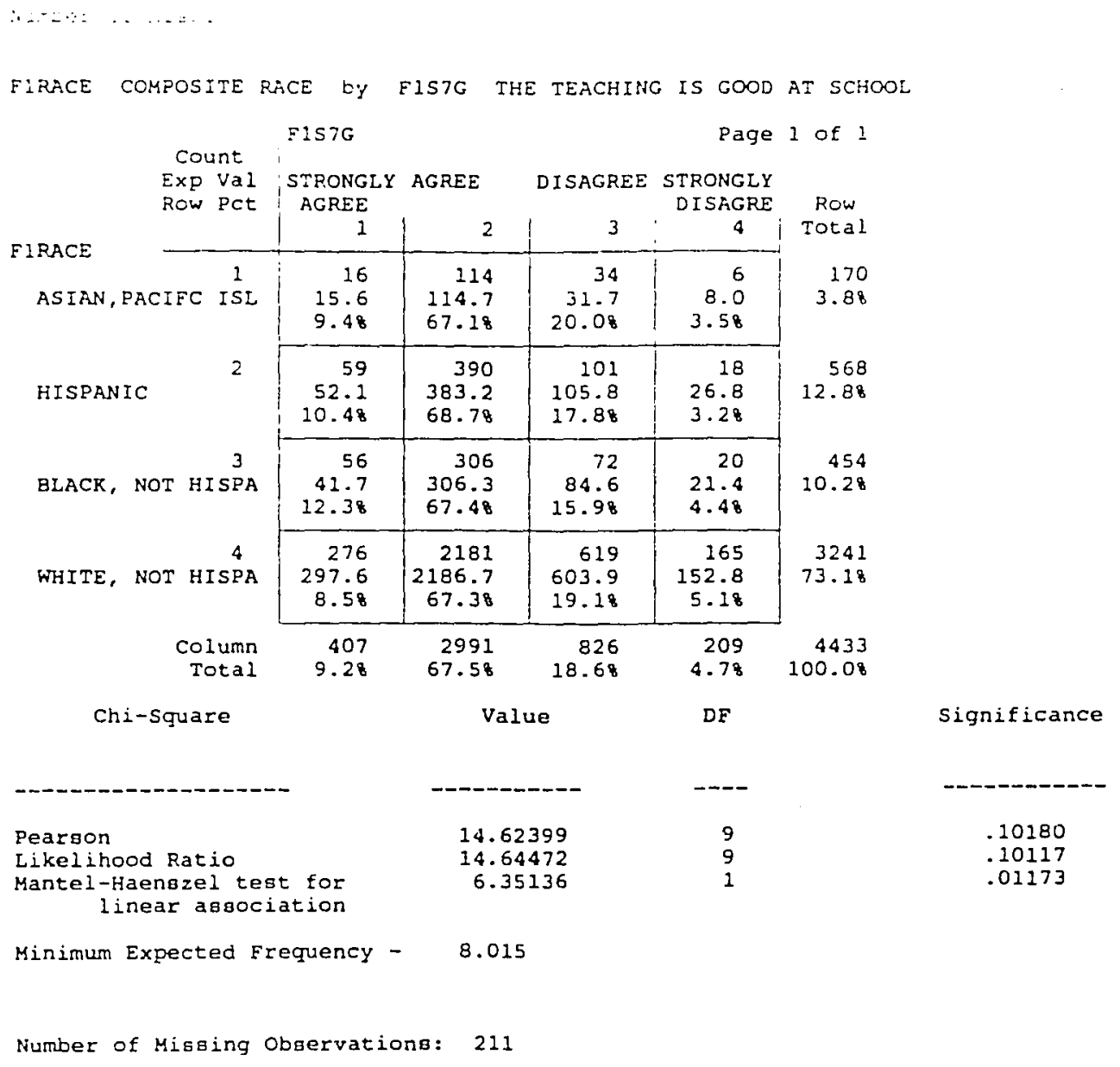




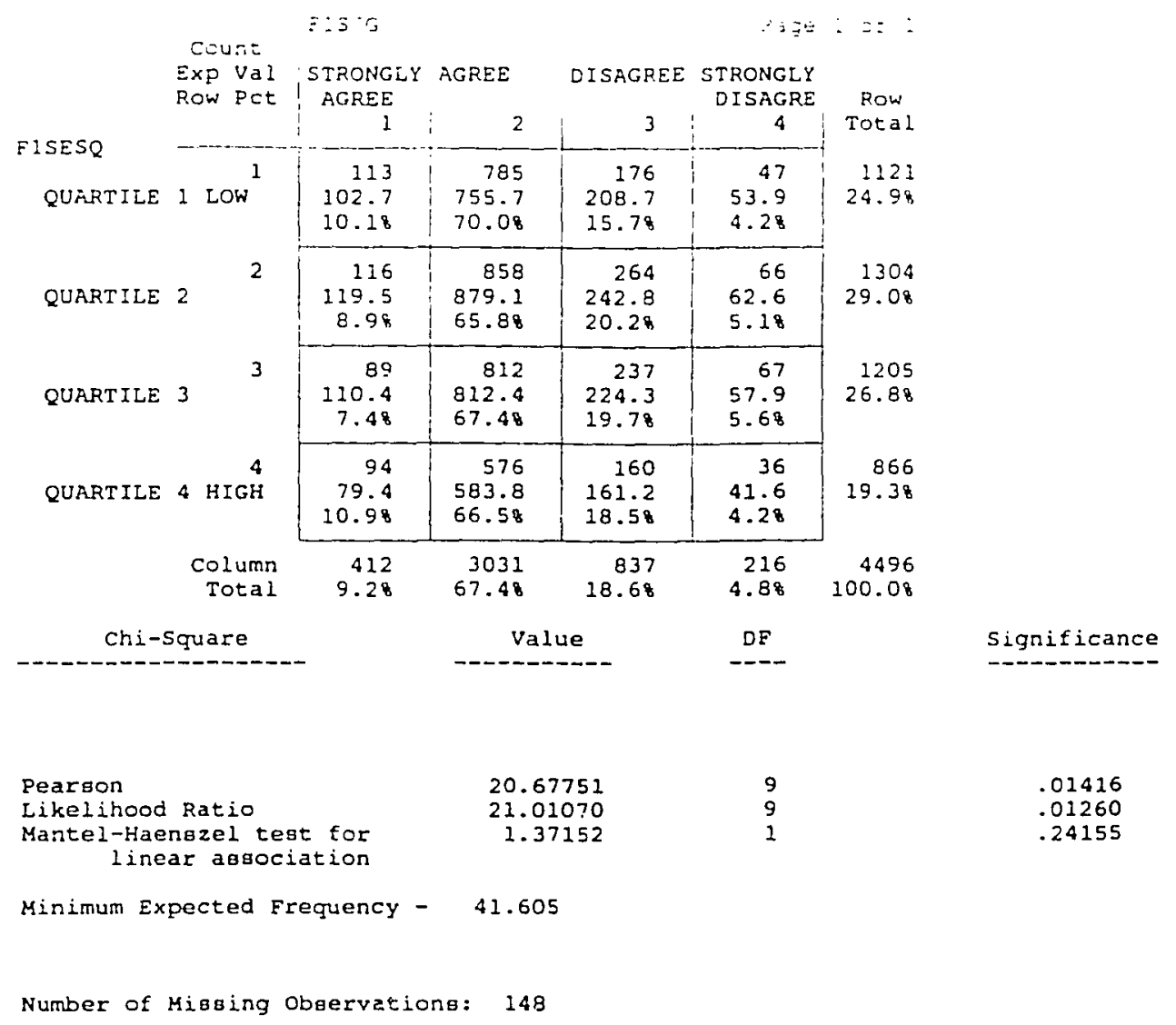


Appendix 3: $\quad$ Teachers are interested in students: as a function of gender, race, and SES.

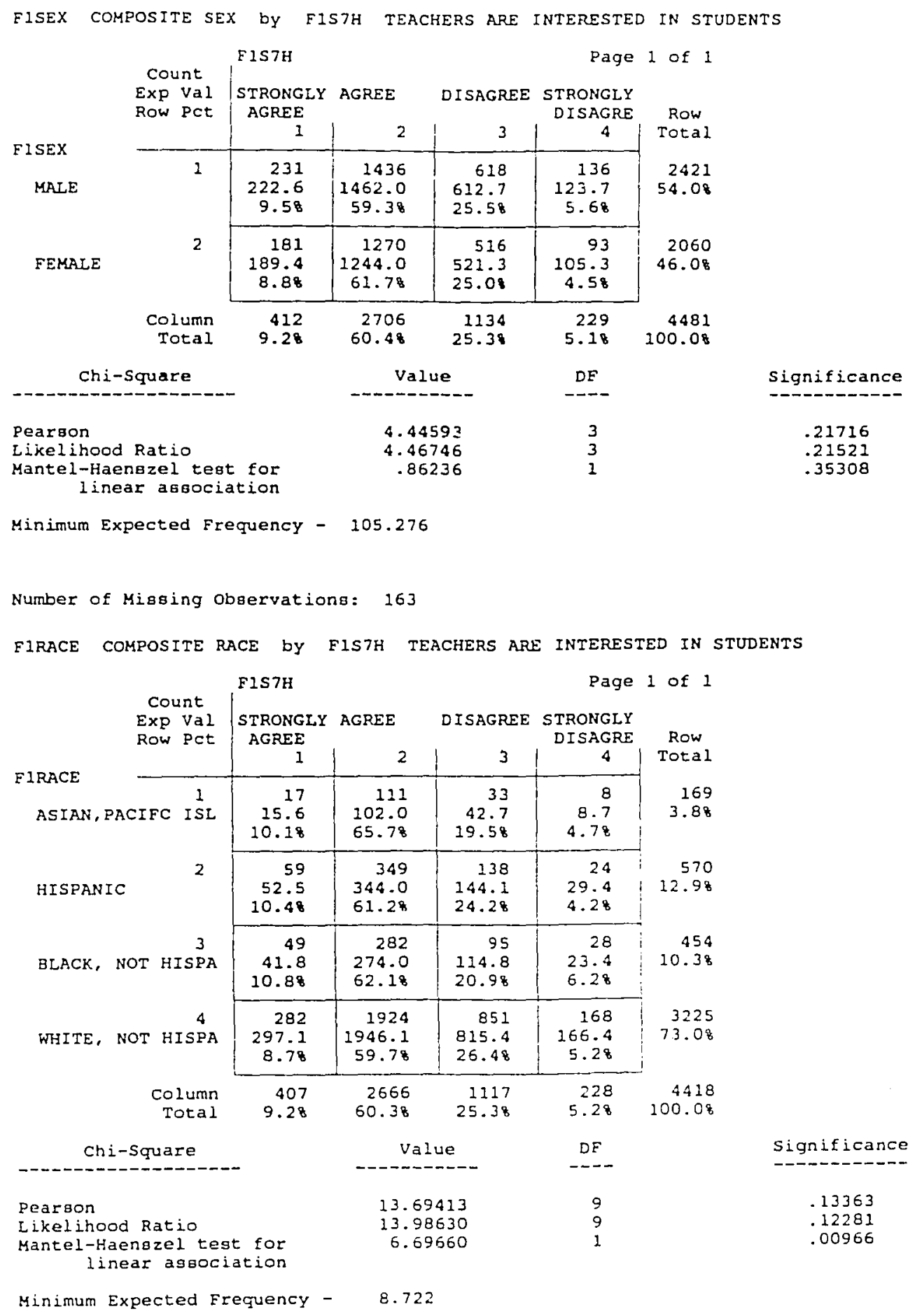




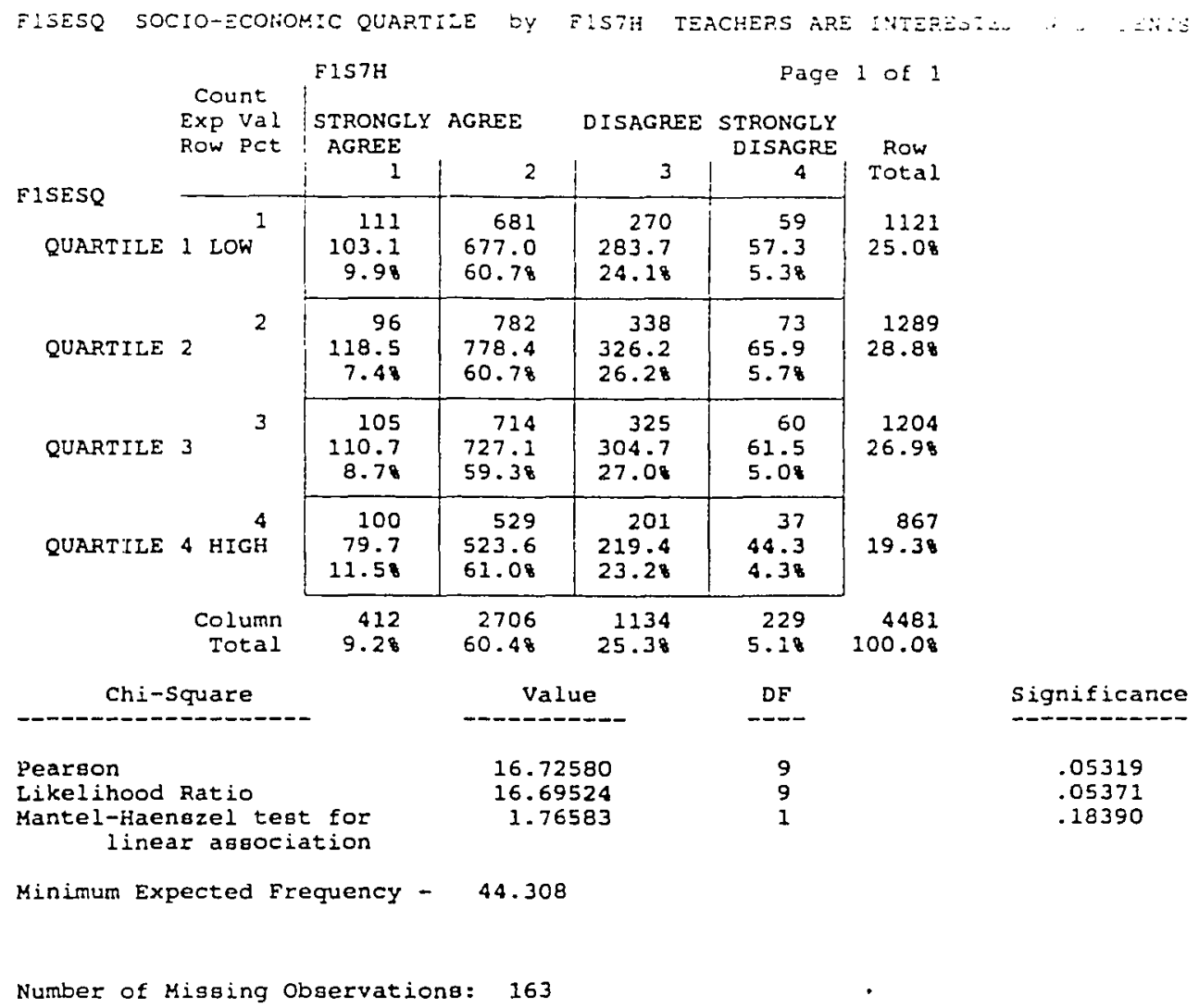


Appendix 4: $\quad$ When $R$ works hard, teachers praise effort: as

a function of gender, race, and SES.

EISEX COMPOSITE SEX bY FISTI WHEN R WORKS HARD TEACHERS PRAISE EFFORT

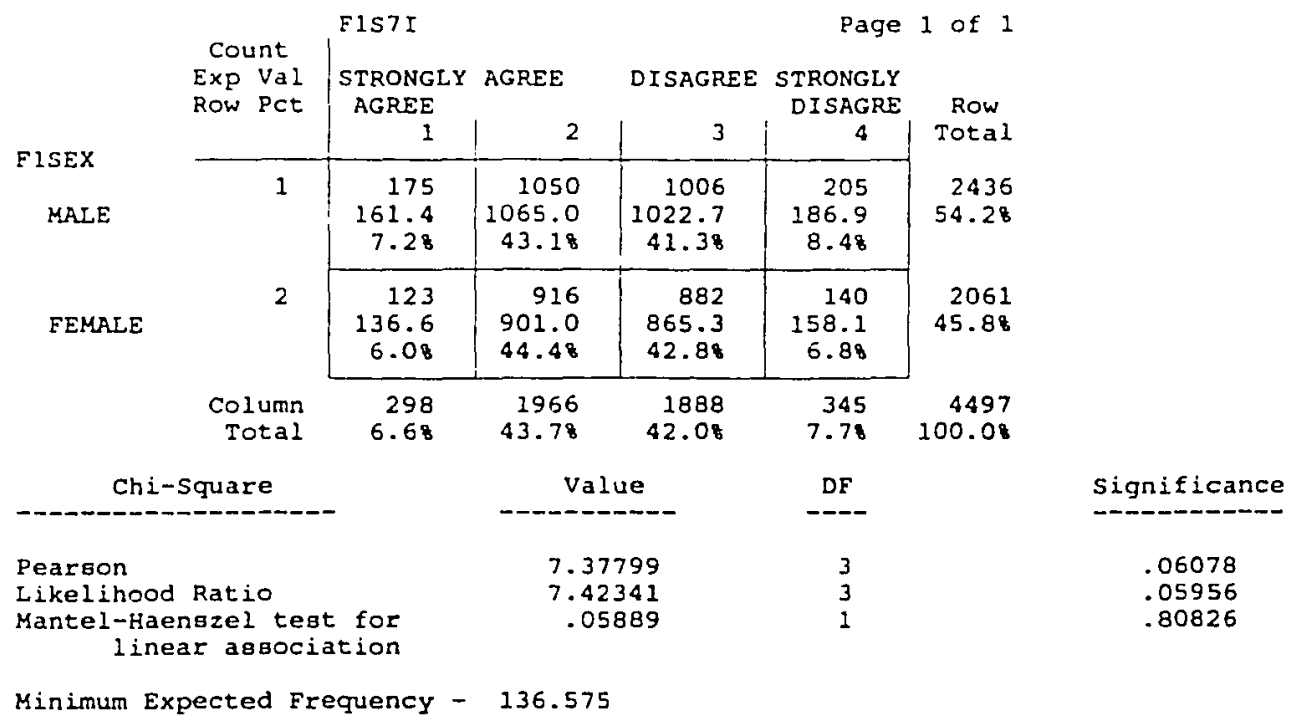

Number of Missing observations: 147

FIRACE COMPOSTTE RACE bY FISTI WHEN R WORKS HARD TEACHERS PRAISE EFFORT

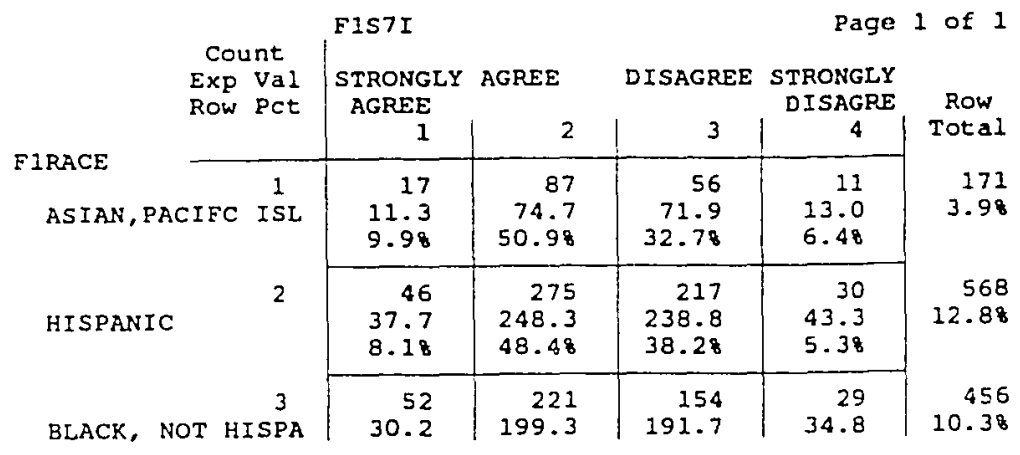

\begin{tabular}{|c|c|c|c|c|c|c|}
\hline \multirow{3}{*}{ WHITE, } & & 11.48 & 48.58 & 33.88 & 6.48 & \multirow[b]{2}{*}{$\begin{array}{r}3239 \\
73.08\end{array}$} \\
\hline & NOT HISPA & $\begin{array}{r}179 \\
214.8 \\
5.58\end{array}$ & $\begin{array}{r}1355 \\
1415.7 \\
41.88\end{array}$ & $\begin{array}{r}1437 \\
1361.6 \\
44.48\end{array}$ & $\begin{array}{r}268 \\
246.9 \\
8.38\end{array}$ & \\
\hline & Column & $\begin{array}{r}294 \\
6.68\end{array}$ & $\begin{array}{r}1938 \\
43.78\end{array}$ & $\begin{array}{r}1864 \\
42.08\end{array}$ & $\begin{array}{r}338 \\
7.68\end{array}$ & $\begin{array}{r}4434 \\
100.08\end{array}$ \\
\hline
\end{tabular}

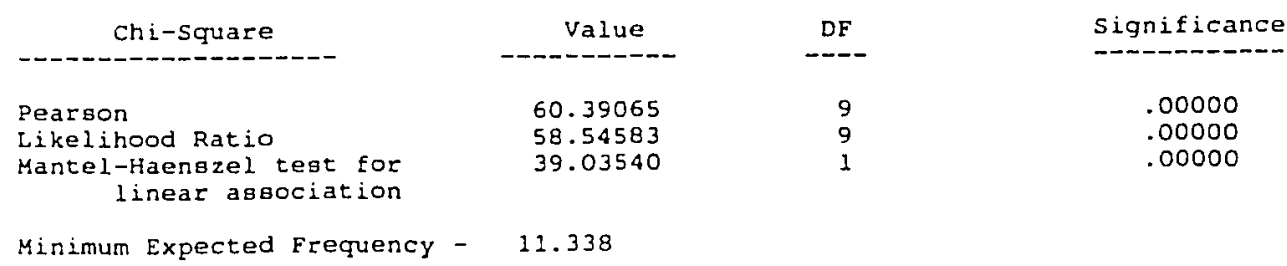




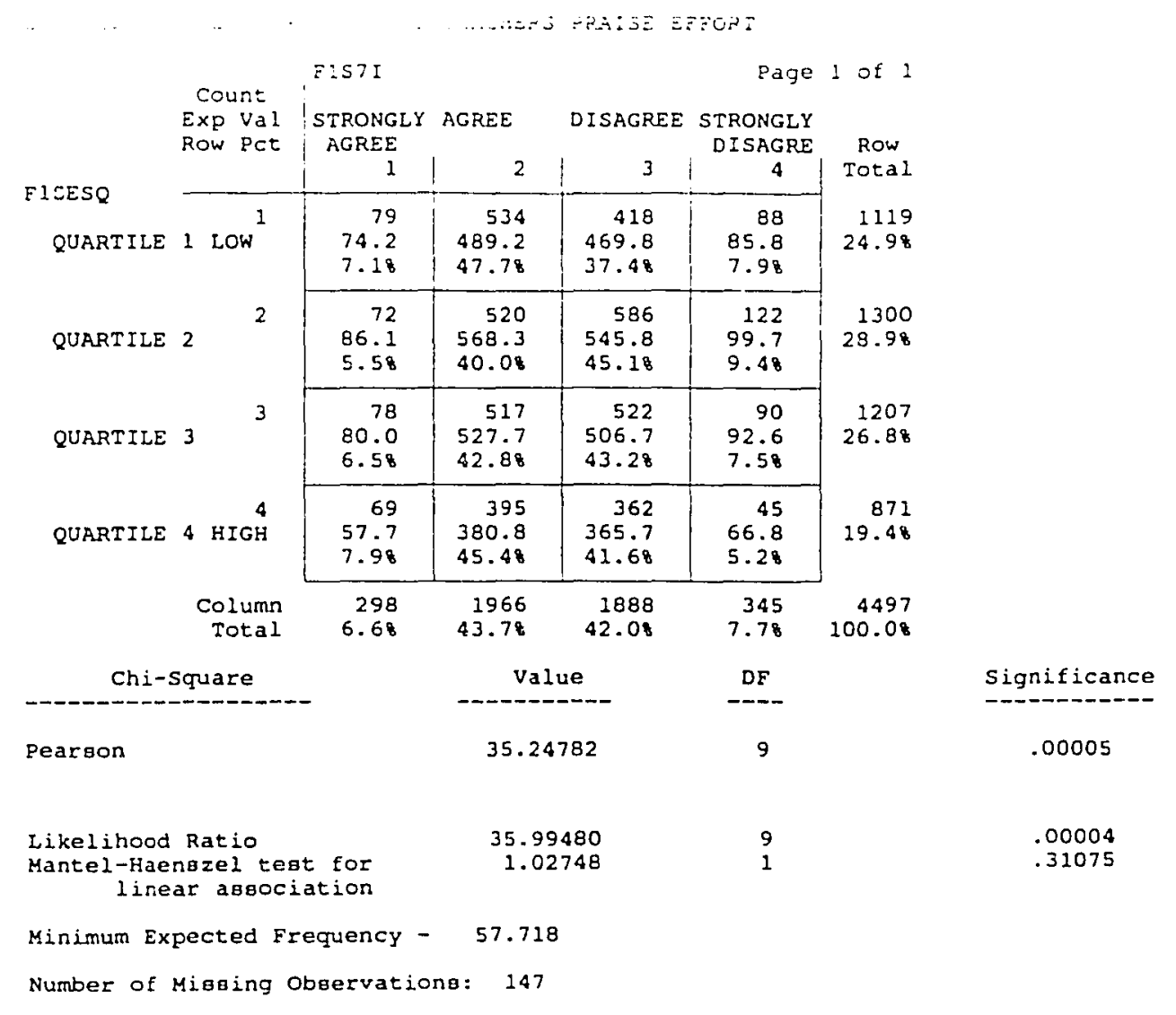




\section{Appendix 5: In class, often feel put down by teachers: as a function of gender, race, and SES. \\ EISEX COMPOSITE SEX bY FISTJ IN CLASS OFTEN FEEL PUT DOWN BY TEACHERS

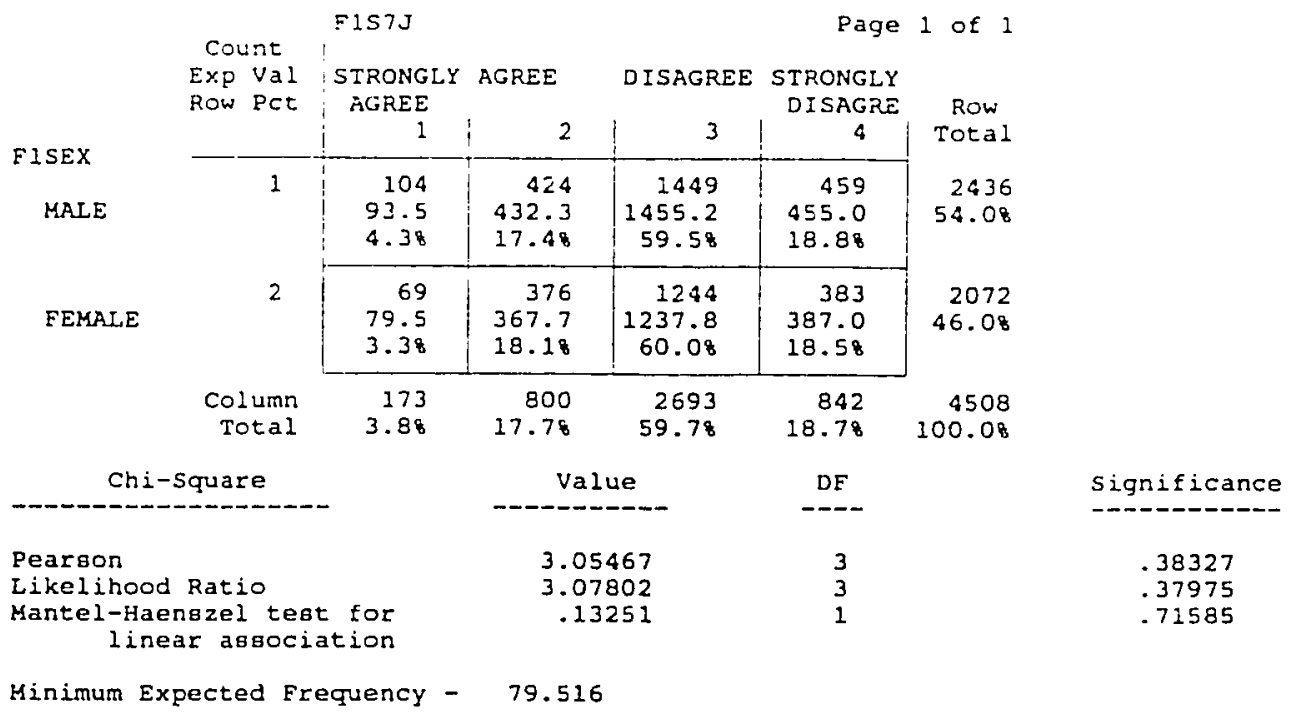

Number of Missing Observations: 136

FIRACE COMPOSITE RACE bY FISTJ IN CLASS OFTEN FEEL PUT DOWN BY TEACHERS

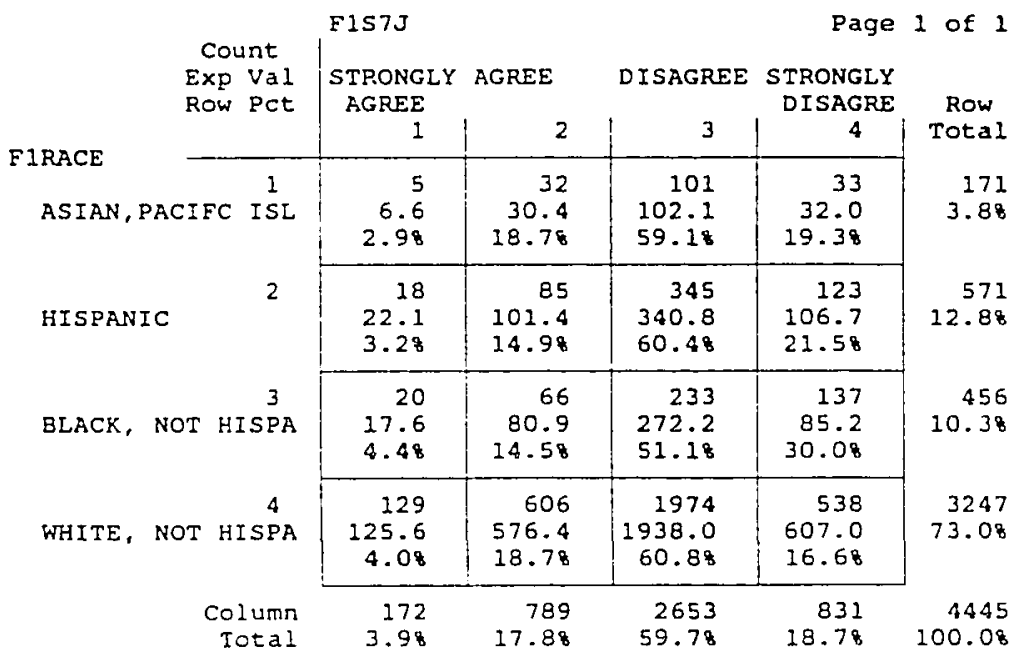

$\begin{array}{lccc}\text { Chi-Square } & \text { Value } & \text { DE } & \text { Significance } \\ \text { Peargon } & -56.70931 & 9 & .00000 \\ \begin{array}{l}\text { Likelihood Ratio } \\ \text { Mantel-Haenszel test for }\end{array} & 52.65425 & 9 & .0000 \\ \text { linear association } & 13.59580 & 1 & .00023 \\ \text { Minimum Expected Frequency - } & 6.617 & & \end{array}$




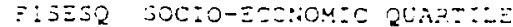

b\% FISTJ ON CLASS OETEN FEEE PUT DOWH BY TEACHERS

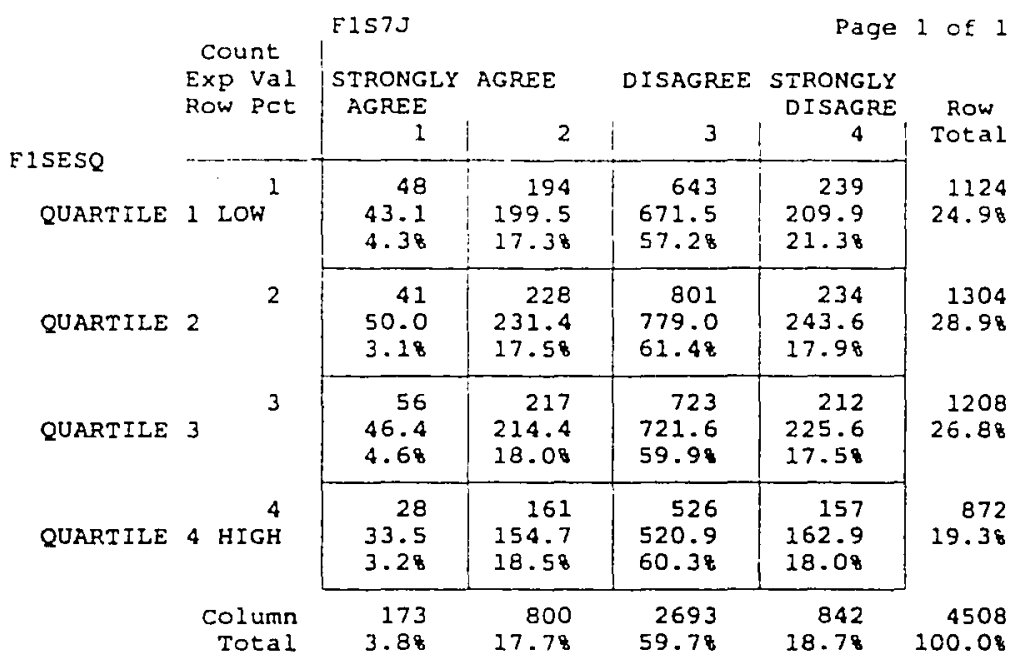

\section{Chi-Square}

Peargon

Likelihood Ratio

Mantel-Haenszel test for

inear association

Minimum Expected Frequency - 33.464
DF

9
Significance

16820

.17404

.21924

Number of Missing Observations: 136 
Appendix 6: $\quad$ Often feel put down by students in class: as a function of gender, race, and SES.

FISEX COMPOSITE SEX bY FISTK OFTEN FEEL PUT DOWN BY STUDENTS IN CLASS

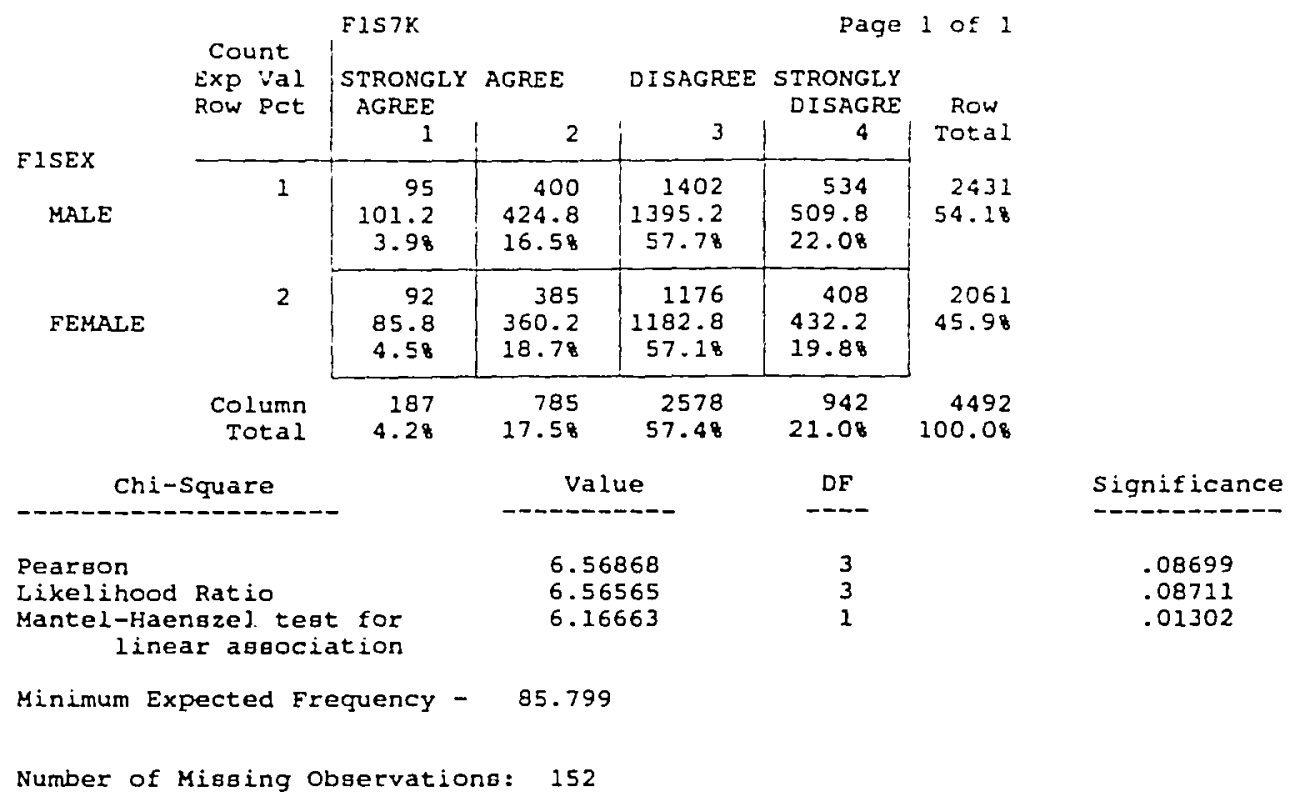




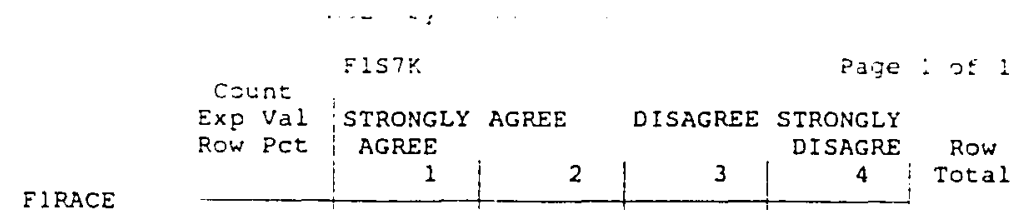

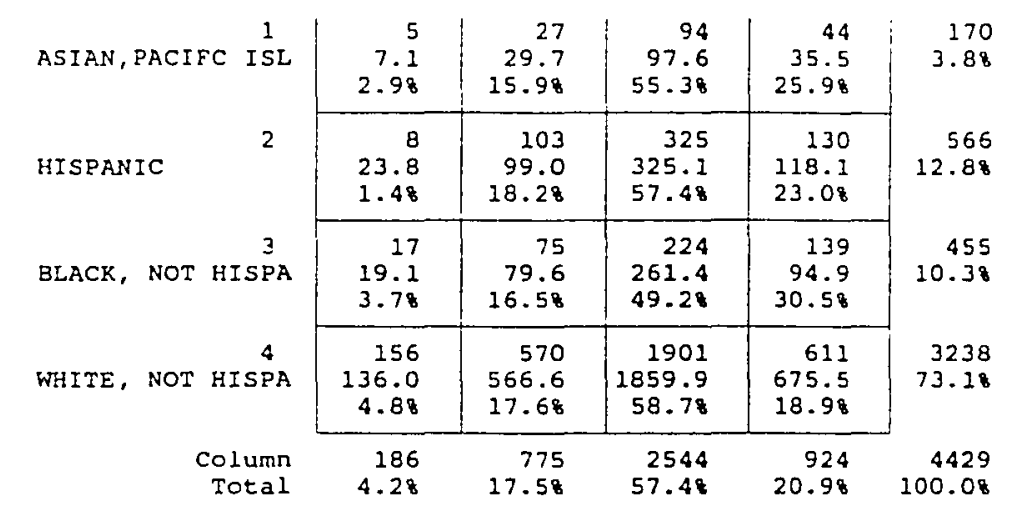

Chi-square

Value
$--0-0$

Significance

\section{Pearson}

Likelihood Ratio

Mantel-Haengel test for

linear association

51.25069

52.56619

17.83476

\section{9
1}

.00000

Minimum Expected Frequency - 7.139

Number of Missing Observations: 215 


\begin{tabular}{|c|c|c|c|c|c|c|c|}
\hline & $\begin{array}{l}\text { Count } \\
\text { Exp Val } \\
\text { Row Pct }\end{array}$ & $\begin{array}{l}\text { FIS7K } \\
\text { STRONGLY } \\
\text { AGPEE } \\
1\end{array}$ & AGREE & $\begin{array}{c}\text { DISAGREE } \\
3\end{array}$ & $\begin{array}{r}\text { Page } \\
\text { STRONGLY } \\
\text { DISAGRE } \\
4\end{array}$ & $\begin{array}{l}1 \text { of } 1 \\
\text { Row } \\
\text { Total }\end{array}$ & \\
\hline $\begin{array}{l}\text { FISESQ } \\
\text { QUARTILE }\end{array}$ & 1 LOW $^{1}$ & $\begin{array}{r}54 \\
46.5 \\
4.88\end{array}$ & $\begin{array}{r}205 \\
195.4 \\
18.38\end{array}$ & $\begin{array}{r}618 \\
641.6 \\
55.38\end{array}$ & $\begin{array}{r}241 \\
234.5 \\
21.68\end{array}$ & $\begin{array}{r}1118 \\
24.98\end{array}$ & \\
\hline QUARTILE & 2 & $\begin{array}{r}48 \\
54.0 \\
3.78\end{array}$ & $\begin{array}{r}239 \\
226.7 \\
18.48\end{array}$ & $\begin{array}{r}740 \\
744.4 \\
57.18\end{array}$ & $\begin{array}{r}270 \\
272.0 \\
20.88\end{array}$ & $\begin{array}{r}1297 \\
28.98\end{array}$ & \\
\hline QUARTILE & $3 \quad 3$ & $\begin{array}{r}56 \\
50.1 \\
4.78\end{array}$ & $\begin{array}{r}189 \\
210.4 \\
15.78\end{array}$ & $\begin{array}{r}716 \\
691.0 \\
59.58\end{array}$ & $\begin{array}{r}243 \\
252.5 \\
20.28\end{array}$ & $\begin{array}{r}1204 \\
26.88\end{array}$ & \\
\hline QUARTILE & $\begin{array}{r}4 \\
4 \mathrm{HIGH}\end{array}$ & $\begin{array}{r}29 \\
36.3 \\
3.38\end{array}$ & $\begin{array}{r}152 \\
152.6 \\
17.48\end{array}$ & $\begin{array}{r}504 \\
501.0 \\
57.78\end{array}$ & $\begin{array}{r}188 \\
183.1 \\
21.58\end{array}$ & $\begin{array}{r}873 \\
19.48\end{array}$ & \\
\hline & $\begin{array}{l}\text { Column } \\
\text { Total }\end{array}$ & $\begin{array}{r}187 \\
4.28\end{array}$ & $\begin{array}{r}785 \\
17.58\end{array}$ & $\begin{array}{r}2578 \\
57.48\end{array}$ & $\begin{array}{r}942 \\
21.08\end{array}$ & $\begin{array}{r}4492 \\
100.08\end{array}$ & \\
\hline Chi-s & Square & & & & DF & & Significance \\
\hline $\begin{array}{l}\text { Peargon } \\
\text { Likelihood } \\
\text { Mantel-Haen } \\
\text { linear }\end{array}$ & $\begin{array}{l}\text { Ratio } \\
\text { Bzel test } \\
\text { I associa }\end{array}$ & $\begin{array}{l}\text { for } \\
\text { ation }\end{array}$ & $\begin{array}{l}9.8 \\
9.9 \\
1.2\end{array}$ & & $\begin{array}{l}9 \\
9 \\
1\end{array}$ & & $\begin{array}{l}.36156 \\
.35230 \\
.26725\end{array}$ \\
\hline Minimum Expe & ected Fre & equency - & 36.34 & & & & \\
\hline
\end{tabular}




\section{Appendix 7: $\quad$ Most teachers listen to $R$ : as a function of gender,} race, and SES.

EISEX COMPOSITE SEX bY FISTL MOST TEACHERS LISTEN TO R

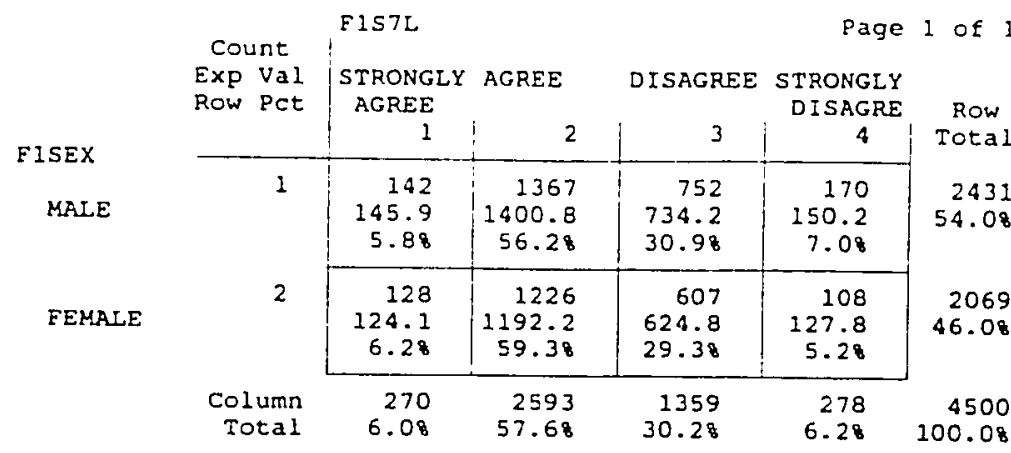

\begin{tabular}{|c|c|c|c|}
\hline $\begin{array}{l}\text { Chi-Square } \\
\text { Chisure }\end{array}$ & Value & DF & Significane \\
\hline $\begin{array}{l}\text { Pearson } \\
\text { Likelihood Ratio } \\
\text { Mantel-Haenszel teat for } \\
\text { linear asoociation }\end{array}$ & $\begin{array}{l}8.62631 \\
8.68957 \\
7.07696\end{array}$ & $\begin{array}{l}3 \\
3 \\
1\end{array}$ & $\begin{array}{l}.03469 \\
.03372 \\
.00781\end{array}$ \\
\hline
\end{tabular}

Minimum Expected Frequency - 124.140

F1RACE COMPOSITE RACE bY FISTL MOST TEACHERS IISTEN TO R

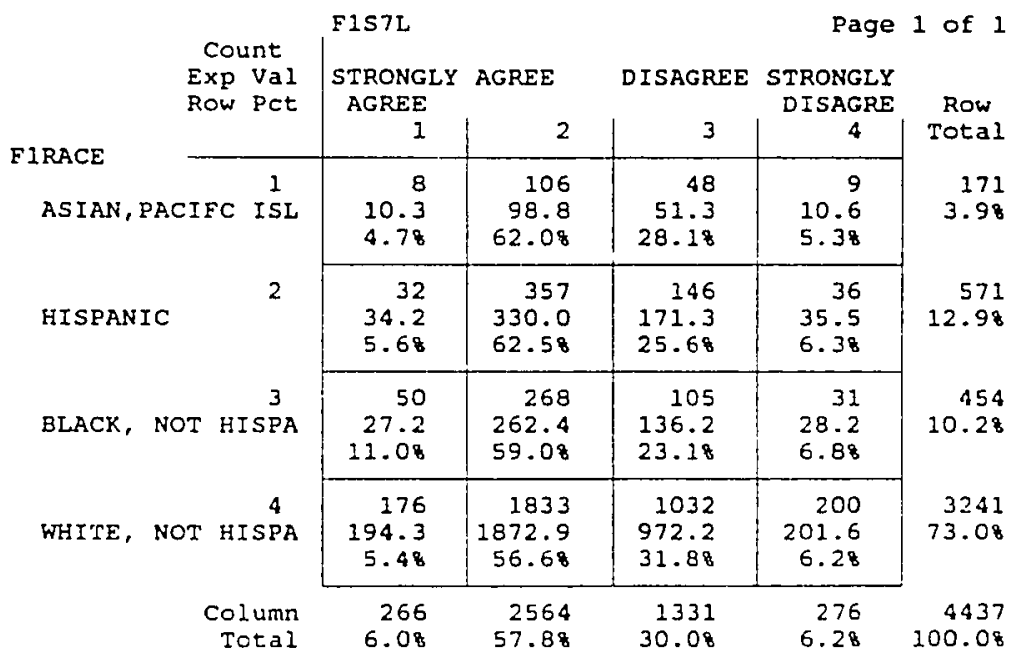

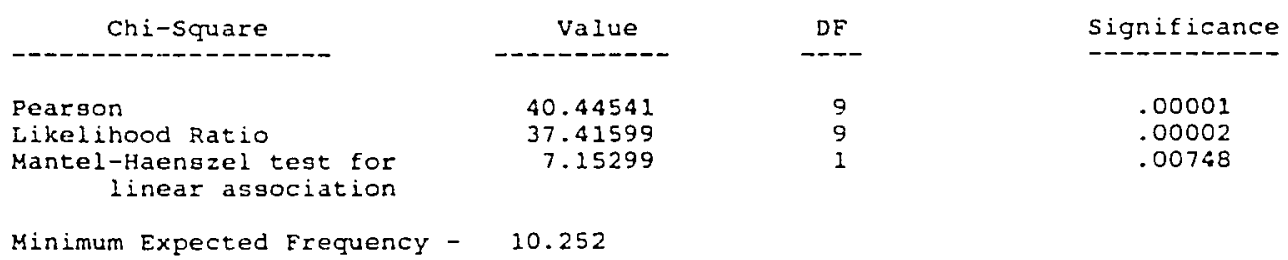




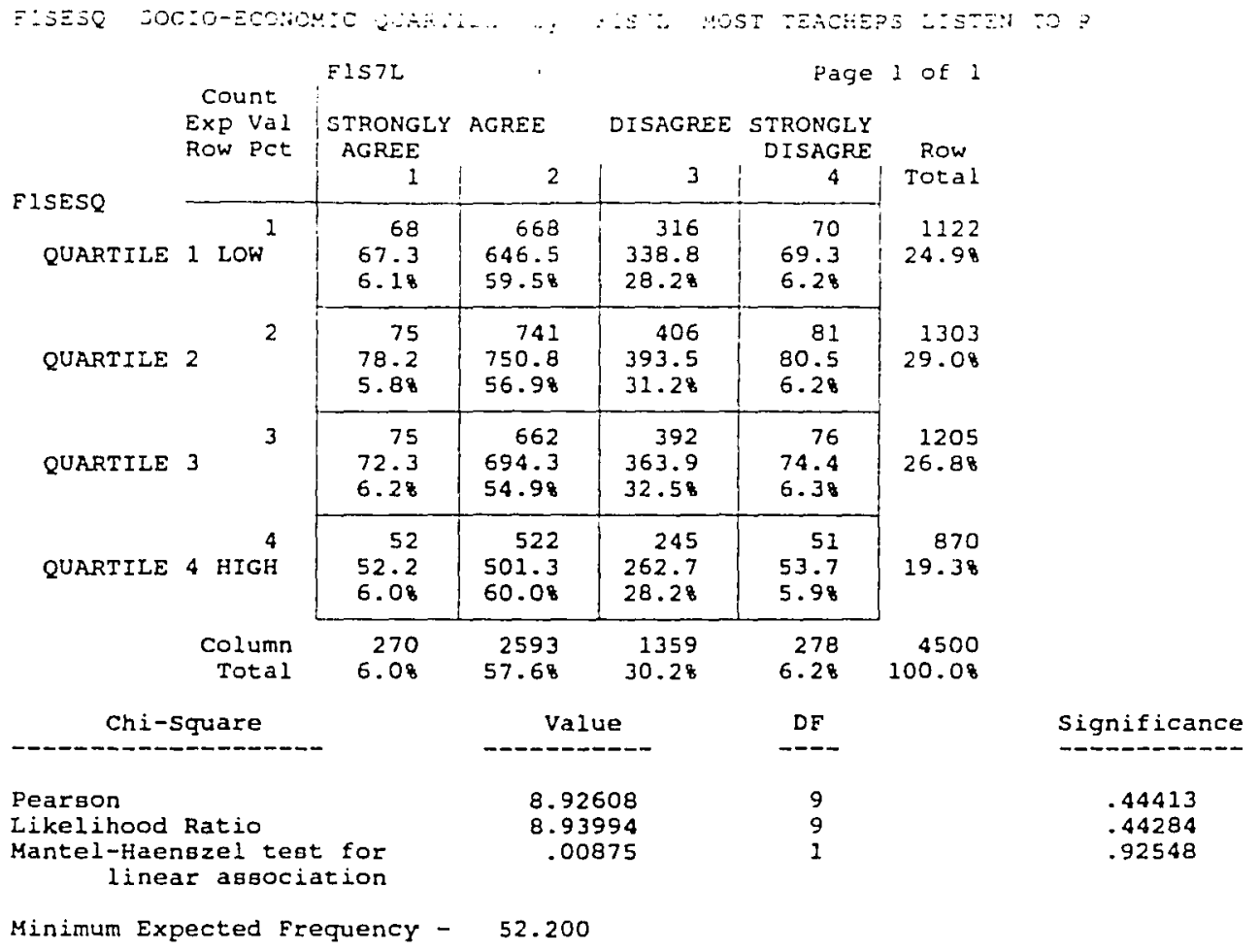

Number of Missing Observations: 144 
Appendix 8: $\quad$ Student's Post High School Educational Expectations (std. reported): as a function of parents' level of education.

\begin{tabular}{|c|c|c|c|c|c|c|}
\hline $\begin{array}{l}\text { Count } \\
\text { Exp Val } \\
\text { Row PCt }\end{array}$ & $\begin{array}{l}\text { F1S49 } \\
\text { LESS THA } \\
\text { N H.S. G } \\
\quad 1\end{array}$ & $\begin{array}{l}\text { H.S GRAD } \\
\text { UATION O } \\
2\end{array}$ & $\begin{array}{l}<2 \text { YRS } \\
\text { TRADE } \$ C \\
3\end{array}$ & $\begin{array}{c}2+Y R S T \\
R A D E S C H \\
4\end{array}$ & $\left\{\begin{array}{c}2 Y R S O \\
\text { COLLEG } \\
5\end{array}\right.$ & $\begin{array}{l}\text { Row } \\
\text { Total }\end{array}$ \\
\hline DID NOT FINISH $\stackrel{\text { I }}{\mathrm{H}}$ & $\begin{array}{r}6 \\
3.0 \\
1.28\end{array}$ & $\begin{array}{r}152 \\
71.1 \\
30.68\end{array}$ & $\begin{array}{r}33 \\
32.9 \\
6.71\end{array}$ & $\begin{array}{r}71 \\
62.7 \\
14.31\end{array}$ & $\begin{array}{r}37 \\
25.6 \\
7.58\end{array}$ & $\begin{array}{r}496 \\
10.98\end{array}$ \\
\hline US GRADUATE OR ${ }^{2} \mathrm{C}$ & $\begin{array}{r}8 \\
6.7 \\
.7\end{array}$ & $\begin{array}{r}212 \\
157.1 \\
19.31\end{array}$ & $\begin{array}{r}106 \\
72.6 \\
9.71\end{array}$ & $\begin{array}{r}168 \\
138.5 \\
15.38\end{array}$ & $\begin{array}{r}67 \\
56.5 \\
6.12\end{array}$ & $\begin{array}{r}1096 \\
24.1\end{array}$ \\
\hline$G R$ US E LT $4 Y R^{3} D$ & $\begin{array}{r}12 \\
12.6 \\
.6\end{array}$ & $\begin{array}{r}248 \\
293.8 \\
12.18\end{array}$ & $\begin{array}{r}143 \\
135.9 \\
7.01\end{array}$ & $\begin{array}{r}272 \\
259.1 \\
13.38\end{array}$ & $\begin{array}{r}106 \\
105.7 \\
5.21\end{array}$ & $\begin{array}{r}2050 \\
45.02\end{array}$ \\
\hline COLLECE GRAD ${ }^{4}$ & $\begin{array}{r}0 \\
3.3 \\
.01\end{array}$ & $\begin{array}{r}25 \\
76.7 \\
4.78\end{array}$ & $\begin{array}{r}11 \\
35.5 \\
2.11\end{array}$ & $\begin{array}{r}45 \\
67.6 \\
8.45\end{array}$ & $\begin{array}{r}15 \\
27.6 \\
2.81\end{array}$ & $\begin{array}{r}535 \\
11.71\end{array}$ \\
\hline M.n. or equivale & $\begin{array}{r}1 \\
1.6 \\
.41\end{array}$ & $\begin{array}{r}9 \\
36.4 \\
3.51\end{array}$ & $\begin{array}{r}4 \\
16.8 \\
1.68\end{array}$ & $\begin{array}{r}16 \\
32.1 \\
6.31\end{array}$ & $\begin{array}{r}7 \\
13.1 \\
2.81\end{array}$ & $\begin{array}{r}254 \\
5.61\end{array}$ \\
\hline PH.D., M.D., OTII & $\begin{array}{r}1 \\
.8 \\
.88\end{array}$ & $\begin{array}{r}7 \\
18.1 \\
5.61\end{array}$ & $\begin{array}{r}5 \\
8.4 \\
4.08\end{array}$ & $\begin{array}{r}4 \\
15.9 \\
3.24\end{array}$ & $\begin{array}{r}3 \\
6.5 \\
2.45\end{array}$ & $\begin{array}{r}126 \\
2.8\end{array}$ \\
\hline $\begin{array}{ll}\text { (Column } & \text { Colunued) } \\
\text { Total }\end{array}$ & $\begin{array}{r}28 \\
.68\end{array}$ & $\begin{array}{r}653 \\
14.38\end{array}$ & $\begin{array}{r}302 \\
6.68\end{array}$ & $\begin{array}{r}576 \\
12.68\end{array}$ & $\begin{array}{r}235 \\
5.21\end{array}$ & $\begin{array}{r}4557 \\
100.08\end{array}$ \\
\hline
\end{tabular}

FIPARED PARENTS HIGHEST EDUCATION LEVEL

bY FIS49 HOW FAR IN SCHOOL R THINKS HE WILL GET

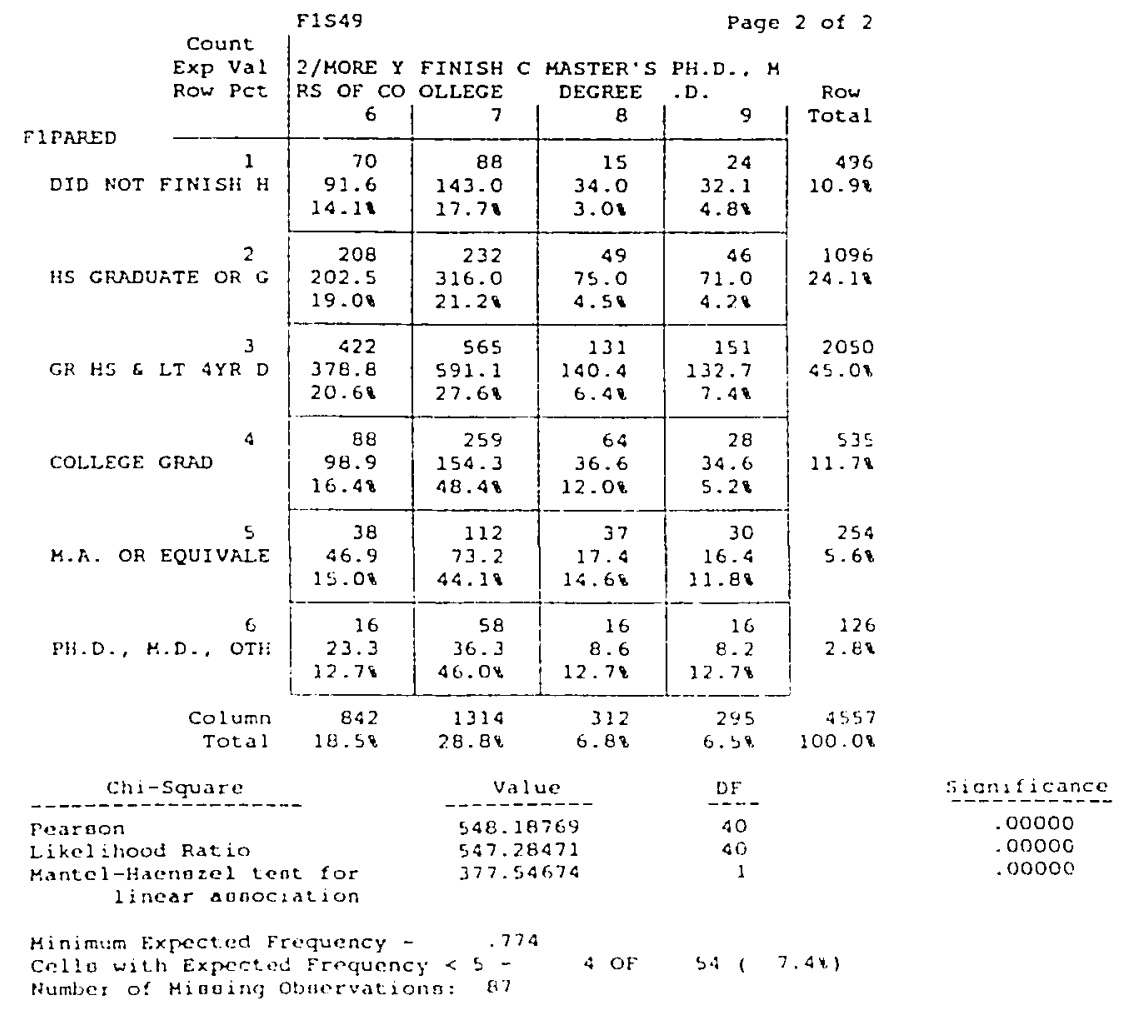


A ppendix 9: $\quad$ Parental Post High School Expectations(std. reported): as a function of parents' level of education.

FIPARED PARENTS HICHEST EDUCATION LEVEI

bY FIS4BA HOW FAR IN SCHOOL FATHER WANTS R TO GO

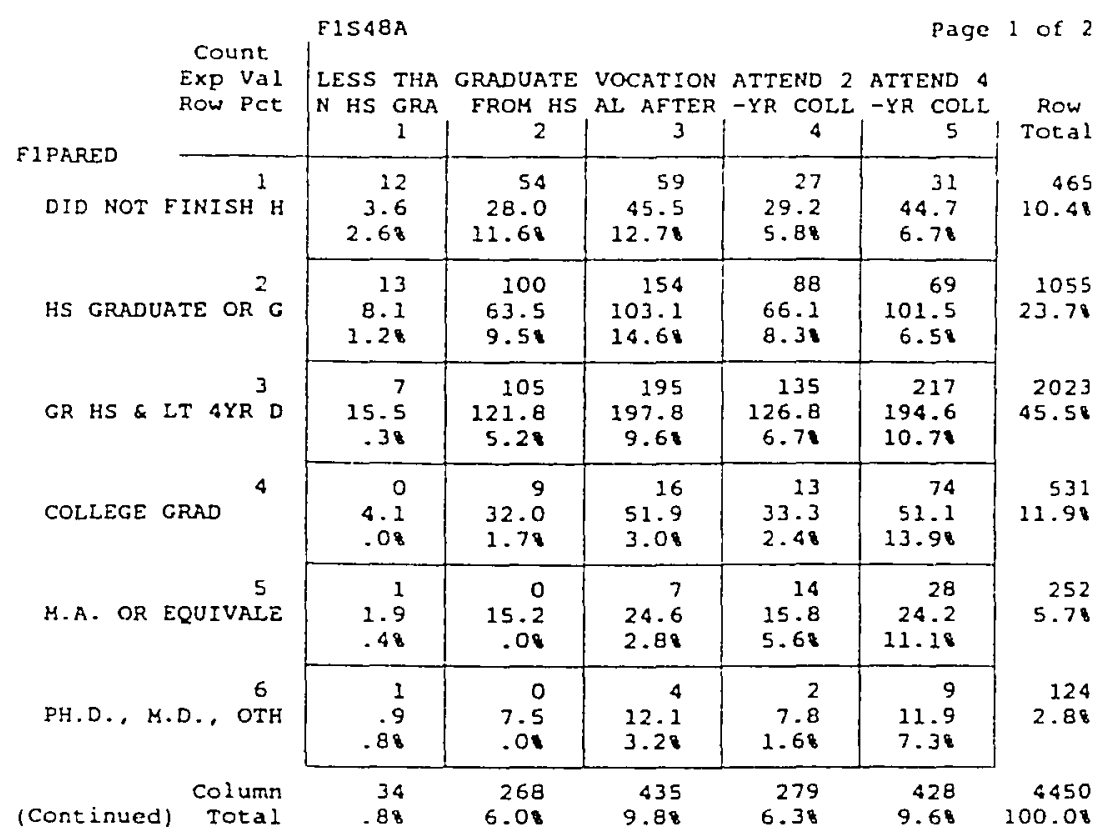

FIPARED PARENTS ' HIGHEST EDUCATION LEVEL

by FIS48A HOW FAR IN SCHOOL FATHER WANTS R TO GO

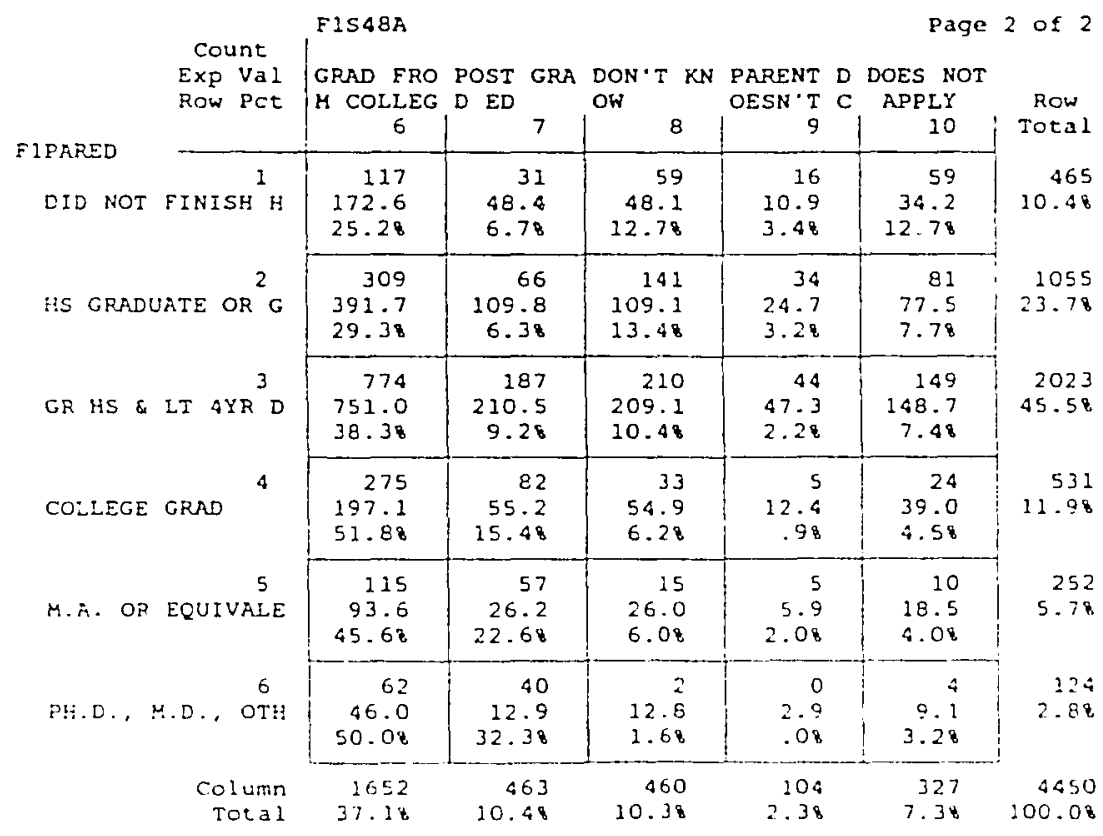




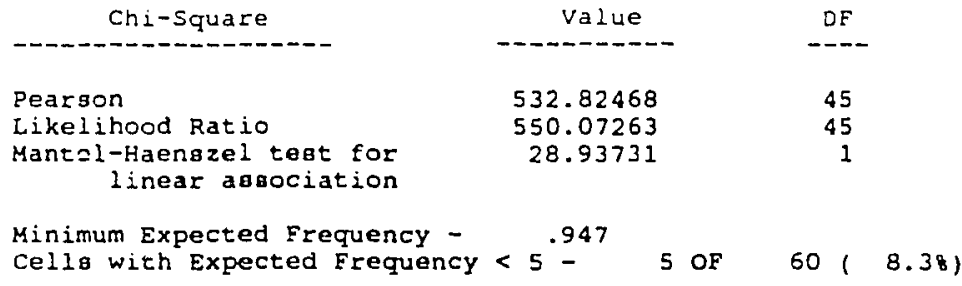

Number of Missing Obgervations: 194 


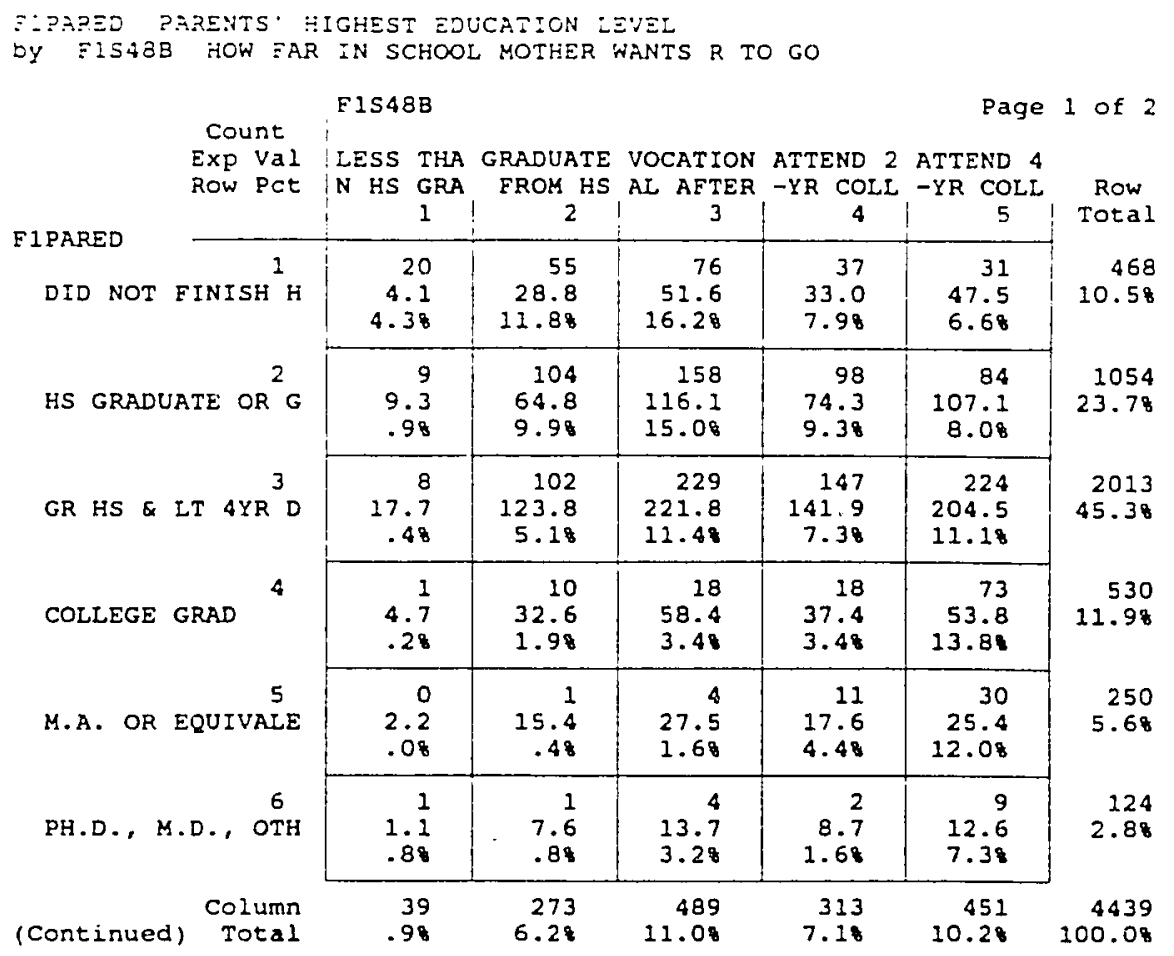

FIPARED PARENTS HIGHEST EDUCATION LEVEL

by FIS48B HOW FAR IN SCHOOL MOTHER WANTS $R$ TO GO

\begin{tabular}{|c|c|c|c|c|c|c|c|}
\hline & $\begin{array}{l}\text { Count } \\
\text { Exp Val } \\
\text { Row PCt }\end{array}$ & $\begin{array}{l}\text { F1S48B } \\
\text { GRAD FRO } \\
M \text { COLLEG } \\
6\end{array}$ & $\begin{array}{l}\text { POST GRA } \\
\text { D ED } \\
\\
7\end{array}$ & $\begin{array}{c}\text { DON'T KN } \\
\text { OW } 8\end{array}$ & $\begin{array}{cc}\text { PARENT } & \text { D } \\
\text { OESN } & \text { T } \\
9 & \end{array}$ & $\begin{array}{r}\text { Page } \\
\text { DOES NOT } \\
\text { APPIY } \\
10\end{array}$ & $\begin{array}{l}\text { Row } \\
\text { Total }\end{array}$ \\
\hline DID NOT & FINISH $\stackrel{1}{\mathrm{H}}$ & $\begin{array}{r}134 \\
186.7 \\
28.68\end{array}$ & $\begin{array}{r}46 \\
58.1 \\
9.88\end{array}$ & $\begin{array}{r}55 \\
44.2 \\
11.88\end{array}$ & $\begin{array}{r}4 \\
6.1 \\
.98\end{array}$ & $\begin{array}{r}10 \\
7.9 \\
2.18\end{array}$ & $\begin{array}{r}468 \\
10.58\end{array}$ \\
\hline HS GRADL & UATE OR $^{2} \mathrm{G}$ & $\begin{array}{r}350 \\
420.5 \\
33.28\end{array}$ & $\begin{array}{r}91 \\
130.8 \\
8.68\end{array}$ & $\begin{array}{r}113 \\
99.5 \\
10.78\end{array}$ & $\begin{array}{r}23 \\
13.8 \\
2.28\end{array}$ & $\begin{array}{r}24 \\
17.8 \\
2.38\end{array}$ & $\begin{array}{r}1054 \\
23.78\end{array}$ \\
\hline GR HS \& & IT $4 Y R^{3} D$ & $\begin{array}{r}807 \\
803.1 \\
40.18\end{array}$ & $\begin{array}{r}244 \\
249.9 \\
12.18\end{array}$ & $\begin{array}{r}195 \\
190.0 \\
9.78\end{array}$ & $\begin{array}{r}26 \\
26.3 \\
1.38\end{array}$ & $\begin{array}{r}31 \\
34.0 \\
1.58\end{array}$ & $\begin{array}{r}20 \\
45\end{array}$ \\
\hline COLLEGE & GRAD & $\begin{array}{r}291 \\
211.5 \\
54.95\end{array}$ & $\begin{array}{r}79 \\
65.8 \\
14.98\end{array}$ & $\begin{array}{r}31 \\
50.0 \\
5.88\end{array}$ & $\begin{array}{r}3 \\
6.9 \\
.68\end{array}$ & $\begin{array}{r}6 \\
9.0 \\
1.18\end{array}$ & $\begin{array}{r}53 \\
11.9\end{array}$ \\
\hline M.A. OR & EQUIVALE & $\begin{array}{r}124 \\
99.7 \\
49.68\end{array}$ & $\begin{array}{r}57 \\
31.0 \\
22.88\end{array}$ & $\begin{array}{r}19 \\
23.6 \\
7.68\end{array}$ & $\begin{array}{r}2 \\
3.3 \\
.88\end{array}$ & $\begin{array}{r}2 \\
4.2 \\
.88\end{array}$ & $5^{2}$ \\
\hline PH.D., & M.D., $\stackrel{6}{6} \mathrm{OTH}$ & $\begin{array}{r}65 \\
49.5 \\
52.48\end{array}$ & $\begin{array}{r}34 \\
15.4 \\
27.48\end{array}$ & $\begin{array}{r}6 \\
11.7 \\
4.88\end{array}$ & $\begin{array}{r}0 \\
1.6 \\
.08\end{array}$ & $\begin{array}{r}2 \\
2.1 \\
1.68\end{array}$ & 2.8 \\
\hline & $\begin{array}{c}\text { Column } \\
\text { Total }\end{array}$ & $\begin{array}{r}1771 \\
39.98\end{array}$ & $\begin{array}{r}551 \\
12.48\end{array}$ & $\begin{array}{r}419 \\
9.48\end{array}$ & $\begin{array}{r}58 \\
1.38\end{array}$ & $\begin{array}{r}75 \\
1.78\end{array}$ & 100. \\
\hline
\end{tabular}

Chi-square

value

$D F$

significance 
?earscn

Likelihood Ratio

Mantel-Haenszel test for

linear aввоciation
453.09103

120.23719

Minimum Expected Frequency - 1.089

Cells with Expected Frequency $<5$ -

Number of Migsing Observations: 205
45

45

.2050

100000

.00000

8 OF

$60(13.38)$ 


\section{Appendix 10: Parental; Post High School Educational} Expectations (std. reported): as a function of SES.

FISESQ SOCIO-ECONOMIC QUARTILE

DY FIS4BA HOW FAR IN SCHOOL FATHER WANTS R TO GO

\begin{tabular}{|c|c|c|c|c|c|c|c|}
\hline & Count & FIS4BA & & & & Page & 1 of 2 \\
\hline & $\begin{array}{l}\text { Exp Val } \\
\text { Row Pct }\end{array}$ & $\begin{array}{c}\text { LESS THA } \\
\text { N HS GRA } \\
1\end{array}$ & $\begin{array}{c}\text { GRADUATE } \\
\text { FROM HS } \\
2\end{array}$ & $\begin{array}{c}\text { VOCATION } \\
\text { AI AFTER } \\
3\end{array}$ & $\begin{array}{c}\text { ATTEND } 2 \\
\text {-YR COLL } \\
4\end{array}$ & $\begin{array}{c}\text { ATTEND } 4 \\
\text {-YR COLL } \\
5\end{array}$ & $\begin{array}{l}\text { Row } \\
\text { Total }\end{array}$ \\
\hline QUARTILE & 1 LOW $^{1}$ & $\begin{array}{r}23 \\
8.4 \\
2.18\end{array}$ & $\begin{array}{r}109 \\
66.3 \\
9.88\end{array}$ & $\begin{array}{r}141 \\
108.6 \\
12.78\end{array}$ & $\begin{array}{r}74 \\
69.5 \\
6.78\end{array}$ & $\begin{array}{r}71 \\
106.8 \\
6.41\end{array}$ & $\begin{array}{r}1108 \\
24.78\end{array}$ \\
\hline QUARTILE & 2 & $\begin{array}{r}7 \\
9.8 \\
.58\end{array}$ & $\begin{array}{r}104 \\
77.3 \\
8.08\end{array}$ & $\begin{array}{r}174 \\
126.6 \\
13.58\end{array}$ & $\begin{array}{r}99 \\
81.0 \\
7.71\end{array}$ & $\begin{array}{r}118 \\
124.6 \\
9.18\end{array}$ & $\begin{array}{r}1292 \\
28.88\end{array}$ \\
\hline QUARTILE & 3 & $\begin{array}{r}3 \\
9.2 \\
.28\end{array}$ & $\begin{array}{r}45 \\
72.2 \\
3.78\end{array}$ & $\begin{array}{r}94 \\
118.3 \\
7.88\end{array}$ & $\begin{array}{r}79 \\
75.7 \\
6.51\end{array}$ & $\begin{array}{r}146 \\
116.4 \\
12.18\end{array}$ & $\begin{array}{r}1207 \\
26.98\end{array}$ \\
\hline QUARTILE & 4 HIGH & $\begin{array}{r}1 \\
6.6 \\
.18\end{array}$ & $\begin{array}{r}10 \\
52.2 \\
1.18\end{array}$ & $\begin{array}{r}30 \\
85.5 \\
3.48\end{array}$ & $\begin{array}{r}29 \\
54.8 \\
3.38\end{array}$ & $\begin{array}{r}97 \\
84.2 \\
11.18\end{array}$ & $\begin{array}{r}873 \\
19.53\end{array}$ \\
\hline (Continued) & $\begin{array}{l}\text { Column } \\
\text { Total }\end{array}$ & $\begin{array}{r}34 \\
.88\end{array}$ & $\begin{array}{r}268 \\
6.08\end{array}$ & $\begin{array}{r}439 \\
9.88\end{array}$ & $\begin{array}{r}281 \\
6.38\end{array}$ & $\begin{array}{r}432 \\
9.68\end{array}$ & $\begin{array}{r}4480 \\
100.08\end{array}$ \\
\hline
\end{tabular}

FISESQ SOCIO-ECONOMIC QUARTILE

by FIS48A HOW FAR IN SCHOOL FATHER WANTS R TO GO

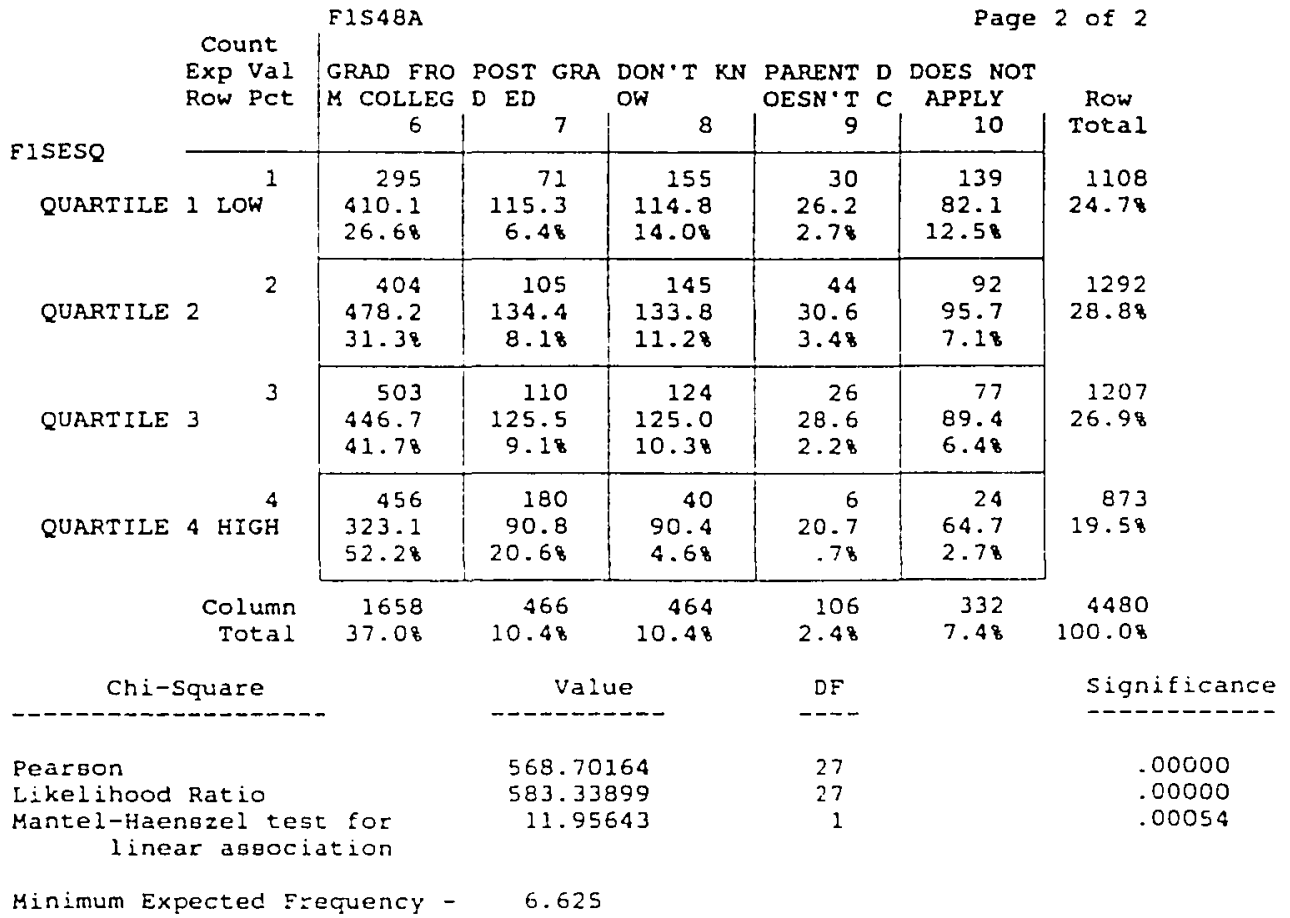

Number of Missing Observations: 164 
FISESQ SOCIO-ECONOMIC QUTRT:EZ

by FIS4BB HOW FAR IN SCHOOL MOTHER NANTS $R$ TO GO

F1S48B

Page 1 of 2

count

Exp Val

LESS THA GRADUATE VOCATION ATTEND 2 ATTEND 4

ROW PCE N HS GRA FROM HS AL AFTER -YR COLL -YR COLL

\begin{tabular}{|c|c|c|c|c|c|c|c|}
\hline & & 1 & 2 & 3 & 4 & 5 & Tota 1 \\
\hline QUARTILE & 1 LOW $^{1}$ & $\begin{array}{r}28 \\
9.7 \\
2.58\end{array}$ & $\begin{array}{r}122 \\
67.7 \\
11.08\end{array}$ & $\begin{array}{r}170 \\
122.5 \\
15.38\end{array}$ & $\begin{array}{r}94 \\
78.4 \\
8.58\end{array}$ & $\begin{array}{r}78 \\
113.3 \\
7.08\end{array}$ & $\begin{array}{r}1108 \\
24.88\end{array}$ \\
\hline QUARTILE & 2 & $\begin{array}{r}6 \\
11.2 \\
.58\end{array}$ & $\begin{array}{r}96 \\
78.6 \\
7.58\end{array}$ & $\begin{array}{r}195 \\
142.2 \\
15.28\end{array}$ & $\begin{array}{r}110 \\
91.0 \\
8.68\end{array}$ & $\begin{array}{r}124 \\
131.5 \\
9.68\end{array}$ & $\begin{array}{r}1286 \\
28.88\end{array}$ \\
\hline QUARTILE & 3 & $\begin{array}{r}4 \\
10.5 \\
.38\end{array}$ & $\begin{array}{r}45 \\
73.6 \\
3.78\end{array}$ & $\begin{array}{r}103 \\
133.2 \\
8.58\end{array}$ & $\begin{array}{r}83 \\
85.2 \\
6.98\end{array}$ & $\begin{array}{r}153 \\
123.3 \\
12.78\end{array}$ & $\begin{array}{r}1205 \\
27.08\end{array}$ \\
\hline QUARTILE & $\begin{array}{r}4 \\
4 \text { HIGH }\end{array}$ & $\begin{array}{r}1 \\
7.6 \\
.18\end{array}$ & $\begin{array}{r}10 \\
53.1 \\
1.28\end{array}$ & $\begin{array}{r}26 \\
96.1 \\
3.08\end{array}$ & $\begin{array}{r}29 \\
61.5 \\
3.38\end{array}$ & $\begin{array}{r}102 \\
88.9 \\
11.78\end{array}$ & $\begin{array}{r}869 \\
19.48\end{array}$ \\
\hline (continued) & $\begin{array}{c}\text { Column } \\
\text { Total }\end{array}$ & $\begin{array}{r}39 \\
.98\end{array}$ & $\begin{array}{r}273 \\
6.18\end{array}$ & $\begin{array}{r}494 \\
11.18\end{array}$ & $\begin{array}{r}316 \\
7.18\end{array}$ & $\begin{array}{r}457 \\
10.28\end{array}$ & $\begin{array}{r}4468 \\
100.08\end{array}$ \\
\hline
\end{tabular}

FISESO SOCIO-ECONOMIC QUARTILE

bY EIS48B HOW FAR IN SCHOOL MOTHER WANTS R TO GO

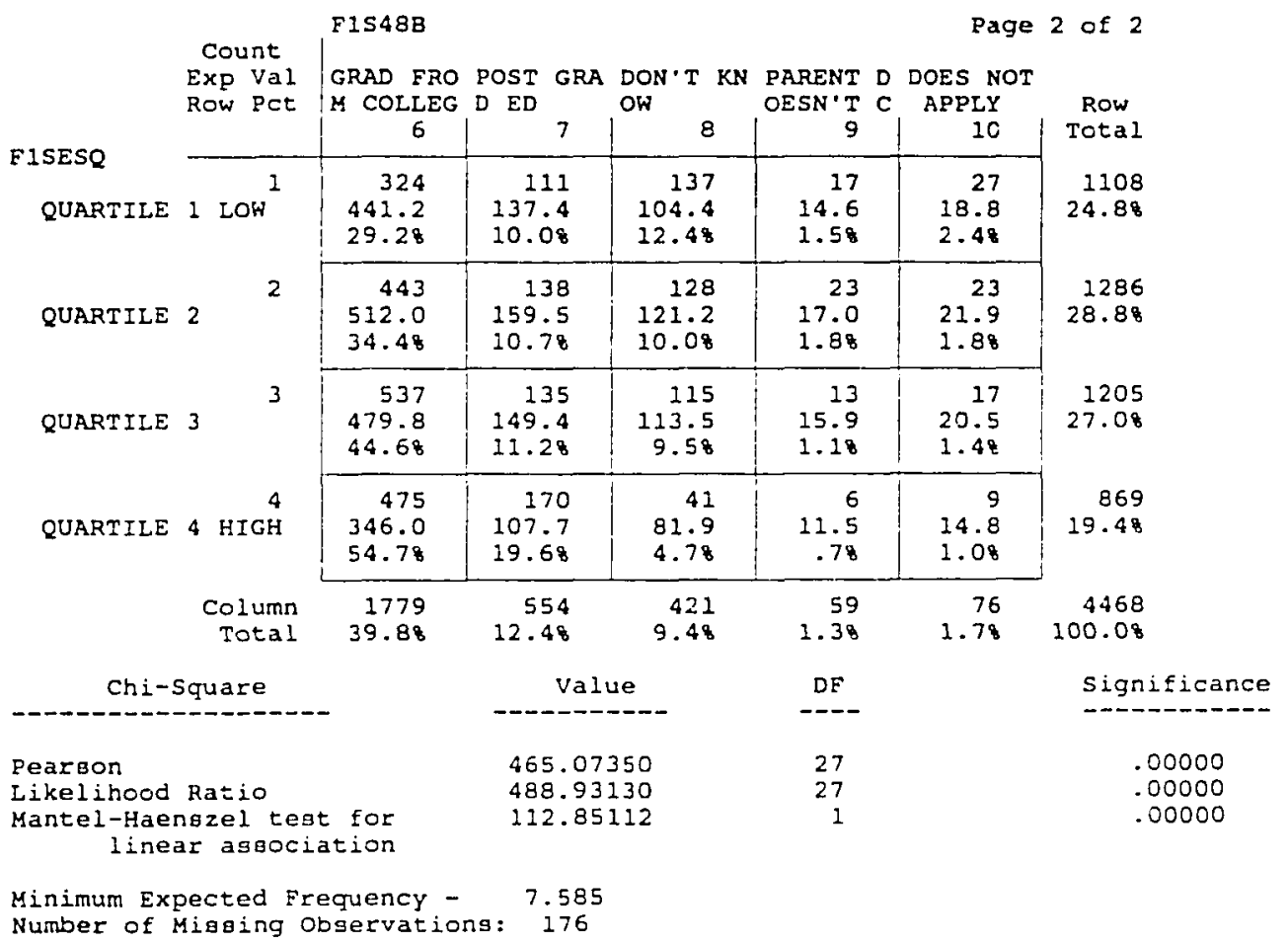


F REQUENCIES

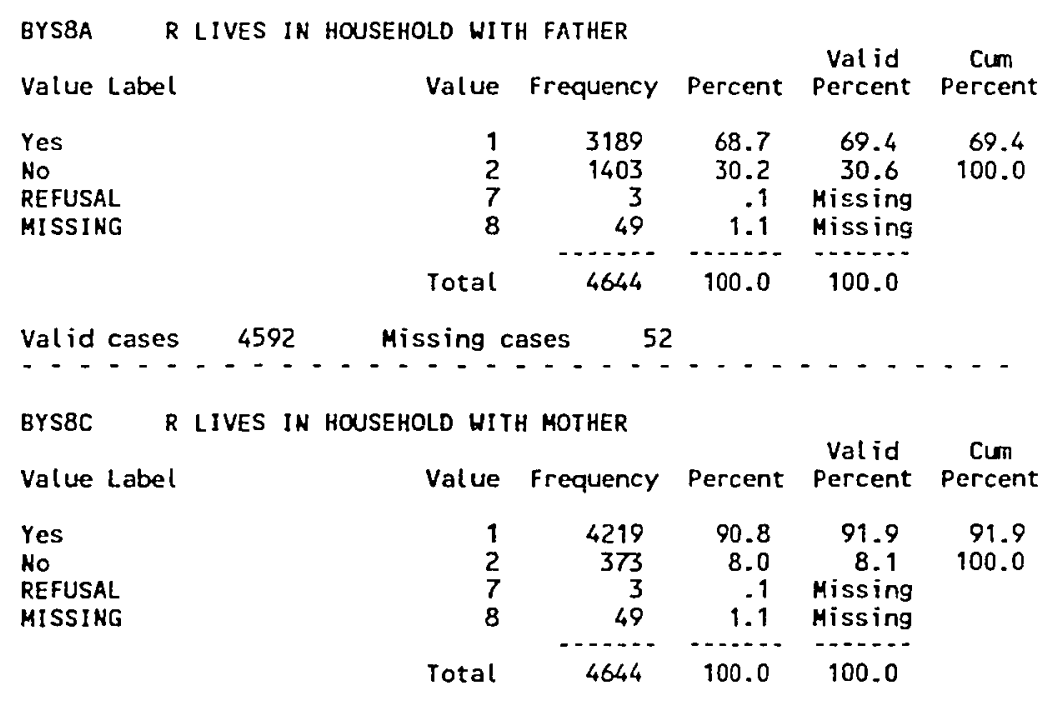

Valid cases $4592 \quad$ Missing cases 52

BYPAQFLG PARENT QUESTIONMAIRE AVAILABLE

\begin{tabular}{|c|c|c|c|c|c|}
\hline Value Label & Value & Frequency & Percent & $\begin{array}{l}\text { Valid } \\
\text { Percent }\end{array}$ & $\begin{array}{l}\text { Cun } \\
\text { Percent }\end{array}$ \\
\hline $\begin{array}{l}\text { Did not complete } \\
\text { Completed }\end{array}$ & $\begin{array}{l}0 \\
1\end{array}$ & $\begin{array}{r}276 \\
4368\end{array}$ & $\begin{array}{r}5.9 \\
94.1\end{array}$ & $\begin{array}{r}5.9 \\
94.1\end{array}$ & $\begin{array}{r}5.9 \\
100.0\end{array}$ \\
\hline & Total & 4646 & 100.0 & 100.0 & \\
\hline
\end{tabular}

Valid cases $\quad 4644 \quad$ Missing cases 0

BYFCOMP FAMILY COMPOSITION COMPOSITE

Value Label

Hother \& father Mother \& male guardn Father \& fem guard.

Mother only

Father only

oth rel/non-relative

MISSING

\begin{tabular}{|c|c|c|c|c|}
\hline Value & Frequency & Percent & $\begin{array}{l}\text { Valid } \\
\text { Percent }\end{array}$ & $\begin{array}{c}\text { Cum } \\
\text { Percent }\end{array}$ \\
\hline $\begin{array}{l}1 \\
2 \\
3 \\
4 \\
5 \\
6 \\
8\end{array}$ & $\begin{array}{r}2946 \\
512 \\
119 \\
761 \\
124 \\
130 \\
52\end{array}$ & $\begin{array}{r}63.4 \\
11.0 \\
2.6 \\
16.4 \\
2.7 \\
2.8 \\
1.1\end{array}$ & $\begin{array}{r}64.2 \\
11.1 \\
2.6 \\
16.6 \\
2.7 \\
2.8 \\
\text { Missing }\end{array}$ & $\begin{array}{r}64.2 \\
75.3 \\
77.9 \\
94.5 \\
97.2 \\
100.0\end{array}$ \\
\hline otal & 4644 & 900.0 & 100.0 & \\
\hline
\end{tabular}

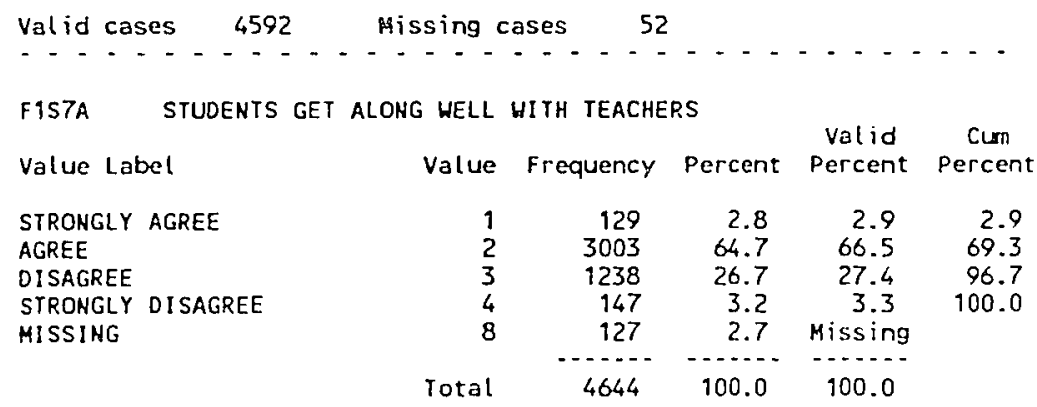




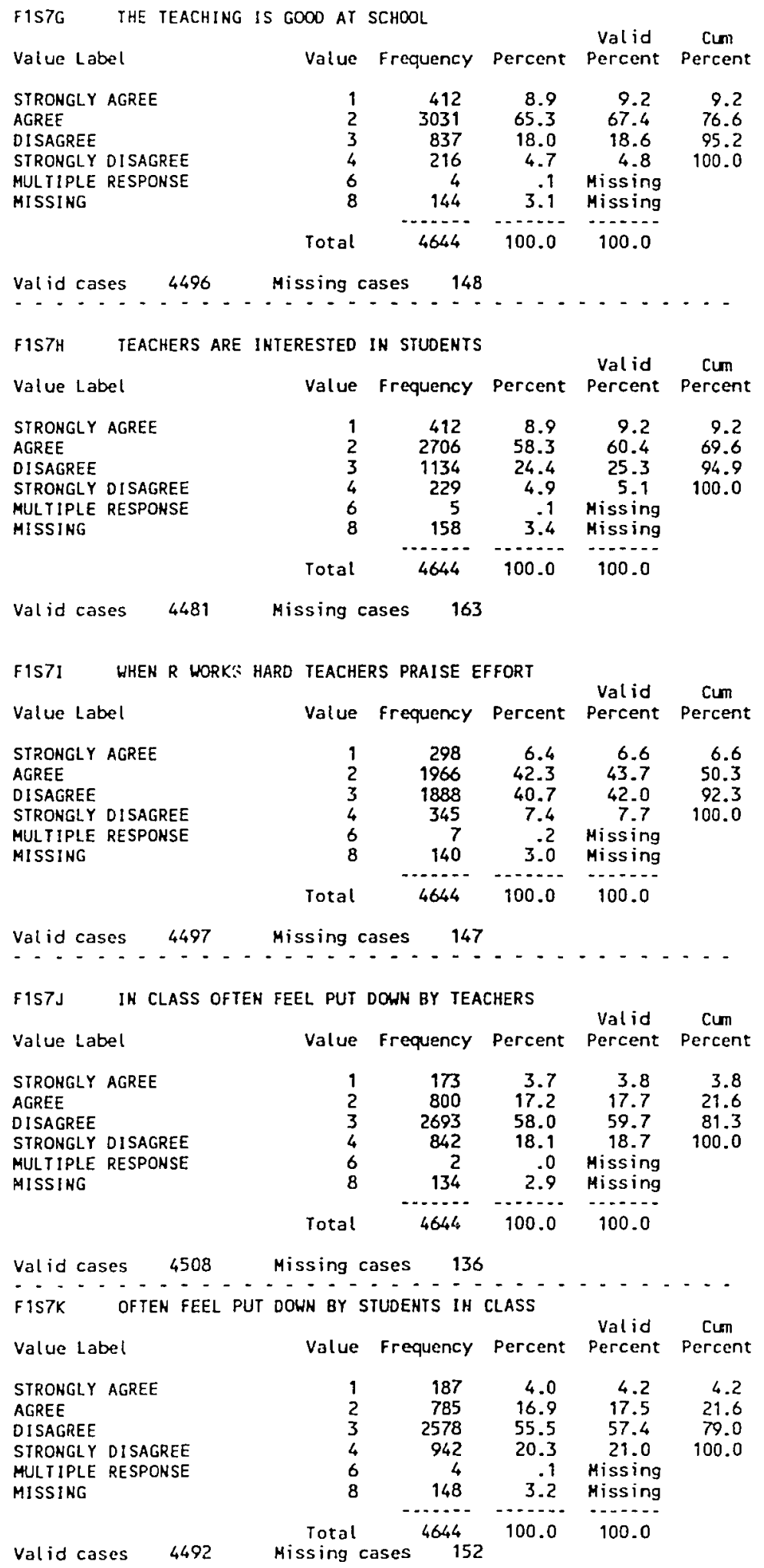




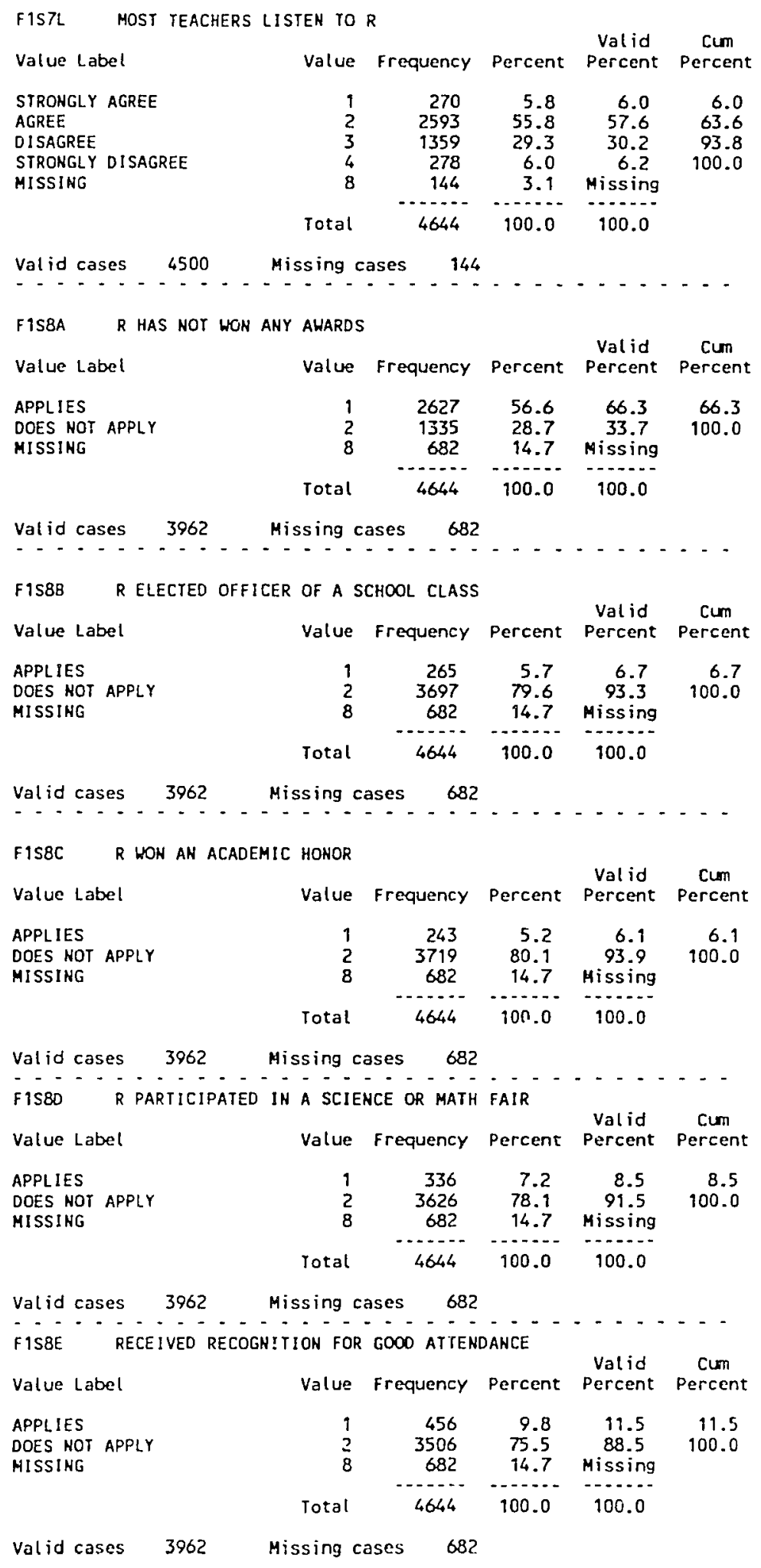




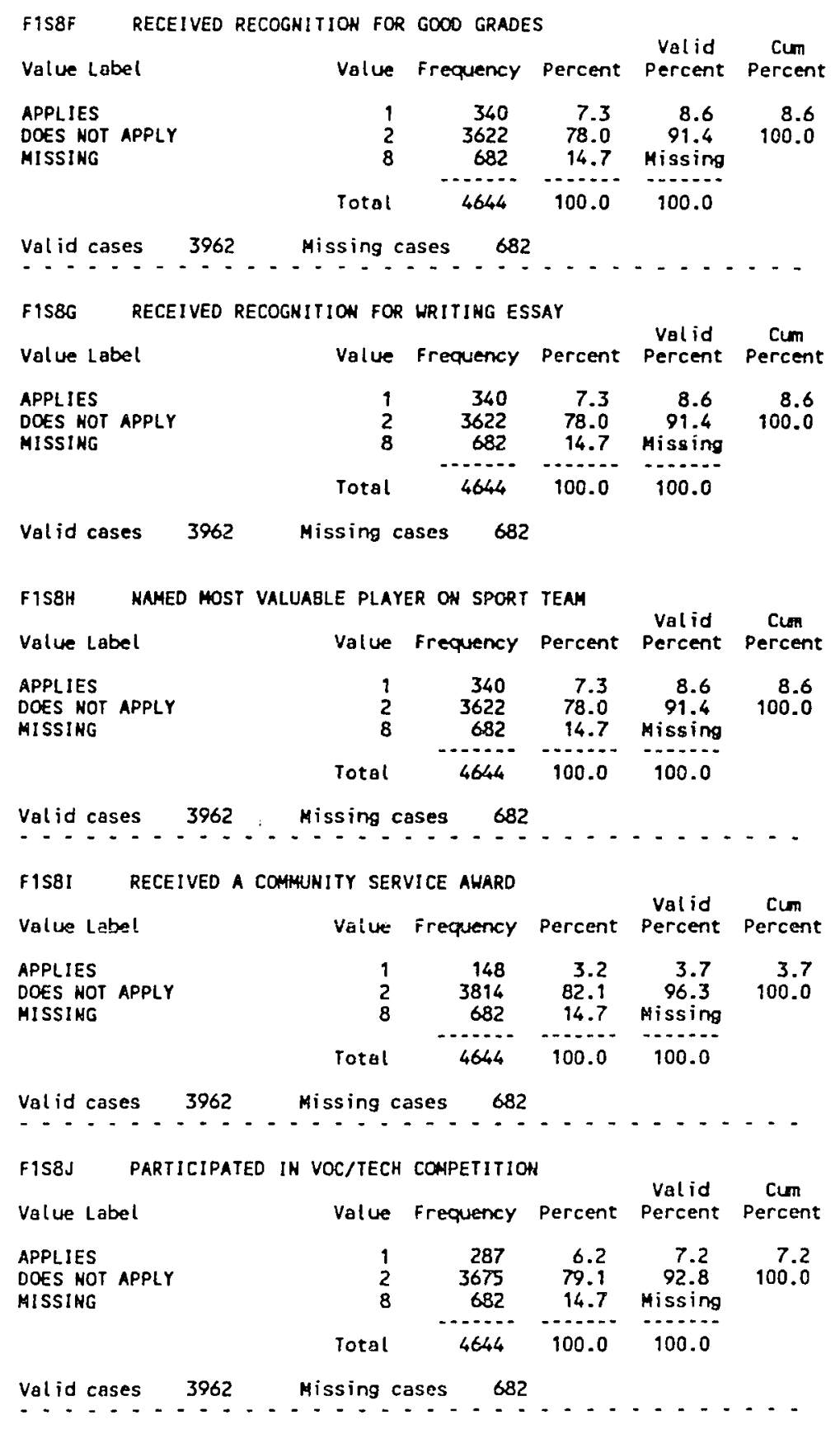




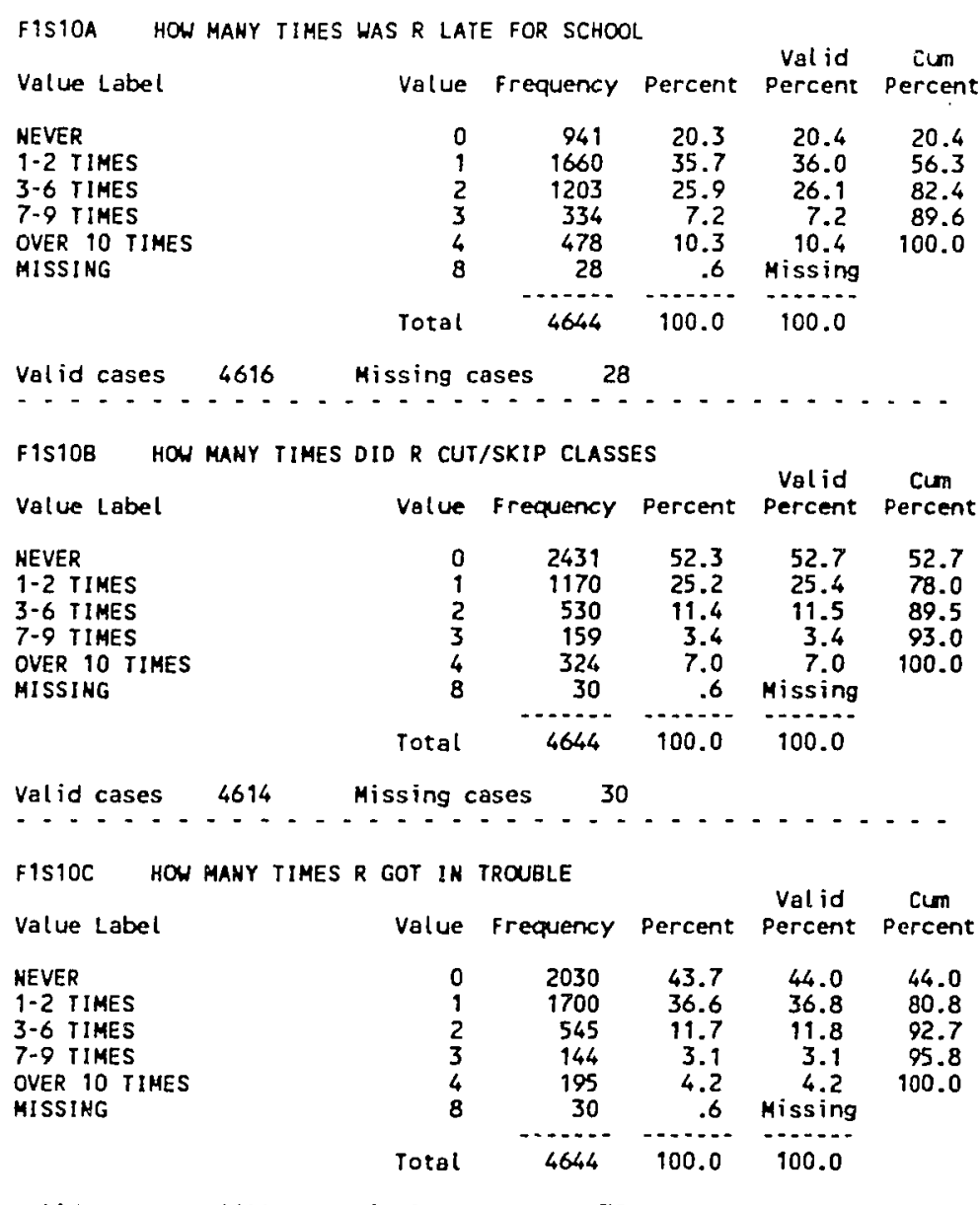

Valid cases $4614 \quad$ Missing cases 30

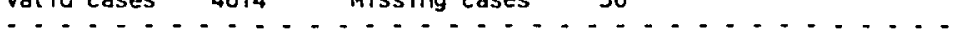

F1S100 HOW MANY TIHES PUT ON IN-SCHL SUSPENSION

\begin{tabular}{|c|c|c|c|c|c|}
\hline $\begin{array}{l}\text { Value Label } \\
\text { HEVER } \\
1-2 \text { IIMES } \\
3-6 \text { TIMES } \\
7-9 \text { TIMES } \\
\text { OVER 10 TIMES } \\
\text { MISSING }\end{array}$ & $\begin{array}{r}\text { Value } \\
0 \\
1 \\
2 \\
3 \\
4 \\
8\end{array}$ & $\begin{array}{c}\text { Frequency } \\
3798 \\
620 \\
147 \\
14 \\
24 \\
41\end{array}$ & $\begin{array}{c}\text { Percent } \\
81.8 \\
13.4 \\
3.2 \\
.3 \\
.5 \\
.9\end{array}$ & $\begin{array}{c}\text { Valid } \\
\text { Percent } \\
82.5 \\
13.5 \\
3.2 \\
.3 \\
.5 \\
\text { Missing }\end{array}$ & $\begin{array}{c}\text { Cum } \\
\text { Percent } \\
82.5 \\
90.0 \\
99.2 \\
99.5 \\
100.0\end{array}$ \\
\hline & & & & & \\
\hline
\end{tabular}

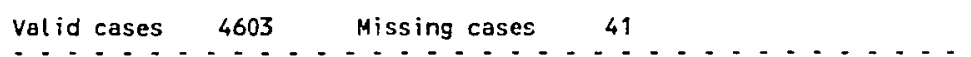

FisIOE HON MANY TIMES R SUSPENDED FROM SCHOOL

$\begin{array}{lrrrrr}\text { Value Label } & \text { Value } & \text { Frequency } & \text { Percent } & \begin{array}{c}\text { Valid } \\ \text { Percent }\end{array} & \begin{array}{c}\text { Cum } \\ \text { Percent }\end{array} \\ \text { MEVER } & 0 & 4116 & 88.6 & 89.3 & 89.3 \\ \text { 1-2 TIMES } & 1 & 424 & 9.1 & 9.2 & 98.5 \\ 3-6 \text { TIMES } & 2 & 49 & 1.1 & 1.1 & 99.5 \\ 7-9 \text { TIMES } & 3 & 10 & .2 & .2 & 99.8 \\ \text { OVER 10 TIMES } & 4 & 19 & .2 & .2 & 100.0 \\ \text { MISSING } & 8 & 34 & .7 & \text { Missing } & \\ & \text { Total } & 4644 & 100.0 & 100.0 & \end{array}$

Valid cases $4610 \quad$ Missing cases $\quad 34$ 


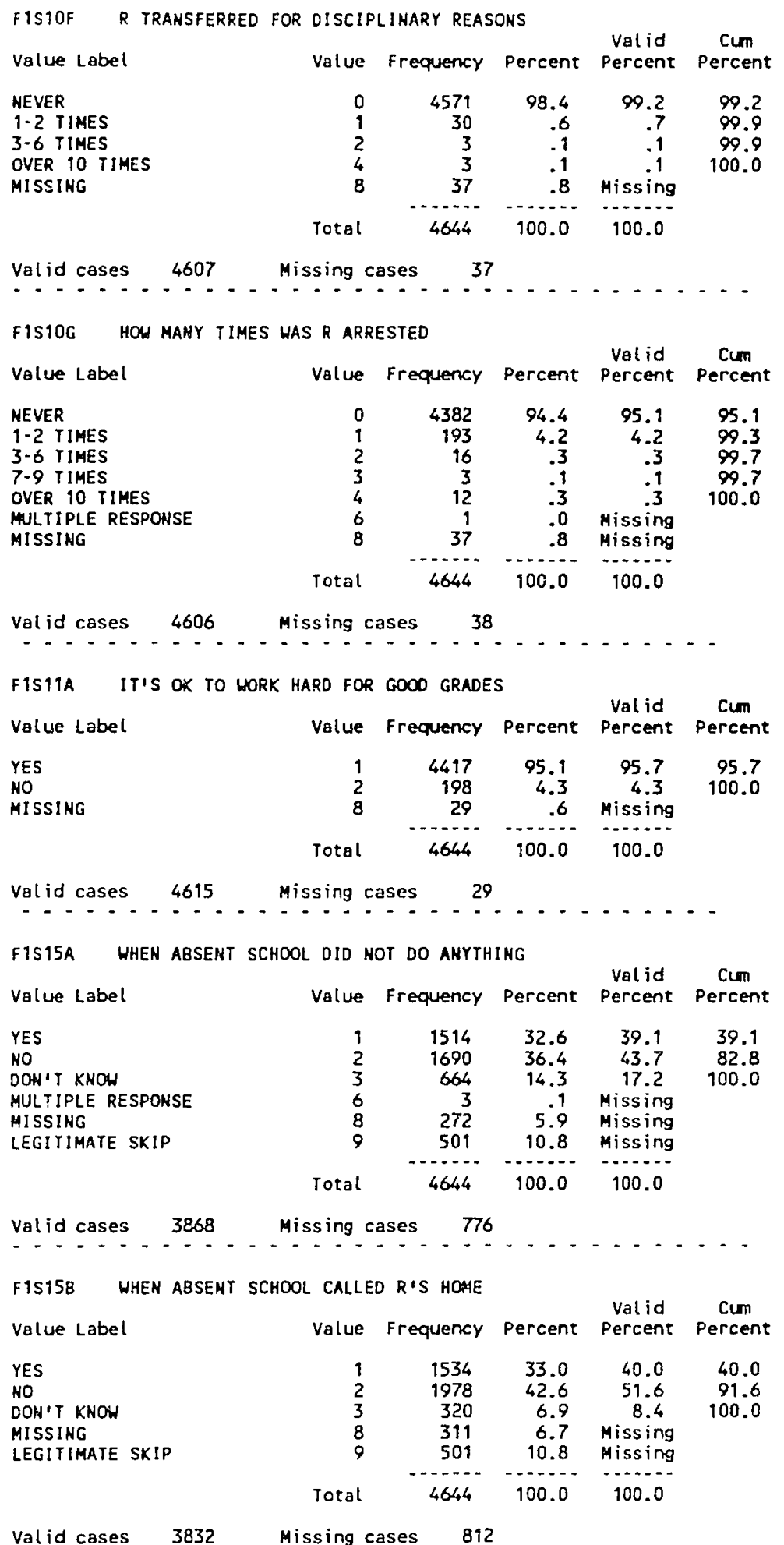


FISISC WHEN ABSENT THE SCHOOL VISITEO R'S HOME

Value Label

YES

No

DON'T KNOH

MISSING

LEGITIMATE SKIP

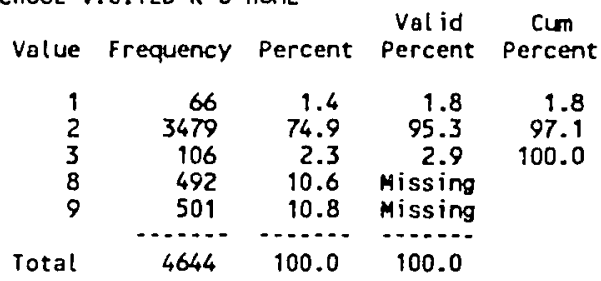

Valid cases $3659 \quad$ Missing cases 993

F1S150 HHEN ABSENT THE SCHL SENT A LETTER HOME

Value Label

Value frequency percent percent percent

YES

MO

DOW'T KNOW

MISSING

LEGITIMATE SKIP

$\begin{array}{rrrrr}1 & 392 & 8.4 & 10.6 & 10.6 \\ 2 & 3107 & 66.9 & 84.4 & 95.0 \\ 3 & 183 & 3.9 & 5.0 & 100.0 \\ 8 & 461 & 9.9 & \text { Missing } & \\ 9 & 501 & 10.8 & \text { Missing } & \\ \text { Total } & 4644 & 100.0 & 100.0 & \end{array}$

Valid cases $3682 \quad$ Missing cases 962

F1S15E WHEN ABSERT R HAD TO SEE A COUNSEL

Value Label

Value frequency percent percent percent

YES

NO

DON'T KNO

MISSING

LEGITIMATE SKIP

$\begin{array}{rrrrr}1 & 99 & 2.1 & 2.7 & 2.7 \\ 2 & 3499 & 7.3 & 95.5 & 98.2 \\ 3 & 67 & 1.4 & 1.8 & 100.0 \\ 8 & 478 & 10.3 & \text { Missing } & \\ 9 & 501 & 10.8 & \text { Missing } & \\ \text { Total } & 4644 & 100.0 & 100.0 & \end{array}$

Valid cases $3665 \quad$ Missing cases 979

F1S16A AFT BEING ABSENT TEACHER HELPED R DO HRK

F1S16A AFT BEING ABSENT TEACHER HELPED R DO HRK
Value Label Value Frequency Percent Percent Percent

\begin{tabular}{|c|c|c|c|c|c|}
\hline $\begin{array}{l}\text { APPLIES } \\
\text { DOES NOT APPLY } \\
\text { MISSING } \\
\text { LEGITIMATE SKIP }\end{array}$ & $\begin{array}{l}1 \\
2 \\
8 \\
9\end{array}$ & $\begin{array}{r}1901 \\
2109 \\
133 \\
501\end{array}$ & $\begin{array}{r}40.9 \\
45.4 \\
2.9 \\
10.8\end{array}$ & $\begin{array}{r}47.4 \\
52.6 \\
\text { Missing } \\
\text { Missing }\end{array}$ & $\begin{array}{r}47.4 \\
100.0\end{array}$ \\
\hline & 15 & 4644 & 100.0 & 100.0 & \\
\hline
\end{tabular}

Valid cases $4010 \quad$ Missing cases 634

F1S16B AFTER BEING ABSENT STUS HELPED R DO WORK

Value Label Value Frequency percent percent percent

\begin{tabular}{|c|c|c|c|c|c|}
\hline $\begin{array}{l}\text { APPLIES } \\
\text { DOES NOT APPLY } \\
\text { MISSING } \\
\text { LEGITIMATE SKIP }\end{array}$ & $\begin{array}{l}1 \\
2 \\
8 \\
9\end{array}$ & $\begin{array}{r}1776 \\
2234 \\
133 \\
501\end{array}$ & $\begin{array}{r}38.2 \\
48.1 \\
2.9 \\
10.8\end{array}$ & $\begin{array}{r}\quad 64.3 \\
55.7 \\
\text { Missing } \\
\text { Missing }\end{array}$ & $\begin{array}{r}44.3 \\
100.0\end{array}$ \\
\hline & tal & 4644 & 100.0 & 100.0 & \\
\hline
\end{tabular}

Volid cases $4010 \quad$ Missing cases 634 


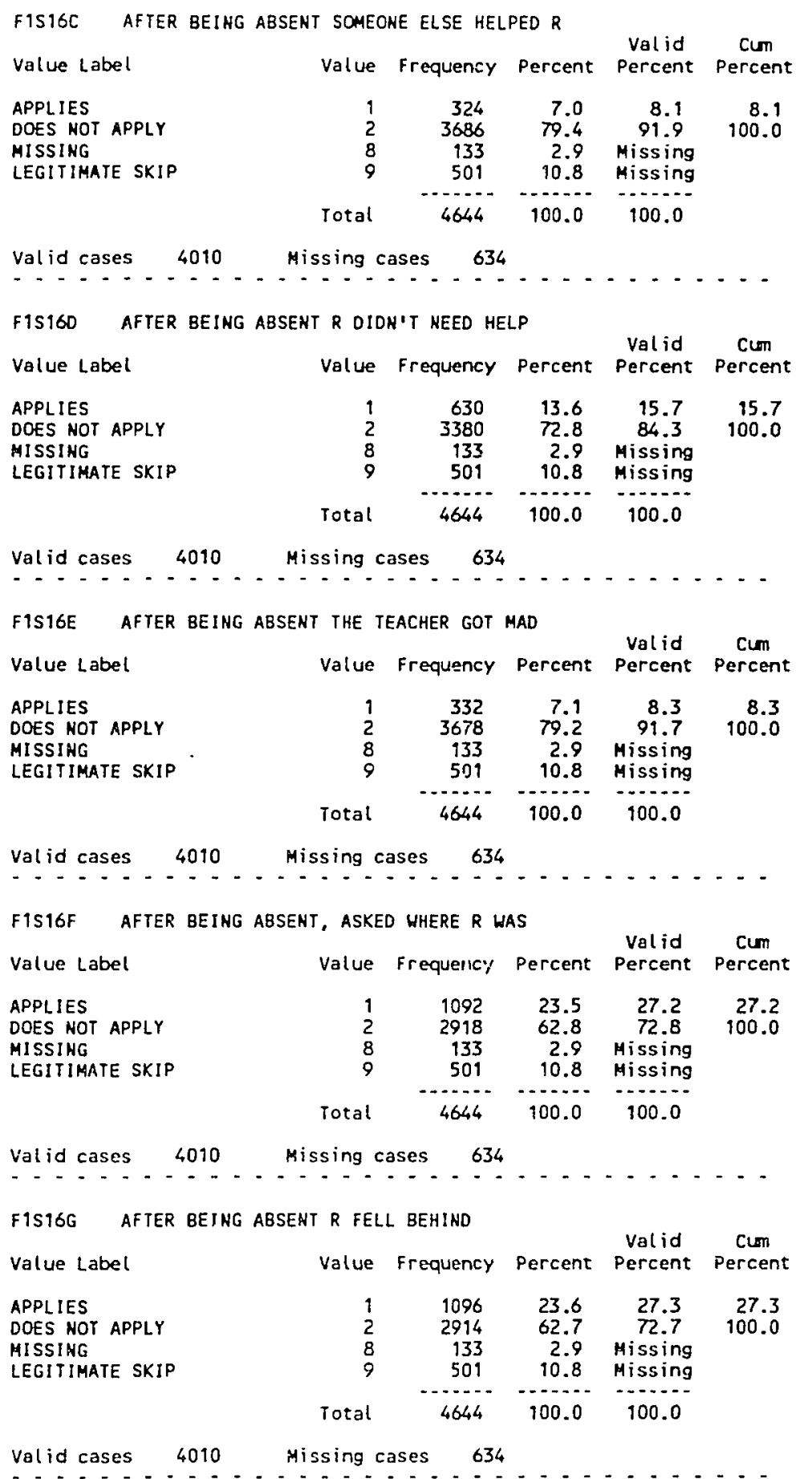


F1S17 HOW HANY YRS WILL IT TAKE R TO GRADUATE

Value Label

Value frequency percent percent percent

1 YEAR

2 YEARS

3 YEARS

4 YEARS

MORE THAN 4 YEARS

DON'T KNOW

MULTIPLE RESPOHSE

MISSING

9
2
3
4
5
6
96
98

\begin{tabular}{rr}
93 & 2.0 \\
4317 & 93.0 \\
123 & 2.6 \\
14 & .3 \\
8 & .2 \\
69 & 1.5 \\
1 & .0 \\
19 & .4 \\
\hline 4644 & 100.0
\end{tabular}

$\begin{array}{rr}2.0 & 2.0 \\ 93.4 & 95.4\end{array}$

$\begin{array}{rr}93.6 & 95.4 \\ 2.7 & 98.0\end{array}$

$.3 \quad 98.3$

$1.5 \quad 100.0$

Total $4644 \quad 100.0$

Valid cases $4624 \quad$ Missing cases 20

- - . - . . . - . . . . . . . . -

FIS18A R SURE TO GRADUATE FROM HIGH SCHOOL

Value Label

value

Valid

Curn

YES/VERY SURE GRAD

PROBABLY

PROBABLY HOT

NO/VERY SURE \& WOW'T

MISSING

$\begin{array}{rrrrr}1 & 3607 & 77.7 & 77.7 & 77.7 \\ 2 & 957 & 20.6 & 20.6 & 98.3 \\ 3 & 31 & .7 & .7 & 99.0 \\ 4 & 46 & 1.0 & 1.0 & 100.0 \\ 8 & 3 & .1 & \text { Missing } & \\ \text { Total } & 4644 & 100.0 & 100.0 & \end{array}$

Valid cases 4641 Missing cases 3

FIST8B R SURE TO FURTHER EOUCATION AFTER H.S

Value Label

Value Frequency percent percent percent

VERY SURE I'LL GO

PROBABLY WILL GO

PROBABLY HON'T GO

VERY SURE I WOA'T GO

MULTIPLE RESPONSE

AISSING

$\begin{array}{rrrrr}1 & 2092 & 45.0 & 45.3 & 45.3 \\ 2 & 1882 & 40.5 & 40.7 & 86.0 \\ 3 & 486 & 10.5 & 10.5 & 96.5 \\ 4 & 161 & 3.5 & 3.5 & 100.0 \\ 6 & 2 & .0 & \text { Missing } & \\ 8 & 21 & .5 & \text { Missing } & \\ & -1 . . & -1.5 & -1.2 . . & \end{array}$

Valid cases $4621 \quad$ Missing cases 23

FIS2O DESCRIBE PRESENT HIGH SCHOOL PROGRAM

FIS2O DESCRIBE PRESENT HIGH SCHOOL PROGRAM Valid cum

Value Label

Value Frequency Percent percent percent

GENERAL H.S PROGRAM

COLLEGE PREPARATORY

IHDUSTRIAL ARTS

AGRICULTURAL OCCUPTH

BUSINESS OCCUPATIONS

MARKETING EDUCATION

HEALTH OCCUPATIONS

HOME ECON OCCUPATION

COHSUMER EDUCATION

TECHNICAL OCCUPATION

TRAOE OCCUPATIONS

SPECIALIZED H.S PROG

OTHER

I DON'T KNOW

NULTIPLE RESPONSE

HISSING

$\begin{array}{rrrrr}1 & 2220 & 47.8 & 48.8 & 48.8 \\ 2 & 1044 & 22.5 & 23.0 & 71.8 \\ 3 & 155 & 3.3 & 3.4 & 75.2 \\ 4 & 57 & 1.2 & 1.3 & 76.4 \\ 5 & 139 & 3.0 & 3.1 & 79.5 \\ 6 & 18 & .4 & .4 & 79.9 \\ 7 & 37 & .8 & .8 & 80.7 \\ 8 & 14 & .3 & .3 & 81.0 \\ 9 & 8 & .2 & .2 & 81.2 \\ 10 & 52 & 1.1 & 1.1 & 82.3 \\ 11 & 44 & .9 & 1.0 & 83.3 \\ 12 & 71 & 1.5 & 1.6 & 84.9 \\ 13 & 241 & 5.2 & 5.3 & 90.1 \\ 14 & 448 & 9.6 & 9.9 & 100.0 \\ 96 & 92 & 2.0 & \text { Missing } & \\ 98 & 4 & .1 & \text { Missing } & \\ & -. .- & -. . .- & -1 . . . & \\ \text { Total } & 4644 & 100.0 & 100.0 & \end{array}$

Valid cases $4548 \quad$ Missing cases 96 
FIS26A OFTEN ASKED TO SHOW UNDERSTAND MATH

Value Label

Volue frequency percent percent percent

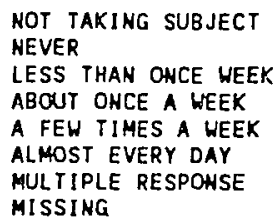

NOT TAKING SUBJECT

NEVER

LESS THAN ONCE HEEK

ABOUT ONCE $A$ WEEK

A FEW TIMES A HEEX

ALMOST EVERY DAY

MULIIPLE RESPOHSE

MISSING

$\begin{array}{rrrrr}1 & 177 & 3.8 & 3.9 & 3.9 \\ 2 & 496 & 10.7 & 11.1 & 15.0 \\ 3 & 605 & 13.0 & 13.5 & 28.5 \\ 4 & 712 & 15.3 & 15.9 & 44.3 \\ 5 & 997 & 21.5 & 22.2 & 66.6 \\ 6 & 1501 & 32.3 & 33.4 & 100.0 \\ 96 & 1 & .0 & \text { Missing } & \\ 98 & 155 & 3.3 & \text { Missing } & \\ \text { Total } & 4644 & 100.0 & 100.0\end{array}$

Volid cases 4488 Missing cases 156

V.

F1S26B OFTEN ASKED TO SHOW UNDERSTAHD ENGLISH

Value Label

Value Frequency Percent Palid Cum

\begin{tabular}{|c|c|c|c|c|}
\hline $\begin{array}{l}\text { NOT TAKING SUBJECT } \\
\text { NEVER } \\
\text { LESS THAN ONCE WEEK } \\
\text { ABOUT ONCE A WEEK } \\
\text { A FEW TIMES A HEEK } \\
\text { ALMOST EVERY DAY } \\
\text { MULTIPLE RESPONSE } \\
\text { MISSING }\end{array}$ & $\begin{array}{r}1 \\
2 \\
3 \\
4 \\
5 \\
6 \\
96 \\
98\end{array}$ & $\begin{array}{r}43 \\
735 \\
764 \\
816 \\
1081 \\
1031 \\
2 \\
172 \\
4644\end{array}$ & $\begin{array}{r}.9 \\
15.8 \\
16.5 \\
17.6 \\
23.3 \\
22.2 \\
.0 \\
3.7 \\
100.0\end{array}$ & $\begin{array}{r}1.0 \\
16.4 \\
17.1 \\
18.3 \\
24.2 \\
23.1 \\
\text { Missing } \\
\text { Missing } \\
100.0\end{array}$ \\
\hline
\end{tabular}

Valid cases $4470 \quad$ Missing cases 174

FIS26C OFTEN ASKED TO SHON UNDERSTAND HISTORY

Value Label

Value Frequency percent Palid Cum

NOT TAKING SUBJECT

NEVER

LESS THAN ONCE WEEK

ABOUT ONCE A WEEK

A FEW TIMES A WEEK

ALAOST EVERY DAY

MISSING

$\begin{array}{rrrrr}1 & 1429 & 30.8 & 32.1 & 32.1 \\ 2 & 657 & 14.1 & 14.7 & 46.8 \\ 3 & 524 & 11.3 & 11.8 & 58.5 \\ 4 & 545 & 11.7 & 12.2 & 70.8 \\ 5 & 649 & 14.0 & 14.6 & 85.3 \\ 6 & 654 & 14.1 & 14.7 & 100.0 \\ 98 & 186 & 4.0 & \text { Missing } & \\ & -\ldots . . & \ldots \ldots . . & \ldots \ldots . . & \\ \text { Total } & 4644 & 100.0 & 100.0 & \end{array}$

Valid cases $4458 \quad$ Missing cases 186

F1S260 OFTEN ASKED TO SHOW UNDERSTAND SCIENCE

Value Label Value Frequency percent percent percent

\begin{tabular}{|c|c|c|c|c|c|}
\hline $\begin{array}{l}\text { NDT TAKING SUBJECT } \\
\text { NEVER } \\
\text { LESS THAH OWCE HEEK } \\
\text { ABOUT ONCE A WEEK } \\
\text { A FEW TIMES A WEEK } \\
\text { ALOMOST EVERY DAY } \\
\text { MULTIPLE RESPONSE } \\
\text { HISSING }\end{array}$ & $\begin{array}{r}1 \\
2 \\
3 \\
4 \\
5 \\
6 \\
96 \\
98\end{array}$ & $\begin{array}{r}432 \\
679 \\
672 \\
773 \\
949 \\
963 \\
2 \\
182 \\
4644\end{array}$ & $\begin{array}{r}9.3 \\
14.6 \\
14.5 \\
16.6 \\
20.3 \\
20.7 \\
.0 \\
3.9 \\
100.0\end{array}$ & $\begin{array}{r}9.7 \\
15.2 \\
15.1 \\
17.3 \\
21.1 \\
21.6 \\
\text { Missing } \\
\text { Missing } \\
100.0\end{array}$ & $\begin{array}{r}9.7 \\
24.9 \\
40.0 \\
57.3 \\
78.4 \\
100.0\end{array}$ \\
\hline
\end{tabular}

Valid cases $4460 \quad$ Missing cases 184 
F1S27A OFTEN WORK HARD IN MATH CLASS

\begin{tabular}{|c|c|c|c|c|c|}
\hline Value Label & Value & Frequency & Percent & $\begin{array}{l}\text { Valid } \\
\text { Percent }\end{array}$ & $\begin{array}{c}\text { Cum } \\
\text { Percent }\end{array}$ \\
\hline $\begin{array}{l}\text { NOT TAKING SUBJECT } \\
\text { NEVER } \\
\text { LESS THAN OWCE WEEK } \\
\text { ABOUT ONCE A WEEK } \\
\text { A FEN TIMES A WEEK } \\
\text { ALMOST EVERY DAY } \\
\text { HULIPLE RESPONSE } \\
\text { MISSING }\end{array}$ & $\begin{array}{r}1 \\
2 \\
3 \\
4 \\
5 \\
6 \\
96 \\
98\end{array}$ & $\begin{array}{r}177 \\
272 \\
315 \\
402 \\
1289 \\
2036 \\
1 \\
152\end{array}$ & $\begin{array}{r}3.8 \\
5.9 \\
6.8 \\
8.7 \\
27.8 \\
43.8 \\
.0 \\
3.3\end{array}$ & $\begin{array}{r}3.9 \\
6.1 \\
7.0 \\
9.0 \\
28.7 \\
45.3 \\
\text { Missing } \\
\text { Missing }\end{array}$ & $\begin{array}{r}3.9 \\
10.0 \\
17.0 \\
26.0 \\
54.7 \\
100.0\end{array}$ \\
\hline & Total & 4644 & 100.0 & 100.0 & \\
\hline
\end{tabular}

Valid cases $4491 \quad$ Missing cases 153

F1S27B OFTEN WORK HARD IN ENGLISH CLASS

\begin{tabular}{|c|c|c|c|c|c|}
\hline Value Label & Value & Frequency & Percent & $\begin{array}{l}\text { Valid } \\
\text { Percent }\end{array}$ & $\begin{array}{l}\text { Cum } \\
\text { Percent }\end{array}$ \\
\hline $\begin{array}{l}\text { NOT TAKING SUBJECT } \\
\text { NEVER } \\
\text { LESS THAN ONCE WEEK } \\
\text { ABOUT OHCE A WEEK } \\
\text { A FEW TIMES A HEEK } \\
\text { ALHOST EVERY OAY } \\
\text { MISSING }\end{array}$ & $\begin{array}{r}1 \\
2 \\
3 \\
4 \\
5 \\
6 \\
98 \\
\text { Total }\end{array}$ & $\begin{array}{r}44 \\
253 \\
322 \\
484 \\
1500 \\
1883 \\
158 \\
4644\end{array}$ & $\begin{array}{r}.9 \\
5.4 \\
6.9 \\
10.4 \\
32.3 \\
40.5 \\
3.4 \\
100.0\end{array}$ & $\begin{array}{r}1.0 \\
5.6 \\
7.2 \\
10.8 \\
33.4 \\
42.0 \\
\text { Missing } \\
100.0\end{array}$ & $\begin{array}{r}1.0 \\
6.6 \\
13.8 \\
24.6 \\
58.0 \\
100.0\end{array}$ \\
\hline
\end{tabular}

Valid cases $4486 \quad$ Hissing cases 158

F1S27C OFTEN WORK HARD IN HISTORY CLASS

\begin{tabular}{|c|c|c|c|c|c|}
\hline Volue Label & Value & Frequency & Percent & $\begin{array}{l}\text { Valid } \\
\text { Percent }\end{array}$ & $\begin{array}{l}\text { Cum } \\
\text { Percent }\end{array}$ \\
\hline $\begin{array}{l}\text { NOT TAKIHG SUBJECT } \\
\text { NEVER } \\
\text { LESS THAH ONCE WEEK } \\
\text { ABOUT ONCE A WEEK } \\
\text { A FEW TIMES A WEEK } \\
\text { ALMOST EVERY DAY } \\
\text { HISSING }\end{array}$ & $\begin{array}{r}1 \\
2 \\
3 \\
4 \\
5 \\
6 \\
98\end{array}$ & $\begin{array}{r}1429 \\
234 \\
243 \\
364 \\
995 \\
1212 \\
167\end{array}$ & $\begin{array}{r}30.8 \\
5.0 \\
5.2 \\
7.8 \\
21.4 \\
26.1 \\
3.6\end{array}$ & $\begin{array}{r}31.9 \\
5.2 \\
5.4 \\
8.1 \\
22.2 \\
27.1 \\
\text { Missing }\end{array}$ & $\begin{array}{r}31.9 \\
37.1 \\
42.6 \\
50.7 \\
72.9 \\
100.0\end{array}$ \\
\hline & Total & 4644 & 100.0 & 100.0 & \\
\hline
\end{tabular}

Valid cases $4477 \quad$ Missing cases 167

F1S2TD OFTEN WORK HARD IN SCIENCE CLASS

Valid Label Cum
Value frequency percent Percent percent

NOT TAKING SUBJECT

NEVER

LESS THAN OHCE WEEK

ABOUT ONCE A WEEK

A FEW TIMES A WEEK

ALROST EVERY DAY

MULTIPLE RESPONSE

AISSING

$\begin{array}{rrrrr}1 & 431 & 9.3 & 9.6 & 9.6 \\ 2 & 223 & 4.8 & 5.0 & 14.6 \\ 3 & 295 & 6.4 & 6.6 & 21.2 \\ 4 & 496 & 10.7 & 11.1 & 32.3 \\ 5 & 1314 & 28.3 & 29.4 & 61.6 \\ 6 & 1717 & 37.0 & 38.4 & 100.0 \\ 96 & 1 & .0 & \text { Hissing } & \\ 98 & 167 & 3.6 & \text { Hissing } & \\ \text { Total } & 4644 & 100.0 & 100.0 & \end{array}$

Valid cases $4476 \quad$ Missing cases 168 


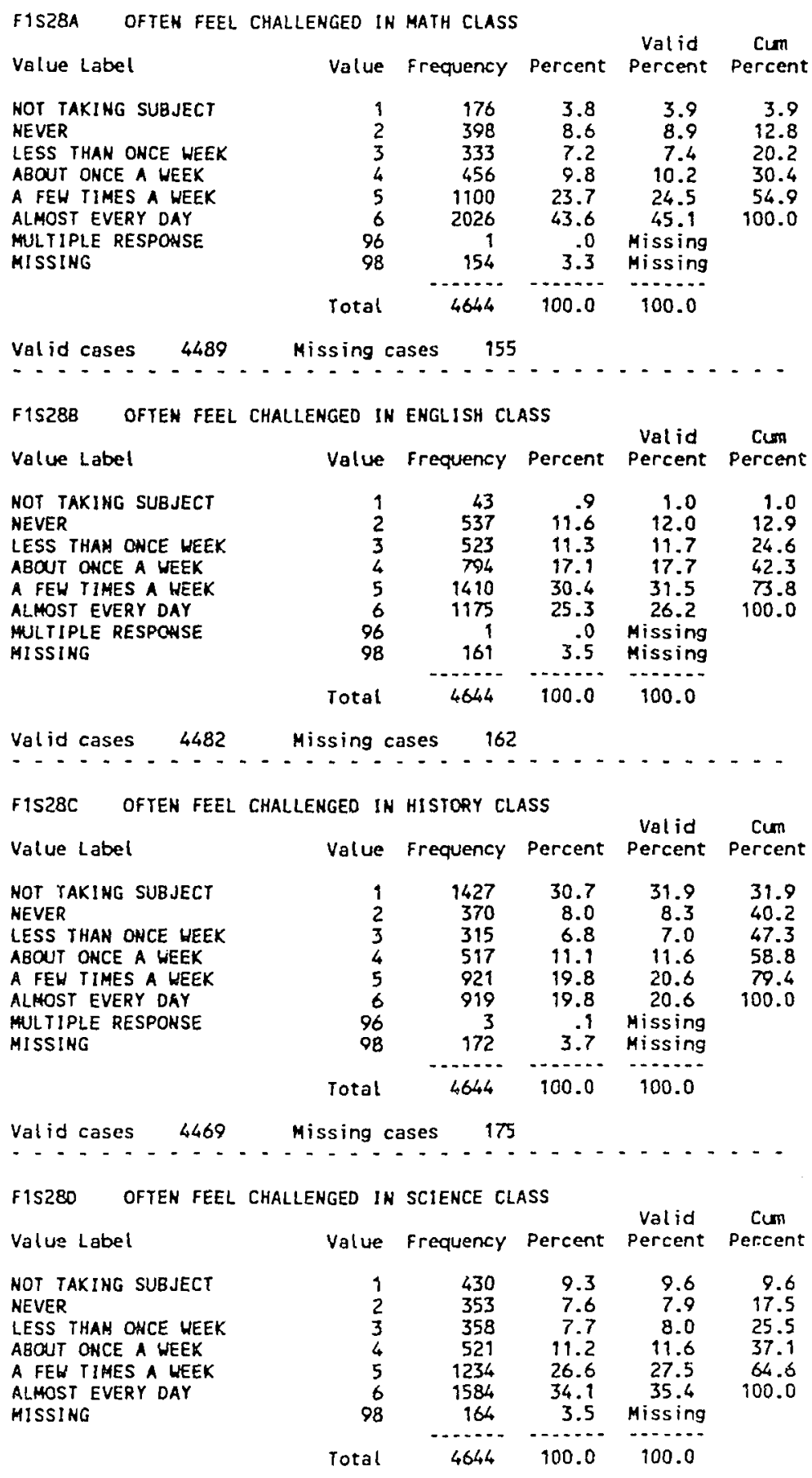

Valid cases $4480 \quad$ Missing cases 164 


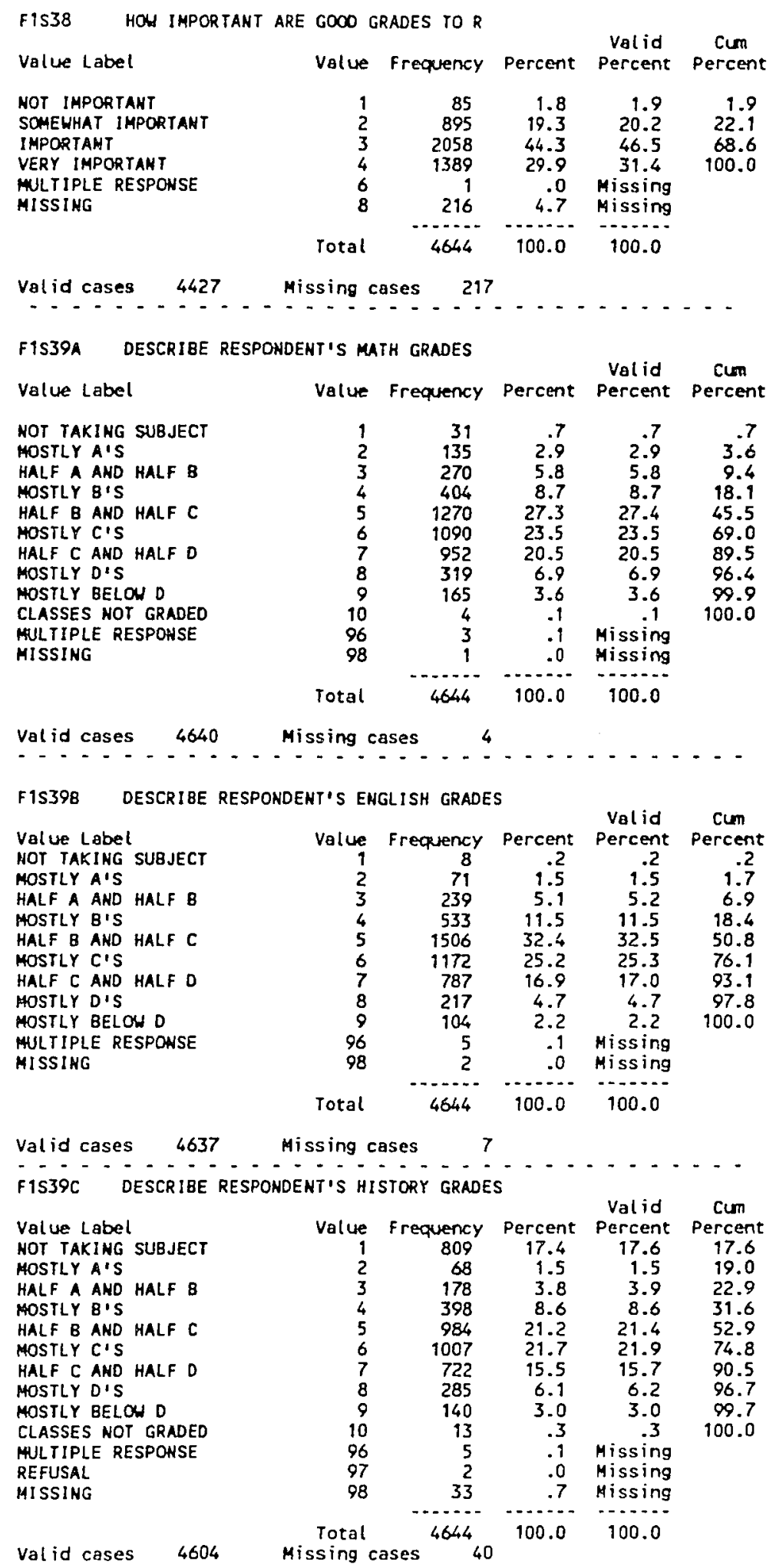


FIS390 OESCRIBE RESPONDENT'S SCIEMCE GRADES

Volue Label

Value frequency Percent Percent percent

NOT TAKING SUBJECT MOSTLY A'S

HALF A AND HALF B

MOSTLY B'S

HALF B AMD HALF $C$

MOSTLY C'S

HALF C AND HALF D

MOSTLY D'S

MOSTLY BELON D

CLASSES NOT GRAOED

MULTIPLE RESPONSE

MISSING
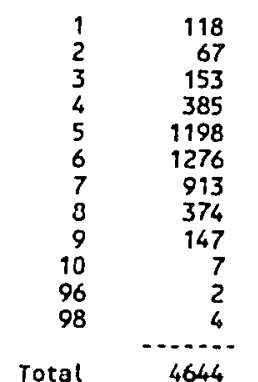

$\begin{array}{r}2.5 \\ 1.4 \\ 3.3 \\ 8.3 \\ 25.8 \\ 27.5 \\ 19.7 \\ 8.1 \\ 3.2 \\ .2 \\ .0 \\ .1 \\ \hline 100.0\end{array}$

$\begin{array}{r}2.5 \\ 1.4 \\ 3.3 \\ 8.3 \\ 25.8 \\ 27.5 \\ 19.7 \\ 8.1 \\ 3.2 \\ .2 \\ \text { issing } \\ \text { issing } \\ \hline 100.0\end{array}$

Valid cases 4638 Missing cases 6

FIS4OA OFTEN GO TO CLASS HITHOUT PENCIL/PAPER

$\begin{array}{lrrrrr}\text { Value Label } & \text { Value } & \text { Frequency } & \text { Percent } & \begin{array}{c}\text { Valid } \\ \text { Percent }\end{array} & \begin{array}{c}\text { Cum } \\ \text { Percent }\end{array} \\ \text { USUALLY } & 1 & 168 & 3.6 & 3.7 & 3.7 \\ \text { OFTEM } & 2 & 407 & 8.8 & 8.9 & 12.6 \\ \text { SELDOM } & 3 & 2113 & 45.5 & 46.2 & 58.8 \\ \text { HEVER } & 4 & 1887 & 40.6 & 41.2 & 100.0 \\ \text { MISSING } & 8 & 69 & 1.5 & \text { Missing } & \\ & \text { Total } & 4644 & 100.0 & 100.0 & \end{array}$

Valid cases $4575 \quad$ Missing cases 69

F1S408 OFTEN GO TO CLASS HITHOUT BOOKS

Value Label Value Frequency percent percent percent

$\begin{array}{lrrrrr}\text { USUALLY } & 1 & 128 & 2.8 & 2.8 & 2.8 \\ \text { OFTEN } & 2 & 217 & 4.7 & 4.8 & 7.6 \\ \text { SELDOM } & 3 & 1964 & 42.3 & 43.0 & 50.6 \\ \text { NEVER } & 4 & 2258 & 48.6 & 49.4 & 100.0 \\ \text { MULTIPLE RESPONSE } & 6 & 7 & .0 & \text { Missing } & \\ \text { MISSING } & 8 & 76 & 1.6 & \text { Missing } & \\ & \text { Total } & 4644 & 100.0 & 100.0 & \end{array}$

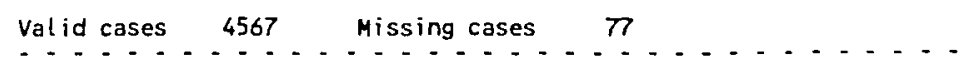

F1S40C OFTEN GO TO CLASS WITHOUT HOMELNORK DONE

Value Label Value frequency percent Percent percent

\begin{tabular}{|c|c|c|c|c|c|}
\hline $\begin{array}{l}\text { USUALLY } \\
\text { OFTEN } \\
\text { SELDOM } \\
\text { NEVER } \\
\text { MULTIPLE RESPONSE } \\
\text { HISSING }\end{array}$ & $\begin{array}{l}1 \\
2 \\
3 \\
4 \\
6 \\
8\end{array}$ & $\begin{array}{r}310 \\
858 \\
2865 \\
545 \\
2 \\
64\end{array}$ & $\begin{array}{r}6.7 \\
18.5 \\
61.7 \\
11.7 \\
.0 \\
1.4\end{array}$ & $\begin{array}{r}6.8 \\
18.7 \\
62.6 \\
11.9 \\
\text { Missing } \\
\text { Missing }\end{array}$ & $\begin{array}{r}6.8 \\
25.5 \\
88.1 \\
100.0\end{array}$ \\
\hline & Total & 4644 & 100.0 & 100.0 & \\
\hline
\end{tabular}

Valid cases $4578 \quad$ Missing cases 66 
F1S41MA PLAYED BASEBALL/SOFTBALL AT SCKOOL

Volue Label

SCHOOL DOES NOT HAVE

DID NOT PARTICIPATE

INTRAMURAL SPORTS

JUAIOR VARSITY TEAH

VARSITY TEAK

CAPTAIN CO-CAPTAIN

MULTIPLE RESPOWSE

MISSING
Value Frequenc

$\begin{array}{rrrrr}1 & 193 & 4.2 & 4.5 & 4.5 \\ 2 & 3450 & 74.3 & 81.0 & 85.5 \\ 3 & 153 & 3.3 & 3.6 & 80.1 \\ 4 & 265 & 5.7 & 6.2 & 95.3 \\ 5 & 181 & 3.8 & 4.2 & 99.6 \\ 6 & 19 & .4 & .4 & 100.0 \\ 96 & 7 & .2 & \text { Missing } & \\ 98 & 376 & 8.1 & \text { Missing } & \\ & \ldots . . .0 & -. . . . & -. . .0 & \end{array}$

Volid cases 4269 Missing cases 383

f1S41AB PLAYED Basketball at SCHOOL

Value Label

Value Frequency Percent Percent percent

SCHOOL DOES NOT HAVE

DID NOT PARTICIPATE

IHTRAHURAL SPORTS

JUNIOR VARSITY TEAM

VARSITY TEAM

CAPTAIN CO-CAPTAIA

MULTIPLE RESPONSE

HISSING

$$
\begin{array}{rrrrr}
1 & 35 & .8 & .8 & .8 \\
2 & 3481 & 75.0 & 81.6 & 82.4 \\
3 & 215 & 4.6 & 5.0 & 87.4 \\
4 & 338 & 7.3 & 7.9 & 95.4 \\
5 & 170 & 3.7 & 4.0 & 99.3 \\
6 & 28 & .6 & .7 & 100.0 \\
96 & 5 & .1 & \text { Missing } & \\
98 & 372 & 8.0 & \text { Hissing } & \\
& -1 .-. & -1 .-. & -. . . . &
\end{array}
$$

Volid cases $4267 \quad$ Missing cases 377

Valid cases

F1S49AC PLAYED FOOTBALl at SCHOOL

Value Label

SCHOOL DOES HOT HAVE DID MOT PARTICIPATE

INTRAMURAL SPORTS

JUNIOR VARSITY TEAM

VARSITY TEAM

CAPTAIN CO-CAPTAIN

MLTIPLE RESPONSE

MISSING

$\begin{array}{rrrrr}1 & 233 & 5.0 & 5.5 & 5.5 \\ 2 & 3272 & 70.5 & 76.8 & 82.3 \\ 3 & 112 & 2.4 & 2.6 & 84.9 \\ 4 & 364 & 7.8 & 8.5 & 93.5 \\ 5 & 257 & 5.5 & 6.0 & 99.5 \\ 6 & 22 & .5 & .5 & 100.0 \\ 96 & 10 & .2 & \text { Missing } & \\ 98 & 374 & 8.1 & \text { Missing } & \\ & \ldots . . . & -1 . . . & \cdots . . . & \end{array}$

Valid cases $4260 \quad$ Missing cases 384

FISGTAD PLAYED SOCCER AT SCHOOL

Value Label

$$
\text { Value frequency percent Percent percent }
$$

SCHOOL DOES NOT HAVE DID NOT PARTICIPATE

INTRAWURAL SPORTS

JUNIOR VARSITY TEAM

VARSITY TEAH

CAPTAIN CO-CAPTAIN

HULTIPLE RESPONSE

MISSIHG

$\begin{array}{rrrrr}1 & 911 & 19.6 & 21.6 & 21.6 \\ 2 & 3002 & 64.6 & 71.3 & 92.9 \\ 3 & 84 & 1.8 & 2.0 & 94.9 \\ 4 & 105 & 2.3 & 2.5 & 97.4 \\ 5 & 99 & 2.1 & 2.4 & 99.7 \\ 6 & 11 & .2 & .3 & 100.0 \\ 96 & 4 & .1 & \text { Missing } & \\ 98 & 428 & 9.2 & \text { Missing } & \\ & -1 . . . & -. . . & -\ldots . . . & \end{array}$

Valid cases $4212 \quad$ Missing cases 432 


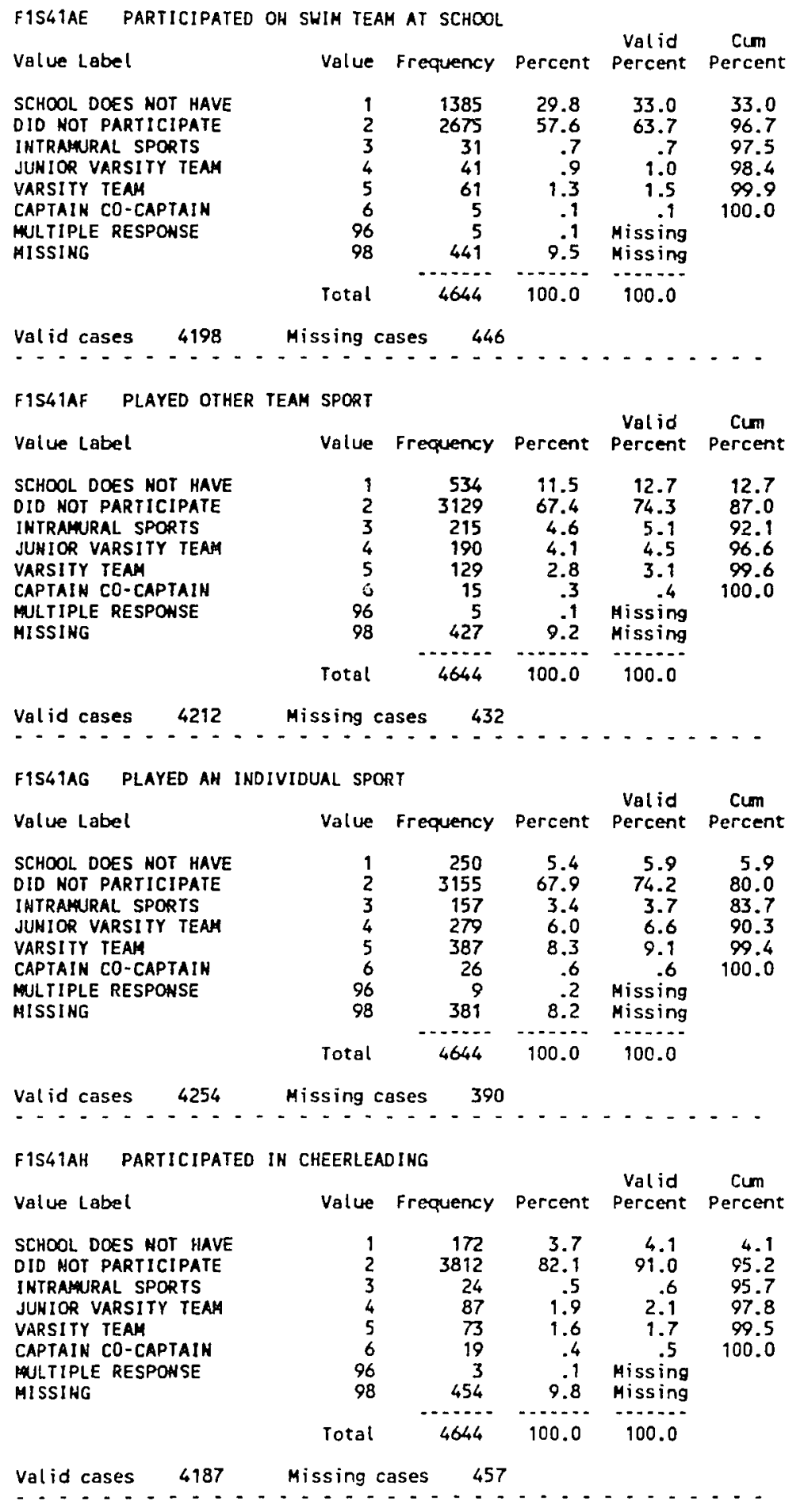


FISGTAI PARTICIPATED ON POM-POM, ORILL TEAM

$\begin{array}{lrrrrr}\text { Value Label } & \text { Value } & \text { Frequency } & \text { Percent } & \begin{array}{c}\text { Valid } \\ \text { Percent }\end{array} & \begin{array}{c}\text { Cim } \\ \text { Percent }\end{array} \\ \text { SCHOOL DOES NOT HAVE } & 1 & 606 & 13.0 & 14.5 & 14.5 \\ \text { OID NOT PARTICIPATE } & 2 & 3424 & 73.7 & 81.8 & 96.3 \\ \text { INTRAMURAL SPORTS } & 3 & 35 & .8 & .8 & 97.1 \\ \text { JUNIOR VARSITY TEAM } & 4 & 42 & .9 & 1.0 & 98.1 \\ \text { VARSITY TEAM } & 5 & 60 & 1.3 & 1.4 & 99.5 \\ \text { CAPTAIN CO-CAPTAIN } & 6 & 19 & .4 & .5 & 100.0 \\ \text { MULTIPLE RESPOWSE } & 96 & 3 & .1 & \text { Missing } & \\ \text { MISSING } & 98 & 455 & 9.8 & \text { Missing } & \\ & \text { Total } & 4644 & 100.0 & 100.0 & \end{array}$

Valid cases $4186 \quad$ Hissing cases 458

FISGIBA PARTICIPATED IN SCHOOL BAND, ORCHESTRA

Value Label

SCHL DOES NOT OFFER

DID NOT PARTICIPATE

PARTICIPAYED

PARTICIPATED OFFICER

HISSIKG

$$
\begin{aligned}
& \text { Value frequency percent percent percent } \\
& \begin{array}{rrrrr}
1 & 97 & 2.1 & 2.2 & 2.2 \\
2 & 3458 & 74.5 & 78.6 & 80.8 \\
3 & 796 & 17.1 & 18.1 & 98.8 \\
4 & 51 & 1.1 & 1.2 & 100.0 \\
8 & 242 & 5.2 & \text { Missing } & \\
\text { Total } & 4644 & 100.0 & 100.0 &
\end{array}
\end{aligned}
$$

Valid cases $4402 \quad$ Missing cases 242

F1S41BB PARTICIPATED IN SCHOOL PLAY OR MUSICAL

Value Label

$$
\text { Value Frequency percent Percent percent }
$$

SCHL DOES NOT OFFER

DID NOT PARTICIPATE

PARTICIPATED

PARTICIPATED OFFICER

MISSING

$\begin{array}{rrrrr}1 & 177 & 3.8 & 4.0 & 4.0 \\ 2 & 3807 & 82.0 & 86.7 & 90.8 \\ 3 & 378 & 8.1 & 8.6 & 99.4 \\ 4 & 28 & .6 & .6 & 100.0 \\ 8 & 254 & 5.5 & \text { Missing } & \\ \text { Total } & 4644 & 100.0 & 100.0 & \end{array}$

Valid cases $4390 \quad$ Missing cases 254

FIS 4 IBC PARTICIPATED IN STUDENT GOVERNMENT

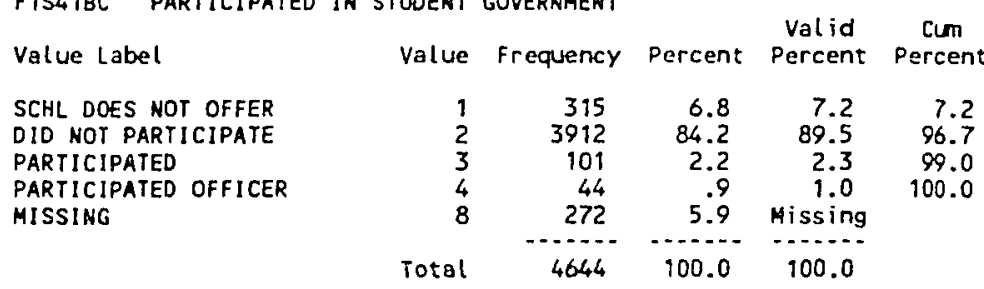

Valid cases $\quad 4372 \quad$ Missing cases 272

FIS4TBD PARTICIPATED IN ACADEMIC HONOR SOCIETY

Value Label

SCHL DOES HOT OFFER

DID NOT PARTICIPATE

PARTICIPATED

PARTICIPATED OFFICER

MISSING

Valid cases $\quad 4381$ value frequency percent Percent Percent

$$
\begin{array}{rrrrr}
1 & 217 & 4.7 & 5.0 & 5.0 \\
2 & 4126 & 88.8 & 94.2 & 99.1 \\
3 & 34 & .7 & .8 & 99.9 \\
4 & 4 & .1 & .1 & 100.0 \\
8 & 263 & 5.7 & \text { Hissing } & \\
\text { Total } & 4644 & 100.0 & 100.0 &
\end{array}
$$

Missing cases 263 
F1S418E PARTICIPATED IN SCHL YEARBOOK, NEHSPAPER

Value Label

Value frequency percent percent cum

SCHL DOES NOT OFFER

DID NOT PARTICIPATE

PARTICIPATED

PARTICIPATED OFFICER

MISSING

$\begin{array}{rrrrr}1 & 58 & 1.2 & 1.3 & 1.3 \\ 2 & 4079 & 87.7 & 92.9 & 94.2 \\ 3 & 236 & 5.1 & 5.4 & 99.6 \\ 4 & 18 & .4 & .4 & 100.0 \\ 8 & 269 & 5.6 & \text { Missing } & \\ \text { Total } & 4644 & 100.0 & 100.0 & \end{array}$

Valid cases $4383 \quad$ Missing cases 261

FIS4IBF PARTICIPATED IN SCHOOL SERVICE CLUBS

Value Label

Value frequency percent percent percent

SCHL DOES NOT OFFER

DID NOT PARTICIPATE

PARTICIPATED

PARTICIPATED OFFICER

MULTIPLE RESPONSE

MISSING

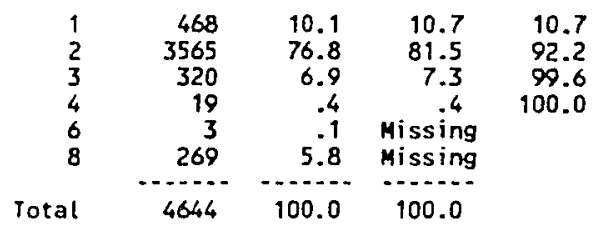

Valid cases 4372 Missing cases 272

F1S4TBG PARTICIPATED IN SCHOOL ACADEMIC CLUBS

Volue Label

CHOOL ACADEAIC CLUBS

SCHL DOES NOT OFFER

DID NOT PARTICIPATE

PARTICIPATEO

PARTICIPATED OFFICER

MULTIPLE RESPOHSE

HISSING

Value Frequency Percent

Val id

Cum

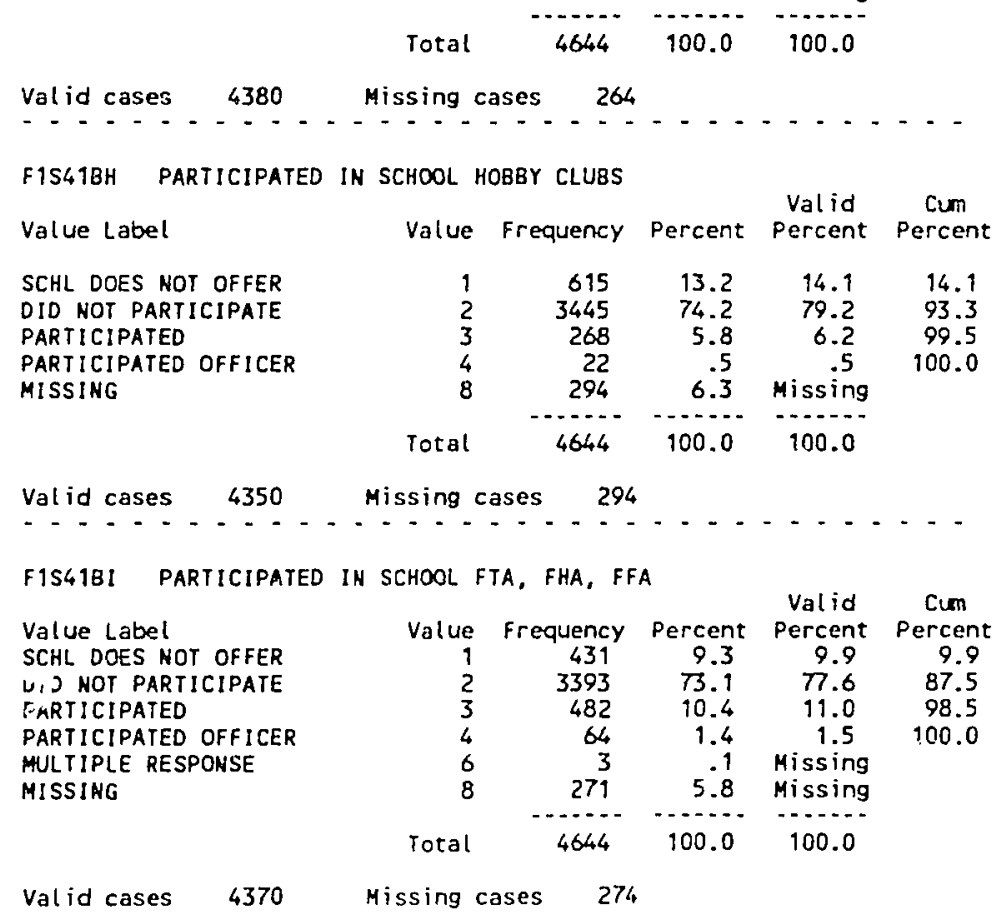


FIS44A VISIT WITH FRIENDS AT LOCAL HANGOUT

Value Label

Value frequency Cum

RARELY OR NEVER

LESS THAN ONCE WEEK

ONCE OR TWICE A WEEK

EVERY DAY OR ALMOST

MISSING

$\begin{array}{rrrrr}1 & 635 & 13.7 & 14.2 & 14.2 \\ 2 & 611 & 13.2 & 13.6 & 27.8 \\ 3 & 1834 & 39.5 & 40.9 & 68.7 \\ 4 & 1401 & 30.2 & 31.3 & 100.0 \\ 8 & 163 & 3.5 & \text { Missing } & \\ & \ldots & -1 . . & \\ \text { Total } & 4644 & 100.0 & 100.0 & \end{array}$

Val id cases 4481 Missing cases 963

FIS44B HOW OFTEN DOES R USE PERSOHAL COMPUTERS

$\begin{array}{lrrrrr}\text { Value Label } & \text { Value } & \text { Frequency } & \text { Percent } & \begin{array}{c}\text { Valid } \\ \text { Percent }\end{array} & \begin{array}{c}\text { Cum } \\ \text { Percent }\end{array} \\ \text { RARELY OR HEVER } & 1 & 3439 & 74.1 & 77.1 & 77.1 \\ \text { LESS THAN OHCE HEEK } & 2 & 516 & 11.1 & 11.6 & 88.7 \\ \text { OHCE OR THICE A WEEK } & 3 & 327 & 7.0 & 7.3 & 96.0 \\ \text { EVERY DAY OR ALHOST } & 4 & 178 & 3.8 & 4.0 & 100.0 \\ \text { MISSING } & 8 & 184 & 4.0 & \text { Missing } & \\ & \text { Total } & 4644 & 100.0 & 100.0 & \end{array}$

Valid cases $4460 \quad$ Missing cases 184

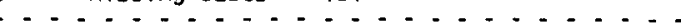

FIS44C HOW OFTEN DOES R WORK ON MOBBIES

Value Label

Value Frequency percent Palid Cum

RARELY OR NEVER

LESS THAN ONCE WEEK

ONCE OR TWICE A WEEK

EVERY DAY OR ALMOST

MULTIPLE RESPOASE

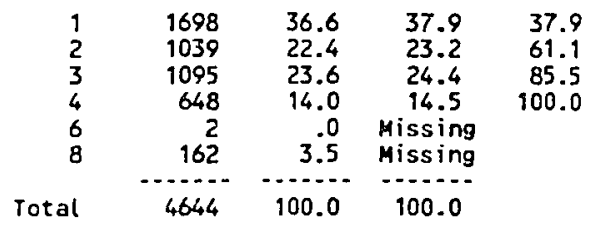

Valid cases $4480 \quad$ Missing cases 164

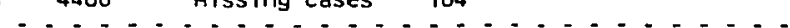

F1544D HOW OFTEN DOES R READ FOR PLEASIJRE

Value Label

Value Frequency percent Palid Cum

RARELY OR NEVER

LESS THAN ONCE WEEX

ONCE OR THICE A HEEK

EVERY DAY OR ALMOST

MISSING

$\begin{array}{rrrrr}1 & 1976 & 42.5 & 44.5 & 44.5 \\ 2 & 926 & 19.9 & 20.8 & 65.3 \\ 3 & 933 & 20.9 & 21.0 & 86.3 \\ 4 & 607 & 13.1 & 13.7 & 100.0 \\ 8 & 202 & 4.3 & \text { Missing } & \\ \text { Total } & 4644 & 100.0 & 100.0 & \end{array}$

Valid cases 4442 Missing cases 202

F1S44E HOW OFTEN DCES $R$ GO TO THE PARK, GYM,POOL

Value Label Value frequency Percent Percent percent

RARELY OR NEVER

LESS THAN OHCE WEEK

ONCE OR THICE A WEEK

EVERY DAY OR ALYOST

WULTIPLE RESPONSE

MISSING

$\begin{array}{rrrrr}1 & 1457 & 31.4 & 32.7 & 32.7 \\ 2 & 1000 & 21.5 & 22.5 & 55.2 \\ 3 & 1318 & 28.4 & 29.6 & 84.8 \\ 4 & 675 & 14.5 & 15.2 & 100.0 \\ 6 & 3 & .1 & \text { Missing } & \\ 8 & 199 & 4.1 & \text { Missing } & \\ \text { Total } & 4644 & 100.0 & 100.0 & \end{array}$

Valid cases $4450 \quad$ Missing cases 194 


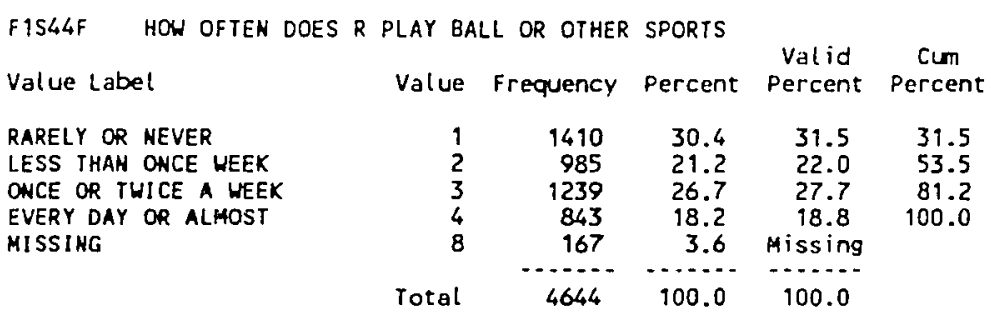

Volid cases $4477 \quad$ Missing cases $167 \ldots \ldots$

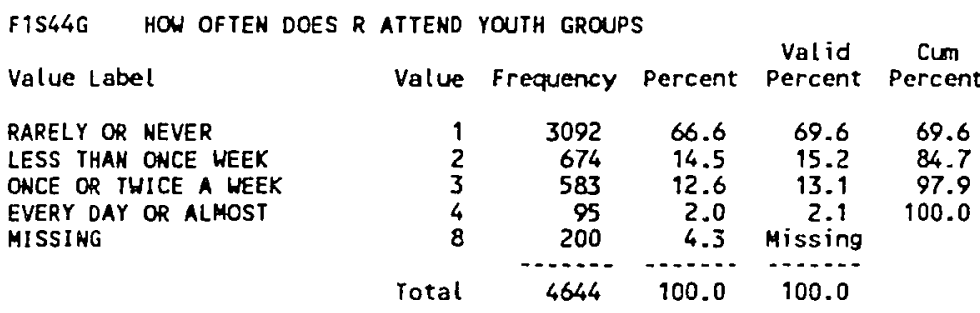

Valid cases $4444 \quad$ Missing cases 200

FIS44H HOW OFTEN R PERFORMS COAMUNITY SERVICES

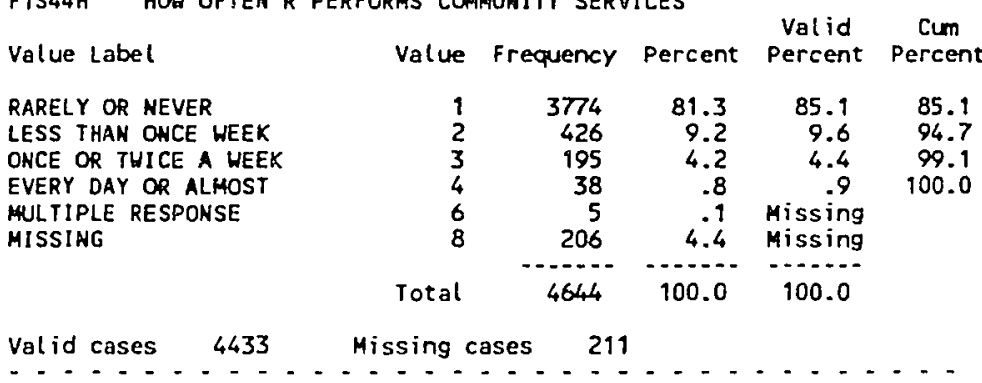

F1S44I HOW OFTEN DOES R DRIVE OR RIDE AROUND

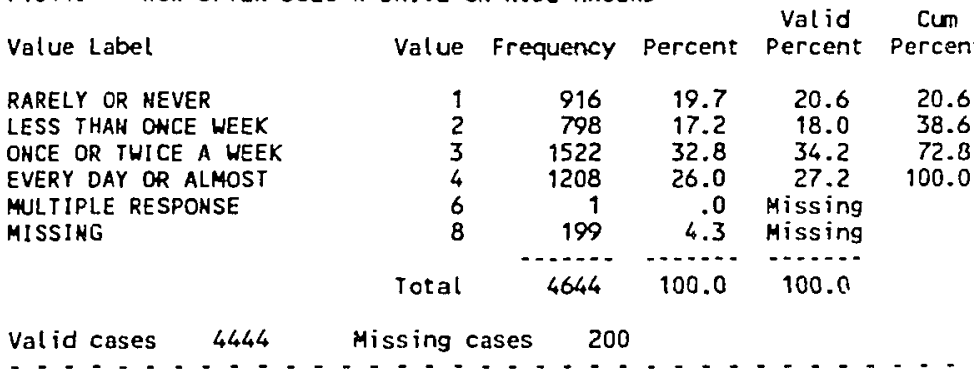

FIS44J HOW OFTEN R TALKS ON PHONE WITH FRIENDS

Value Label

RARELY OR MEVER

LESS THAN ONCE WEEK

ONCE OR THICE A WEEK

EVERY DAY OR ALMOST

HULTIPLE RESPONSE

HISSING

Valid cases

4434 value Frequency percent percent percent

$$
\begin{array}{rrrrr}
1 & 394 & 8.5 & 8.9 & 8.9 \\
2 & 460 & 9.9 & 10.4 & 19.3 \\
3 & 840 & 18.1 & 18.9 & 38.2 \\
4 & 2740 & 59.0 & 61.8 & 100.0 \\
6 & 1 & .0 & \text { Missing } & \\
8 & 209 & 4.5 & \text { Missing } & \\
\text { Total } & 4644 & 100.0 & 100.0 &
\end{array}
$$




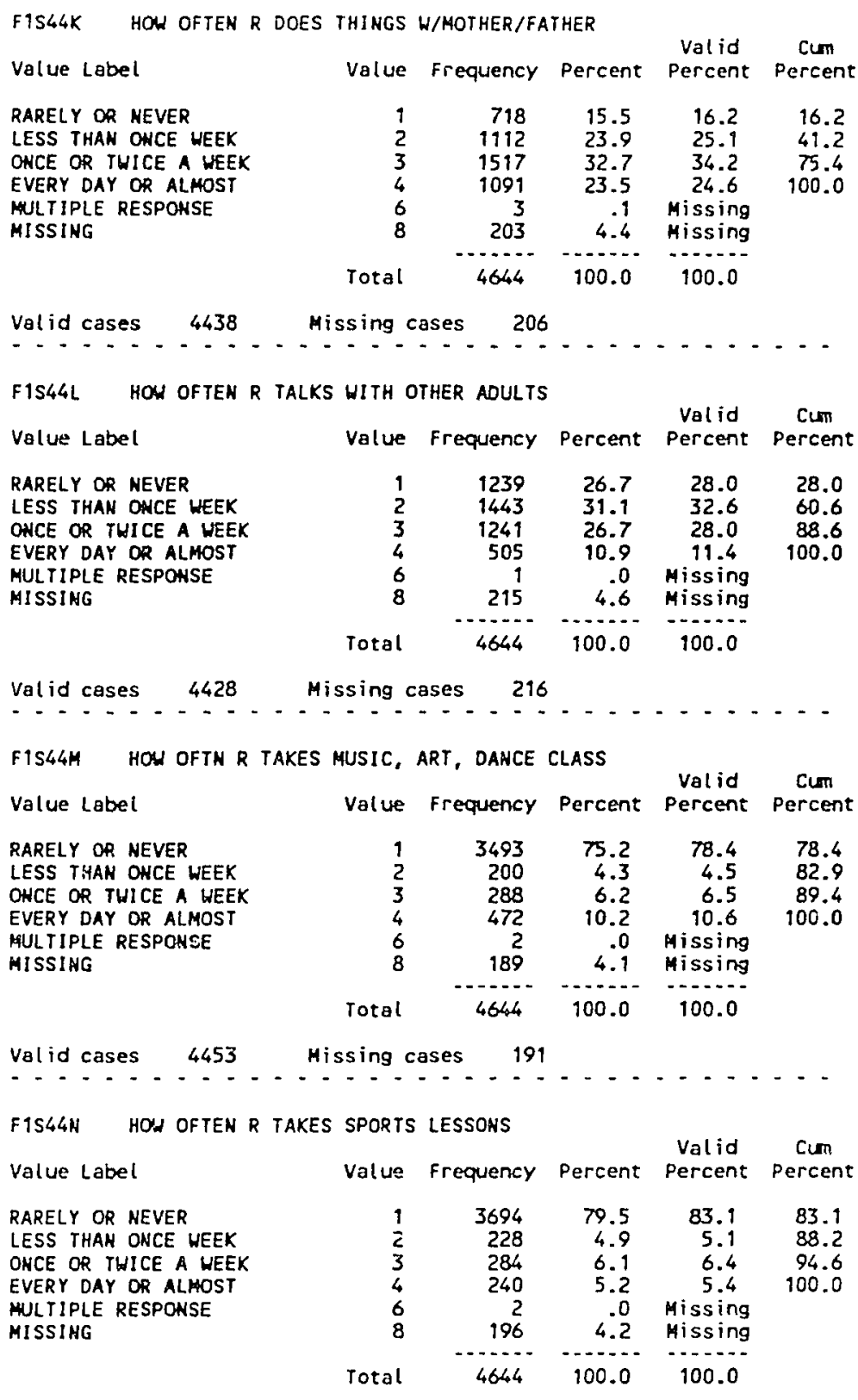

valid cases $4446 \quad$ Missing cases 198 


\begin{tabular}{|c|c|c|c|c|c|}
\hline \multirow{2}{*}{$\begin{array}{l}\text { F1S440 HOW OFTEH R } \\
\text { Value Label }\end{array}$} & \multicolumn{3}{|c|}{ S RELIGIOUS } & \multirow{2}{*}{$\begin{array}{l}\text { Valid } \\
\text { Percent }\end{array}$} & \multirow{2}{*}{$\begin{array}{l}\text { Cum } \\
\text { Percent }\end{array}$} \\
\hline & Value & Frequency & Percent & & \\
\hline $\begin{array}{l}\text { RARELY OR NEVER } \\
\text { LESS THAH ONCE WEEK } \\
\text { OHCE OR THICE A HEEK } \\
\text { EVERY DAY OR ALLOST } \\
\text { MULTIPLE RESPONSE } \\
\text { MISSING }\end{array}$ & $\begin{array}{l}1 \\
2 \\
3 \\
4 \\
6 \\
8\end{array}$ & $\begin{array}{r}2652 \\
718 \\
999 \\
88 \\
1 \\
186\end{array}$ & $\begin{array}{r}57.1 \\
15.5 \\
21.5 \\
1.9 \\
.0 \\
4.0\end{array}$ & $\begin{array}{r}59.5 \\
16.1 \\
22.4 \\
2.0 \\
\text { Missing } \\
\text { Missing }\end{array}$ & $\begin{array}{r}59.5 \\
75.6 \\
98.0 \\
100.0\end{array}$ \\
\hline & Total & 4644 & 100.0 & 100.0 & \\
\hline
\end{tabular}

Valid cases $4457 \quad$ Missing cases 187

FISL8A HOW FAR IN SCHOOL FATHER WANTS R TO GO

\begin{tabular}{|c|c|c|c|c|c|}
\hline Value Label & Value & Frequency & Percent & $\begin{array}{l}\text { Valid } \\
\text { Percent }\end{array}$ & $\begin{array}{l}\text { Cum } \\
\text { Percent }\end{array}$ \\
\hline $\begin{array}{l}\text { LESS THAN HS GRAD } \\
\text { GRADUATE FROA HS } \\
\text { VOCATIONAL AFTER HS } \\
\text { ATIEND } 2 \text {-YR COLLEGE } \\
\text { ATIEND } 4-Y R \text { COLLEGE } \\
\text { GRAD FROA COLLEGE } \\
\text { POST GRAD ED } \\
\text { OOH'T KNOW } \\
\text { PARENT DOESN'T CARE } \\
\text { DOES NOT APPLY } \\
\text { MISSIMG }\end{array}$ & $\begin{array}{r}1 \\
2 \\
3 \\
4 \\
5 \\
6 \\
7 \\
8 \\
9 \\
10 \\
98\end{array}$ & $\begin{array}{r}34 \\
268 \\
439 \\
281 \\
432 \\
1658 \\
466 \\
464 \\
106 \\
332 \\
164\end{array}$ & $\begin{array}{r}.7 \\
5.8 \\
9.5 \\
6.1 \\
9.3 \\
35.7 \\
10.0 \\
10.0 \\
2.3 \\
7.1 \\
3.5\end{array}$ & $\begin{array}{r}.8 \\
6.0 \\
9.8 \\
6.3 \\
9.6 \\
37.0 \\
10.4 \\
10.4 \\
2.4 \\
7.4 \\
\text { Hissing }\end{array}$ & $\begin{array}{r}.8 \\
6.7 \\
16.5 \\
22.8 \\
32.5 \\
69.5 \\
79.9 \\
90.2 \\
92.6 \\
100.0\end{array}$ \\
\hline & Total & 4644 & 100.0 & 100.0 & \\
\hline
\end{tabular}

Valid cases $4480 \quad$ Missing cases 164

F1S488 HON FAR IN SCHOOL MOTHER WANTS R TO GO

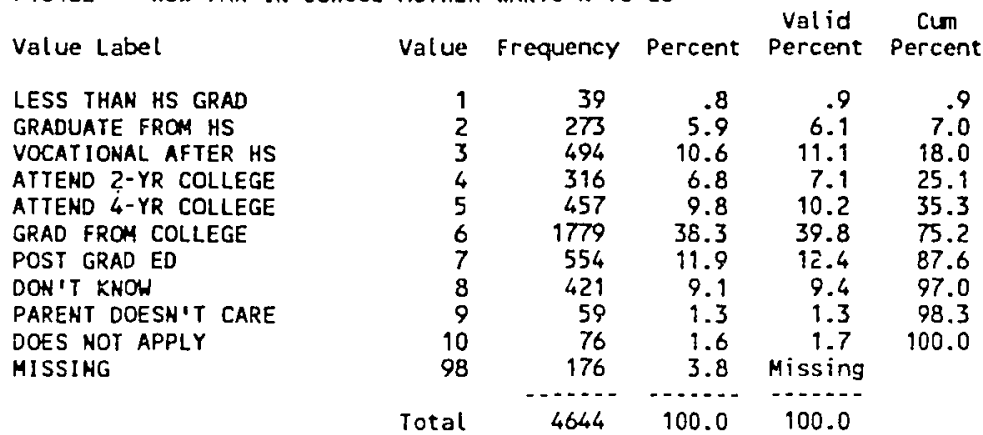

Valid cases $4468 \quad$ Missing cases 176

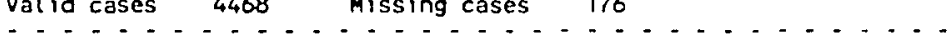

F1S49 HOW FAR IN SCHOOL R THINKS HE WILL GET

Value Label

LESS THAN H.S. GRAD

H.S GRAOUATION ONLY

$<2$ YRS TRADE SCHOOL

$2+$ YRS TRADE SCHOOL

< 2YRS OF COLLEGE

2/HORE YRS OF COLL

FIHISH COLLEGE

MASTER'S DEGREE

PH.D., H.D.

REFUSAL

MISSING

\begin{tabular}{|c|c|c|c|c|}
\hline Value & Frequency & Percent & $\begin{array}{l}\text { Valid } \\
\text { Percent }\end{array}$ & $\begin{array}{c}\text { Cum } \\
\text { Percent }\end{array}$ \\
\hline & 28 & .6 & .6 & .6 \\
\hline$\frac{2}{3}$ & 658 & 14.2 & 14.3 & 14.9 \\
\hline 3 & $\begin{array}{l}304 \\
589\end{array}$ & 6.5 & 6.6 & 21.6 \\
\hline $\begin{array}{l}4 \\
5\end{array}$ & $\begin{array}{l}581 \\
239\end{array}$ & $\begin{array}{r}12.5 \\
5.1\end{array}$ & $\begin{array}{r}12.7 \\
5.2\end{array}$ & $\begin{array}{l}34.2 \\
39.4\end{array}$ \\
\hline 6 & 852 & 18.3 & 18.6 & 58.0 \\
\hline 7 & 1319 & 28.4 & 28.7 & 86.7 \\
\hline 8 & 314 & 6.8 & 6.8 & 93.6 \\
\hline 9 & 296 & 6.4 & 6.4 & 100.0 \\
\hline 97 & 1 & .0 & Missing & \\
\hline 98 & 52 & 1.1 & Missing & \\
\hline Total & 4064 & 100.0 & 100.0 & \\
\hline
\end{tabular}

Valid cases $4591 \quad$ Missing cases 53 
FISS1 DOES R PLAN TO GO TO COLLEGE AFTER H.S.

$\begin{array}{lrrrrr}\text { Value Label } & \text { Value } & \text { Frequency } & \text { Percent } & \begin{array}{c}\text { Valid } \\ \text { Percent }\end{array} & \begin{array}{c}\text { Cum } \\ \text { Percent }\end{array} \\ \text { NO,DOW'T PLM COLLEGE } & 1 & 870 & 18.7 & 19.4 & 19.4 \\ \text { YES, RIGHT AFTER H.S } & 2 & 1991 & 42.9 & 44.5 & 63.9 \\ \text { YES, AFTER ONE YEAR } & 3 & 852 & 18.3 & 19.0 & 83.0 \\ \text { YES, AFTER OVER A YR } & 4 & 133 & 2.9 & 3.0 & 85.9 \\ \text { DON' I KNOW } & 5 & 629 & 13.5 & 14.1 & 100.0 \\ \text { MULTIPLE RESPONSE } & 6 & 6 & .1 & \text { Missing } & \\ \text { MISSING } & 8 & 163 & 3.5 & \text { Missing } & \\ & \text { Total } & 4644 & 100.0 & 100.0 & \end{array}$

Valid cases $4475 \quad$ Missing cases 169

FIS62A R FEELS GOOO ABOUT HIH/HERSELF

$\begin{array}{lrrrrr}\text { Value Label } & \text { Value } & \text { Frequency } & \text { Percent } & \begin{array}{c}\text { Valid } \\ \text { Percent }\end{array} & \begin{array}{c}\text { Cum } \\ \text { Percent }\end{array} \\ \text { STRONGLY AGREE } & 1 & 1302 & 28.0 & 29.6 & 29.6 \\ \text { AGREE } & 2 & 2651 & 57.1 & 60.2 & 89.8 \\ \text { DISAGREE } & 3 & 388 & 8.4 & 8.8 & 98.6 \\ \text { STRONGLY DISAGREE } & 4 & 62 & 1.3 & 1.4 & 100.0 \\ \text { MISSING } & 8 & 241 & 5.2 & \text { Missing } & \\ & \text { Total } & 4644 & 100.0 & 100.0 & \end{array}$

Valid cases $4403 \quad$ Missing cases 241

FIS62B R DOESh'T HAVE ENOUGH CONTROL OVER LIFE

\begin{tabular}{|c|c|c|c|c|c|}
\hline Value Label & Value & Frequency & Percent & $\begin{array}{l}\text { Valid } \\
\text { Percent }\end{array}$ & $\begin{array}{l}\text { Cum } \\
\text { Percen }\end{array}$ \\
\hline $\begin{array}{l}\text { STRONGLY AGREE } \\
\text { AGREE } \\
\text { DISAGREE } \\
\text { SIRONGLY DISAGREE } \\
\text { MULTIPLE RESPONSE } \\
\text { MISSING }\end{array}$ & $\begin{array}{l}1 \\
2 \\
3 \\
4 \\
6 \\
8\end{array}$ & $\begin{array}{r}213 \\
1019 \\
2266 \\
890 \\
2 \\
254\end{array}$ & $\begin{array}{r}4.6 \\
21.9 \\
48.8 \\
19.2 \\
.0 \\
5.5\end{array}$ & $\begin{array}{r}4.9 \\
23.2 \\
51.6 \\
20.3 \\
\text { Missing } \\
\text { Missing }\end{array}$ & $\begin{array}{r}4.9 \\
28.1 \\
79.7 \\
100.0\end{array}$ \\
\hline & Total & 4644 & 100.0 & 100.0 & \\
\hline
\end{tabular}

Valid coses $4388 \quad$ Missing cases 256

..... 4388 . Missing cases . $256 \ldots . . . .$.

F1S62C GOOO LUCK MORE IMPORTAHT THAN HARD WORK

Value Label

Valid cum

Value Label

Value frequency percent percent percent

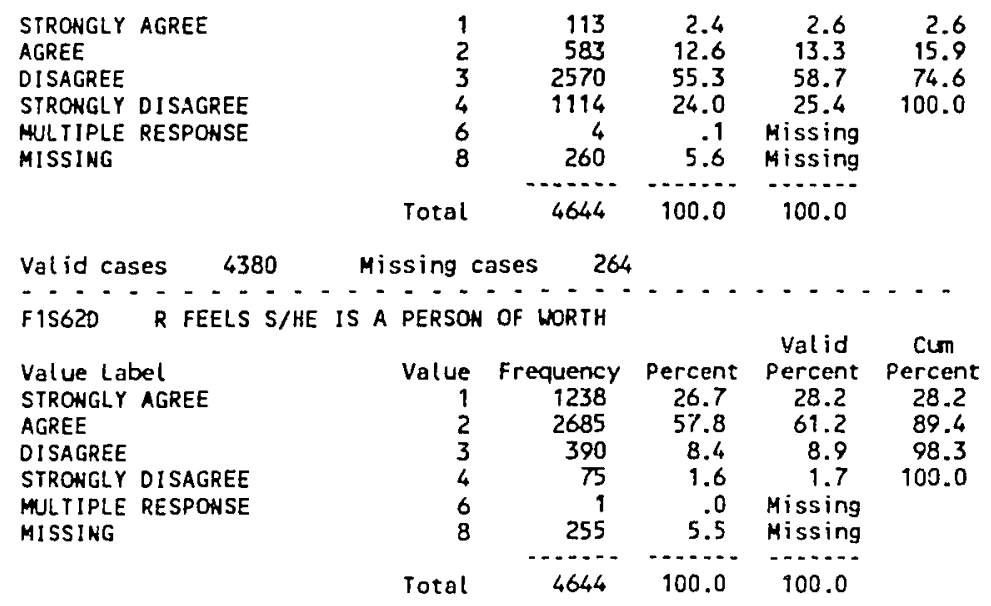

Valid cases 4388 Missing cases 256 


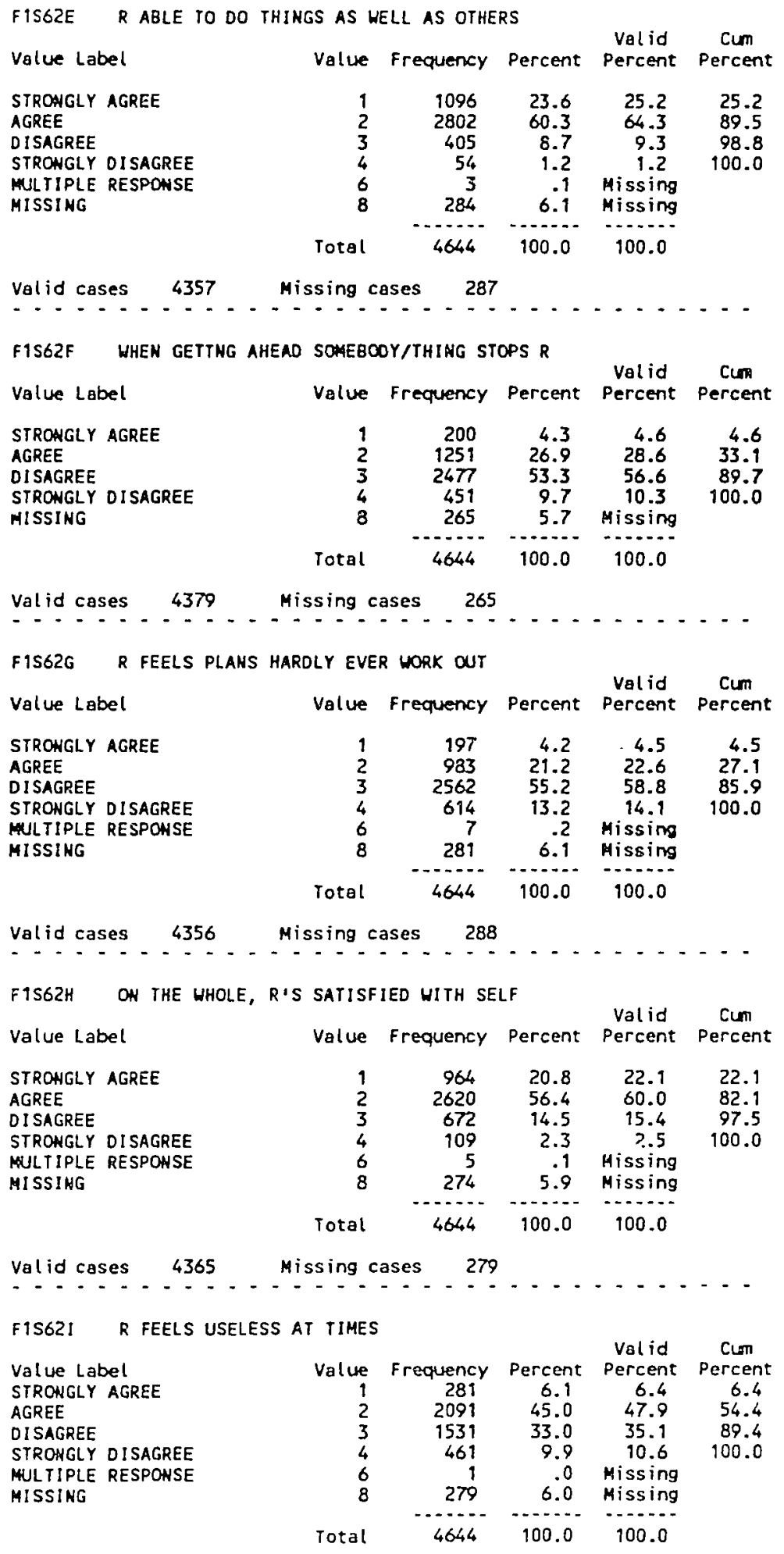

Valid cases 4364 Missing cases 280 
FIS62J AT TIMES, R THINKS HE IS NO GOOO AT ALL

Value Label

Value Frequency Percent

Valid Cum

STRONGLY AGREE

AGREE

DISAGREE

STRONGLY DISAGREE

MULTIPLE RESPONSE

MISSING

$\begin{array}{rrrrr}1 & 278 & 6.0 & 6.4 & 6.4 \\ 2 & 1583 & 34.1 & 36.4 & 42.8 \\ 3 & 1748 & 37.6 & 40.2 & 83.0 \\ 4 & 741 & 16.0 & 17.0 & 100.0 \\ 6 & 4 & .1 & \text { Missing } & \\ 8 & 290 & 6.2 & \text { Missing } & \\ \text { Total } & 4644 & 100.0 & 100.0 & \end{array}$

Valid cases $4350 \quad$ Missing cases 294

FISG2K WHEK MAKES PLAHS R'S CERTAIK THEY WORK

Value Label

value frequency Percent Percent percent

STRONGLY AGREE

AGREE

DISAGREE

STRONGLY DISAGREE

MULTIPLE RESPONSE

MISSING

$\begin{array}{rrrrr}1 & 537 & 11.6 & 12.3 & 12.3 \\ 2 & 2692 & 58.0 & 61.8 & 74.2 \\ 3 & 1009 & 21.6 & 23.0 & 97.2 \\ 4 & 124 & 2.7 & 2.8 & 100.0 \\ 6 & 2 & .0 & \text { Missing } & \\ 8 & 283 & 6.2 & \text { Missing } & \\ & -1 . & -10.0 & -\ldots 0.0 & \end{array}$

Valid cases $4354 \quad$ Missing cases 290

FIS62L R DOES NOT HAVE MUCH TO BE PRONO OF

Value Label

\begin{tabular}{|c|c|c|c|c|c|}
\hline Value Label & Value & Frequency & Percent & $\begin{array}{l}\text { Val id } \\
\text { Percent }\end{array}$ & $\begin{array}{c}\text { Cum } \\
\text { Percent }\end{array}$ \\
\hline $\begin{array}{l}\text { STRONGLY AGREE } \\
\text { AGREE } \\
\text { DISAGREE } \\
\text { STRONGLY DISAGREE } \\
\text { MULTIPLE RESPONSE } \\
\text { MISSING }\end{array}$ & $\begin{array}{l}1 \\
2 \\
3 \\
4 \\
6 \\
8\end{array}$ & $\begin{array}{r}153 \\
828 \\
2307 \\
1063 \\
2 \\
291\end{array}$ & $\begin{array}{r}3.3 \\
17.8 \\
49.7 \\
22.9 \\
.0 \\
6.3\end{array}$ & $\begin{array}{r}3.5 \\
19.0 \\
53.0 \\
24.4 \\
\text { Missing } \\
\text { Missing }\end{array}$ & $\begin{array}{r}3.5 \\
22.5 \\
\sqrt{35} .6 \\
100.0\end{array}$ \\
\hline & Total & 4644 & 100.0 & 100.0 & \\
\hline
\end{tabular}

Valid cases $4351 \quad$ Missing cases 293

FISG 24 CHAHCE IUCK VERY IMPORTANT FOR RIS LIFE

FIS62H Valid cum

value Label Value Frequency Percent Percent Percent

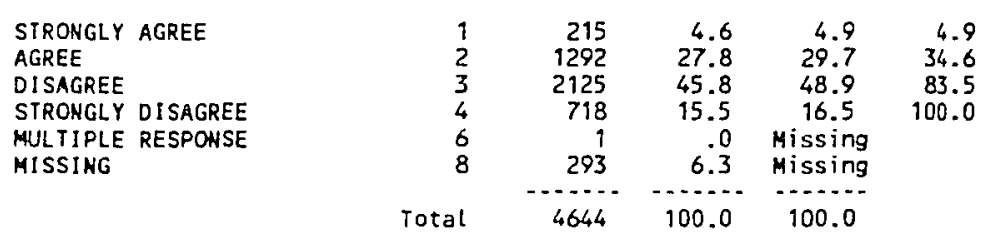

Yalid cases $4350 \quad$ Missing cases 294

FIS62H FEEL EMOTIONALLY EMPTY MOST OF THE TIME

Value Label

SIROHGLY AGREE

AGREE

DISAGREE

SIRONGLY DISAGREE

MULTIPLE RESPONSE

MISSING

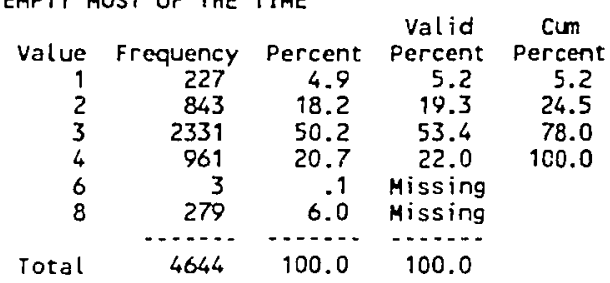

Valid cases $4362 \quad$ Missing cases 282 
F1S100A HON OFTEN PARENTS CHECK R'S HOMELORK

$\begin{array}{lrrrrr}\text { Value Label } & \text { Value } & \text { Frequency } & \text { Percent } & \begin{array}{c}\text { Valid } \\ \text { Percent }\end{array} & \begin{array}{c}\text { Cum } \\ \text { Percent }\end{array} \\ \text { OFTEN } & 1 & 973 & 21.0 & 23.0 & 23.0 \\ \text { SOMETIMES } & 2 & 1309 & 28.2 & 31.0 & 54.0 \\ \text { RARELY } & 3 & 1136 & 24.5 & 26.9 & 80.9 \\ \text { NEVER } & 4 & 808 & 17.4 & 19.1 & 100.0 \\ \text { MISSING } & 8 & 418 & 9.0 & \text { Missing } & \\ & \text { Total } & 4644 & 100.0 & 100.0 & \end{array}$

Valid cases $4226 \quad$ Missing cases 418

FIS100B HOU OFTEN PARENTS HELP R WITH HOMELORK

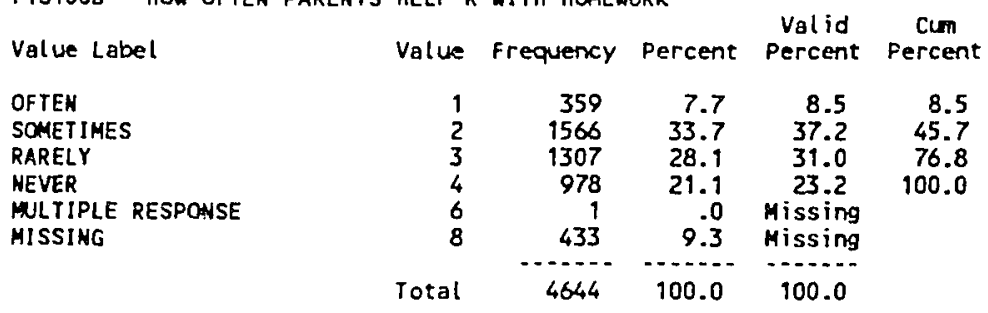

Valid cases $4210 \quad$ Missing cases 434

FISIOOC SPECIAL PRIVILEGES GIVEN FOR GOOO GRADES

\begin{tabular}{|c|c|c|c|c|c|}
\hline Val ue Label & Value & Frequency & Percent & $\begin{array}{l}\text { Valid } \\
\text { Percent }\end{array}$ & $\begin{array}{c}\text { Cum } \\
\text { Percent }\end{array}$ \\
\hline $\begin{array}{l}\text { OFTEN } \\
\text { SONETIMES } \\
\text { RARELY } \\
\text { HEVER } \\
\text { MULTIPLE RESPONSE } \\
\text { MISSING }\end{array}$ & $\begin{array}{r}1 \\
2 \\
3 \\
4 \\
6 \\
8 \\
\text { Total }\end{array}$ & $\begin{array}{r}757 \\
1546 \\
993 \\
909 \\
2 \\
437 \\
4644\end{array}$ & $\begin{array}{r}16.3 \\
33.3 \\
21.4 \\
19.6 \\
.0 \\
9.4 \\
100.0\end{array}$ & $\begin{array}{r}18.0 \\
36.8 \\
23.6 \\
21.6 \\
\text { Missing } \\
\text { Missing } \\
100.0\end{array}$ & $\begin{array}{r}18.0 \\
54.8 \\
78.4 \\
100.0\end{array}$ \\
\hline
\end{tabular}

Valid cases $4205 \quad$ Missing cases 439

F1S1000 PARENTS LIMIT PRIVILEGES DUE POOR GRADES

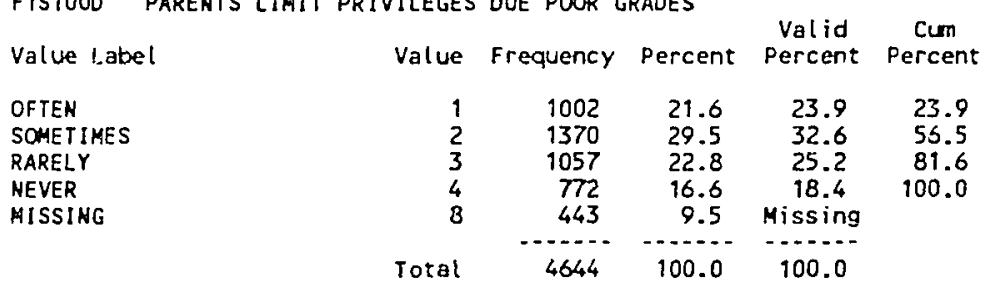

Valid cases $4201 \quad$ Missing cases 443

-...................................

FIS100E R REQUIRED TO WORK AROUHO THE HOUSE

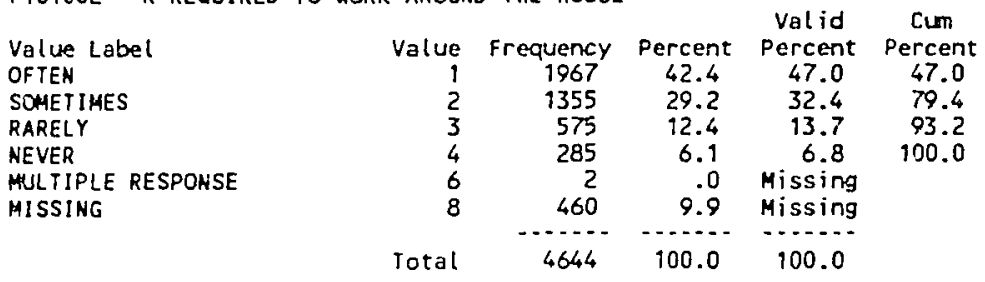

Valid cases $4182 \quad$ Missing cases 462 


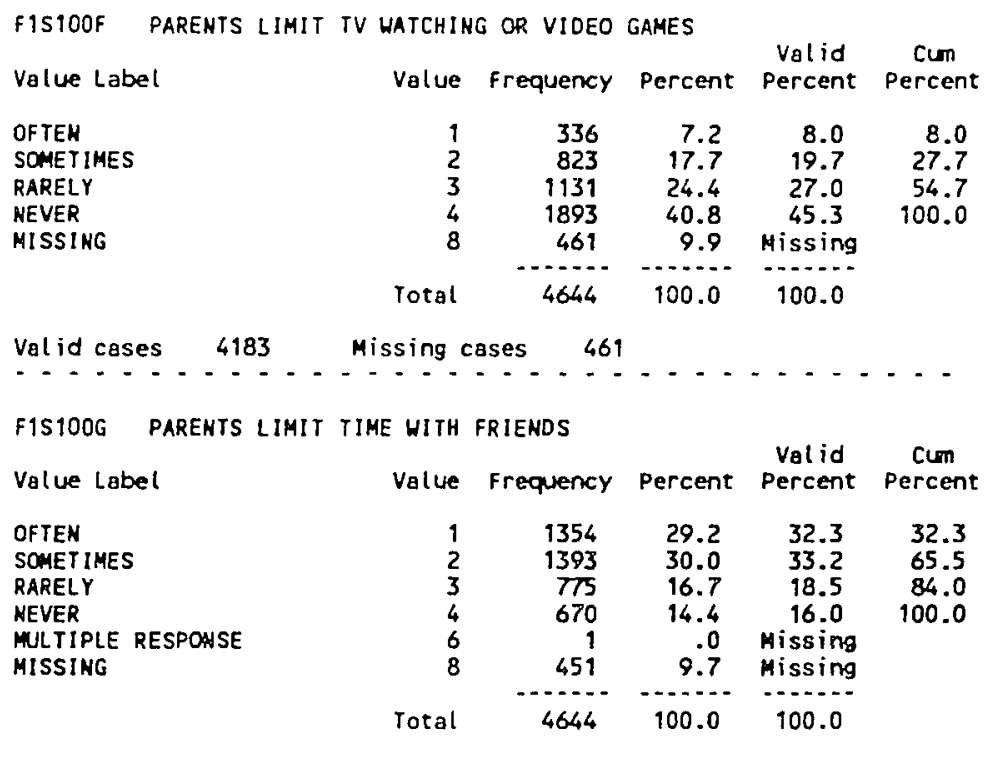

Valid cases $4192 \quad$ Missing cases 452

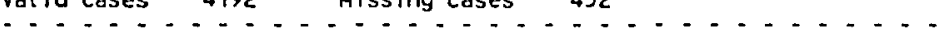

F1S101 LATEST R CAN STAY OUT OH SCHOOL HIGHTS

Value Label

Value frequency percent Percent percent

\begin{tabular}{|c|c|c|c|c|c|}
\hline $\begin{array}{l}\text { HOT ALLOWED OUT } \\
\text { HO LATER THAH } 8 \\
\text { NO LATER THAN } 9 \\
\text { NO LATER THAN } 10 \\
\text { NO LATER THAN } 11 \\
\text { NO LATER THAN } 12 \\
\text { AS LATE AS I HANT } \\
\text { MULIIPLE RESPOHSE } \\
\text { MISSING }\end{array}$ & $\begin{array}{r}0 \\
1 \\
2 \\
3 \\
4 \\
5 \\
6 \\
96 \\
98\end{array}$ & $\begin{array}{r}296 \\
328 \\
784 \\
1489 \\
731 \\
300 \\
287 \\
5 \\
432\end{array}$ & $\begin{array}{r}6.4 \\
7.1 \\
16.9 \\
31.9 \\
15.9 \\
6.5 \\
6.2 \\
.1 \\
9.3\end{array}$ & $\begin{array}{r}7.0 \\
7.8 \\
18.6 \\
35.2 \\
97.4 \\
7.1 \\
6.8 \\
\text { Missing } \\
\text { Missing }\end{array}$ & $\begin{array}{r}7.0 \\
14.8 \\
33.5 \\
68.7 \\
86.0 \\
93.2 \\
100.0\end{array}$ \\
\hline & 1 & 4644 & 100.0 & 100.0 & \\
\hline
\end{tabular}

Valid cases $4207 \quad$ Missing cases 437

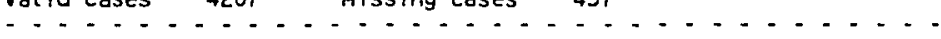

F1S105A DISCUSSED SCHOOL COURSES WITH PARENT

Value Label Value frequency percent percent percent

\begin{tabular}{|c|c|c|c|c|c|}
\hline $\begin{array}{l}\text { NEVER } \\
\text { SOMETIMES } \\
\text { OFTEN } \\
\text { MISSING }\end{array}$ & $\begin{array}{l}1 \\
2 \\
3 \\
8\end{array}$ & $\begin{array}{r}903 \\
2596 \\
649 \\
504\end{array}$ & $\begin{array}{l}19.4 \\
55.9 \\
13.8 \\
10.9\end{array}$ & $\begin{array}{r}21.8 \\
62.7 \\
15.5 \\
\text { missing }\end{array}$ & $\begin{array}{r}21.8 \\
84.5 \\
100.0\end{array}$ \\
\hline & & 4664 & 100.0 & 100.0 & \\
\hline
\end{tabular}

Valid cases 4140 Missing cases $504 \ldots \ldots \ldots \ldots$

FIS1OSB OISCUSSEO SCHOOL ACTIVITIES WITH PARENT

Value ! obel

HEVER

SOMETIMES

OFTEN

MULTIPLE RESPONSE

MISSING

$\begin{array}{rcccc}\text { Yalue } & \text { Frequency } & \text { Percent } & \begin{array}{c}\text { Valid } \\ \text { Percent }\end{array} & \begin{array}{c}\text { Cum } \\ \text { Percent }\end{array} \\ 1 & 1089 & 23.4 & 26.4 & 26.4 \\ 2 & 2292 & 49.4 & 55.5 & 81.8 \\ 3 & 751 & 16.2 & 18.2 & 100.0 \\ 6 & 1 & .0 & \text { Missing } & \\ 8 & 511 & 11.0 & \text { Missing } & \\ & -1 . . & -1 . . . & \ldots \ldots . . . & \\ \text { Total } & 4644 & 100.0 & 100.0 & \end{array}$

Valid cases $4132 \quad$ Missing cases 512 


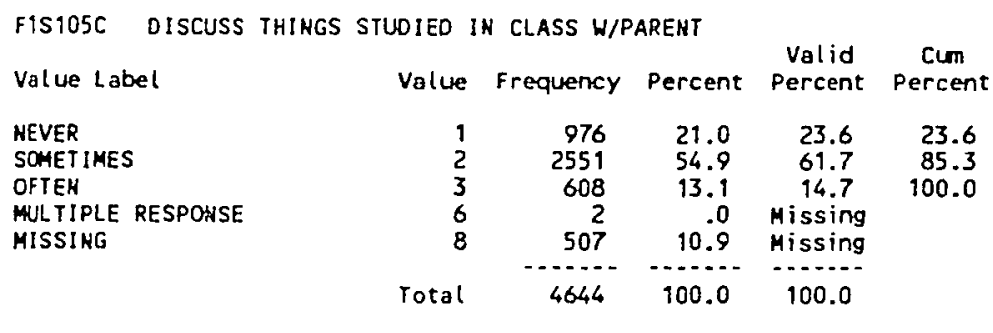

Valid cases $4135 \quad$ Missing cases 509

FISTOSD HOW OFTEN DISCUSSED GRADES WITH PAREHTS

\begin{tabular}{|c|c|c|c|c|c|}
\hline Value Label & Value & Frequency & Percent & $\begin{array}{l}\text { Valid } \\
\text { Percent }\end{array}$ & $\begin{array}{c}\text { Cum } \\
\text { Percent }\end{array}$ \\
\hline $\begin{array}{l}\text { NEVER } \\
\text { SOMETIMES } \\
\text { OFTEN } \\
\text { HULTIPLE RESPONSE } \\
\text { MISSING }\end{array}$ & $\begin{array}{r}1 \\
2 \\
3 \\
6 \\
8 \\
\text { Total }\end{array}$ & $\begin{array}{r}312 \\
2063 \\
1756 \\
1 \\
512 \\
4644\end{array}$ & $\begin{array}{r}6.7 \\
44.4 \\
37.8 \\
.0 \\
11.0 \\
100.0\end{array}$ & $\begin{array}{r}7.6 \\
49.9 \\
42.5 \\
\text { Hissing } \\
\text { Missing } \\
100.0\end{array}$ & $\begin{array}{r}7.6 \\
57.5 \\
100.0\end{array}$ \\
\hline
\end{tabular}

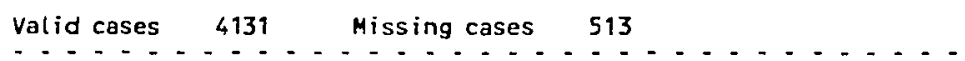

ISIOSE DISCUSSED TRAHSFERRING TO AHOTHER SCHOOL

\begin{tabular}{|c|c|c|c|c|c|}
\hline Value Label & Value & Frequency & Percent & $\begin{array}{l}\text { Valid } \\
\text { Percent }\end{array}$ & $\begin{array}{c}\text { Cum } \\
\text { Percent }\end{array}$ \\
\hline $\begin{array}{l}\text { NEVER } \\
\text { SOMETIMES } \\
\text { OFTEN } \\
\text { WULTIPLE RESPCHSE } \\
\text { MISSING }\end{array}$ & $\begin{array}{r}1 \\
2 \\
3 \\
6 \\
8 \\
\text { Total }\end{array}$ & $\begin{array}{r}2942 \\
930 \\
260 \\
1 \\
511 \\
4644\end{array}$ & $\begin{array}{r}63.4 \\
20.0 \\
5.6 \\
.0 \\
11.0 \\
100.0\end{array}$ & $\begin{array}{r}71.2 \\
22.5 \\
6.3 \\
\text { Missing } \\
\text { Missing } \\
100.0\end{array}$ & $\begin{array}{r}71.2 \\
93.7 \\
100.0\end{array}$ \\
\hline
\end{tabular}

Valid cases $\quad 4132 \quad$ Missing cases 512

.....................................

FIS105F DISCUSSED PREP FOR THE ACT/SAT TEST

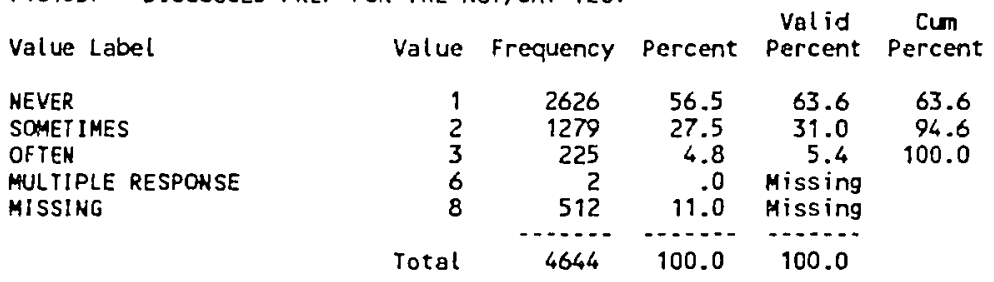

Valid cases $\quad 4130 \quad$ Missing cases 594

FIS105G DISCUSSED GOING TO COLLEGE HITH PARENTS

Value Label Value Frequency Percent percent percent

NeVER

$\begin{array}{lrrrrr}\text { NEVER } & 1 & 808 & 17.4 & 19.5 & 19.5 \\ \text { SOMEIIMES } & 2 & 2139 & 46.1 & 51.8 & 71.3 \\ \text { OFTEN } & 3 & 1186 & 25.5 & 28.7 & 100.0 \\ \text { MISSIHG } & 8 & 511 & 11.0 & \text { Missing } & \\ & & -\ldots 11 & -1.2 & -100.0 & \end{array}$

Valid cases $\quad 4133 \quad$ Missing cases 511 
FIS106A HOW OFTEN PARENTS ATTEND SCHOOL MEET!HCS

\begin{tabular}{|c|c|c|c|c|c|}
\hline Volue Label & Value & Frequency & Percent & $\begin{array}{l}\text { Valid } \\
\text { Percent }\end{array}$ & $\begin{array}{l}\text { Cum } \\
\text { Percent }\end{array}$ \\
\hline $\begin{array}{l}\text { NEVER } \\
\text { ONCE OR TWICE } \\
\text { MORE THAN TWICE } \\
\text { I DOW'T KNOW } \\
\text { MISSING }\end{array}$ & $\begin{array}{l}0 \\
1 \\
2 \\
3 \\
8\end{array}$ & $\begin{array}{r}2163 \\
1382 \\
407 \\
101 \\
591\end{array}$ & $\begin{array}{r}46.6 \\
29.8 \\
8.8 \\
2.2 \\
12.7\end{array}$ & $\begin{array}{r}53.4 \\
34.1 \\
10.0 \\
2.5 \\
\text { Missing }\end{array}$ & $\begin{array}{r}53.4 \\
87.5 \\
97.5 \\
100.0\end{array}$ \\
\hline & Total & 4644 & 100.0 & 100.0 & \\
\hline
\end{tabular}

Valid cases 4053 Missing cases $591 \ldots \ldots$

F1S1068 HOW OFTEN PARENT PHONED TEACHR, COUNSELOR

Value Label

Value frequency percent percent percent

NEVER

ONCE OR THICE

MORE THAH TWICE

I DON T T KHOH

MULTIPLE RESPONSE

MISSING

$\begin{array}{rrrrr}0 & 1612 & 34.7 & 39.7 & 39.7 \\ 1 & 1698 & 36.6 & 41.8 & 81.5 \\ 2 & 624 & 13.4 & 15.4 & 96.9 \\ 3 & 127 & 2.7 & 3.1 & 100.0 \\ 6 & 2 & .0 & \text { Missing } & \\ 8 & 581 & 12.5 & \text { Missing } & \\ & -\ldots . . & -\ldots . . & -\ldots . . . & \end{array}$

Valid cases $4061 \quad$ Hissing cases 583

F1S106C HOW OFTEN PARENTS ATTENDED SCHOOL EVENT

$\begin{array}{lrrrrr}\text { Value Label } & \text { Value } & \text { Frequency } & \text { Percent } & \begin{array}{c}\text { Valid } \\ \text { Percent }\end{array} & \begin{array}{c}\text { Cum } \\ \text { Percent }\end{array} \\ \text { HEVER } & 0 & 2049 & 44.1 & 50.7 & 50.7 \\ \text { ONCE OR THICE } & 1 & 844 & 18.2 & 20.9 & 71.6 \\ \text { MORE THAH THICE } & 2 & 1063 & 22.9 & 26.3 & 97.9 \\ \text { I DON'T KHOW } & 3 & 83 & 1.8 & 2.1 & 100.0 \\ \text { HISSING } & 8 & 605 & 13.0 & \text { Missing } & \\ & \text { Total } & 4644 & 100.0 & 100.0 & \end{array}$

Valid cases $4039 \quad$ Missing cases 605

FIS1060 PARENTS ACTED AS VOLUNTEER AT R'S SCHOOL

\begin{tabular}{|c|c|c|c|c|c|}
\hline Value Label & Value & Frequency & Percent & $\begin{array}{l}\text { Valid } \\
\text { Percent }\end{array}$ & $\underset{\text { Percent }}{\text { Cum }}$ \\
\hline $\begin{array}{l}\text { HEVER } \\
\text { OHCE OR TWICE } \\
\text { MORE THAN TWICE } \\
\text { I DON'T KHOW } \\
\text { MISSING }\end{array}$ & $\begin{array}{r}0 \\
1 \\
2 \\
3 \\
8 \\
\text { Total }\end{array}$ & $\begin{array}{c}3147 \\
544 \\
214 \\
119 \\
620 \\
4644\end{array}$ & $\begin{array}{r}67.8 \\
11.7 \\
4.6 \\
2.6 \\
13.4 \\
100.0\end{array}$ & $\begin{array}{r}78.2 \\
13.5 \\
5.3 \\
3.0 \\
\text { Missing } \\
100.0\end{array}$ & $\begin{array}{r}78.2 \\
91.7 \\
97.0 \\
100.0\end{array}$ \\
\hline
\end{tabular}

Valid cases $4024 \quad$ Missing cases 620

fIS107A PAREHTS REC'D haRnING ABOUT R ATTENDANCE

Value Label

Value Frequency percent percent percent

HEVER

ONCE OR TWICE

MORE THAN TWICE

MULTIPLE RESPONSE

MISSING

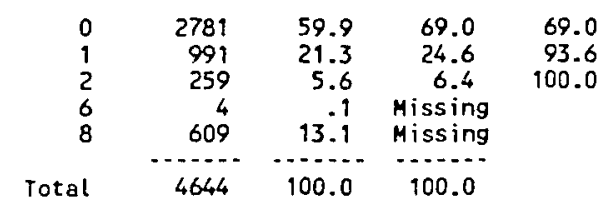

Valid cases $4031 \quad$ Missing cases 613 


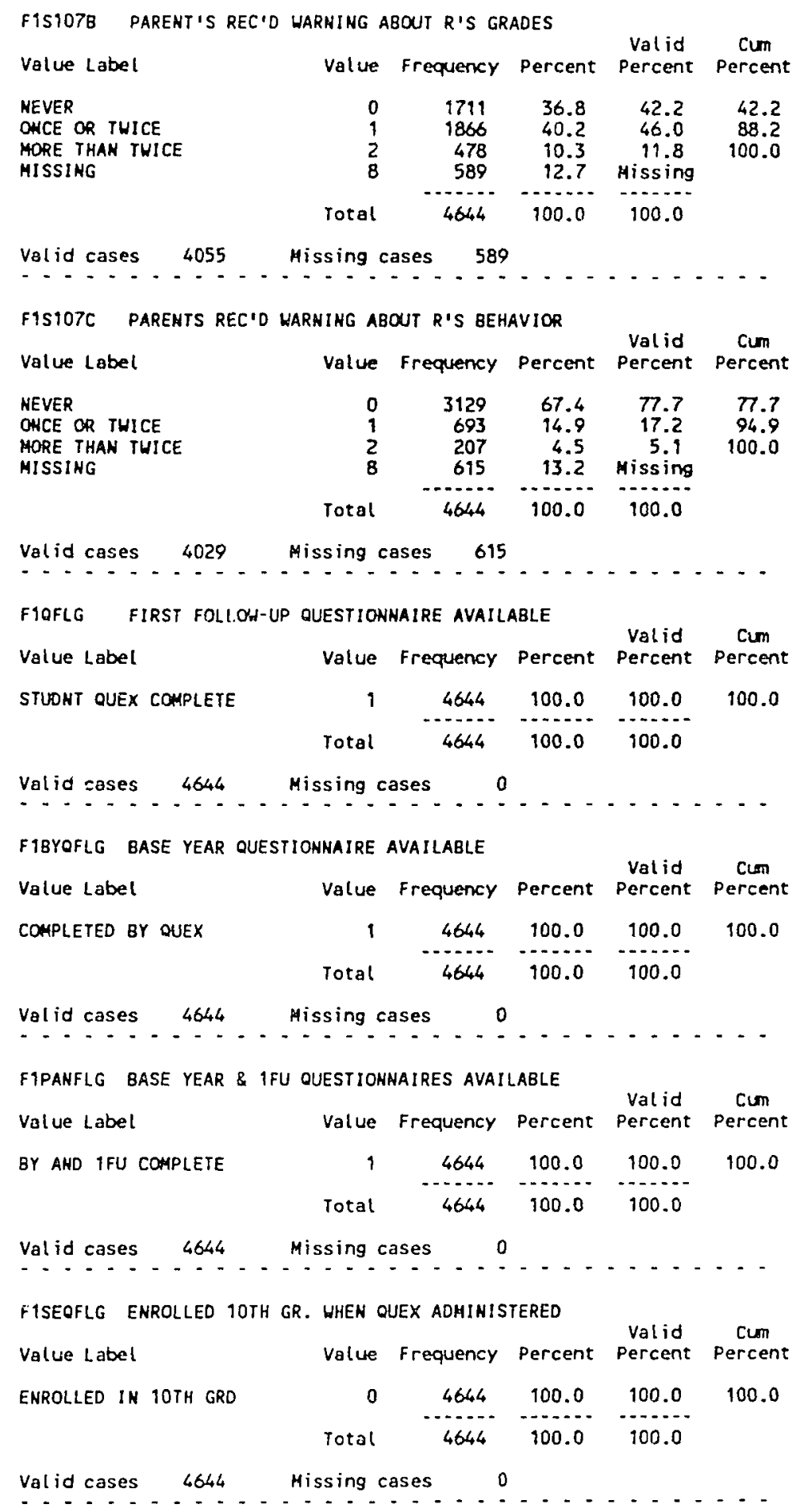




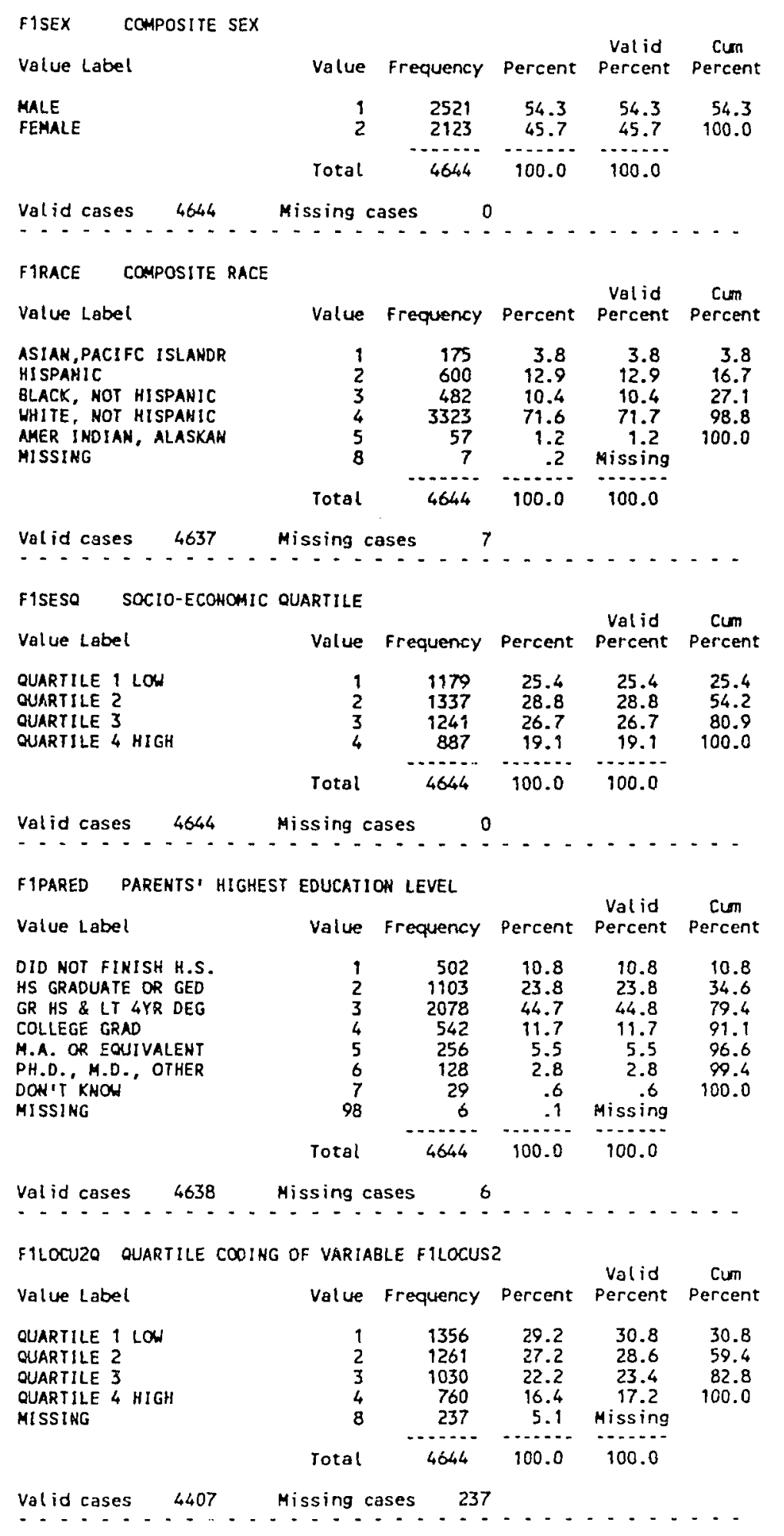


F1CNCP2O QUARTILE COOING OF VARIABLE F1CNCPT2

$\begin{array}{lrrrrr}\text { Value Label } & \text { Value } & \text { Frequency } & \text { Percent } & \begin{array}{c}\text { Valid } \\ \text { Percent }\end{array} & \begin{array}{c}\text { Cum } \\ \text { Percent }\end{array} \\ \text { QUARTILE 1 LON } & 1 & 1497 & 32.2 & 33.9 & 33.9 \\ \text { QUARTILE 2 } & 2 & 1112 & 23.9 & 25.2 & 59.2 \\ \text { QUARTILE 3 } & 3 & 990 & 21.3 & 22.4 & 81.6 \\ \text { QUARTILE 4 HIGH } & 4 & 811 & 17.5 & 18.4 & 100.0 \\ \text { MISSING } & 8 & 234 & 5.0 & \text { Missing } & \\ & \text { Total } & 4644 & 100.0 & 100.0 & \end{array}$

Valid cases $4410 \quad$ Missing cases 234

G1OCTRLI SCHOOL CLASSIFICATION REPORTED BY SCHOOL

\begin{tabular}{|c|c|c|c|c|c|}
\hline Value Label & Value & Frequency & Percent & Percent & $\begin{array}{l}\text { Cum } \\
\text { Percent }\end{array}$ \\
\hline $\begin{array}{l}\text { PUBLIC } \\
\text { CATHOLIC } \\
\text { PRIVATE, OTH RELIGION } \\
\text { PRIVATE, NOW-RELIG. } \\
\text { PRIV, NOT ASCERTAINED } \\
\text { AISSING }\end{array}$ & $\begin{array}{r}1 \\
2 \\
3 \\
4 \\
5 \\
98\end{array}$ & $\begin{array}{r}4144 \\
251 \\
93 \\
129 \\
11 \\
16\end{array}$ & $\begin{array}{r}89.2 \\
5.4 \\
2.0 \\
2.8 \\
.2 \\
.3\end{array}$ & $\begin{array}{r}89.5 \\
5.4 \\
2.0 \\
2.8 \\
.2 \\
\text { Missing }\end{array}$ & $\begin{array}{r}89.5 \\
95.0 \\
97.0 \\
99.8 \\
100.0\end{array}$ \\
\hline & Total & 4644 & 100.0 & 100.0 & \\
\hline
\end{tabular}

Valid cases $4628 \quad$ Missing cases 16

GIOURBAM URBANICITY OF THE STUDENT'S SCHOOL

$\begin{array}{lrrrrr}\text { Value Label } & \text { Value } & \text { Frequency } & \text { Pcrcent } & \begin{array}{c}\text { Valid } \\ \text { Percent }\end{array} & \begin{array}{c}\text { Cum } \\ \text { Percent }\end{array} \\ \text { UR8AN } & 1 & 1214 & 26.1 & 26.3 & 26.3 \\ \text { SUBURBAN } & 2 & 2652 & 57.1 & 57.5 & 83.8 \\ \text { RURAL - QUTSIDE MSA } & 3 & 750 & 16.1 & 16.2 & 100.0 \\ \text { MISSING } & 8 & 28 & .6 & \text { Missing } & \\ & \text { Total } & 4644 & 100.0 & 100.0 & \end{array}$

Valid cases $4616 \quad$ Missing cases 28

LIOREGOH REGION OF THE COUNTRY (4 CENSUS REgIONS)

Value tabel Valid Cum

Percent Percent Percent

NORTHEAST

NORTH CEHTRAL

SOUTH

UEST

MISSING

$\begin{array}{rrrrr}1 & 811 & 17.5 & 17.5 & 17.5 \\ 2 & 1377 & 29.7 & 29.7 & 47.3 \\ 3 & 1490 & 32.1 & 32.2 & 79.5 \\ 4 & 951 & 20.5 & 20.5 & 100.0 \\ 98 & 15 & .3 & \text { Missing } & \\ & -.1 . . & -. . . . & -1.2 .- & \end{array}$

Valid cases 4629 Missing cases 15

FISCENRL ENTIRE SCHOOL ENROLLMENT

Value Label
$10-399$
$400-599$
$600=799$
$800-999$
$1000=1199$
$1200=1599$
$1600=1999$
$2000=2499$
$2500+$
AISSING

\begin{tabular}{|c|c|c|c|c|}
\hline & Freaduency & Percent & Valid & Cum \\
\hline $\begin{array}{r}1 \\
2 \\
3 \\
4 \\
5 \\
6 \\
7 \\
8 \\
9 \\
98\end{array}$ & $\begin{array}{r}519 \\
558 \\
454 \\
552 \\
621 \\
780 \\
573 \\
276 \\
295 \\
16\end{array}$ & $\begin{array}{r}11.2 \\
12.0 \\
9.8 \\
11.9 \\
13.4 \\
16.8 \\
12.3 \\
5.9 \\
6.4 \\
.3\end{array}$ & $\begin{array}{r}11.2 \\
12.1 \\
9.8 \\
11.9 \\
13.4 \\
16.9 \\
12.4 \\
6.0 \\
6.4 \\
\text { Missing }\end{array}$ & $\begin{array}{r}11.2 \\
23.3 \\
33.1 \\
45.0 \\
58.4 \\
75.3 \\
87.7 \\
93.6 \\
100.0\end{array}$ \\
\hline Total & 4644 & 100.0 & 100.0 & \\
\hline
\end{tabular}

Valid cases $4628 \quad$ Missing cases $\quad 16$ 